YATSEN JEPTHE MALDONADO SOTO

ADEQUAÇÃO DE FORMULAÇÕES PARA A PRODUÇÃO DE PLACAS DE FIBROCIMENTO POR EXTRUSÃO

São Paulo 
YATSEN JEPTHE MALDONADO SOTO

\section{ADEQUAÇÃO DE FORMULAÇÕES PARA A PRODUÇÃO DE PLACAS DE FIBROCIMENTO POR EXTRUSÃO}

Tese apresentada à Escola

Politécnica da Universidade de São

Paulo para a obtenção do título de

Doutor em Engenharia

São Paulo 
YATSEN JEPTHE MALDONADO SOTO

\title{
ADEQUAÇÃO DE FORMULAÇÕES PARA A PRODUÇÃO DE PLACAS DE FIBROCIMENTO POR EXTRUSÃO
}

\author{
Tese apresentada à Escola \\ Politécnica da Universidade de São \\ Paulo para a obtenção do título de \\ Doutor em Engenharia \\ Área de Concentração: \\ Construção Civil e Urbana \\ Orientador: \\ Prof. Dr. Holmer Savastano Junior
}

São Paulo 
FICHA CATALOGRÁFICA

Soto, Yatsen Jepthe Maldonado

Adequação de formulações para a produção de placas de fibrocimento por extrusão / Y.J.M. Soto. -- São Paulo, 2010 $150 \mathrm{p}$.

Tese (Doutorado) - Escola Politécnica da Universidade de São Paulo. Departamento de Engenharia de Construção Civil.

1. Extrusão 2. Fibrocimento 3. Reologia I. Universidade de São Paulo. Escola Politécnica. Departamento de Engenharia de Construção Civil II. t. 


\section{AGRADECIMENTOS}

Ao meu pai Martin Jepthe Maldonado Perez, ao meu praticamente irmão Pether Jannz Maldonado Perez e ao estimado tio Sipsem Amalio Maldonado Perez pelo apoio e carinho brindados no desenvolvimento da pesquisa.

Aos meus abuelos Amalio Amadeo Maldonado e Prima Perez pelo incentivo e apoio brindados ao longo dos anos.

À todos meus familiares que mesmo estando distantes estão sempre presentes.

À minha querida Sabri pelo carinho e apoio nestes últimos anos.

Ao Prof. Dr. Holmer Savastano Junior pela orientação, confiança e por acreditar no desenvolvimento deste trabalho abrindo as portas do mundo dos compósitos cimentícios.

Ao Prof. Dr. P. Shah Surendra e equipe pela grata acolhida e suporte na pesquisa de fibrocimento extrudado.

Ao amigo Guanghua Li pela companhia e auxílio nos experimentos em Evanston no inverno de 2008.

À empresa DJ em especial ao técnico Carlos pelo grande apoio no desenvolvimento das peças desta pesquisa.

À Engracia pelo grande apoio brindado no inicio deste trabalho.

Ao Prof. Antonio Figueiredo pelas entusiásticas aulas e pela sua amizade.

Ao Prof. Giulliano Pileggi, meu querido amigo, quem iniciou meus conhecimentos de reologia.

Aos colegas da Poli: Cleber Dias, Cesar, Rui e Brunoro.

Aos professores Vanderley e Maria Alba Cincotto.

Ao técnico de laboratório Mário Souza Takeashi.

Aos colegas da FZEA: Sergio, Zaqueu, Camila, Melissa, Ronaldo e Gustavo pelo auxílio nas diversas atividades de pesquisa.

Às empresas que forneceram matérias-primas: Grace, Elkem, Basf, Dow Chemicals. 
Às empresas Infibra Ltda. e Imbralit Ltda., pela bolsa de estudos oferecida por intermédio do Projeto Cim-Cel em cooperação com a Poli/USP e a FZEA/USP (vigência: 01/09/2005 a 30/08/2006 - 12 meses).

Aos amigos da Solinova: Prof. Celso Oliveira, Prof. Celso Carrer, Christian Vorobieff, Rafael Gonçales e Adriana Barros.

Aos colegas da sala de estudo "buraco negro" pelas longas jornadas de estudo e reflexões do cotidiano.

Aos amigos da FZEA.

A FAPESP pelo apoio financeiro.

A todos aqueles que direta ou indiretamente contribuíram para 0 desenvolvimento desta pesquisa. 


\section{RESUMO}

Este trabalho propõe contribuir no desenvolvimento do processo de extrusão para a produção de compósitos cimentícios, mediante metodologia que possibilite a obtenção de formulações extrudáveis utilizando cimento Portland de alta resistência inicial, sílica ativa, calcário, polpa de celulose de eucalipto, fibras de polipropileno e aditivos. Para isso, foram caracterizadas as matérias-primas como subsidio para as discussões. $O$ efeito dos diferentes componentes da formulação no comportamento reológico da mistura foi avaliado utilizando reômetro extrusor. As propriedades físicas e mecânicas dos compósitos elaborados com combinações de calcário, sílica ativa e cimento foram modeladas estatisticamente com o propósito de estimar o comportamento das matrizes. A demanda de água dos sistemas cimentícios foi determinada experimentalmente e utilizada na extrusão das matrizes. Selecionada uma matriz, suas propriedades mecânicas e físicas foram modeladas, estatisticamente, com diferentes teores de polpa celulósica de eucalipto e fibras de polipropileno. As formulações com características desejadas foram avaliadas ao envelhecimento acelerado por 200 ciclos de imersão-secagem. Finalmente foi analisada a reprodutibilidade utilizando o módulo de Weibull para as formulações selecionadas. O estudo reológico constatou que as fibras de polipropileno apresentam os maiores aumentos nos valores dos parâmetros reológicos se comparados com os efeitos do calcário, sílica ou celulose de eucalipto, repercutindo em maiores pressões de extrusão. $O$ incremento do modificador reológico hidroxipropilmetilcelulose reduz no compósito cimentício o módulo de ruptura mesmo que durante o processamento, promova o incremento da pressão de extrusão. Os modelos estatísticos empregados para modelar a matriz reforçada foram de maior complexidade e com menor coeficiente de determinação se comparados com os utilizados na modelagem das matrizes. O preço de mercado do fibrocimento é aproximadamente $64 \%$ menor do que os determinados utilizando unicamente os valores das matérias-primas e aditivos do fibrocimento extrudado no presente estudo.

Palavras-chave: Extrusão. Fibrocimento. Reologia. 
This work intends to contribute in the development of the extrusion process for the production of cementitious composites, through methodology that makes it possible to obtain formulas using high resistance Portland cement, silica fume, limestone, eucalyptus pulp, polypropylene fibers and admixtures. With this intention, the raw materials were characterized as a support for the discussions. The effects of the different components of the formula on the rheological behavior of the mixture were evaluated using an extrusion rheometer. The physical and mechanical properties of the composites elaborated with the combinations of limestone, silica fume and cement were modeled statistically with the purpose of estimating the behavior of the matrix. The water demand of the cementitious systems was determined experimentally and used in the matrixes extrusion. After the Matrix Selection, their mechanical and physical properties were modeled statistically, with different pulp eucalyptus and polypropylene fibers quantities. The formulas with the expected characteristics were evaluated to the accelerated aging for 200 wet-drying cycles. Finally the reproducibility was analyzed using the Weibull module for the selected formulas. The rheological studies verified that the polypropylene fibers demonstrate the largest increase in the values of the rheological parameters when compared with the effects of the limestone, silica fume or eucalyptus pulp, inducing larger extrusion pressures. The increment of the rheological modifier hydroxypropyl methylcellulose decreases the module of rupture in the cementitious composite, and simultaneously during the process it promotes the increment of the extrusion pressure. The statistical models used to reinforce the matrix modeling were of large complexity and with smaller coefficient determination when compared to matrixes used for modeling. The fiber cement market price is approximately $64 \%$ smaller than the raw materials and admixtures used in extruded fiber cement in this study.

Keywords: Extrusion. Fiber cement. Rheology. 


\section{LISTA DE ABREVIATURAS E SIGLAS}

AA

ADVA FLOW

C

CC

CP

CPFT

CPII-E

CPIII-30-RS

CPV

CPV-ARI

CSF

DA

EE

FVS

HPMC

ICDD

LOP

$\mathrm{M}$

MET

MEV

MOE

MOR

PA

PAN-ICSD

PGI

PP

PVA

$\mathrm{S}$ absorção aparente de água

nome comercial do dispersante poliéter carboxílico produzido pela Grace

celulose de eucalipto

calcário

corpo-de-prova

porcentagem acumulada de partículas menores que um

determinado diâmetro

cimento Portland composto com adição de escória

cimento Portland de alta resistência, com resistência de $30 \mathrm{MPa}$, resistente à sulfato

cimento Portland de alta resistência inicial

cimento Portland de alta resistência inicial

método Canadian Standard Freeness

densidade aparente

energia específica

fração volumétrica de sólidos

hidroxipropilmetilcelulose

Internacional Centre for Diffraction Data (2003)

limite da proporcionalidade

matriz

método de cálculo de área superficial específica

microscopia eletrônica de varredura

módulo de elasticidade

módulo de ruptura

porosidade aparente

PAN analytical Inorganic Crystal Structure Database (2007)

lubrificante propilenoglicol

fibras de polipropileno

polivinil-álcool

sílica ativa 


\section{LISTA DE SÍMBOLOS}

\begin{tabular}{|c|c|}
\hline $\mathrm{C}_{3} \mathrm{~A}$ & aluminato tricálcico \\
\hline $\mathrm{S}_{1}$ & camada secundária externa da célula da fibra vegetal \\
\hline $\mathrm{S}_{2}$ & camada secundária intermediária da célula da fibra vegetal \\
\hline $\mathrm{S}_{3}$ & camada secundária interna da célula da fibra vegetal \\
\hline$\tau$ & tensão de cisalhamento \\
\hline$k$ & tensão de escoamento \\
\hline$\dot{\gamma}$ & taxa de cisalhamento \\
\hline$\mu$ & viscosidade plástica \\
\hline$C$ & consistência \\
\hline$n$ & índice da lei de Power \\
\hline$\mu_{\infty}$ & viscosidade em alta taxa de cisalhamento \\
\hline $\mathrm{D}_{0}$ & diâmetro do barril \\
\hline $\mathrm{D}$ & diâmetro da boquilha \\
\hline $\mathrm{L}$ & comprimento da boquilha \\
\hline$v$ & velocidade de extrusão \\
\hline $\mathrm{P}_{\text {tot }}$ & pressão total de extrusão \\
\hline$A_{0}$ & área do barril \\
\hline$l_{0}$ & comprimento inicial de deslocamento do barril \\
\hline$A$ & área da boquilha \\
\hline$l$ & deslocamento da boquilha \\
\hline$\sigma$ & tensão \\
\hline$\sigma_{0}$ & tensão de escoamento correspondente à velocidade zero \\
\hline$P_{1}$ & pressão de extrusão devido ao trabalho \\
\hline$\alpha$ & efeito da velocidade na tensão de escoamento \\
\hline$\eta$ & viscosidade \\
\hline$P_{2}$ & $\begin{array}{l}\text { força resultante do cisalhamento entre o corpo da boquilha e a } \\
\text { mistura }\end{array}$ \\
\hline$\beta$ & efeito da velocidade na tensão de cisalhamento \\
\hline$\tau_{0}$ & tensão inicial de cisalhamento \\
\hline
\end{tabular}


taxa de volume de vazios em relação ao volume aparente do material particulado

$u$

$\varepsilon_{W}$

$u_{w}$

$\varepsilon_{a}$

$u_{w}$

$\phi$

$p$

$y_{i}$

$X_{q}$

$\bar{x}$

$\sigma_{2}$

$\beta_{o}$

$\beta_{i}$

$\beta_{i j}$

$X_{i}, X_{j}$

$\hat{y}$

$y$

$b_{0}, b_{i}, b_{i j}$

$e_{i}$

$q$

m

$x_{i}$

$F$

$\sigma$

$\sigma_{0 w}$

taxa de volume de vazios em relação ao volume sólido dos particulados

taxa de água em relação ao volume aparente do material particulado

taxa de volume de água em relação ao volume sólido do material particulado

taxa de volume de ar em relação ao volume aparente do material particulado

taxa de volume de ar em relação ao volume sólido dos

particulados

taxa de volume sólido do material particulado em relação

ao volume aparente do material particulado

número de variáveis independentes

resposta observada para a i-ésima determinação

parâmetros dos modelos

média populacional

variância

valor populacional da média global

valores populacionais dos efeitos por unidade de $X_{i}$ e $X_{j}$

valores populacionais das interações por unidade de $X_{i}$ e $X_{j}$

níveis das variáveis independentes

valor previsto

valor experimental

estimativa dos parâmetros do modelo

erro associado

número de fatores

número de níveis menos 1

coordenadas do sistema simplex

probabilidade de fratura

módulo de ruptura

constante de normalização do módulo de Weibull 


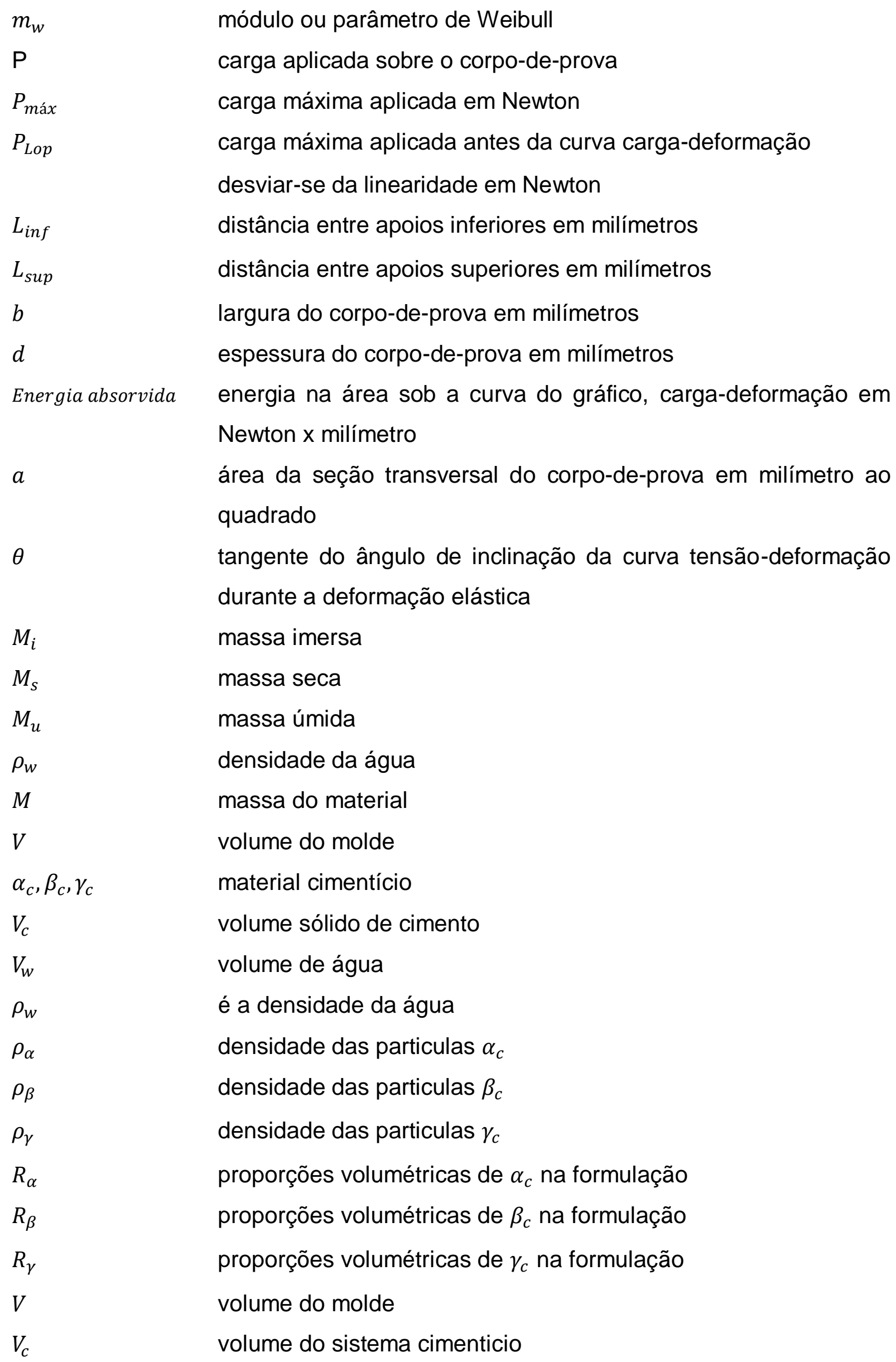
carga aplicada sobre o corpo-de-prova carga máxima aplicada em Newton carga máxima aplicada antes da curva carga-deformação desviar-se da linearidade em Newton distância entre apoios inferiores em milímetros distância entre apoios superiores em milímetros largura do corpo-de-prova em milímetros espessura do corpo-de-prova em milímetros energia na área sob a curva do gráfico, carga-deformação em Newton x milímetro área da seção transversal do corpo-de-prova em milímetro ao quadrado tangente do ângulo de inclinação da curva tensão-deformação durante a deformação elástica massa imersa massa seca massa úmida densidade da água massa do material volume do molde material cimentício volume sólido de cimento volume de água é a densidade da água densidade das particulas $\alpha_{c}$ densidade das particulas $\beta_{c}$ densidade das particulas $\gamma_{c}$ proporções volumétricas de $\alpha_{c}$ na formulação proporções volumétricas de $\beta_{c}$ na formulação proporções volumétricas de $\gamma_{c}$ na formulação volume do molde volume do sistema cimenticio 


$\begin{array}{ll}V_{A} & \text { volume de ar no sistema cimenticio } \\ V_{w} & \text { volume da água no sistema cimenticio } \\ V_{S} & \text { volume de sólidos no sistema cimenticio } \\ u & \text { taxa de volume de vazios em relação ao volume de sólidos } \\ u_{A} & \text { taxa do volume de ar em relação ao volume sólido; } \\ \mathrm{L}_{1} & \text { comprimento do corpo da boquilha de } 12,70 \mathrm{~mm} \\ \mathrm{~L}_{2} & \text { comprimento do corpo da boquilha de } 50,80 \mathrm{~mm} \\ \mathrm{~L}_{3} & \text { comprimento do corpo da boquilha de } 101,60 \mathrm{~mm} \\ \mathrm{~L}_{0} & \text { comprimento do corpo do barril } \\ P_{e} & \text { pressão de extrusão } \\ v_{0} & \text { velocidade do pistão } \\ \tau_{v} & \text { tensão de cisalhamento na velocidade de extrusão } \\ \sigma_{v} & \text { tensão de escoamento na velocidade de extrusão }\end{array}$




\section{LISTA DE FIGURAS}

Figura 1 - Processo Hatschek, extraído de Dias; Savastano Jr e John (2010) .........26

Figura 2 - Esquema de extrusão a vácuo ..........................................................27

Figura 3 - Movimento das fibras na extrusão, Srinivasan et al. (1999).....................29

Figura 4 - Estrutura das células de fibra vegetal, adaptado de Gram (1988); Illston et

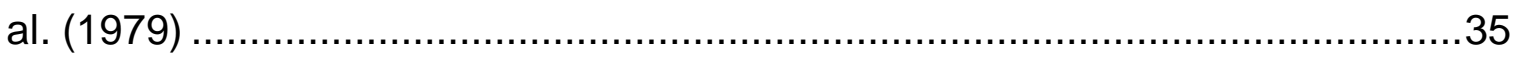

Figura 5 - Reômetro extrusor, adaptado de BENBOW et al. (1991) .........................45

Figura 6 - Metodologia para o desenvolvimento de formulações ............................57

Figura 7 - Esquema do ensaio de flexão a quatro pontos. P é a carga aplicada sobre

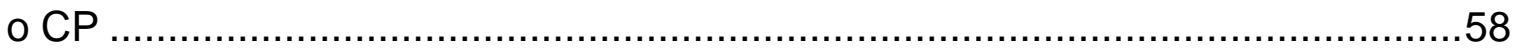

Figura 8 - Máquina universal de ensaios mecânicos............................................59

Figura 9 - Dispositivo de ensaio de tração na flexão .................................................59

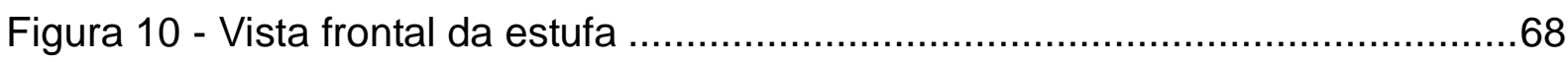

Figura 11 - Painel de controle e reservatório de água.............................................68

Figura 12 - Sentido de circulação de ar quente (etapa de secagem) .......................68

Figura 13 - Micrografias de partículas de sílica ativa aglomerada (a) e esfericidade

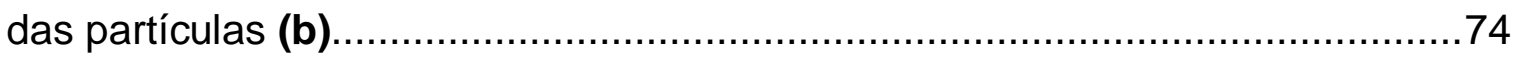

Figura 14 - Micrografias de partículas de calcário sem aglomeração (a) e com

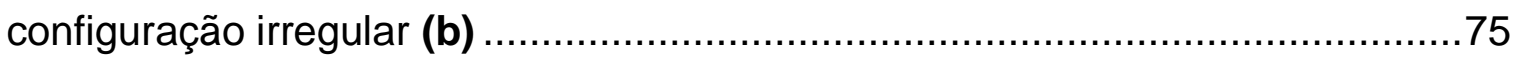

Figura 15 - Micrografias de partículas de cimento CPV sem aglomeração (a) e com

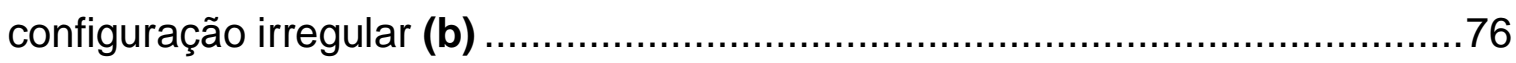

Figura 16 - Micrografias de partículas de cimento CPII E sem aglomeração (a) e com

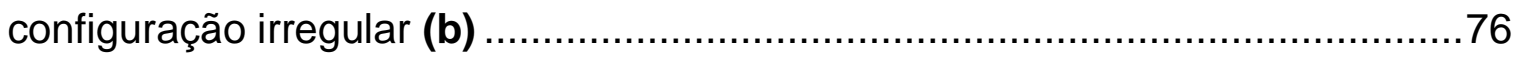

Figura 17 - Micrografias de partículas de cimento CPIII sem aglomeração (a) e com

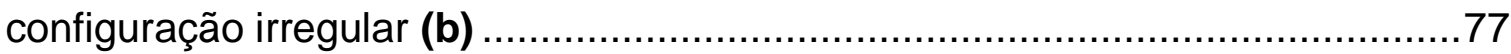

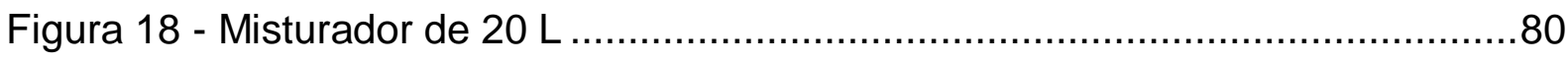

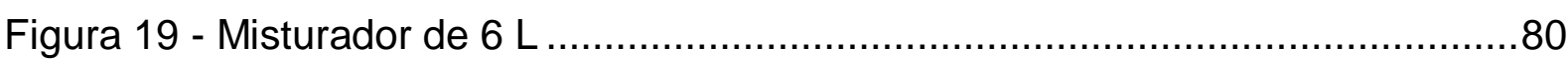

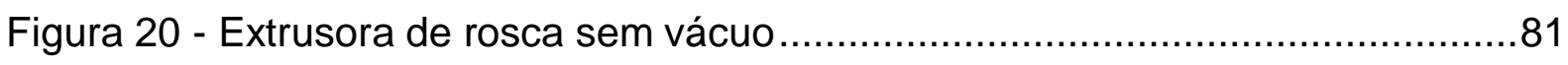

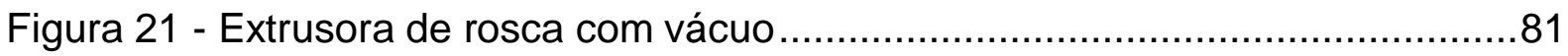

Figura 22 - Elementos do reômetro extrusor, boquilhas (a) e barril (b) .....................83

Figura 23 - Reômetro acoplado à maquina de ensaios mecânicos ..............................84

Figura 24 - Preparação do reômetro extrusor para ensaio ..........................................85 


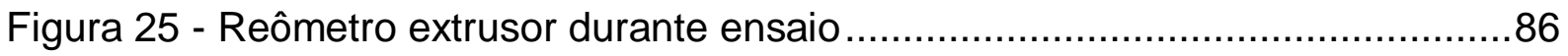




\section{LISTA DE TABELAS}

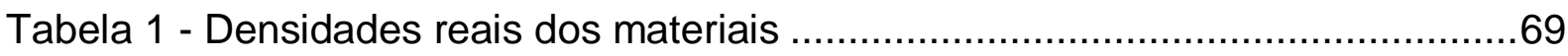

Tabela 2 - Composição química dos cimentos em \% massa ....................................71

Tabela 3 - Composição química do calcário em \% massa .......................................71

Tabela 4 - Composição química da sílica ativa em \% massa....................................71

Tabela 5 - Área de superfície específica das matérias-primas .................................72

Tabela 6 - Composição mineralógica da sílica ativa..............................................73

Tabela 7 - Composição mineralógica do calcário …………………......................73

Tabela 8 - Propriedades das fibras celulósicas …………....................................... 78

Tabela 9 - Propriedades das fibras de PVA Kuralon KII .......................................79

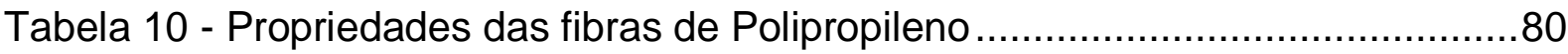

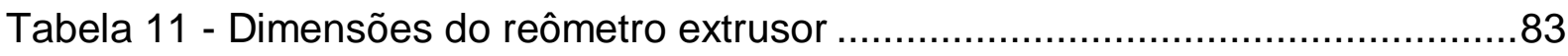

Tabela 12 - Formulações com variações dos componentes em porcentagem...........90

Tabela 13 - Formulações com variações dos componentes em massa .....................91

Tabela 14 - Parâmetros reológicos de Benbow para as componentes .....................92

Tabela 15 - Formulações com variação dos aditivos em \% massa ..........................101

Tabela 16 - Formulações com variação dos aditivos em massa .............................102

Tabela 17 - Parâmetro reológicos de Benbow para as formulações variando os aditivos

Tabela 18- Propriedades mecânicas dos compósitos com diferentes teores de HPMC

Tabela 19- Propriedades físicas dos compósitos com adição de HPMC

Tabela 20 - Propriedades mecânicas dos compósitos com variações de teor de

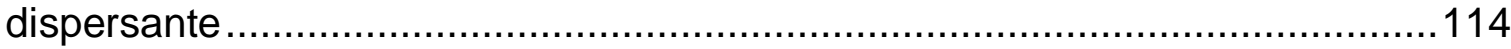

Tabela 21- Propriedades físicas dos compósitos com diferentes teores de dispersante.

Tabela 22 - Formulações para determinação de coeficientes dos modelos. 119

Tabela 23 - Análise dos modelos para as propriedades mecânicas da matriz 120

Tabela 24 - Modelos ajustados para a modelagem das propriedades mecânicas da matriz. 120

Tabela 25 - Análise dos modelos para as propriedades físicas da matriz 125

Tabela 26 - Modelos implementados para o comportamento físico das matrizes ...125 
Tabela 27 - Demanda de água e fração volumétrica de sólidos (FVS) para as matrizes

Tabela 28 - Análise dos modelos linear e quadrático para a/s e FVS das matrizes 129

Tabela 29 - Modelos quadráticos implementados para a/s e FVS das matrizes .....130

Tabela 30 - Delineamento experimental para determinação dos coeficientes dos modelos para a matriz reforçada ........................................................ 133

Tabela 31 - Análise dos modelos para as propriedades mecânicas da matriz reforçada 134

Tabela 32 - Modelos implantados para o comportamento mecânico da matriz reforçada 135

Tabela 33 - Análise dos modelos para as propriedades físicas da matriz reforçada 139

Tabela 34 - Modelos implementados para o comportamento físico da matriz reforçada 140

Tabela 35 - Propriedades físicas e mecânicas das formulações com e sem envelhecimento

Tabela 36 - Propriedades físicas dos compósitos reforçados com celulose com e sem envelhecimento 152

Tabela 37 - Formulações utilizadas para determinar os módulos de Weibull. 154

Tabela 38 - Custo unitário das matérias-primas 157

Tabela 39 - Custos das formulações da matriz para a determinação dos coeficientes do modelo para uma tonelada de compósito. 157

Tabela 40 - Modelo quadrático aplicado ao custo da matriz 158

Tabela 41 - Custos das formulações reforçadas para a determinação dos coeficientes do modelo. 159

Tabela 42 - Modelo quadrático aplicado ao custo do reforço 159 


\section{LISTA DE GRÁFICOS}

Gráfico 1 - Curvas com comportamento reológico de fluidos: (1) newtoniano; (2) Bingham; (3) pseudoplástico (4) pseudoplástico com tensão de escoamento; (5) dilatante; (6) dilatante com tensão de escoamento, extraído de Oliveira et al. (2000)

Gráfico 2 - Representação esquemática da relação viscosidade em função da taxa de cisalhamento, Barnes et al. (1989)

Gráfico 3 - Curvas de tensão de cisalhamento em função da taxa de cisalhamento por diferentes modelos

Gráfico 4 - Sistema de coordenadas simplex .53

Gráfico 5 - Curva carga-deslocamento do pistão extrusor 61

Gráfico 6 - Método de cálculo dos parâmetros reológicos de Benbow. 62

Gráfico 7 - Curvas Pressão de extrusão-L/D para cálculo dos parâmetros de extrusão 62

Gráfico 8 - Porcentagem acumulada de partículas das matérias-primas. .70

Gráfico 9 - EDS da sílica ativa. .74

Gráfico 10 - EDS do calcário .75

Gráfico 11 - Ensaio de repetitividade da pressão de extrusão em diferentes velocidades

Gráfico 12 - Efeito da configuração da boquilha na pressão de extrusão em diferentes velocidades .87

Gráfico 13 - Etapas do processo de mistura (autor anônimo) .89

Gráfico 14 - Tensão de escoamento inicial dos componentes vs. \% massa das adições 96

Gráfico 15 - Tensão de cisalhamento inicial dos componentes vs. \% massa das adições

Gráfico 16 - Influência da velocidade na tensão de escoamento vs. \% massa das adições

Gráfico 17 - Influência da velocidade na tensão de cisalhamento vs. \% massa das adições

Gráfico 18 - Pressão total de extrusão para os teores de adições 98

Gráfico 19 - Pressão total para teores de polipropileno 
Gráfico 20 - Tensão de escoamento inicial vs. adições de polipropileno .99

Gráfico 21 - Tensão de cisalhamento inicial vs adições de polipropileno .99

Gráfico 22 - Influência da velocidade na tensão de escoamento vs. \%massa de fibras de polipropileno 100

Gráfico 23 - Influência da velocidade na tensão de cisalhamento vs. \%massa de

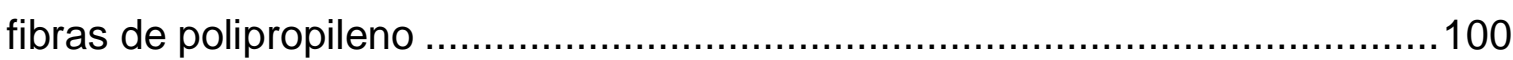

Gráfico 24 - Tensão de escoamento inicial vs. teor de aditivos..............................106

Gráfico 25 - Tensão de cisalhamento inicial vs. teor de aditivos .............................107

Gráfico 26 - Efeito da velocidade na tensão de escoamento vs. teor de aditivos....107 Gráfico 27 - Efeito da velocidade na tensão de cisalhamento para os aditivos .......108

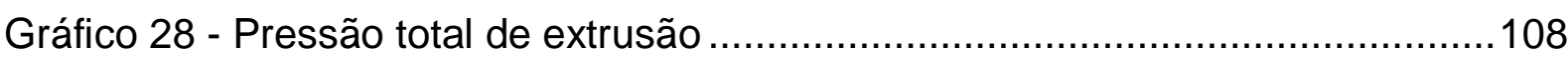

Gráfico 29 - Módulo de ruptura do compósito com diferentes teores de HPMC......110 Gráfico 30 - Energia específica do compósito com diferentes teores de HPMC .....111 Gráfico 31 - Absorção de água do compósito com diferentes teores de HPMC......112 Gráfico 32 - Densidade aparente de compósitos com diferentes teores de HPMC.112 Gráfico 33 - Porosidade aparente de compósitos com diferentes teores de HPMC 113 Gráfico 34 - Módulo de ruptura do compósito com diferentes teores de dispersantes

Gráfico 35 - Energia específica do compósito com diferentes teores de dispersante 115

Gráfico 36 - Porosidade aparente do compósito com diferentes teores de dispersante 116

Gráfico 37 - Absorção de água do compósito com diferentes teores de dispersante 116

Gráfico 38 - Valores de MOR estimados com o modelo quadrático para as matrizes 122

Gráfico 39 - Valores de LOP estimado com o modelo quadrático para as matizes.122 Gráfico 40 - Valores de MOE estimado com o modelo quadrático para as matrizes

Gráfico 41 - Valores de EE estimado com o modelo cúbico para as matrizes 124

Gráfico 42 - Valores de AA estimado com o modelo quadrático para as matrizes ..126

Gráfico 43 - Valores de DA estimado com o modelo linear para as matrizes.

Gráfico 44 - Valores de PA estimado com o modelo quadrático para as matrizes ..128 Gráfico 45 - Comportamento da demanda de água nas formulações cimenticias ..130 
Gráfico 46 - Comportamento da FVS dos sistemas particulados 132

Gráfico 47 - Valores de MOR estimado com modelo cúbico para o reforço. 136

Gráfico 48 - Valores de LOP estimado com modelo cúbico para o reforço 137

Gráfico 49 - Valores de MOE estimado com modelo cúbico para o reforço 138

Gráfico 50 - Valores de EE estimado com modelo cúbico completo para o reforço 138 Gráfico 51 - Valores de AA estimado com modelo linear para o reforço. 140

Gráfico 52 - Valores de PA estimado com modelo linear para o reforço 141

Gráfico 53 - Valores de DA estimado com modelo linear para o reforço 142 Gráfico 54 - MOR das formulações com teores de $4 \%$, $8 \%$ e $12 \%$ de polpa de celulose com e sem envelhecimento.

Gráfico 55 - EE das formulações com teores de 4\%, 8\% e 12\% de polpa de celulose com e sem envelhecimento 148

Gráfico 56 - Curvas de tensão x flecha específica das formulações sem envelhecimento 148

Gráfico 57 - Curvas de tensão x flecha específica das formulações com 200 ciclos de envelhecimento

Gráfico 58 - Curvas representativas de tensão x flecha específica das formulações com $4 \%$ de celulose com e sem envelhecimento

Gráfico 59 - Curvas representativas de tensão x flecha específica das formulações com $8 \%$ de celulose com e sem envelhecimento 151

Gráfico 60 - Curvas representativas de tensão x flecha específica das formulações com $12 \%$ de celulose com e sem envelhecimento

Gráfico 61 - AA das formulações com teores de 4\%, 8\% e 12\% de polpa de celulose com e sem envelhecimento 153

Gráfico 62 - DA das formulações com teores de 4\%, 8\% e 12\% de polpa de celulose com e sem envelhecimento 153

Gráfico 63 - Linearização dos valores de MOR da formulação da matriz sem reforço para determinação do módulo de Weibull 155

Gráfico 64 - Linearização dos valores de MOR da formulação da matriz com reforço para determinação do módulo de Weibull 155

Gráfico 65 - Variação do custo da matriz com combinações de CPV, S e CC ........158

Gráfico 66 - Variação do custo da matriz reforçada com PP e C 160 


\section{SUMÁRIO}

\section{AGRADECIMENTOS}

\section{RESUMO}

\section{ABSTRACT}

\section{LISTA DE ABREVIATURAS E SIGLAS}

LISTA DE SÍMBOLOS

\section{LISTA DE FIGURAS}

\section{LISTA DE TABELAS}

\section{LISTA DE GRÁFICOS}

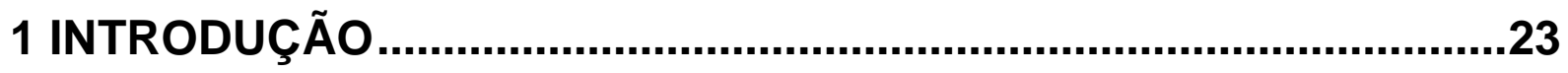

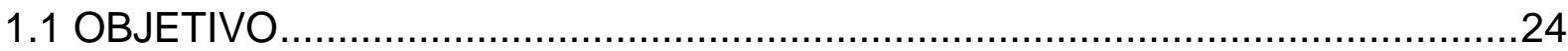

1.2 CONTEÚDO

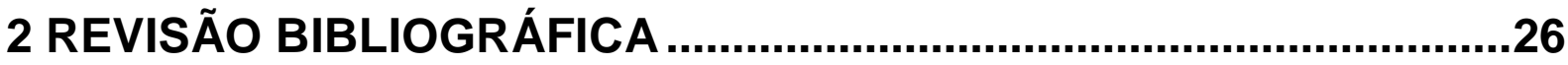

2.1 PROCESSOS DE FABRICAÇÃO DE FIBROCIMENTO ….................................26

2.2 ASPECTOS QUE INFLUENCIAM A EXTRUSÃO …….................................27

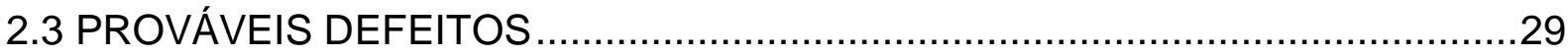

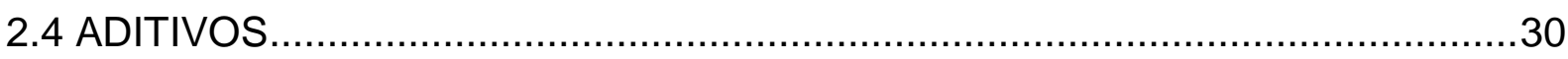

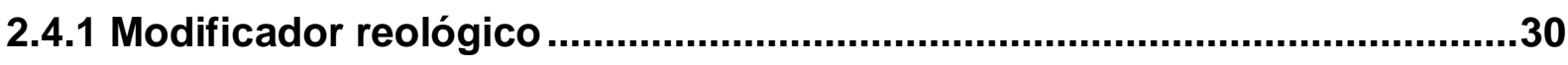

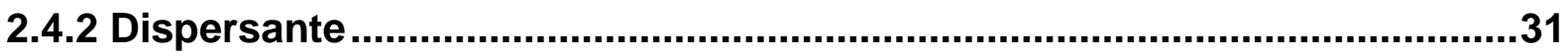

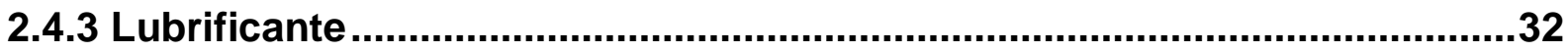

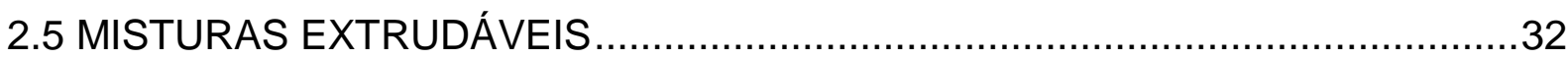

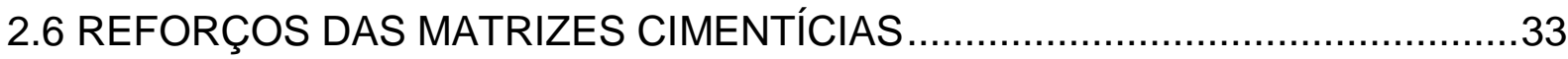

2.6.1 Efeito das propriedades das fibras.................................................................3

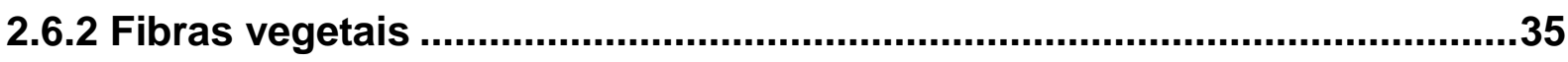

2.6.3 A utilização de fibras celulósicas em fibrocimentos..................................36

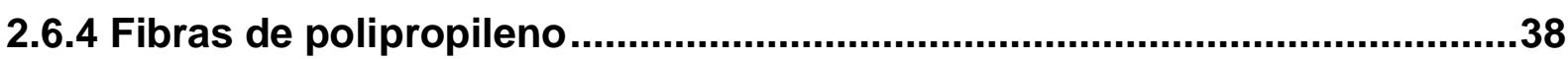

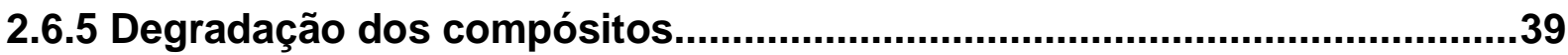

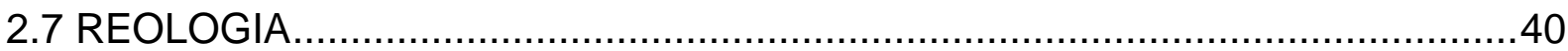

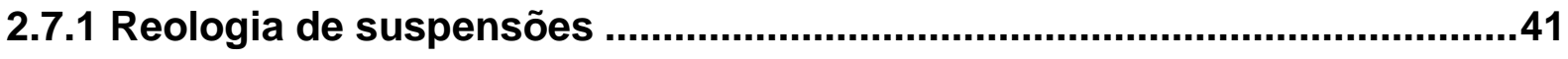

2.7.2 Equações constitutivas simplificadas ....................................................... 42 


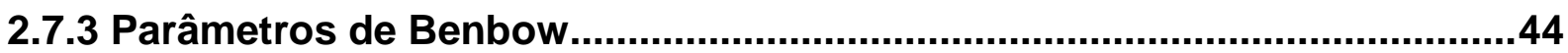

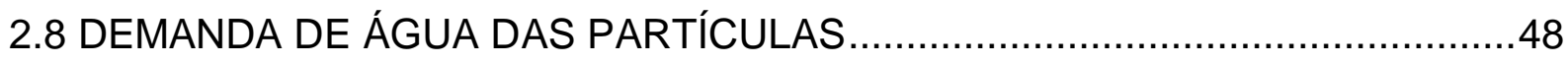

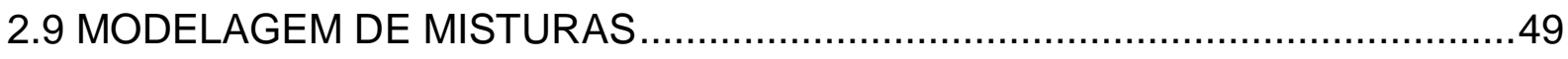

2.10 AVALIAÇÃO DE CONFIABILIDADE DO PROCESSO ....................................53

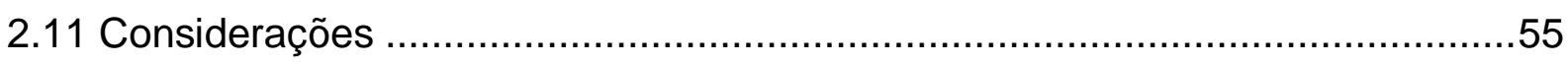

3 MATERIAIS E MÉTODOS .............................................................56

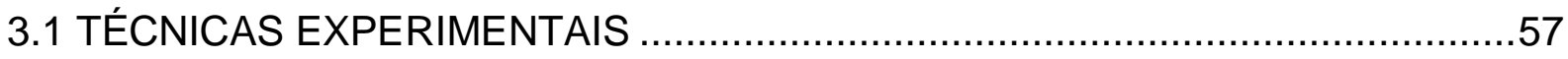

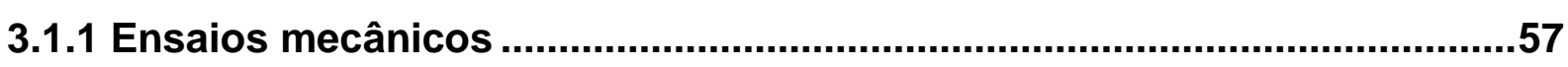

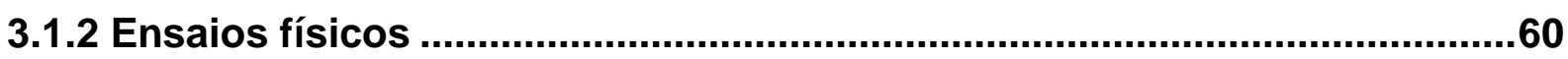

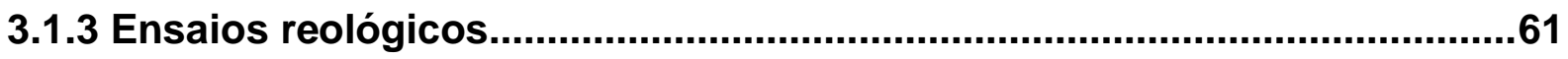

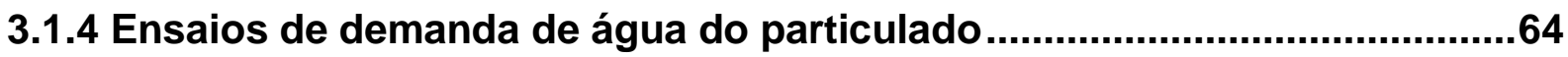

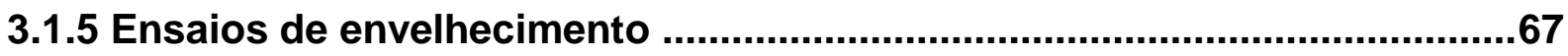

3.2 PROPRIEDADES DAS MATÉRIAS-PRIMAS DA MATRIZ .............................68

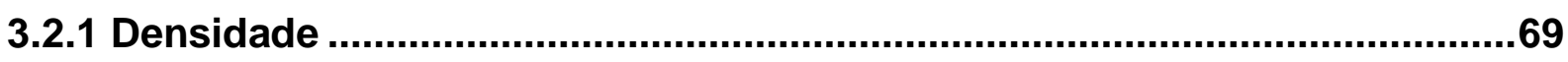

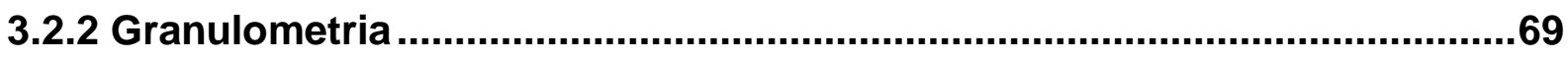

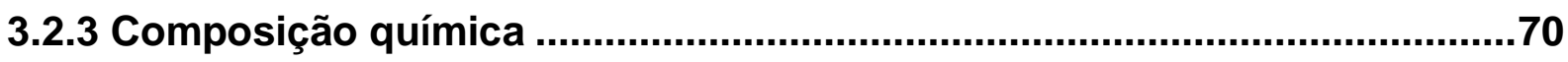

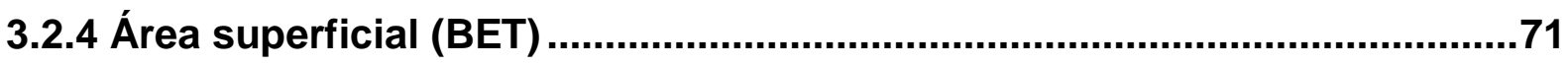

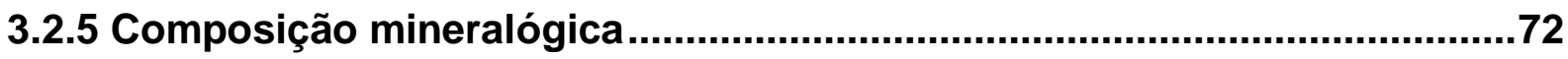

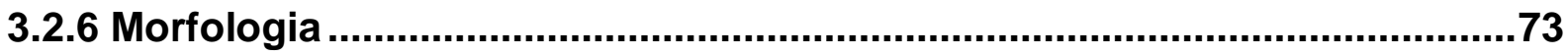

3.3 PROPRIEDADES DAS FIBRAS DE REFORÇO ….....................................77

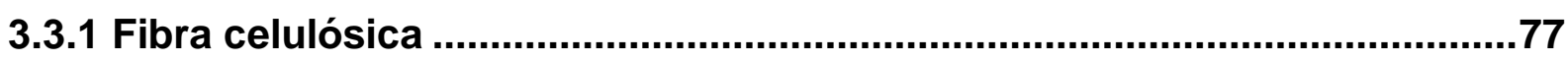

3.3.1.1 Características morfológicas das fibras celulósicas de eucalipto ..................77

3.3.1.2 Umidade das fibras celulósicas de eucalipto ..........................................78

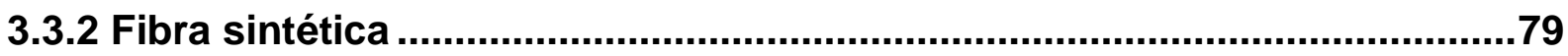

3.3.1.3 Fibras de polivinil-álcool ....................................................................

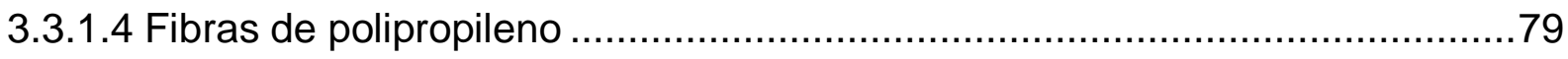

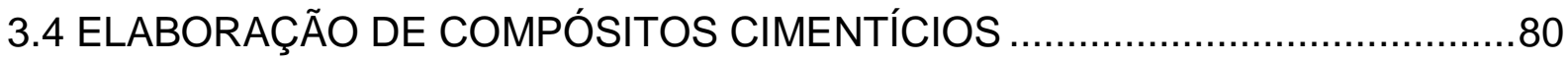

3.4.1 Equipamentos utilizados para a extrusão de compósitos..........................80

3.4.2 Elaboração de corpos-de-prova por extrusão ..........................................81

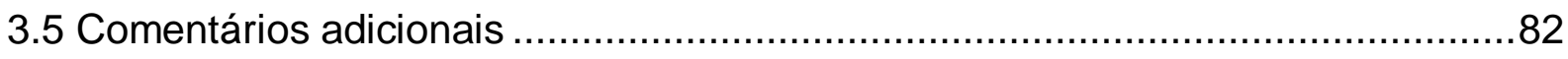

4 ESTUDO REOLÓGICO ................................................................83

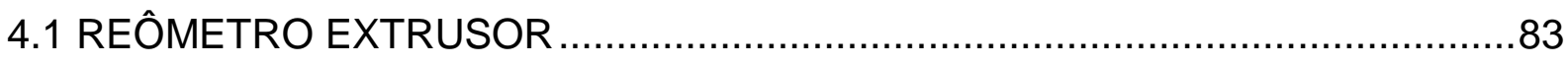

4.1.1 Análise da repetitividade dos dados do equipamento...............................84 


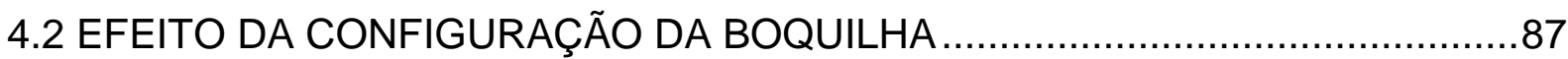

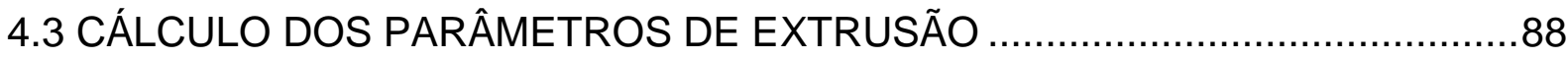

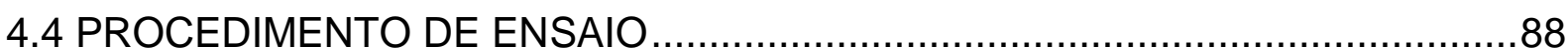

4.5 INFLUÊNCIA DOS COMPONENTES DA FORMULAÇÃO NA REOLOGIA DO

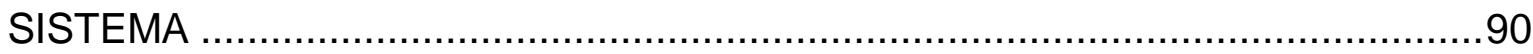

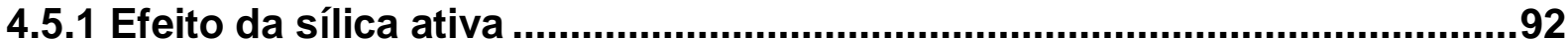

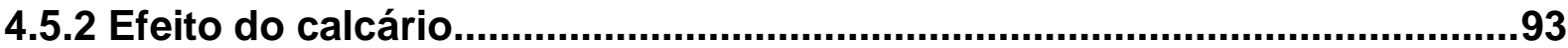

4.5.3 Efeito da polpa de celulose de eucalipto ...................................................94

4.5.4 Efeito do conteúdo de fibras de polipropileno ...........................................95

4.6 INFLUÊNCIA DOS ADITIVOS NA REOLOGIA DO SISTEMA ….....................101

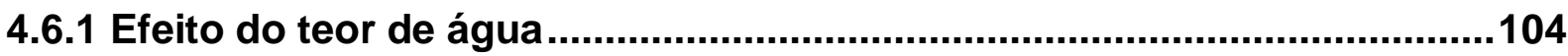

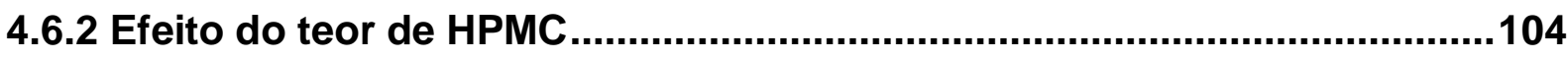

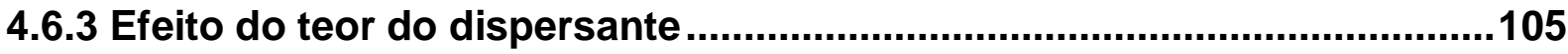

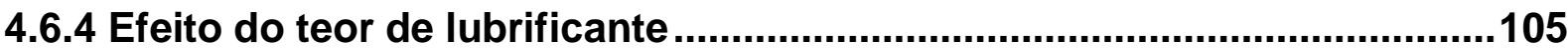

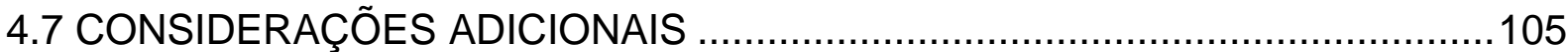

5 COMPÓSITOS ELABORADOS POR EXTRUSÃO..........................109

5.1 EFEITO DO HPMC NO COMPÓSITO DE CIMENTO ELABORADO POR EXTRUSÃO 109

5.2 EFEITO DO DISPERSANTE NO COMPÓSITO DE CIMENTO ELABORADO

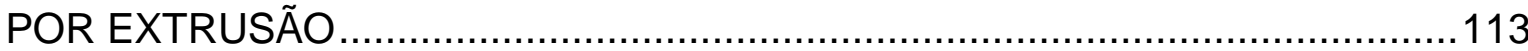

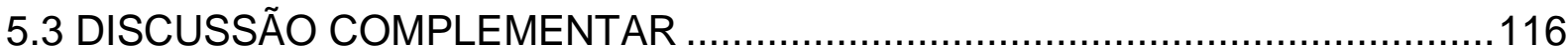

6 MODELAGEM ESTATÍSTICA DO COMPÓSITO...............................118

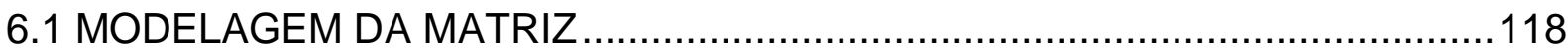

6.1.1 Modelagem das propriedades mecânicas...............................................119

6.1.2 Modelagem das propriedades físicas.....................................................124

6.1.3 Modelagem da demanda de água do particulado....................................128

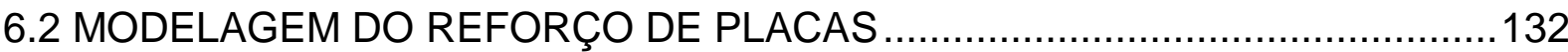

6.2.1 Modelagem das propriedades mecânicas...................................................133

6.2.2 Modelagem das propriedades físicas ......................................................139

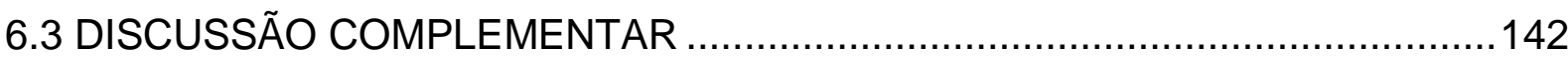

7 ESTUDOS COMPLEMENTARES .................................................144

7.1 ENVELHECIMENTO DE PLACAS CIMENTÍCIAS ........................................144

7.1.1 Resultados do envelhecimento e discussão ..........................................145 
7.2 REPRODUTIBILIDADE DA PRODUÇÃO DE COMPÓSITOS EXTRUDADOS

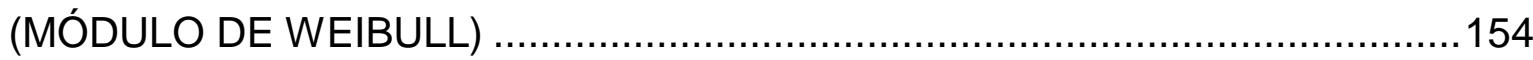

7.3 CUSTOS DA PRODUÇÃO DE COMPÓSITOS EXTRUDADOS …...................156

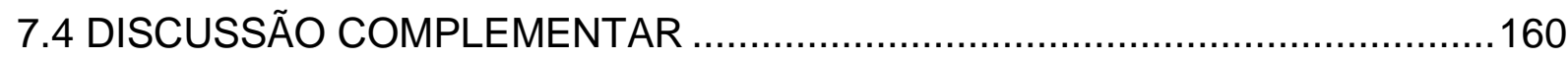

8 CONSIDERAÇÕES ....................................................................162

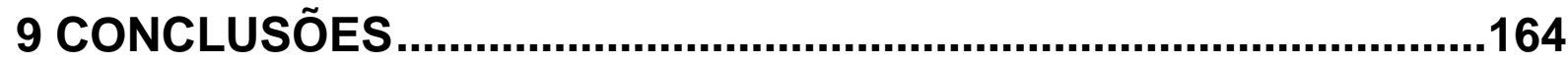

9.1 PROPOSTA PARA TRABALHOS FUTUROS ….....................................167

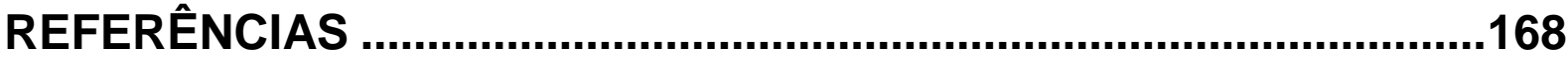

APÊNDICE A - Estudo Preliminar das FormulaçõesErro! Indicador não definido.

APÊNDICE B - Resultados das propriedades mecânicas, físicas e demanda de água das formulações utilizadas na modelagem dos compósitos extrudados 


\section{INTRODUÇÃO}

A extrusão é um processo de conformação em contínuo que consiste em forçar a passagem de uma mistura altamente viscosa através de uma boquilha. É um candidato em potencial para a produção industrial de compósitos cimentícios, como telhas, placas e tubos, entre outros. Exibe versatilidade na elaboração de componentes de construção de configuração transversal variada, não se limitando a placas, como em muitos processos convencionais.

Estudos recentes apresentam o processo de extrusão como alternativa economicamente viável de manufatura de elementos construtivos elaborados com matrizes cimentícias (QIAN et al., 2003; TAKASHIMA et al.,2003).

O sucesso da extrudabilidade requer controle das propriedades das matériasprimas, parâmetros de processo assim como da reologia da mistura. Adequar esses conjuntos de aspectos para viabilizar a extrusão não tem se mostrado tarefa trivial, dificultando a viabilização do processo na indústria nacional de compósitos cimentícios.

A implantação do processo de extrusão de materiais de fibrocimento no setor produtivo brasileiro permitirá a implantação de fábricas em regiões de baixa densidade demográfica, graças ao baixo custo de montagem da linha de produção. Como efeito, a barreira de altos investimentos para a implantação de uma fábrica de fibrocimento seria quebrada com a viabilização do processo de extrusão, que permitirá, assim, o surgimento de novos fornecedores e produtos no mercado, tornando-o mais competitivo. Tal panorama beneficiará os consumidores, como consequência da competição mais acirrada, com produtos potencialmente melhores e diversificados. 


\subsection{OBJETIVO}

O objetivo deste trabalho é contribuir para o desenvolvimento do processo de extrusão para a produção de compósitos fibrosos à base de matriz de cimento Portland.

Objetivos específicos:

Avaliar a influência das matérias-primas e aditivos nos parâmetros reológicos utilizando reômetro extrusor;

> Implementar modelos estatísticos de misturas para matrizes puras e matrizes reforçadas, com a finalidade de descrever a influência das matérias-primas no desempenho mecânico e físico dessas misturas;

- Determinar a demanda de água dos sistemas particulados das matrizes, e respectivos efeitos das componentes, utilizando modelagem estatística e técnica experimental proposta;

> Estudar a viabilidade da metodologia de envelhecimento acelerado de imersão/secagem com 200 ciclos nas propriedades mecânicas e físicas dos compósitos extrudados;

> Estudar o módulo de Weibull na avaliação da reprodutibilidade da propriedade mecânica do módulo de ruptura (MOR) dos compósitos extrudados;

> Determinar a competitividade econômica aproximada dos compósitos cimentícios elaborados por extrusão e os encontrados no mercado.

\subsection{CONTEÚDO}

O presente trabalho foi desenvolvido seguindo a seguinte sequência: no capítulo 1 são apresentados a introdução e os objetivos; a seguir, no capítulo 2 é apresentada a revisão na literatura dos aspectos relevantes ao tema em questão. As principais técnicas experimentais aplicadas são descritas no capítulo 3. No mesmo 
capítulo 3 são descritos as respectivas caracterizações dos materiais utilizados no estudo. O comportamento reológico do sistema cimentício devido à respectiva influência de cada componente é apresentado no capítulo 4. No capítulo 5 está descrito o efeito dos componentes aditivos no desempenho físico e mecânico do compósito endurecido.

O capítulo 6 apresenta o estudo da modelagem estatística da matriz com a finalidade de determinar a influência dos diferentes componentes no desempenho mecânico e físico, ainda nesse item, é realizado o modelamento estatístico da demanda de água do material particulado. No tópico 6.2 é implementado o modelo do reforço da matriz com as respectivas influências do reforço com fibras de polipropileno e celulose de eucalipto. O estudo de durabilidade para as formulações reforçadas com celulose e fibras poliméricas é apresentado no capítulo 7. O estudo do módulo de Weibull e custos dos compósitos cimentícios são apresentados no capítulo 7. As conclusões finais do trabalho são apresentadas no capítulo 8 e as recomendações para estudos futuros são apresentadas no tópico 8.1. 


\section{REVISÃO BIBLIOGRÁFICA}

\subsection{PROCESSOS DE FABRICAÇÃO DE FIBROCIMENTO}

O fibrocimento tem sido fabricado predominantemente pelo processo Hatschek, como pode ser observado no esquema da Figura 1. O processo de extrusão é uma tecnologia utilizada recentemente na elaboração de fibrocimento e uma de suas características principais é a necessidade de utilizar relações água/cimento (a/c) baixas, entre 0,2 a 0,3 , assim como também utilizar misturas que apresentam comportamento reológico pseudoplástico. O mesmo permite uma ampla variedade de secções transversais de elementos construtivos (BENBOW et al, 1991; BURBIDGE; BRIDGWATER, 1995; HORST, 2002; SHAO, 1995; VLACHOPOULOS; WAGNER, 2001).

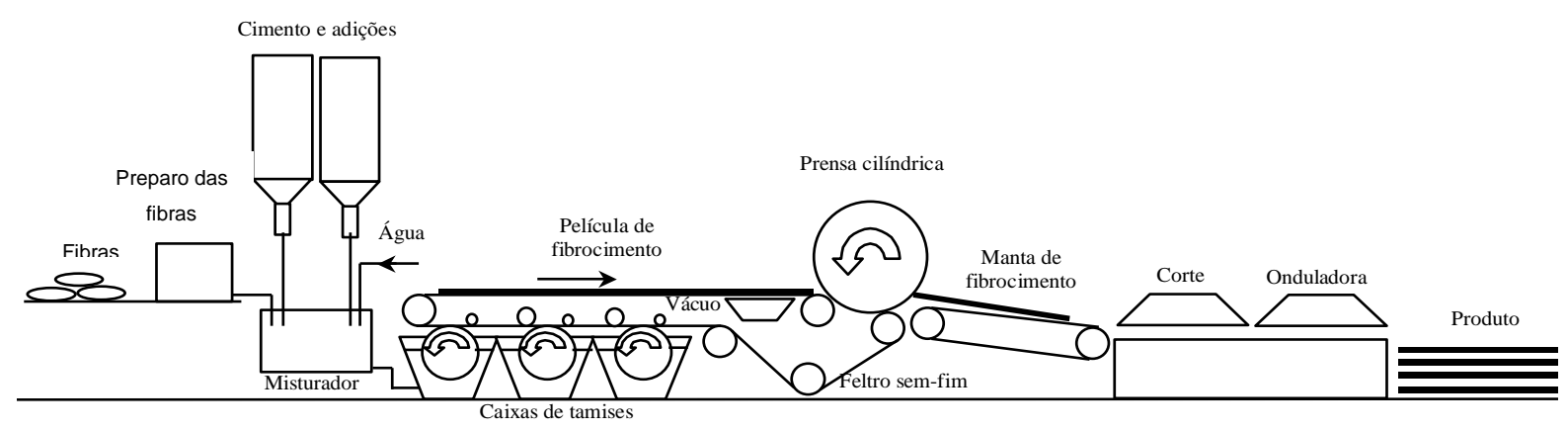

Figura 1 - Processo Hatschek, extraído de Dias; Savastano Jr e John (2010)

A extrusão consiste em comprimir um material com comportamento pseudoplástico, com tensão de escoamento, através de uma abertura obtendo-se o fluxo desse material e atingindo uma configuração geométrica conferida pela geometria da boquilha. Nesse processo, o material é submetido a altas tensões tangenciais e normais.

As extrusoras podem ser conceitualmente de dois mecanismos: a extrusora por pistão (ram extruder) e a extrusora a rosca (auger extruder). A primeira se diferencia da segunda pelo fato de funcionar em regime intermitente em comparação com a segunda que trabalha em regime contínuo. As extrusoras a rosca podem ser fabricadas com uma câmara de vácuo com o propósito de reduzir a quantidade de 
vazios existentes na mistura extrudada. As partes de uma extrusora de vácuo são apresentadas na Figura 2, sendo salientada a câmara de mistura, a câmara de vácuo ou de desaeração e a câmara de compactação.

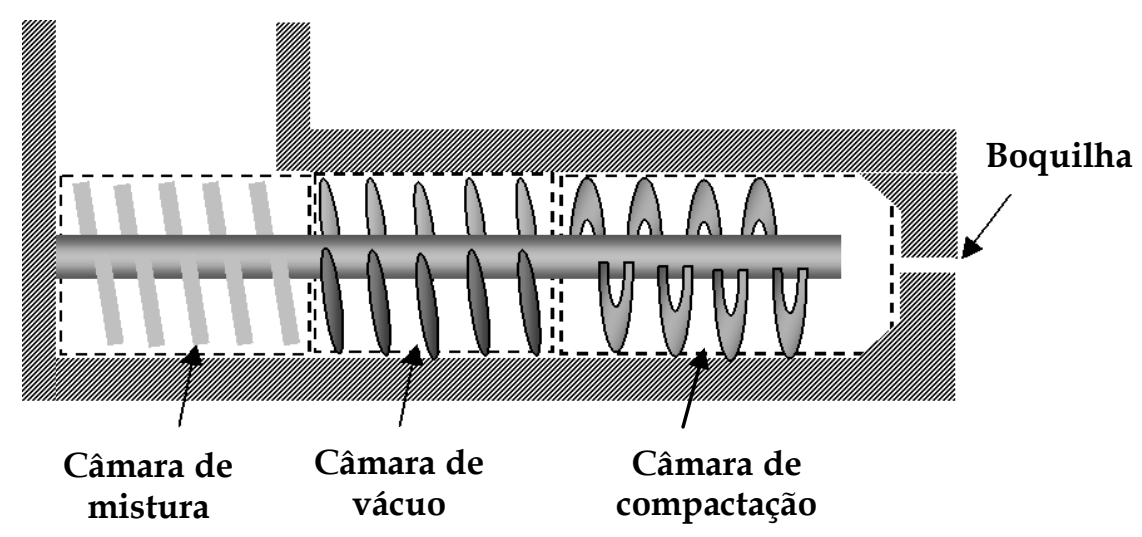

Figura 2 - Esquema de extrusão a vácuo

\subsection{ASPECTOS QUE INFLUENCIAM A EXTRUSÃO}

O êxito do processo de extrusão depende do comportamento reológico da formulação, das características da máquina extrusora, da geometria da boquilha e da boa homogeneização das matérias-primas (LI, 2001; QIAN et al., 2003; SHAO et al., 1995; SHAO et al., 2000; SHAO; SHAH, 1997; SRINIVASAN; DEFORD; SHAH, 1999; TAKASHIMA et al., 2003).

As características relevantes da extrusora são: a geometria da rosca, o comprimento das seções de alimentação, de desaeração e de compactação, velocidade da rosca e as pressões de vácuo exercidas na seção de desaeração (SHAO, 1995).

O propósito da boquilha é promover a compactação final da mistura cimentícia e formar a desejada geometria da seção transversal do produto. Para garantir a saída de produtos extrudados com bom acabamento, deve-se evitar gradientes de velocidade a fim de que as formulações cimentícias fluam uniformemente através da boquilha. Se elas fluírem com taxas de velocidade diferentes, geram-se gradientes de tensões durante 0 processo e 0 produto 
extrudado deformará assim que sair da boquilha (BURBIDGE et al., 1995; CHEN; MURAKAMI, 2000).

O comportamento reológico da mistura cimentícia é um dos aspectos de fundamental importância no processo de extrusão. Para que a mistura flua quando pressionada na boquilha e posteriormente mantenha a configuração que esta lhe confere, é necessário que a mistura tenha um comportamento pseudoplástico com tensão inicial de escoamento, conforme apresentado no Gráfico 1 correspondente à curva 4 ao Gráfico 1(a) e 1(b). Os Gráficos referem-se ao material que flui quando submetido às tensões tangenciais e normais, na ausência das mesmas ele não flui, sendo necessária uma tensão de cisalhamento inicial para que isso ocorra. Esse tipo de comportamento é chamado de pseudoplástico com tensão inicial de escoamento.

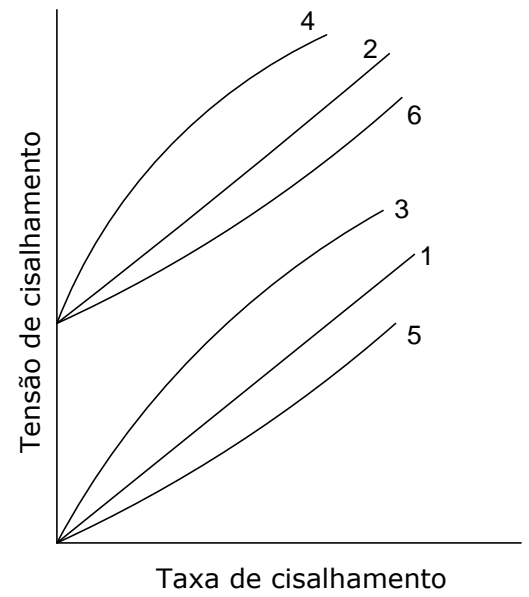

(a)

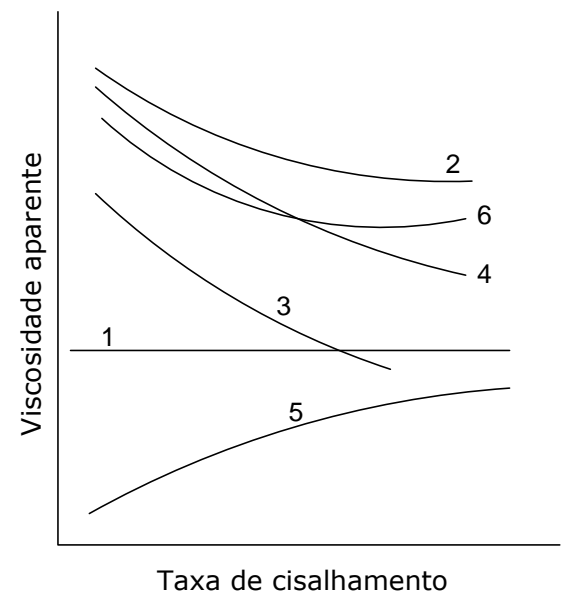

(b)

Gráfico 1 - Curvas com comportamento reológico de fluidos: (1) newtoniano; (2) Bingham; (3) pseudoplástico (4) pseudoplástico com tensão de escoamento; (5) dilatante; (6) dilatante com tensão de escoamento, extraído de Oliveira et al. (2000)

A mistura é influenciada, nesse caso, pela fase líquida, pela fase sólida e pela fase fibra. Em relação à mistura, pode-se afirmar que:

$\mathrm{Na}$ fase sólida há influência da distribuição granulométrica, da química da superfície, da fração volumétrica, da morfologia das partículas e da densidade de empacotamento;

$>$ As fibras se apresentam principalmente como um obstáculo ao movimento das outras duas fases. Durante o processo, elas tendem a ficar alinhadas na direção do fluxo da pasta e sendo esse o posicionamento que menos obstrui o movimento do particulado, o que pode ser observado na Figura 3. 


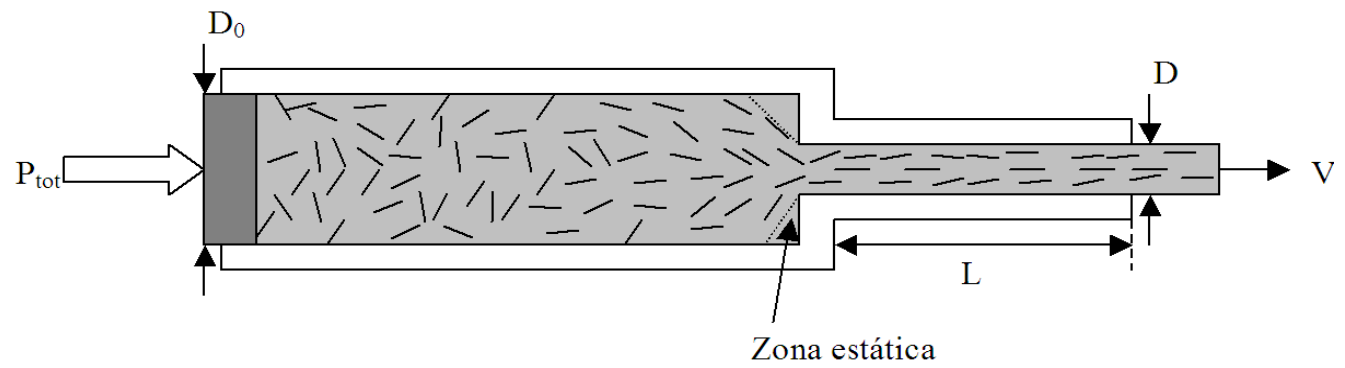

Figura 3 - Movimento das fibras na extrusão, Srinivasan et al. (1999).

A fase líquida influencia a extrusão devido à capacidade de molhar as superfícies dos particulados, reagirem com o cimento, assim como ter o seu próprio comportamento reológico devido à presença de modificadores reológicos no processo de mistura.

\subsection{PROVÁVEIS DEFEITOS}

Os defeitos que podem ocorrer durante a extrusão são (REED, 1995; SHEN, 2003):

> Migração da fase: onde a fase líquida abandona a fase sólida levando a um congestionamento da boquilha, pois a mistura deixa de ter um comportamento pseudoplástico. Isso acontece devido à deficiência na formulação da mistura em ter um comportamento reológico pseudoplástico, nas tensões a que é submetida;

> Defeitos de superfície no produto extrudado: isso acontece devido ao atrito que ocorre na interface entre a mistura e a boquilha;

> Podem ocorrer defeitos por fluxo laminar entre dois setores do extrudado: isso acontece devido ao dimensionamento inadequado da boquilha que promove gradiente no fluxo. 


\subsection{ADITIVOS}

Os aditivos com potencial de uso no processo de extrusão são aqueles que podem reter a água dentro da mistura quando a mesma está sendo submetida a tensões tangenciais e normais no processo. Outro tipo de aditivo útil no processo é aquele capaz de reduzir as tensões entre a parede da boquilha e a mistura, pois tensões elevadas geram imperfeições na superfície do produto elaborado. É extremamente importante a utilização de dispersante para reduzir a quantidade de água utilizada no processo, não unicamente para evitar a migração de fase, mas também para garantir a hidratação dos componentes anidros do cimento e evitar a aglomeração do cimento atuando como mecanismo eletro estérico. Para a retenção de água, apresentam-se úteis os retentores de água como o Hidroxipropilmetilcelulose, Carboximetilcelulose e Poliacrilamida entre outros. Esses aditivos não apenas retêm água na mistura, como também promovem 0 comportamento pseudoplástico da fase contínua. Para a redução do atrito entre a parede da boquilha e a mistura, são úteis os lubrificantes como o polipropileno glicol e o polietileno glicol, ambos solúveis em água, entre outros (ONADA, 1979; PELED, 2000; QIAN, 2003; SHEN, 2003).

Portanto, mostram-se úteis pelas considerações anteriores os aditivos dispersantes, retentores de água também conhecidos como modificadores reológicos e lubrificantes.

\subsubsection{Modificador reológico}

Os modificadores reológicos são aditivos que consistem de polímeros sintéticos e orgânicos solúveis em água como os éteres celulósicos, poliacrilamidas e gomas (RACMACHANDRA, 1995).

As formas de ação dos éteres celulósicos podem ser classificadas em três categorias: i) adsorção: as moléculas poliméricas de cadeia longa aderem na periferia das moléculas de água, adsorvendo e fixando parte da água do sistema e aumentando a viscosidade da mistura; ii) associação: podem surgir forças de 
atração entre as moléculas adjacentes, dificultando ainda mais, a movimentação da água, causando a formação de um gel e aumento da viscosidade; iii) entrelaçamento: em altas concentrações e sob baixas tensões de cisalhamento, as cadeias poliméricas podem se entrelaçar causando um aumento da viscosidade aparente (KHAYAT, 1998).

\subsubsection{Dispersante}

Os dispersantes de alto desempenho são conhecidos na área de cimento como superplastificantes. Muitos dos superplastificantes são polímeros lineares contendo grupos de ácidos sulfonados ligados a estrutura polimérica. Os sulfonados melamina-formaldeidos condensados e nafhtaleno formaldeidos-condensados são os mais comuns (MINDESS; YOUNG, 1981).

A propriedade mais importante de um superplastificante é a habilidade de dispersar partículas de cimento. Baseado em teorias de forças atômicas, estudos de adsorção e evidências de potencial zeta, o mecanismo de dispersão consiste em uma combinação de repulsão eletrostática e estabilização estérica (DAIMOND; ROY, 1978; UCHIKAWA, 1997). Devido a sua capacidade dispersiva, os dispersantes reduzem drasticamente a tensão de escoamento e a viscosidade da pasta de cimento. Para a dosagem significativa de superplastificante a tensão de escoamento da pasta de cimento é reduzido próximo a zero e o comportamento do fluido se aproxima ao newtoniano (ASAGA; ROY, 1980; BANFILL, 1981).

Além de contribuir para a fluidez da pasta de cimento, os superplastificantes retardam a hidratação dessa pasta (MINDESS; YOUNG, 1981). Inúmeros mecanismos foram propostos para explicar como os aditivos orgânicos afetam a hidratação, porém ainda existem debates relacionados a esse fenômeno. É geralmente aceito que os superplastificantes são adsorvidos pelos componentes de $\mathrm{C}_{3} \mathrm{~A}$ das partículas de cimento (ASAGA; ROY 1980). A adsorção e o possível desenvolvimento de estruturas complexas que atuam como barreiras da hidratação sendo finalmente removidos da solução ao serem incorporados na estrutura dos produtos da hidratação (YOUNG, 1972). 


\subsubsection{Lubrificante}

Aditivos que tenham a capacidade de reduzir significativamente a resistência ao deslizamento são considerados lubrificantes efetivos.

A lubrificação por fluido é promovida por um filme líquido como, por exemplo, água ou óleo, que devem migrar rapidamente para a interface massa-boquilha durante a atividade das tensões tangenciais e normais, lubrificando a superfície pela redução do cisalhamento (REED,1988).

A utilização de lubrificante é de vital importância quando tem-se em questão a utilização de boquilhas de complexa configuração, uma vez que o principal efeito lubrificante ocorre na interface material extrudado e o corpo da boquilha (DAS; MADHUSOODANA; OKADA, 2002).

\subsection{MISTURAS EXTRUDÁVEIS}

A mistura para extrusão deve ter um comportamento reológico pseudoplástico com tensão de escoamento, esse comportamento pode ser atingido a partir das seguintes considerações:

> Trabalhar com o empacotamento do material particulado e com a reologia da fase líquida: $O$ material particulado deve ser dimensionado utilizando coeficientes de empacotamento que levem a um comportamento pseudoplástico, sem perder de vista a consideração do efeito parede (OLIVEIRA et al., 2000). Isso pode ser atingido com a utilização de modelos de empacotamento como, por exemplo, o de Andreasen ou Alfred. Para atingir o melhor desempenho mecânico possível é necessária uma configuração de partículas que cumpra o requerimento de pseudoplasticidade com a menor porosidade possível;

> A fase líquida: Deve estar ajustada de tal forma que forneça água suficiente para a hidratação do cimento, assim como permitir o molhamento do restante do material particulado; 
> Aditivo dispersante: Calculado com o teor necessário para promover a diminuição de água necessária para hidratar as partículas de cimento;

> Aditivo retentor de água: Com o teor suficiente para reter a água na mistura sem permitir o fenômeno de migração de fase.

\subsection{REFORÇOS DAS MATRIZES CIMENTÍCIAS}

A indústria nacional de fibras como reforços para compósitos cimentícios têm fornecido principalmente fibras de baixo módulo elástico como as polpas celulósicas de eucalipto e as fibras de polipropileno. As fibras de alto módulo elástico têm sido disponibilizadas no pais mediante importação.

\subsubsection{Efeito das propriedades das fibras}

Inúmeras propriedades das fibras afetam o comportamento do compósito cimentício como: a propriedade do material, a sua ligação com a matriz cimentícia (aderência), seu comprimento, diâmetro, volume, alinhamento e dispersão exercem importante efeito no comportamento mecânico do compósito.

A energia de fratura aumenta linearmente com o aumento do volume das fibras, porém se desvia dessa apresentando um comportamento assintótico. Isto foi relacionado à deterioração da aderência em altos volumes devido à interação entre as fibras (MAALEJ et al., 1995). Elevadas frações de volume das fibras podem aumentar a porosidade total da matriz. A porosidade induzida pelas fibras pode reduzir os módulos da matriz, tenacidade e a aderência da interfase (LI et al., 1996).

O comprimento da fibra é um importante parâmetro, o qual afeta a resistência e a tenacidade do compósito (BENTUR, 1990). Um comprimento mínimo é levado em consideração quando se discute o efeito do comprimento da fibra, sendo chamado de comprimento crítico, que é o mínimo requerido para utilizar ao máximo a capacidade mecânica da fibra. Compósitos com comprimentos de fibras inferiores ao crítico colapsam sem fraturar mediante o arrancamento das mesmas. Em 
compósitos com comprimentos de fibras maiores que o comprimento crítico, as propriedades mecânicas das fibras são aproveitadas ao máximo de seu desempenho, assim as falhas do compósito são governadas pelo colapso das fibras. $\mathrm{O}$ incremento na aderência das fibras aumenta a resistência do compósito, porém diminui a tenacidade (BENTUR, 1989).

Com o aumento do comprimento das fibras a possibilidade das fibras interceptarem as fissuras, geradas durante o carregamento, aumenta. Comprimentos longos de fibras podem também aumentar a deformação durante o carregamento (SHAO et al., 1997). Em ensaio axial de tração feito com fibras de 3 e $6 \mathrm{~mm}$, mostrou que maiores comprimentos de fibras levam a maior absorção de energia comparada as de comprimento menor e fibras com maior comprimento também levam a maiores resistências (LANGE et al., 1996).

Para comprimentos maiores e volumes reduzidos de fibras as resistências à tração são similares. Fibras longas levam a maiores capacidades de deformação e auxiliam no alinhamento das fibras ao longo do comprimento do corpo-de-prova (LI et al., 1996). Segundo Samarri et al. (1974), observa-se uma pequena melhoria na resistência do compósito com a redução do diâmetro da fibra devido à redução do espaçamento entre as mesmas, também destaca que elevados teores de fibras dificultam a sua dispersão na matriz.

Quanto menor o tamanho de microfibras curtas maior o número de fibras no compósito provendo assim efetivo reforço contra as microfissuras prevenindo a coalescência delas em macrofissuras instáveis (BATHIA; BETTERMAN et al., 1995; KANDA et al., 1998; MAGGIO et al., 1997).

A dispersão das fibras se apresenta como aspecto crítico para proporcionar resistência à propagação de fissuras na matriz (SHAH et al., 1991). A tensão da primeira fissuração aumenta com a redução do espaçamento das fibras, o qual pode ser expresso em função do volume e do raio das fibras (BENTUR, 1989). Características do material como viscosidade e volume das fibras afetam a dispersão das fibras na matriz (SHAO et al., 1997). 


\subsubsection{Fibras vegetais}

As fibras vegetais individuais compõem-se de micro fibrilas dispostas em camadas de diferentes espessuras e ângulos de orientação (SAVASTANO JR., 1992). Essas fibras individuais são aglomeradas pela lamela intercelular ou lamela média, composta de hemicelulose, extrativos e principalmente lignina. A Figura 4 ilustra esquematicamente a estrutura de uma célula individual, mostrando as camadas de microfibrilas que formam a parede celular. As microfibrilas são compostas por moléculas orientadas de celulose aglomeradas por hemicelulose amorfa, lignina e ainda por alguma quantidade de extrativos. Segundo Gram (1988),as microfibrilas são compostas basicamente por quatro camadas de microfibrilas: (i) camada primária $P$, mais externa, de estrutura reticulada, com grande conteúdo de hemicelulose; (ii) Camada secundária S1, onde as microfibrilas estão orientadas em espiral segundo um ângulo de aproximadamente 45 graus, com relação ao eixo longitudinal da célula; (iii) camada secundária S2, também com as microfibrilas em forma de espiral; e (iv) camada secundária S3, mais interna, reticulada.

A camada S2 é a de maior espessura e, também, a de maior teor de celulose. No interior da célula, há uma cavidade central de secção elíptica, com dimensão de 5 a $10 \mu m$, denominada lúmen.

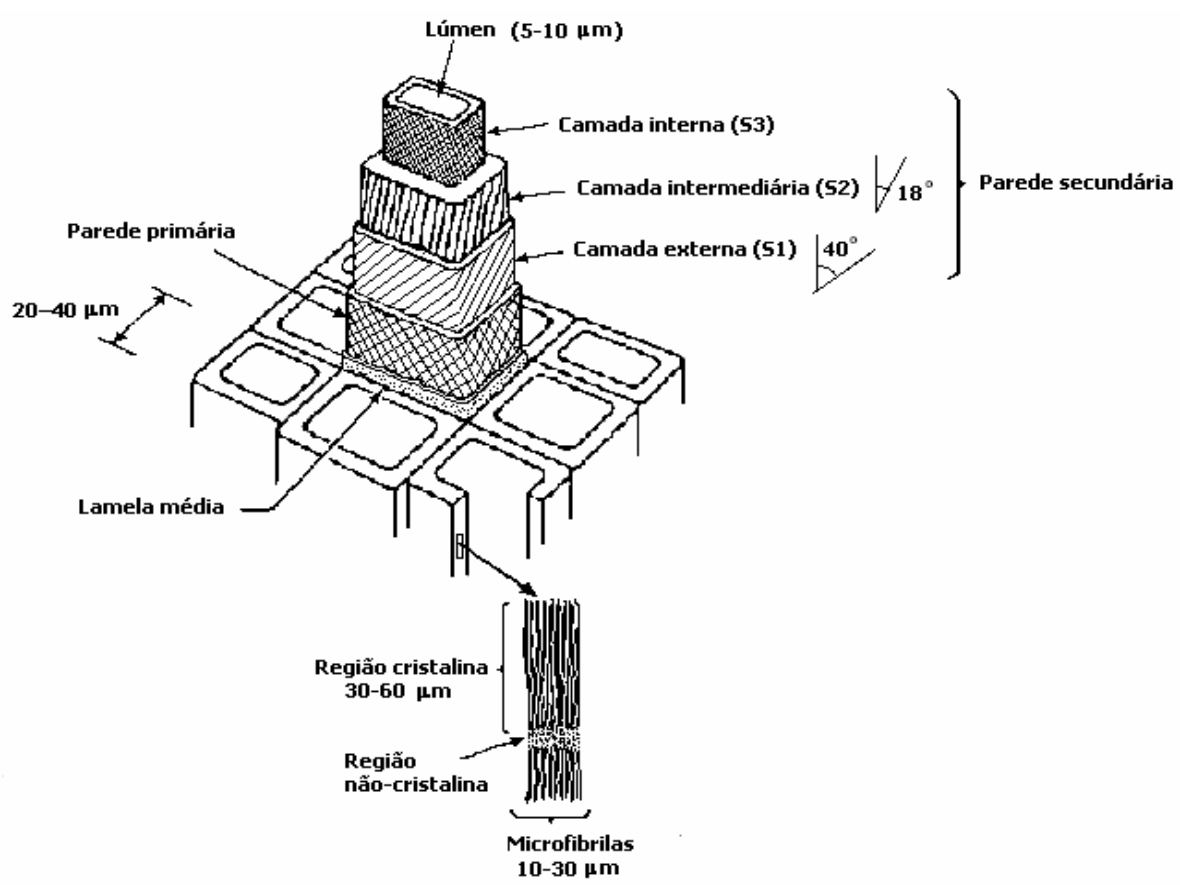

Figura 4 - Estrutura das células de fibra vegetal, adaptado de Gram (1988); Illston et al. (1979) 
Muitas fibras apresentam potencial para utilização como reforço em compósitos. A escolha de métodos de produção e aproveitamento do desempenho ótimo das fibras celulósicas (COUTTS, 1992). Conforme salientado por Tolêdo Filho (1997), muitos estudos ainda são necessários, tanto para caracterização da matériaprima fibrosa como para o desenvolvimento de novos produtos e métodos de produção. O estudo da estrutura da interface fibra-matriz tem importante papel no desenvolvimento dos compósitos fibrosos, para que o seu comportamento mecânico se torne ótimo.

\subsubsection{A utilização de fibras celulósicas em fibrocimentos}

Durante as últimas três décadas várias pesquisas vêm sendo desenvolvidas para encontrar fibras substitutas ao amianto em produtos de fibrocimento amplamente utilizadas em construções de baixo custo (COUTTS, 2005). Nos últimos anos, fibras lignocelulósicas receberam considerável atenção no desenvolvimento dos compósitos por possuírem inúmeras vantagens, como por exemplo: a disponibilidade, o baixo custo e quanto às questões ambientais (biodegradabilidade) (MACVICAR, 1999).

Segundo Swamy (1980), o emprego dos compósitos com fibras celulósicas em placas, telhas de cobertura e componentes pré-fabricados, pode representar significativa contribuição para o crescimento da infra-estrutura de países em desenvolvimento da América do Sul, América Central e Caribe. Também nos países desenvolvidos, o uso de fibrocimentos que utilizam polpa celulósica tem sido consagrado, graças a constantes melhoramentos das matérias-primas, processos produtivos com consumo racionalizado de energia e custos de investimento cada vez menores (COUTTS, 2005).

Por ser o Brasil um dos maiores produtores de fibras celulósicas de eucalipto, demonstra um grande potencial em adaptar o uso dessas fibras no reforço de compósitos cimentícios, como uma alternativa ao uso das fibras celulósicas de Pinus, que são amplamente utilizadas na produção de fibrocimentos para construções de baixo custo. As fibras de eucalipto possuem um número maior de filamentos por unidade de massa ou volume, comparadas às fibras longas de Pinus. 
A grande quantidade de elementos de reforço supostamente interrompe o desenvolvimento das microfissuras dentro da matriz cimentícia, aumentando sua resistência à flexão (BLANKENHORN et al., 2001). Todavia, muitos aspectos sobre o preparo e a melhor condição da polpa de eucalipto para o fibrocimento ainda devem ser mais bem explorados.

O Instituto Americano do Concreto (American Concrete Institute - ACI 544) recomenda o uso de fibras de polpa Kraft como reforço em materiais cimentícios, já que grande parte da lignina e hemiceluloses, que são menos resistentes à alcalinidade do que a celulose, são retiradas durante o processo de polpação (MOHR et al., 2005).

Fibras celulósicas obtidas de polpas processadas quimicamente são tipos dominantes usados na produção de elementos construtivos em países desenvolvidos. Porém o efeito do branqueamento da fibra na performance do compósito antes e após os ciclos de envelhecimento ainda não é bem esclarecido. Segundo Bentur \& Akers (1989) polpas celulósicas contém quantidades negligenciáveis de lignina e espera-se que sofram menor ataque alcalino do cimento. Adicionalmente, segundo Hachmi e Moslemi (1989) a presença de extrativos na superfície das fibras afeta a hidratação exotérmica característica do cimento Portland, tendo efeito inibitório na hidratação do cimento.

Em pesquisas recentes (MOHR et al., 2005; MOHR et al., 2006) com polpas branqueadas e não-branqueadas de madeira (pinus), as polpas com baixo conteúdo de lignina mostraram acelerada mineralização, se comparadas às polpas nãobranqueadas. A lignina pode funcionar como uma barreira à formação de produtos de hidratação (hidróxido de cálcio, por exemplo) dentro da parede celular, diminuindo a mineralização da fibra. Nanko et al. (1991) e MOHR et al. (2006) destacam que polpas com maiores conteúdos de lignina apresentam maior estabilidade dimensional e por isso podem resultar em compósitos com maior resistência à degradação pela diminuição do descolamento fibra-matriz. Sugere-se que a lignina enrijece a parede celular da fibra preenchendo os espaços entre as microfibrilas de celulose, melhorando a estabilidade dimensional, embora diminuindo a resistência à tração da fibra. Segundo Mohr et al. (2006) as mudanças dimensionais durante os ciclos de molhagem e secagem, geram o descolamento fibra-matriz cimentícia e a presença de lignina interfere na adesão entre as camadas internas das fibras. Se as ligações entre camadas da parede celular (S1 e S2, por 
exemplo) forem mais fortes que a ligação fibra-matriz, o descolamento fibra-cimento será esperado, ou vice-versa.

Polpas Kraft de Pinus em diferentes seqüências de branqueamento foram avaliadas quanto à composição química da superfície das fibras por Gustafsson et al. (2003). A retirada da lignina durante um branqueamento intenso aumenta a rugosidade superficial das fibras pela exposição da estrutura fibrilar da celulose. A rugosidade superficial melhora as ligações físicas das fibras com a matriz cimentícia, promovendo uma tendência maior de descolamento das camadas da parede celular da fibra, quando comparadas com fibras não-branqueadas (MOHR et al., 2006).

Parece, portanto, haver uma competição entre os fenômenos de degradação alcalina da lignina e das hemiceluloses e a prevenção da formação de produtos de hidratação pela presença de lignina e extrativos na superfície das fibras. Outros aspectos ainda permanecem pouco esclarecidos, como a durabilidade das fibras branqueadas e não branqueadas na matriz cimentícia e a cinética envolvida na degradação das fibras ao longo da vida útil do compósito.

\subsubsection{Fibras de polipropileno}

As fibras de polipropileno são produzidas em uma grande variedade de formas e com diferentes propriedades. Essas fibras apresentam resistência ao meio alcalino, elevada ductilidade e absorção de energia, alto ponto de fusão. Porém, apresentam características desvantajosas associado ao baixo módulo de elasticidade, fracas ligações químicas vinculado a sua hidrofobicidade, baixa ancoragem mecânica à matriz relacionada com as propriedades físicas, baixa resistência ao fogo e sensibilidade aos raios ultravioleta e oxigênio (HANNANT, 1986). Essas propriedades adversas podem ser superadas se utilizadas em compósitos cimentícios uma vez que a matriz protege as fibras da intempérie e raios ultravioletas. As propriedades mecânicas em particular o módulo de elasticidade e as ligações químicas podem ser melhoradas dando lugar a fibras com melhores desempenhos em compósitos cimentícios (BENTUR; MINDESS, 2007).

As fibras são produzidas com polipropileno de alto peso molécular. Devido ao arranjo atômico regular das moléculas, elas podem ser produzidas em forma 
cristalina alongando-se até alcançar um alto grau de orientação, necessário para obter fibras com boas propriedades (BENTUR; MINDESS, 2007).

Fibras de polipropileno têm sido estudadas como reforço de fibrocimento, sendo hoje uma das fibras utilizadas como reforço na fabricação de telhas e placas cimentícias na indústria nacional.

\subsubsection{Degradação dos compósitos}

Problemas de degradação dos compósitos podem surgir ligados à deterioração da fibra em uma matriz cimentícia altamente alcalina exposta à umidade. Deste modo, é necessário compreender o comportamento em longo prazo dos compósitos cimentícios reforçados com fibras celulósicas devido às alternações de períodos secos e úmidos que ocorrem em circunstâncias naturais. A durabilidade dos compósitos é também influenciada pelo tipo de fibra, tipos de matriz e métodos de envelhecimento (MACVICAR, 1999). Há evidências de que as fibras sofrem alterações no seu desempenho mecânico, em conjunto com a matriz, dependendo da idade do compósito e das condições de exposição. A degradação dos compósitos pode ser estudada por ensaios acelerados, cuja vantagem é a de fornecer resultados em menor intervalo de tempo (SAVASTANO JR., 1992).

Muitas tentativas de produção de argamassas ou pastas de cimento Portland comum reforçadas com fibras vegetais fracassaram, por apresentarem vida útil entre dois e quatro anos (AGOPYAN, 1991). Uma das principais razões para essa rápida degradação é a elevada alcalinidade da água presente nos poros da matriz de cimento Portland, com pH próximo de 13, que leva à rápida decomposição da lignina e da hemicelulose presentes nas fibras. A região da matriz em torno da fibra (zona de transição) é caracterizada pela porosidade elevada, permitindo acúmulo de água, e pela maior concentração de hidróxido de cálcio, propiciando elevada alcalinidade (SAVASTANO JR. et al., 1994).

A durabilidade do compósito é diminuída, como uma conseqüência da redução da resistência e da tenacidade (AKERS; STUDINKA, 1989). Esse comportamento está associado ao aumento da resistência da fratura da fibra e à redução do arrancamento devido à combinação do enfraquecimento das fibras pelo 
ataque alcalino, mineralização da fibra e variação do volume devido à sua alta absorção de água (TOLEDO FILHO, 2000). Testes mostraram que a degradação das propriedades mecânicas não ocorre linearmente com o aumento do número de ciclos sendo que a maioria das perdas em resistência e tenacidade dos compósitos ocorre nos primeiros ciclos de envelhecimento, ou seja, parece haver mais de um mecanismo contribuindo para as mudanças micro-estruturais do compósito (MOHR et al., 2006).

\subsection{REOLOGIA}

A reologia dedica-se ao estudo da deformação e do fluxo da matéria. Existem duas propriedades fundamentais na reologia para descrever um material, tensão de escoamento e viscosidade. A tensão de escoamento inicial é a tensão necessária para iniciar o escoamento, porém nem todos os materiais têm tensão de escoamento como por exemplo a água. A viscosidade é a resistência apresentada pelo material opondo-se ao movimento do sistema.

Os reômetros são equipamentos especialmente desenvolvidos para a leitura do comportamento reológico do material, esses instrumentos aplicam uma taxa de cisalhamento ao material e realizam leituras da tensão de cisalhamento resultante ou vice-versa para obter tensão de escoamento inicial e viscosidade.

Os parâmetros que controlam a reologia de uma pasta de cimento podem ser classificados em dois grupos: parâmetros químicos e parâmetros físicos. Os parâmetros físicos que impõem significativa influência na reologia na mistura cimentícia são: a densidade de empacotamento; a área superficial do material, assim como a configuração geométrica dos materiais cimentícios. Os parâmetros químicos incluindo a composição química dos materiais cimentícios, a estrutura química dos aditivos e a compatibilidade entre os aditivos químicos e o material cimentício. 


\subsubsection{Reologia de suspensões}

O comportamento reológico de uma combinação líquido-sólido é diferente do que para uma fase líquida isolada. A adição de partículas a um líquido newtoniano resulta em uma mistura que exibe comportamento não newtoniano.

Barnes et al. (1989) discutem a forma geral da curva viscosidade em função da taxa de cisalhamento para uma suspensão concentrada, a curva pode ser observada no Gráfico 2. Em baixas taxas de cisalhamento a curva apresenta o patamar A com comportamento newtoniano, o qual é seguido por um comportamento pseudoplástico na região $B$, continuando em um segundo patamar newtoniano C. O comportamento pseudoplástico é associado ao desenvolvimento de uma microestrutura durante o fluxo o qual facilita a deformação. Uma vez atingida uma taxa de cisalhamento elevada a estrutura é destruída e ocorre um comportamento de espessamento abrupto com o cisalhamento (dilatância), como observado na parte $D$ da curva. Esse comportamento tem recebido bastante atenção em estudos tanto experimentais como teóricos.

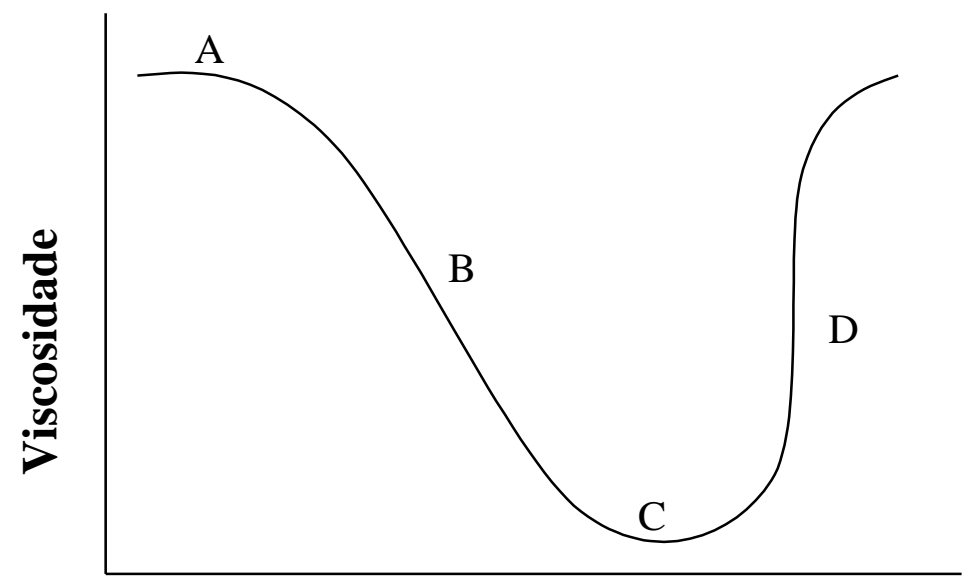

Taxa de cisalhamento

Gráfico 2 - Representação esquemática da relação viscosidade em função da taxa de cisalhamento, Barnes et al. (1989) 


\subsubsection{Equações constitutivas simplificadas}

As equações constitutivas simplificadas para materiais viscoplásticos são de origens empíricas ou semi-empíricas. No Gráfico 3, quando a tensão de cisalhamento $(\tau)$ for menor que a tensão de escoamento $(k)$, o material assume-se perfeitamente rígido. A taxa de cisalhamento $(\dot{\gamma})$ se apresenta como zero:

$$
\dot{\gamma}=0 \text { quando } \tau<k
$$

Quando $\tau \leq k$ o material se deforma e o comportamento da tensão de cisalhamento em função da taxa de cisalhamento pode ter uma variedade de formas. Algumas delas são mostradas no Gráfico 3 , onde as curvas correspondem às equações constitutivas descritas a seguir:

$>$ Modelo de Bingham

Bingham (1922) estudou o comportamento de diferentes materiais em capilaridade, a sua pesquisa sobre sólidos plásticos, suspensão de argilas e tinta é apresentada em Fluidity and Plasticity. Foi proposta uma relação empírica para esses materiais, com dois parâmetros do material que são equivalentes a tensão de escoamento $k$ e a viscosidade plástica $\mu$. A equação pode ser escrita como:

$$
\tau=k+\mu \dot{\gamma}
$$

A curva tensão de cisalhamento em função da taxa de cisalhamento é uma linha reta que não passa pela origem a não ser que $k$ seja igual a zero (correspondendo a um fluido newtoniano).

> Modelo de Herschel-Bulkley

Herschel e Bulkley (1926) estudaram soluções de goma e benzeno e encontraram um comportamento não linear, o qual forneceu suporte para propor uma relação empírica com três parâmetros do material. Esta equação é considerada como a relação mais simples e geral para descrever sólidos brandos. A equação é descrita abaixo: 


$$
\tau=k+C \dot{\gamma}^{n}
$$

A eq. (3) é uma relação da lei de Power com a adição da tensão de escoamento sendo $C$ a consistência e $n$ o índice da lei de Power.

$>$ Modelo de Casson

Casson (1959), trabalhando com tinta de impressão encontrou um comportamento não linear da curva de tensão de cisalhamento em função da taxa de cisalhamento e propôs a seguinte relação semi empírica entre as quantidades, com dois parâmetros do material:

$$
\sqrt{\tau}=\sqrt{k}+\sqrt{\mu_{\infty} \dot{\gamma}}
$$

Onde $\mu_{\infty}$ é a viscosidade com alta taxa de cisalhamento.

Os argumentos que levam a essa equação são baseados na existência de um grupo de cadeias de partículas no fluido em repouso os quais são quebrados durante o cisalhamento.

$>$ Modelo de plasticidade perfeita

Neste modelo as equações anteriores se reduzem a seguinte forma:

$$
\tau=k
$$

Este tipo de material é descrito como perfeitamente plástico. O modelo tem sido amplamente utilizado para descrever metais sólidos. 


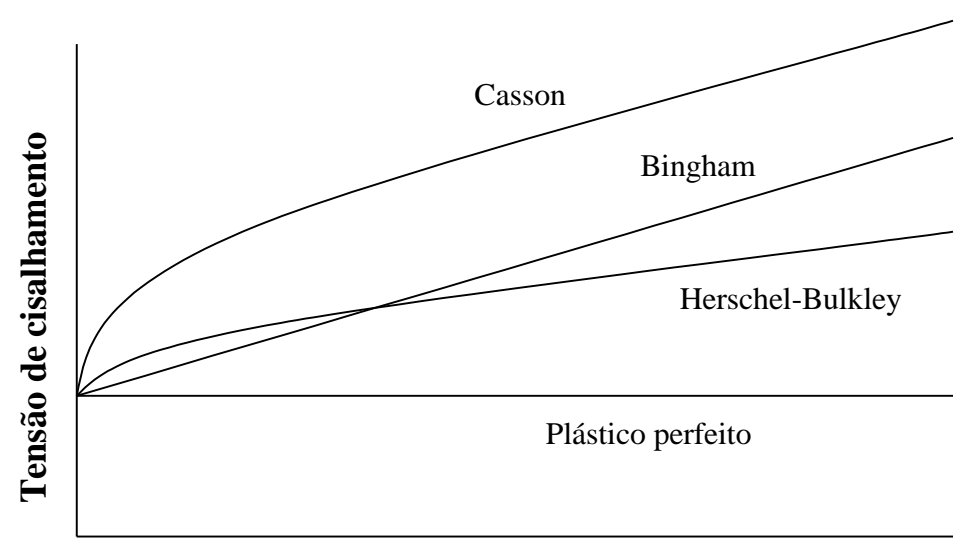

Taxa de cisalhamento

Gráfico 3 - Curvas de tensão de cisalhamento em função da taxa de cisalhamento por diferentes modelos

\subsubsection{Parâmetros de Benbow}

Os reômetros comerciais disponíveis para avaliar a reologia de pastas fornecem baixa capacidade de torque, não sendo possível a sua utilização na avaliação de pastas de elevada coesão como é o caso das pastas extrudáveis. Benbow e Bridgwater (1993) propõem o método do reômetro extrusor com a finalidade de descrever o fluxo de pasta durante a extrusão. A pasta, nesse método, é avaliada utilizando um extrusor de pistão com diferentes comprimentos de boquilha e auxilio de uma expressão semi-empírica que descreve o fluxo do material durante a extrusão. Assim, são obtidos os quatro parâmetros característicos da pasta: a tensão de escoamento correspondente à velocidade de zero $\sigma_{0}$, o fator que caracteriza o efeito da velocidade $\alpha$, a tensão de cisalhamento na parede correspondente a velocidade de zero $\tau_{0}$ e é o fator de velocidade da parede $\beta$.

$\mathrm{Na}$ indústria, são utilizadas predominantemente extrusoras de rosca. Os efeitos de pressão gerados tanto para o extrusor de pistão quanto para o extrusor de rosca, são idênticos. Isto é, o fluxo através da boquilha é comum para ambos os tipos de extrusores. Assim um importante aspecto da extrusão da pasta é a relação entre a pressão e a velocidade da extrusão, e estes dois dados podem ser facilmente adquiridos mediante uma máquina de ensaios mecânicos. A Figura 5 apresenta um modelo esquemático da seção transversal de uma extrusora de pistão. 


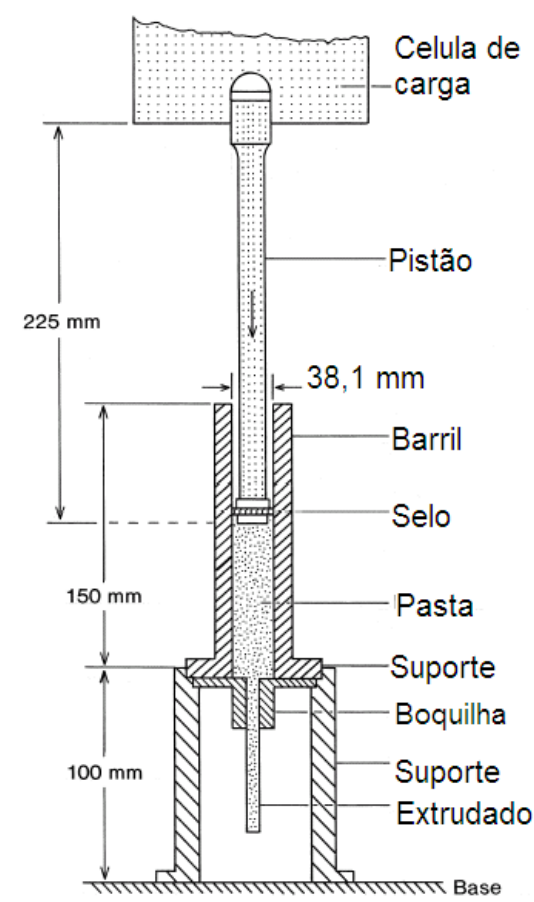

Figura 5 - Reômetro extrusor, adaptado de BENBOW et al. (1991)

A pasta é contida no barril de diâmetro $D_{0}$ e é forçada para a região da boquilha de diâmetro $\mathrm{D}$ e de comprimento L. Fluindo do barril para a região da boquilha, a pasta se estende na direção do fluxo e a sua seção transversal decresce. Na região da boquilha onde a velocidade principal é $v$, a pasta tem que superar a tensão de cisalhamento entre a boquilha e a pasta. No sistema existem também as tensões de cisalhamento nas paredes do barril, porém essas tensões serão negligenciadas nesse tratamento preliminar, já que a queda de pressão devido ao atrito com o barril é muito pequena se comparada aos demais parâmetros. Isso será evidenciado nos capítulos posteriores, onde os dados completos dos testes reológicos são mostrados. O sistema se compõe de duas partes: fluxo da pasta do barril para a região do molde e fluxo da pasta na região do molde. Na prática, uma pequena região estática de pasta é gerada no canto do barril.

Se a pasta é homogeneamente misturada, pode-se assumir a hipótese de incompressibilidade, e a mudança de volume durante o processo de compressão pode ser desprezada.

$$
A_{0} l_{0}=A l
$$

Onde $A_{0}$ é a área do barril e $l_{0}$ é o comprimento inicial, e seu produto $A_{0} l_{0}$ é uma constante, ou $d\left(A_{0} l_{0}\right)=0$. 
Conseqüentemente, diferenciando a eq.(6)

$$
\frac{d A}{A}+\frac{d l}{l}=0
$$

ou

$$
\frac{d A}{A}+\frac{A d l}{A_{0} l_{0}}=0
$$

O trabalho realizado para incrementar a dimensão longitudinal da pasta de comprimento $l$ e seção transversal $A$ em $d l$ é $\sigma A d l$.

Da eq.(8), temos:

$$
A d l=-\frac{A_{0} l_{0} A}{A}
$$

O trabalho $\sigma A d l$ vem a ser:

$$
\sigma A d l=-\frac{\sigma A_{0} l_{0} d A}{A}
$$

O trabalho realizado para que a pasta de seção transversal de área $A_{0} \mathrm{e}$ comprimento $l_{0}$ se obtenha uma seção transversal $A$ e comprimento $l$ é:

$$
\int_{0}^{l} \sigma A d l=\int_{A_{0}}^{A}-\frac{\sigma A_{0} l_{0} d A}{A}=\sigma A_{0} l_{0} \ln \left(\frac{A_{0}}{A}\right)
$$

O trabalho realizado pela pressão da extrusão $\mathrm{P}_{1}$ é $\mathrm{P}_{1} A_{0} \mathrm{~L}_{0}$. Onde:

$$
\mathrm{P}_{1}=\sigma \ln \left(\frac{A_{0}}{A}\right)
$$

Para um barril circular e para uma boquilha circular, o trabalho será: 


$$
\mathrm{P}_{1}=2 \sigma \ln \left(\frac{\mathrm{D}_{0}}{\mathrm{D}}\right)
$$

Desde que a fase líquida seja significativamente viscosa. Foi determinado experimentalmente que $\sigma=\sigma_{0}+\alpha v$, e daí:

$$
\mathrm{P}_{1}=2\left(\sigma_{0}+\alpha v\right) \ln \left(\frac{\mathrm{D}_{0}}{\mathrm{D}}\right)
$$

Onde $v$ é a velocidade da pasta no corpo da boquilha. Aqui $\sigma_{0}$ é a tensão de escoamento correspondente à velocidade de zero e $\alpha$ é o fator que caracteriza 0 efeito da velocidade. Assim $\alpha v$ é análogo ao $\eta \dot{\gamma}$ em líquidos de fluxo cisalhante, onde $\eta$ é a viscosidade e $\dot{\gamma}$ taxa de cisalhamento. A taxa de extensão é proporcional a $v$ e assim $\sigma_{0}+\alpha v$ pode ser considerado como a tensão de escoamento aparente corrigida para a taxa de cisalhamento.

Considerando o movimento no corpo da boquilha, se marcadores são introduzidos no fluxo, observa-se que a massa do material move-se a velocidade constante igual à velocidade da saída do extrudado, com unicamente uma fina camada próxima à parede da boquilha submetida a deformações de tensões de cisalhamento. A queda de pressão no corpo da boquilha $\mathrm{P}_{2}$ gera uma força na pasta de $\mathrm{P}_{2} \pi \mathrm{D}^{2} / 4$ a qual se opõe à tensão de cisalhamento, obtida pelo produto da tensão da parede $\tau$ e o perímetro molhado do corpo da boquilha, $\pi D \mathrm{~L}$. Equacionando, obtém-se:

$$
\mathrm{P}_{2}=4 \tau(\mathrm{L} / \mathrm{D})
$$

$\mathrm{Na}$ fina camada de líquido próximo à parede da boquilha, onde $\mathrm{o}$ cisalhamento acontece, o efeito da viscosidade é significativo. Caso uma aproximação newtoniana seja apropriada para a camada líquida, esta viscosidade é proporcional a $v$, então obtém a eq. (16). 


$$
\mathrm{P}_{2}=4\left(\tau_{0}+\beta v\right)(\mathrm{L} / \mathrm{D})
$$

Onde $\tau_{0}$ e $\beta$ são parâmetros que caracterizam a pasta. O parâmetro $\tau_{0}$ é a tensão de cisalhamento na parede extrapolada para a velocidade de zero e é chamado de tensão inicial de cisalhamento na parede, $\beta$ é um fator que quantifica a influência da velocidade na tensão da parede e é denominado de fator de velocidade da parede.

A pressão total é expressa por:

$$
\begin{gathered}
\mathrm{P}=\mathrm{P}_{1}+\mathrm{P}_{2} \\
\mathrm{P}=2\left(\sigma_{0}+\alpha v\right) \ln \left(\frac{\mathrm{D}_{0}}{\mathrm{D}}\right)+4\left(\tau_{0}+\beta v\right)(\mathrm{L} / \mathrm{D})
\end{gathered}
$$

Os quatro parâmetros que caracterizam o fluxo são $\tau_{0} \alpha, \sigma_{0}$ e $\beta$.

\subsection{DEMANDA DE ÁGUA DAS PARTÍCULAS}

A demanda de água das partículas, que compõem a formulação, é um parâmetro de grande importância no comportamento mecânico, físico e de durabilidade do compósito elaborado. A quantidade de água demandada deve cumprir o requerimento de fornecer uma camada de água ao redor das partículas e preencher os espaços intergranulares do sistema de partículas (HUNGER; BROUWERS, 2009). O conteúdo de água, o grau de hidratação, assim como o tipo e a quantidade do cimento, são os principais responsáveis pelos poros capilares, o que é um indicador direto da durabiliade do compósito (NEVILLE,1997). Toda água adicionada em excesso é unicamente utilizada para ajustar a trabalhabilidade da mistura, isto é, promover a separação das partículas (ORTEGA, PILEGGI, PANDOLFELLI, 1999). A demanda de água, a área superficial, a consistência resultante e o volume de vazios estão relacionados entre si (HUNGER; BROWERS, 2009). 
Existem diferentes opiniões sobre como a demanda de água de um material particulado deve ser definida, levando a diferentes testes como o spread-flow, puntke, vicat, marquardt modificado entre outros, descritos em Hunger e Brouwers (2009).

Wong (2007) propõe a metodologia de determinação de empacotamento de partículas a úmido mediante o cálculo da concentração de sólidos do material granular, definido como a proporção inversa do volume sólido do material granular pelo volume aparente do material granular. Para esse cálculo, são realizados múltiplos ensaios experimentais, até que seja determinada a quantidade de água mínima necessária para formar uma pasta e a partir dessa realizar o cálculo do empacotamento. Esse conteúdo mínimo de água é denominado por Talbot (1921) como conteúdo básico de água, o qual tem a característica de proporcionar o mínimo conteúdo de vazios na pasta.

O presente trabalho considera como demanda de água das partículas a quantidade de água necessária para formar uma pasta, expressa mediante a relação água/sólidos (a/s). De acordo com Powers (1968), este teor apresenta a menor quantidade de vazios na mistura.

\subsection{MODELAGEM DE MISTURAS}

As propriedades do compósito variam em função do teor dos componentes da formulação. Para a obtenção de formulações que cumpram as características desejadas a modelagem estatística apresenta-se como uma ferramenta de extrema utilidade.

Nos últimos anos o desenvolvimento dos microcomputadores, a crescente automação dos instrumentos e a necessidade de se explorarem problemas mais complexos fez com que especialistas das diferentes áreas do conhecimento redescobrissem a importância da estatística multivariada para o planejamento e tratamento dos dados obtidos em um experimento.

No caso de otimização de experimentos os métodos utilizados podem ser sequênciais ou não sequênciais. $O$ primeiro tipo é exemplificado pelo simplex sequencial, que é um polígono (ou seu equivalente multidimensional) de $p+1$ 
vértices, onde $p$ é o número de variáveis independente que se deseja ajustar (BRUNS; BARROS; SCARMINIO, 2003). Os métodos que não são sequênciais, como os métodos fatorial e análise de superfície de resposta, não são de ampla utilização. A superfície de resposta utilizada neste trabalho, é uma superfície de resposta gerada em um gráfico como resposta de um processo, produto de inúmeras reações, etc., contra variáveis ou fatores experimentais que os caracterizam. Esse tipo de gráfico mostra o comportamento de uma resposta com respeito aos valores ou níveis dos fatores de um sistema.

Em geral, a superfície de resposta pode ser descrita por uma função matemática:

$$
y_{i}=M\left(X_{1}, X_{2}, X_{3}, \ldots, X_{q}\right)
$$

Onde $y_{i}$ representa a resposta e $X_{1}, X_{2}, X_{3}, \ldots, X_{q}$ os níveis dos $p$ fatores (BRUNS, BARROS; SCARMINIO, 2003).

Normalmente, como somente alguns pontos da superfície são conhecidos, a prática mais comum é usá-los para determinar uma relação entre a resposta y e os fatores $X_{1}, X_{2}, X_{3}, \ldots, X_{q}$, ou seja, assumir um modelo empírico e encontrar os parâmetros do modelo através de ajuste dos dados (BOX; HUNTER,1978; DEMING; MORGAN, 1990). A escolha dos níveis dos fatores para os ensaios usados na determinação da superfície de resposta é feita baseada em princípios de estatística multivariada para minimizar o número de ensaios necessários e melhorar a precisão dos resultados, sendo base do planejamento experimental.

Em um modelo estatístico a resposta observada é considerada como uma variável aleatória que se distribui em torno de média populacional $\bar{x}$ com uma certa variância $\sigma_{2}$. A partir disso pode-se escrever:

$$
y\left(X_{1}, X_{2}, X_{3}, \ldots, X_{q}\right)=\bar{x}\left(X_{1}, X_{2}, X_{3}, \ldots, X_{4}\right)+\varepsilon\left(X_{1}, X_{2}, X_{3}, \ldots, X_{q}\right)
$$

Os valores de $y$ têm suas contribuições, uma que pode ser modelada:

$$
\bar{x}\left(X_{1}, X_{2}, X_{3}, \ldots, X_{q}\right)=\beta_{0}+\sum_{i=1}^{q} \beta_{i} X_{i}+\sum_{i}^{q} \sum_{i}^{q} \beta_{i j} X_{i} X_{j}
$$


Onde $\beta_{0}$ reprsenta o valor populacional da média global ou valor central das respostas e $\beta_{i}$ e $\beta_{i j}$, representam os valores populacionais dos efeitos e de interação, por unidade de $X_{i}, X_{j}$, etc (BOX; HUNTER,1978; BRUNS; BARROS; SCARMINIO, 2003). E outra parte, $\varepsilon\left(X_{1}, X_{2}, X_{3}, \ldots, X_{q}\right)$ que tem comportamento aleatório.

O modelo estatístico mais simples é o linear aditivo. A equação para esse modelo é dada por:

$$
y=\beta_{0}+\beta_{1} X_{1}+\beta_{2} X_{2}+\beta_{3} X_{3}+\cdots+\varepsilon
$$

Onde $\varepsilon$ não é um parâmetro do modelo e sim um valor da população dos desvios (BRUNS; BARROS; SCARMINIO, 2003). Em outras palavras:

$$
y=\hat{y}+\varepsilon
$$

Onde $y$ é o valor previsto e y é o valor experimental.

Para se determinarem os valores de $\beta^{\prime s}$, seria necessário um número infinito de experimentos. Quando se fazem poucos experimentos, que são especificados no planejamento experimental, obtendo-se é uma estimativa desses parâmetros e, portanto, podemos escrever a eq.(23), como:

$$
y_{i}=b_{0}+\sum_{i=1}^{q} b_{i} X_{i}+\sum_{i \leq}^{q} \sum_{j}^{q} b_{i j} X_{i} X_{j}+\cdots+e_{i}
$$

Onde:

$\begin{array}{lll}y_{i} & \text { - } & \text { resposta observada para a i-esima determinação; } \\ b_{0}, b_{i}, b_{i j} \ldots & \text { - } & \text { estimativa dos parâmetros do modelo; } \\ e_{i} & \text { - } & \text { erro associado a } y_{i} \\ q & \text { - } & \text { número de fatores; } \\ X_{i} & \text { - } & \text { valor ou nível do i-ézimo fator. }\end{array}$


Os planejamentos e os modelos para experimentos com misturas permitem a determinação de valores ótimos para as proporções dos ingredientes relativas a uma ou mais respostas com a execução de um número mínimo de experimentos.

Salvo algumas exceções, a pesquisa em problemas com mistura é ainda uma atividade relativamente pouco explorada. Quase toda a teoria e metodologia apareceram nas últimas três décadas.

A proposta geral de experimentos com mistura é fazer modelagens de dados experimentais através de uma superfície de resposta. O planejamento experimental visa determinar esta superfície com a maior precisão possível usando um número mínimo de ensaios. As etapas de uma investigação desse tipo são:

$>$ considerar um ou mais modelos para descrever a propriedade;

> fazer um planejamento experimental adequado;

$>\quad$ avaliar $\mathrm{o}$ ajuste dos modelos aos resultados experimentais.

A descrição geométrica do espaço contendo $q$ componentes consiste de todos os pontos dentro ou nas laterais de um simplex-regular de dimensão $(q-1)$, onde $q$ é o número de componentes. O planejamento simplex em rede, apropriado para avaliar modelos lineares e quadráticos de misturas, foi introduzido por Scheffe (1985). Esse planejamento consiste em um arranjo ordenado de pontos distribuídos uniformemente no simplex e são chamados de rede $\{q, m\}$, onde $m$ é igual ao número de níveis menos 1 .

Para um sistema de três componentes, o simplex é um triangulo eqüilátero e o sistema de coordenadas usado para os valores $x_{i}$ é chamado de sistema de coordenadas simplex. Com três componentes, por exemplo, as coordenadas podem ser plotadas como linhas paralelas aos lados do triangulo, conforme mostrado no Gráfico 4. 


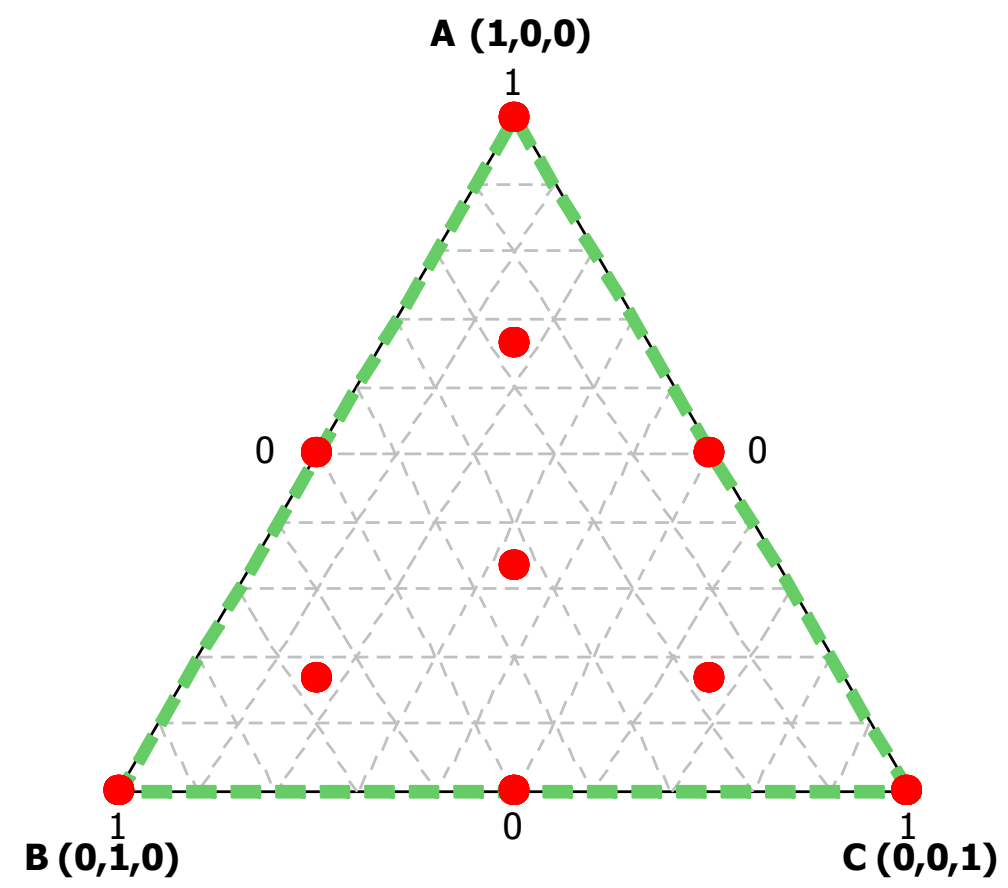

Gráfico 4 - Sistema de coordenadas simplex

Os modelos geralmente implementados para a modelagem de misturas são linear, quadrático, cúbico completo e cúbico especial (CORNELL, 2002).

\subsection{AVALIAÇÃO DE CONFIABILIDADE DO PROCESSO}

As propriedades mecânicas dos compósitos de fibrocimento podem ser consideradas como uma combinação entre as propriedades da matriz, das fibras e das interfaces entre fibra e matriz. $\mathrm{Na}$ avaliação do desempenho mecânico dos compósitos com fibras deve ser observado os seguintes parâmetros microestruturais:

> Características físicas, químicas e mecânicas dos materiais componentes, fibra e matriz;

> Geometria das fibras, seção transversal e comprimento;

$>$ Arranjo das fibras;

> Proporção entre os materiais componente;

> Características da interface dos materiais;

$>$ Porosidade e distribuição de tamanho de poros. 
Os compósitos de fibrocimento podem apresentar comportamento mecânico de materiais frágeis, isto é, absorvem a energia aplicada sobre elas sem se deformar expressivamente, até um ponto crítico no qual podem se romper sem aviso prévio (falha catastrófica). Pode-se dizer que eles são materiais de baixa tenacidade, que praticamente não possuem regime plástico de deformação. Tais características desencadeiam dois aspectos fundamentais da Mecânica da Fratura destes materiais:

$>$ baixa tenacidade à fratura: os defeitos existentes no compósito provocam concentrações de tensão na microestrutura, que se rompe no ponto que primeiro atingir sua tensão crítica (análogo ao caso das correntes, que, ao serem tracionadas, falham no elo mais fraco);

$>$ natureza estatística dos valores mensurados: como a distribuição dos defeitos nestes materiais é aleatória, torna-se impossível conhecer plenamente as concentrações de tensão e a localização do defeito crítico, o que acaba por inferir uma natureza probabilística à resistência mecânica.

Adicionalmente, devido à dificuldade de controlar os parâmetros microestruturais no processo de fabricação, torna-se imprescindível que o módulo de ruptura sofra um tratamento estatístico adequado. Dentre as várias teorias propostas, a que se mostrou mais adequada é a sugerida, em 1939, pelo físico sueco Ernest Weibull. O pesquisador estabeleceu uma interessante analogia baseada no fato das correntes nunca serem mais resistentes do que seu elo mais fraco, rompendo-se neste ponto. Assim, ao estender esse conceito para as cerâmicas, ele representou os elos por pequenos volumes da peça, sendo, o elo mais fraco, equivalente à região que contém a falha crítica.

Weibull propôs também uma função empírica de distribuição de probabilidade de falhas e obteve a expressão para a probabilidade de fratura acumulada, conhecida como Distribuição de Weibull:

$$
F=1-\exp \left[-\left(\frac{\sigma}{\sigma_{0 w}}\right)^{m_{w}}\right]
$$

Onde $F$ é a probabilidade de fratura, $\sigma$ é o módulo de ruptura, $\sigma_{0 w}$ é a constante de normalização correspondente ao módulo cuja probabilidade de falha é $63,2 \%$, e $m_{w}$ é o módulo ou parâmetro de Weibull. 
O coeficiente $m_{w}$ é adimensional e fornece uma avaliação da homogeneidade do material e, consequentemente, da dispersão de seus valores de resistência e de sua confiabilidade. Quanto menor essa constante, mais próxima da unidade estará a probabilidade $F$, tornando o material suscetível à falhas em uma vasta faixa de tensões. Já para valores elevados do parâmetro, a probabilidade de falha torna-se unitária apenas em um estreito intervalo em torno de $\sigma_{0 w}$. Assim, quanto maior o $m_{w}$, maior é a confiabilidade do compósito, pois a dispersão dos módulos de ruptura medidos é menor.

\subsection{CONSIDERAÇÕES}

A revisão bibliográfica realizada enfatizou aspectos relacionados ao processo produtivo, com maior ênfase na extrusão, matérias-primas, aditivos, reologia de suspensões, demanda de água, modelagem de misturas, que foram considerados itens importantes para entendimento do problema a ser estudado na tese. Esses tópicos estão perfeitamente relacionados ao objetivo de se produzir um compósito cimentício extrudado, e foram reunidos a partir de uma literatura escassa, que requereu a sua adaptação para a montagem da metodologia do trabalho, apresentada no capitulo seguinte. Essa dificuldade de um tema pouco explorado e divulgado pela literatura técnica (patentes e direitos industriais) e científica (artigos em periódicos e anais de congressos) fez com que a abordagem deste trabalho fosse bastante exploratória, o que se refletiu na forma mais abrangente da revisão ora realizada. 


\section{MATERIAIS E MÉTODOS}

A metodologia proposta para o desenvolvimento de formulações utilizadas na extrusão encontra-se descrita na Figura 6. Inicia-se com a caracterização das matérias-primas a fim de fornecer subsídios na interpretação dos resultados das etapas seguintes. Continua-se com a avaliação da influência das matérias-primas e aditivos no comportamento reológico das misturas utilizando reômetro extrusor e o modelo semi-empírico de Benbow descrito no item 2.7.3. Prossegue com a modelagem da matriz e da demanda de água do material cimentício com a finalidade de estimar o comportamento físico e mecânico da matriz, e também a determinação da demanda de água e modelagem para as possíveis combinações de material cimentício. Uma vez escolhida a matriz, a partir da etapa de modelagem da matriz, inicia a modelagem do reforço com fibras de polipropileno e polpa de celulose obtendo a estimativa dos desempenhos mecânicos e físicos dos compósitos. A formulação que satisfaça o desempenho desejado em curtas idades, isto é, com 28 dias de cura ou semelhante (cura acelerada) é selecionada para avaliação ao envelhecimento acelerado. A formulação que atenda 0 requerimento de envelhecimento segue finalmente para avaliação da reprodutibilidade, pelo módulo de Weibull, como dado adicional da formulação a ser selecionada. 


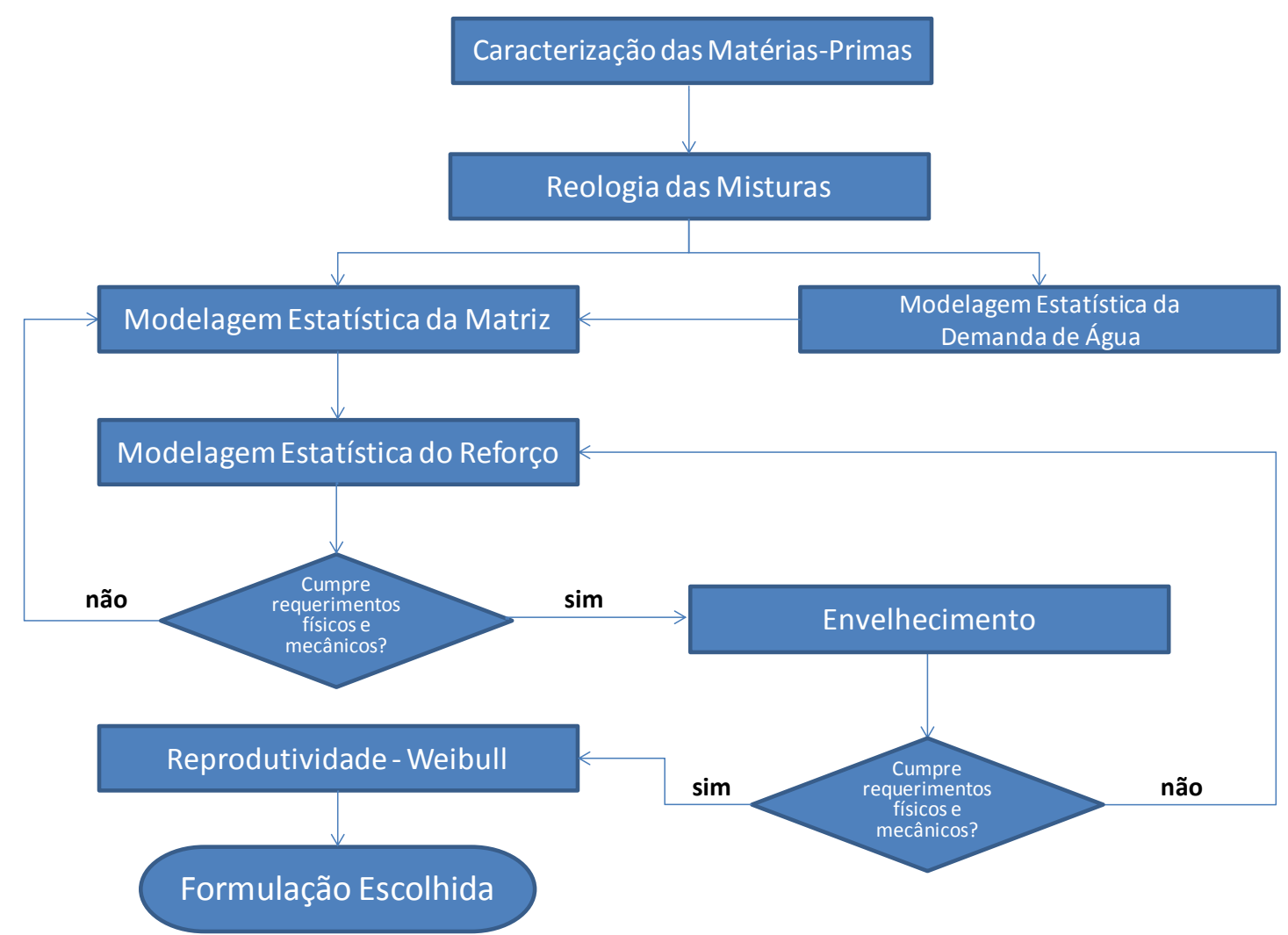

Figura 6 - Metodologia para o desenvolvimento de formulações

\subsection{TÉCNICAS EXPERIMENTAIS}

\subsubsection{Ensaios mecânicos}

As propriedades mecânicas foram obtidas por meio de ensaio de tração na flexão com quatro cutelos, com vão inferior igual a $135 \mathrm{~mm}$, vão superior igual a 45 $\mathrm{mm}$ e velocidade de deslocamento de $1,5 \mathrm{~mm} / \mathrm{min}$, baseada nas recomendações da RILEM (Testing Methods for Fibre Reinforced Cement-Based Composites) TECHNICAL COMMITTEE 49 TFR. Através de um computador munido de um software chamado Tesc, versão 1.3, interligado à máquina universal de ensaios mecânicos, marca EMIC, modelo DL 30.000 juntamente com seus acessórios (célula de carga com capacidade de $1 \mathrm{kN}$ e deflectômetro para medição de pequenas deformações até $30 \mathrm{~mm}$ ), foi determinada a força aplicada e a deflexão sofrida pelo material. 
O uso desse programa permite adquirir dados como o módulo de elasticidade, - limite de proporcionalidade (carga máxima aplicada antes da curva cargadeformação, desviar-se da linearidade), o módulo de ruptura à tração na flexão (carga máxima aplicada na curva carga-deformação) e a energia absorvida (área sob a curva no gráfico carga-deformação). A finalização do ensaio ocorre ao se constatar redução de $50 \%$ da carga máxima de ruptura, para cálculo da energia específica, que é a energia absorvida dividida pela área da seção transversal do corpo-de-prova (CP).

Antes da execução do ensaio, o CP deve ficar imerso em água por cerca de $24 \mathrm{~h}$ à temperatura ambiente. Após completar esse tempo, retira-se o $\mathrm{CP}$ da água $\mathrm{e}$ enxuga-se levemente sua superfície para retirar o excesso de água, medem-se em três pontos diferentes, a largura e a espessura do CP com um paquímetro digital e calcula-se a média entre as medidas. Em seguida, posiciona-se a amostra nos apoios inferiores no dispositivo de flexão a quatro pontos da máquina universal de ensaios mecânicos para realização do ensaio, conforme mostram as Figuras 7 a 9 .

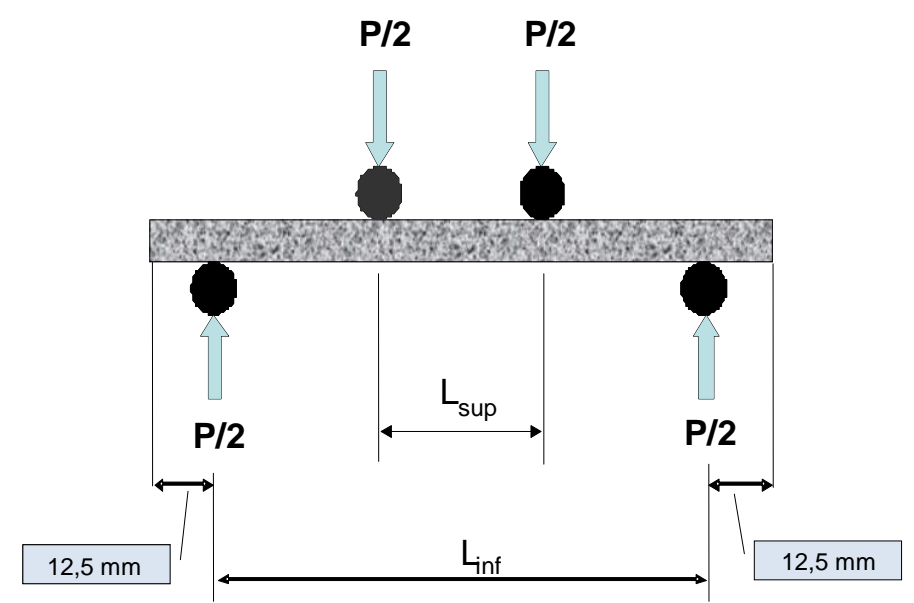

Figura 7 - Esquema do ensaio de flexão a quatro pontos. P é a carga aplicada sobre o CP 


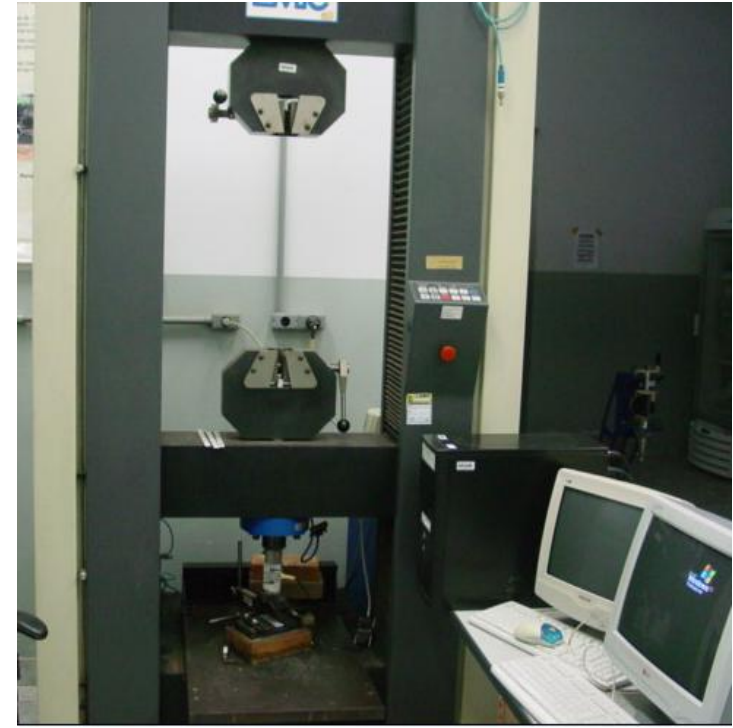

Figura 8 - Máquina universal de ensaios mecânicos

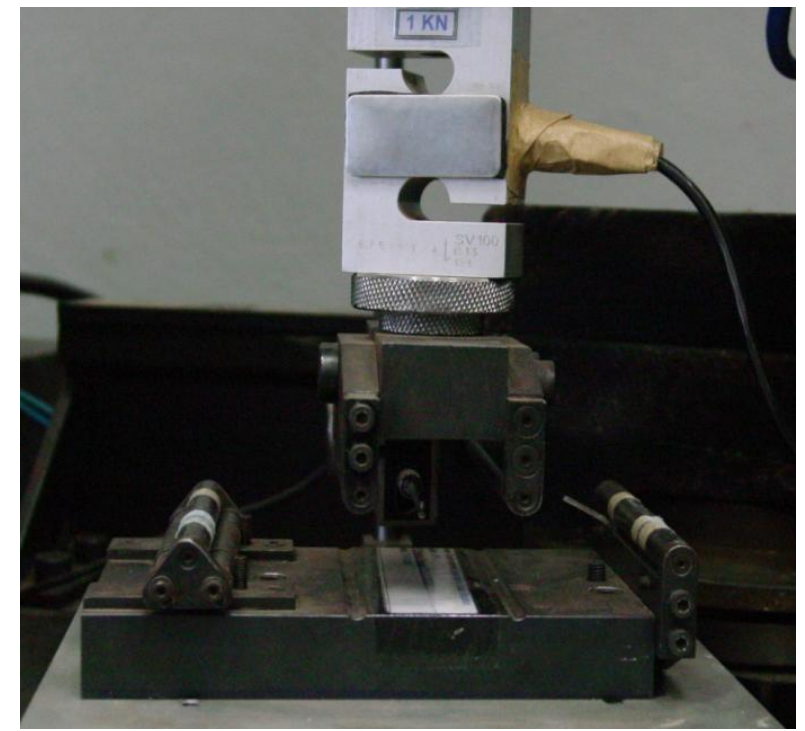

Figura 9 - Dispositivo de ensaio de tração na flexão

Para determinar as propriedades mecânicas utilizaram-se as seguintes equações:

Módulo de Ruptura $(M P a)=\frac{3 * P_{\text {máx }} *\left(L_{\text {inf }}-L_{\text {sup }}\right)}{2 * b * d^{2}}$

Limite de Proporcionalidade $(M P a)=\frac{3 * P_{L O P} *\left(L_{\text {inf }}-L_{\text {sup }}\right)}{2 * b * d^{2}}$

Energia Específica $\left(\mathrm{kJ} / \mathrm{m}^{2}\right)=\frac{\text { Energia absorvida }}{a}$

Módulo de Elasticidade $(M P a)=\frac{276 *\left(L_{\text {inf }}\right)^{3}}{1296 * b * d^{3}} * \theta$

Onde:

$P_{\text {máx }} \quad$ - $\quad$ carga máxima aplicada em Newton;

$P_{L O P} \quad$ - carga máxima aplicada antes da curva carga-deformação desviar-se da linearidade em Newton;

$L_{\text {inf }} \quad$ - distância entre apoios inferiores em milímetros;

$L_{\text {sup }} \quad$ - distância entre apoios superiores em milímetros;

$b$ - largura do corpo-de-prova em milímetros; 
d - espessura do corpo-de-prova em milímetros;

Energia absorvida - energia na área sob a curva do gráfico, cargadeformação em Newton x milímetro;

a - área da seção transversal do corpo-de-prova em milímetro ao quadrado;

$\theta \quad$ - $\quad$ tangente do ângulo da curva força versus flecha, de acordo ao descrito em Tonoli et al. (2011).

Desta forma ficam determinadas as propriedades mecânicas: limites da proporcionalidade (LOP), módulo de ruptura (MOR), módulo de elasticidade (MOE) e energia específica (EE).

\subsubsection{Ensaios físicos}

Para as medidas de absorção de água, densidade e porosidade aparentes utilizou-se a técnica de imersão, baseada na norma ASTM C-948-81 (Standard test method for dry and wet bulk density, water absorption, and apparent porosity of thin sections of glass-fiber reinforced concrete), na qual os corpos-de-prova são submersos, por $24 \mathrm{~h}$, à temperatura ambiente, pesando-se a massa imersa $M_{i}$ (com a amostra dentro da água) e a massa úmida $M_{u}$ (retirando a amostra da água e enxugando levemente sua superfície para retirada do excesso com um pano limpo e seco). Após a secagem das amostras $24 \mathrm{~h}$, realizada em estufa com circulação de ar, a $105 \pm 5{ }^{\circ} \mathrm{C}$, pesa-se a massa seca $M_{S}$.

Para determinação da absorção de água, densidade e porosidade aparentes utilizaram-se as seguintes equações:

$$
\begin{gathered}
\text { Absorção de água aparente }(\%)=\frac{M_{u}-M_{s}}{M_{s}} * 100 \\
\text { Densidade aparente }\left(\mathrm{g} / \mathrm{cm}^{3}\right)=\frac{M_{s}}{M_{u}-M_{i}} * \rho_{w}
\end{gathered}
$$




$$
\text { Porosidade aparente }(\%)=\frac{M_{u}-M_{s}}{M_{u}-M_{i}} * 100
$$

Onde:

$\rho_{w} \quad-\quad$ densidade da água igual a $1 \mathrm{~g} / \mathrm{cm}^{3}$.

Obtêm-se assim propriedades físicas de absorção aparente de água (AA), porosidade aparente (PA) e densidade aparente (DA).

\subsubsection{Ensaios reológicos}

Para realizar a caracterização reológica do material a ser extrudado, aplica-se o modelo de Benbow.

Uma curva típica, tensão-deformação, de uma mistura extrudada com sucesso é apresentada no Gráfico 5. Uma vez que o pistão está em constante contato com a pasta, a parte anterior da pasta é empurrada no corpo da boquilha e a pressão aumenta. Logo a pressão diminui até um mínimo de Y na medida em que a área úmida do barril diminui. Quando o pistão começa a entrar na zona de pasta estática, a qual está associada à região de entrada do corpo da boquilha, a pressão de extrusão se incrementa rapidamente a $\mathrm{Z}$.

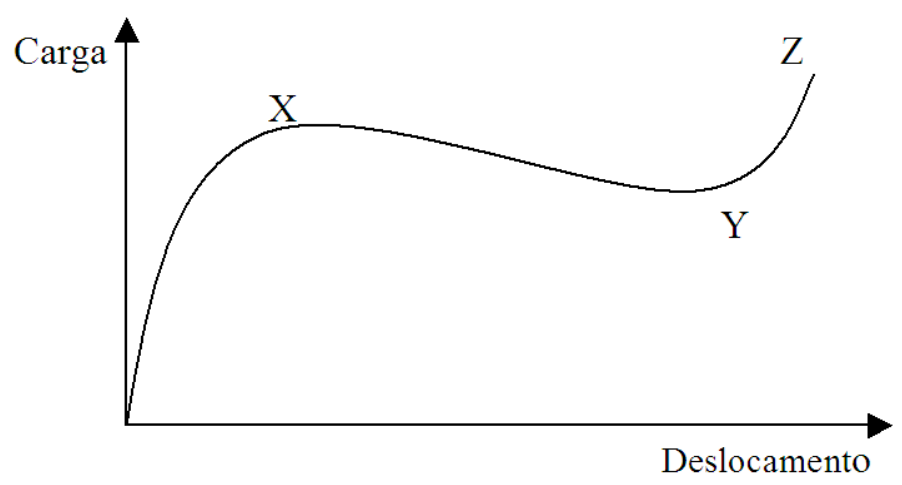

Gráfico 5 - Curva carga-deslocamento do pistão extrusor 
Para caracterizar uma pasta, comumente é suficiente a utilização de três boquilhas com o mesmo diâmetro, porém com diferentes comprimentos. As proporções L/D utilizadas são de 1, 4 e 8 respectivamente. Idealmente o pistão é operado a cinco ou seis velocidades, começando na maior e retornando a ela no final. O método generlizado está apresentado no Gráfico 6 e 7, e será descrito brevemente a seguir.

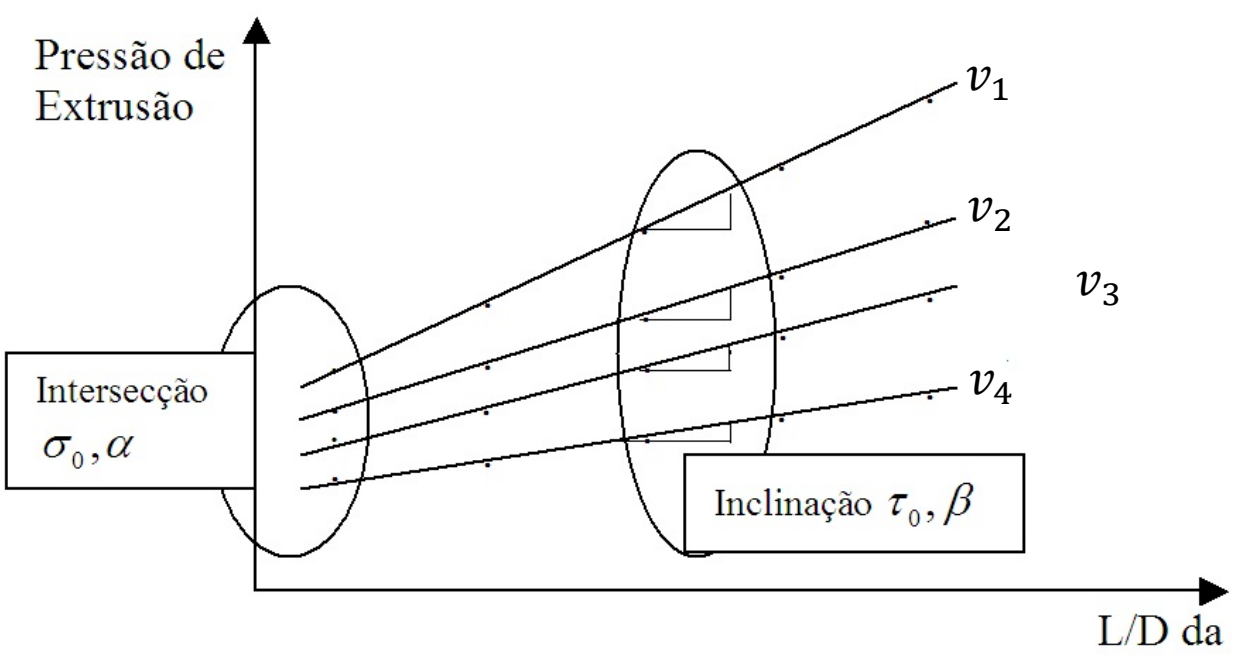

Boquilha Gráfico 6 - Método de cálculo dos parâmetros reológicos de Benbow.

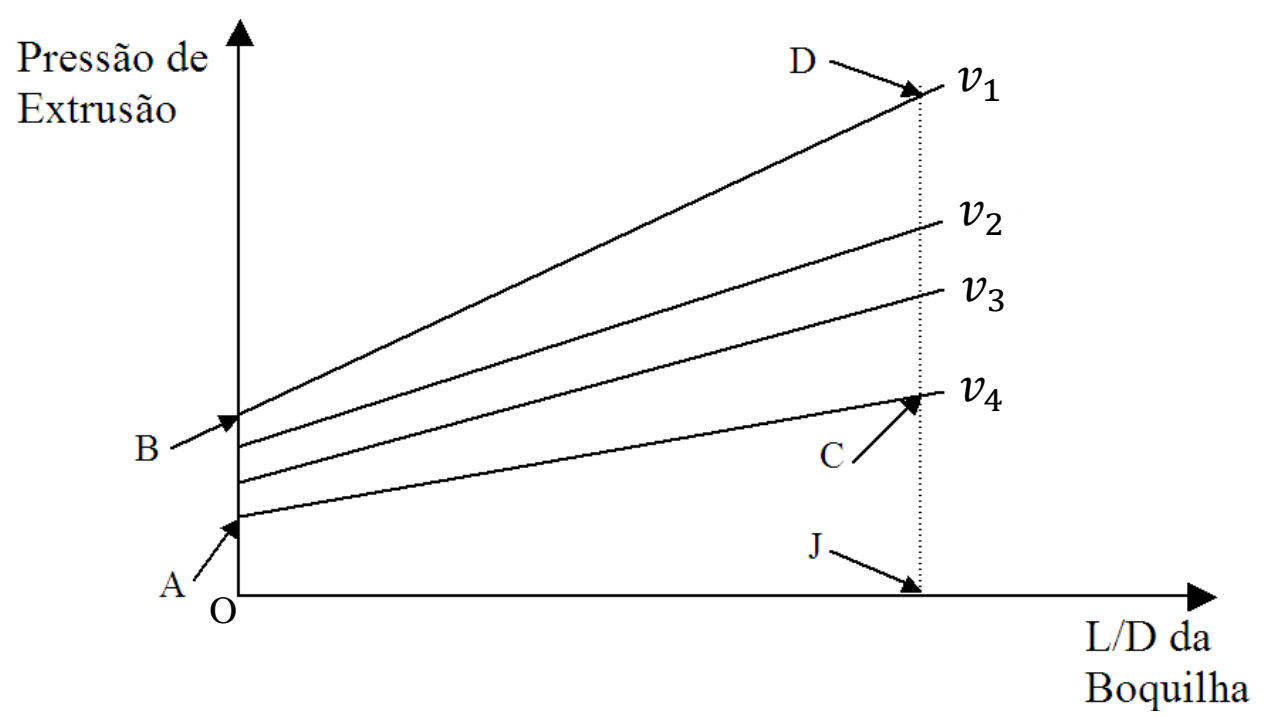

Gráfico 7 - Curvas Pressão de extrusão-L/D para cálculo dos parâmetros de extrusão 
No Gráfico 7 as interseções (OA) e (OB) são dadas por:

$$
\begin{aligned}
& (\mathrm{OA})=2\left(\sigma_{0}+\alpha v_{1}\right) \ln \left(\frac{\mathrm{D}_{0}}{\mathrm{D}}\right) \\
& (\mathrm{OB})=2\left(\sigma_{0}+\alpha v_{2}\right) \ln \left(\frac{\mathrm{D}_{0}}{\mathrm{D}}\right)
\end{aligned}
$$

Daí obtém:

$$
\begin{gathered}
\sigma_{0}=\frac{(\mathrm{OA}) v_{2}-(\mathrm{OB}) v_{1}}{2\left(v_{2}-v_{1}\right) \ln \left(\frac{\mathrm{D}_{0}}{\mathrm{D}}\right)} \\
\alpha=\frac{(\mathrm{OB})-(\mathrm{OA})}{2\left(v_{2}-v_{1}\right)}
\end{gathered}
$$

Para diferentes taxas de L/D, o termo $2\left(\sigma_{0}+\alpha v\right) \ln \left(\frac{\mathrm{D}_{o}}{\mathrm{D}}\right)$ é constate para dada velocidade de extrusão. Assim:

$$
4\left(\tau_{0}+\beta v_{1}\right)=\frac{(\mathrm{CJ})-(\mathrm{OA})}{(\mathrm{OJ})}
$$

e

$$
4\left(\tau_{0}+\beta v_{2}\right)=\frac{(\mathrm{DJ})-(\mathrm{OB})}{(\mathrm{OJ})}
$$

$\log 0$

$$
\tau_{0}=\frac{v_{2}[(\mathrm{CJ})-(\mathrm{OA})]-v_{1}[(\mathrm{DJ})-(\mathrm{OB})]}{4(\mathrm{OJ})\left(v_{2}-v_{1}\right)}
$$

e

$$
\beta=\frac{[(\mathrm{DJ})-(\mathrm{OB})]-[(\mathrm{CJ})-(\mathrm{OA})]}{4(\mathrm{OJ})\left(v_{2}-v_{1}\right)}
$$

Assim, os quatro parâmetros reológicos de Benbow ficam determinados. 


\subsubsection{Ensaios de demanda de água do particulado}

Para descrever o método cálculo de demanda de água das partículas, definem-se as equações a seguir:

$$
\begin{gathered}
\varepsilon=\frac{u}{1+u} \\
\varepsilon_{w}=\frac{u_{w}}{1+u_{w}+u_{A}} \\
\varepsilon_{A}=\frac{u_{A}}{1+u_{w}+u_{A}}
\end{gathered}
$$

Onde:

$\begin{array}{lll}\varepsilon & - & \text { conteúdo de vazios; } \\ \varepsilon_{A} & - & \text { conteúdo de ar; } \\ \varepsilon_{w} & - & \text { conteúdo de água; } \\ u & - & \text { taxa de volume de vazios em relação ao volume de sólidos; } \\ u_{w} & - & \text { taxa de volume de água em relação ao volume sólido; } \\ u_{A} & - & \text { taxa de volume de ar em relação ao volume sólido; }\end{array}$

A taxa de vazios da mistura se altera de acordo com a variação da relação água/sólidos $(\mathrm{a} / \mathrm{s})$. Quando essa relação é relativamente alta, as partículas sólidas são dispersas na água, resultando em uma taxa de vazios crescente à medida que tal relação aumenta. Por outro lado, quando a relação a/s é muito pequena, o conteúdo de água não é suficiente para permitir uma mistura completa e formar uma pasta, resultando numa taxa de vazios também crescente. Existe uma relação a/s quando a menor taxa de vazios é atingida. A menor taxa de vazios ocorre quando as partículas estão compactadas entre si e essa relação a/s é tomada como a demanda de água do particulado. Consequentemente, para determinar a demanda de água do particulado, é necessário executar a medição da densidade aparente em úmido com diferentes relações a/s dentro de um intervalo suficientemente amplo para conter a relação a/s ótima, isto é, a demanda de água. 
Os procedimentos para a medição são descritos a seguir:

1) Estabelecer a relação água/sólidos (a/s) a partir da qual o ensaio terá início;

2) Determinar a quantidade de água requerida e os particulados em recipientes separados;

3) Misturar o material particulado a seco previamente por 2 min em baixa rotação;

4) Colocar toda a água no recipiente de mistura;

5) Adicionar a metade do material cimentício e misturar em baixa velocidade por $3 \mathrm{~min}$;

6) Dividir o material cimentício remanescente em quatro porções iguais;

7) Adicionar à mistura uma porção do material cimentício por vez e misturar por 3 min a velocidade alta até completar todas as porções;

8) Transferir a massa ao molde até ela mesma exceder o molde. Em seguida aplicar compactação,

9) Finalmente remover o excesso de massa e determinar o conteúdo de massa no molde.

Repetir os passos 1 até 9 sucessivamente diminuindo a relação a/s até que a máxima concentração de sólidos seja atingida, isto é, a demanda de água do sistema seja atingida.

A partir dos resultados do ensaio obtém-se a taxa de vazios e, baseando-se nessa taxa, determina-se a relação a/s, que corresponde à demanda de água do particulado. A sequência de cálculos a realizar inicia-se com a determinação da massa do sistema cimentício, denotada por $M$, e do volume do molde denotado por $V$. Quando o material cimentício consiste em diversos materiais, denotados por $\mathrm{w}_{\mathrm{c}}$, $\alpha_{c}, \beta_{c}$ e $\gamma_{c}$, o volume da pasta cimenticia $V_{c}$ e o volume da água $V_{w}$ no molde, são obtidos das seguintes equações:

$$
\begin{gathered}
V_{c}=\frac{M}{\rho_{w} R_{w}+\rho_{\alpha} R_{\alpha}+\rho_{\beta} R_{\beta}+\rho_{\gamma} R_{\gamma}} \\
V_{w}=\frac{M-\rho_{\alpha} R_{\alpha} V_{c}-\rho_{\beta} R_{\beta} V_{c}-\rho_{\gamma} R_{\gamma} V_{c}}{\rho_{w}} \\
V_{s}=V_{c}-V_{w}
\end{gathered}
$$


Tendo obtido $V_{c}$ e $V_{w}$, a taxa de vazios $u$, a taxa de ar $u_{A}$ e a taxa de água $u_{w}$, são determinados por:

$$
\begin{gathered}
u=\frac{V-V_{s}}{V_{S}} \\
u_{A}=\frac{V-V_{s}-V_{w}}{V_{S}} \\
u_{w}=\frac{V-V_{s}-V_{A}}{V_{S}}
\end{gathered}
$$

Onde:

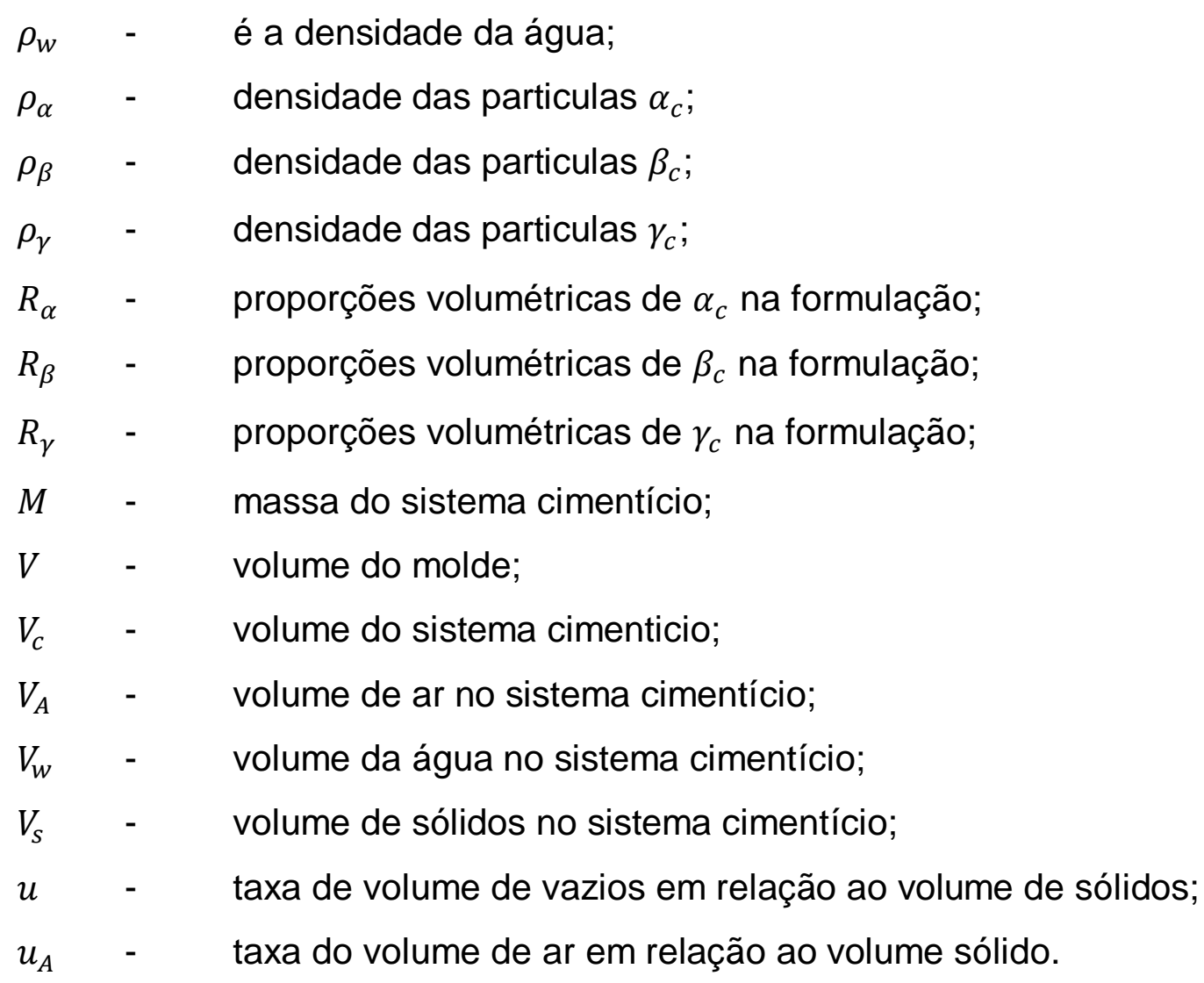

Para os ensaios experimentais do cálculo da demanda de água do particulado, foi utilizada uma balança de precisão de 0,001g, um misturador mecânico planetário, marca Emic, modelo AG5 com velocidades de $140 \mathrm{rpm}$ na baixa rotação, $285 \mathrm{rpm}$ na alta rotação e um recipiente tronco cônico com diâmetro 
interno superior e inferior de $8,1 \mathrm{~cm} \mathrm{e} 7 \mathrm{~cm}$ respectivamente, com altura de $4 \mathrm{~cm}$, contendo volume interno de $179,4 \mathrm{~cm}^{3}$.

\subsubsection{Ensaios de envelhecimento}

$\mathrm{Na}$ introdução de uma nova tecnologia, o estudo da durabilidade é de vital importância, e os ensaios de envelhecimento acelerado fornecem resposta em curto prazo. O ensaio mais utilizado para avaliar a durabilidade de compósitos de fibrocimento é o de ciclos de imersão e secagem, com o intuito de reproduzir os principais mecanismos de degradação esperados em situações normais de uso. Em estudos realizados em compósitos reforçados com fibras de celulose, Silva (2002) conclui que o método de envelhecimento acelerado de imersão e secagem simula eficientemente os efeitos do ambiente externo sobre as propriedades do compósito.

O equipamento utilizado é denominado estufa de imersão-secagem e seu funcionamento baseia-se na norma européia EN-494. No presente experimento, utilizou-se a estufa automática marca Marconi, modelo MA 035, que é composta por um painel com temporizador e controle de temperatura, um conjunto de bombas para circulação de água do tanque ao reservatório e vice-versa, um tanque para armazenagem das amostras com capacidade de $300 \mathrm{~L}$ e um reservatório de água de aço inox com capacidade de $500 \mathrm{~L}$.

Foram utilizados suportes à base de tubo de PVC cortados para colocar os corpos-de-prova (CPs). As amostras foram colocadas na estufa em sentido paralelo à circulação de ar, para que não haja nenhum esforço sobre elas, evitando-se eventuais fissuras ou quebras, os equipamentos e a disposição dos CPs podem ser observados nas Figuras de 10, 11 e 12.

O uso do equipamento com o procedimento estabelecido permite simular um envelhecimento acelerado, com o objetivo de analisar a durabilidade (fissuras, trincas, degradação da polpa) e as propriedades mecânicas e físicas do material em um tempo reduzido.

Após o endurecimento os CPs foram introduzidos no tanque da estufa e submetidos a 200 ciclos de imersão-secagem. Cada ciclo corresponde a $2 \mathrm{~h}$ e $50 \mathrm{~min}$ em estufa a $60^{\circ} \mathrm{C}$ com circulação de ar, denominada fase de secagem (calor), 
seguido de mais 2 h e 50 min em água à temperatura ambiente, denominada fase de imersão e um intervalo de 10 min entre as fases, totalizando $6 \mathrm{~h}$.

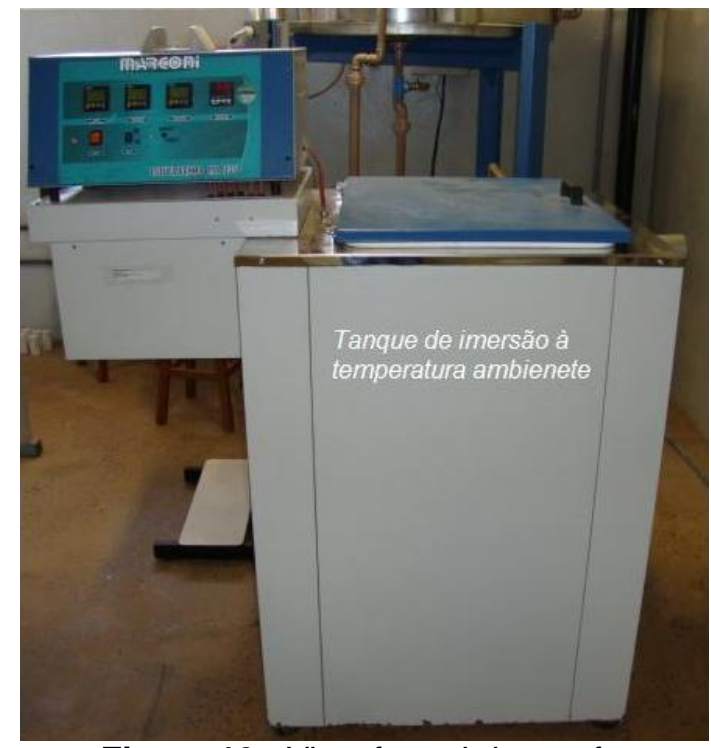

Figura 10 - Vista frontal da estufa imersão-secagem

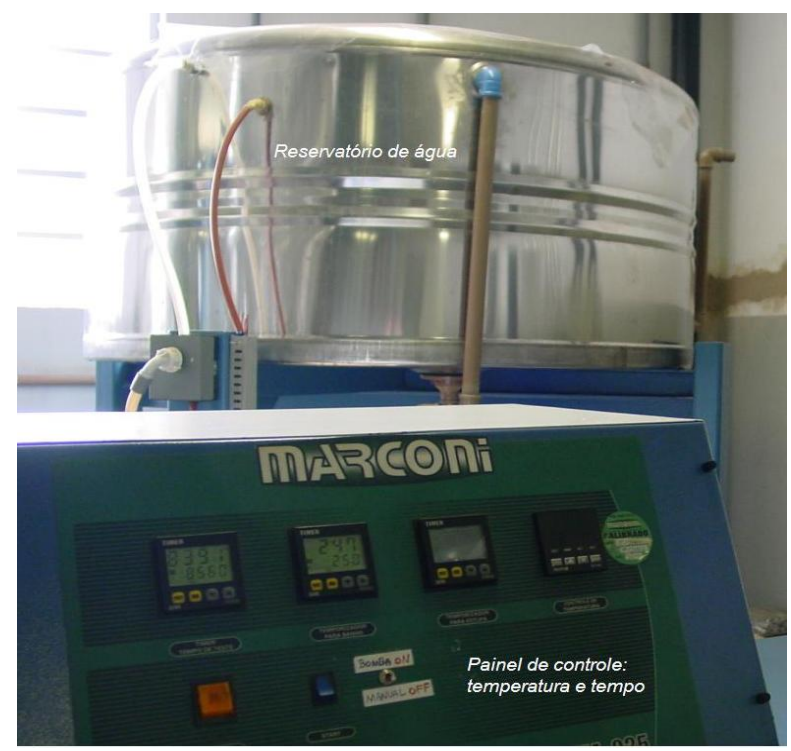

Figura 11 - Painel de controle e reservatório de água

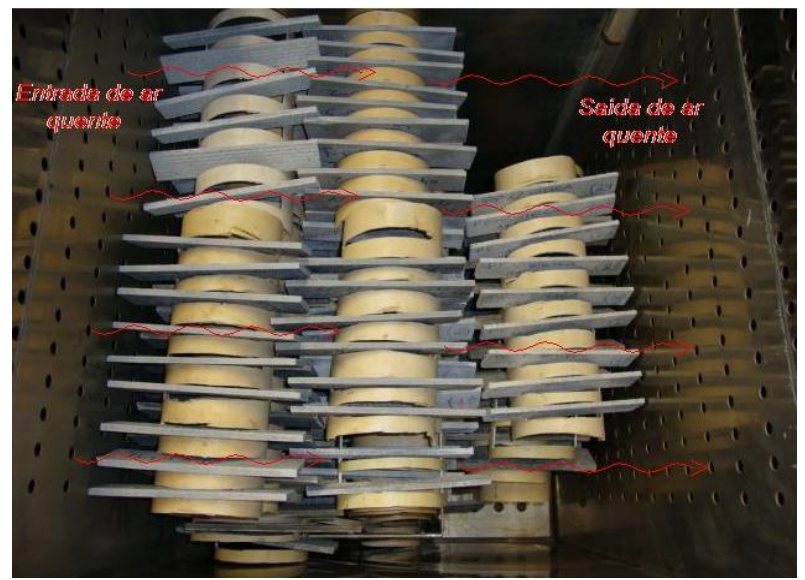

Figura 12 - Sentido de circulação de ar quente (etapa de secagem)

\subsection{PROPRIEDADES DAS MATÉRIAS-PRIMAS DA MATRIZ}

As caracterizações realizadas para o material particulado foram: densidade real, distribuição granulométrica a laser, composição química com fluorescência de raios $\mathrm{x}$, área específica mediante $\mathrm{BET}$, análise de fases por difração de raios $\mathrm{x} e$ microscopia eletrônica de varredura MEV. 


\subsubsection{Densidade}

A análise de densidade dos materiais foi realizada utilizando a técnica de picnometria a gás hélio com o equipamento Multipycnometer da Quantachrome. Os resultados obtidos são apresentados na Tabela 1. Excepcionalmente apresentam-se aqui as densidades das fibras utilizadas como reforço.

Tabela 1 - Densidades reais dos materiais

\begin{tabular}{lc}
\hline Material & Densidade real $\mathbf{( g / \mathbf { c m } ^ { 3 } )}$ \\
\hline CPV ARI & 3,11 \\
Sílica ativa & 2,27 \\
Calcário & 2,80 \\
HPMC & 1,32 \\
Fibras de PVA & 1,30 \\
Fibras de polipropileno & 0,92 \\
Celulose de eucalipto & 1,58 \\
\hline
\end{tabular}

\subsubsection{Granulometria}

Foi realizada a análise granulométrica dos cimentos CPV ARI, CPIIE, CPIII 30 RS, sílica ativa comercializada pela Elkem, e calcário comercializado pela Votoram com nome comercial de calcário Itaú.

A porcentagem acumulada de partículas (CPFT) para as matérias-primas utilizadas é apresentada no Gráfico 8. No caso dos cimentos, como é de se esperar, o cimento CPV ARI apresenta $50 \%$ do material inferior ao diâmetro de $10,98 \mu \mathrm{m}$ e $90 \%$ inferior a $27,27 \mu \mathrm{m}$, o que condiz com o requerimento de um cimento de alta resistência inicial. O cimento CPII E apresenta 50\% do material inferior a 14,35 $\mu \mathrm{m}$ e 90\% inferior a 43,08 $\mu \mathrm{m}$. Para o cimento CPIII a distribuição granulométrica apresenta $50 \%$ das partículas inferiores a $13,82 \mu \mathrm{m}$ e $90 \%$ do volume inferior a 46,00 $\mu \mathrm{m}$. O cimento CPV pelo requerimento de alta resistência inicial requerida 
deve apresentar tamanhos de partículas inferiores comparados aos demais cimentos, uma vez que os parâmetros que influenciam na reatividade de um cimento são a área especifica, granulometria e fases predominantes no cimento.

A sílica ativa, de acordo a empresa Elkem, apresenta tamanho de partículas médias da ordem de $0,15 \mu \mathrm{m}$, isto é, tamanho submicron, o qual não é observado no tamanho médio de partículas, apresentando tamanho médio de 12,36 $\mu \mathrm{m}$, na distribuição granulométrica obtida para esse material dispersas por ultra-som. As partículas nessa ordem de tamanho são extremamente influenciadas pelas forças de superfície. Pode-se assumir que a distribuição granulométrica obtida é de aglomerados de partículas primárias de sílica ativa como é observado nas microscopias desse material.

O calcário apresenta partículas $50 \%$ do volume inferior a $16,15 \mu \mathrm{m}$ e $90 \%$ inferior a $64,41 \mu \mathrm{m}$, esses bastante próximos ao perfil apresentado pelos aglomerados de sílica ativa.

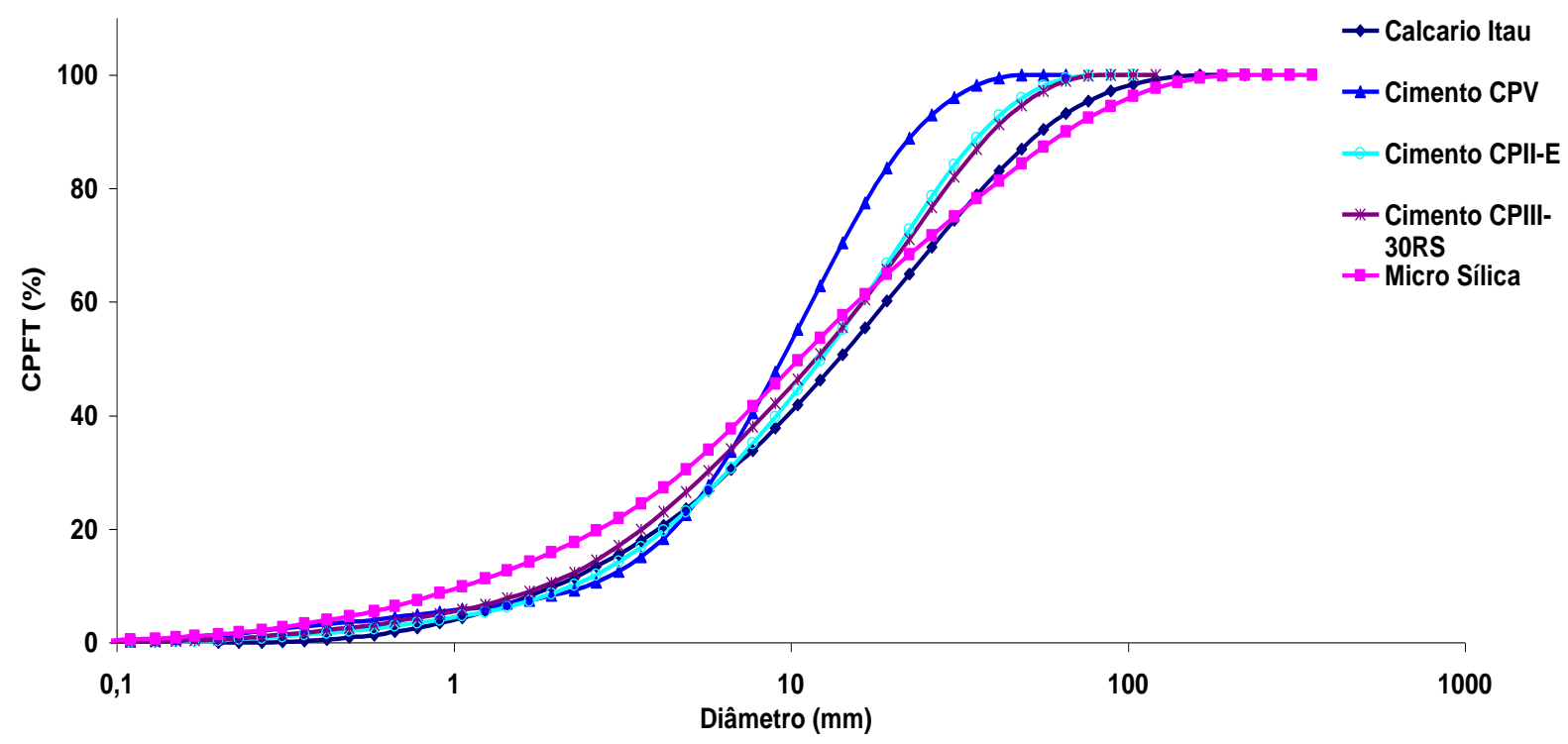

Gráfico 8 - Porcentagem acumulada de partículas das matérias-primas

\subsubsection{Composição química}

Foram realizadas análises da composição química por fluorescência de raios X dos cimentos CPV ARI, CPIIE, CPIII 30 RS, sílica ativa comercializada pela Elkem 
e calcário comercializado pela empresa Votoram com nome comercial de calcário Itaú. Os resultados são apresentados nas Tabelas 2, 3 e 4.

Tabela 2 - Composição química dos cimentos em \% massa

\begin{tabular}{lccccccccc}
\hline Amostra & $\mathbf{C a O}$ & $\mathrm{MgO}$ & $\mathrm{SiO}_{2}$ & $\mathrm{Al}_{2} \mathrm{O}_{3}$ & $\mathrm{Fe}_{2} \mathrm{O}_{3}$ & $\mathrm{Na}_{2} \mathrm{O}$ & $\mathrm{K}_{2} \mathrm{O}$ & $\mathbf{S O}_{3}$ & $\mathbf{P F}$ \\
\hline Cimento CPV & 63,5 & 3,13 & 19,4 & 4,11 & 2,30 & 0,24 & 1,09 & 2,97 & 3,29 \\
Cimento CPIIE & 57,0 & 4,29 & 22,7 & 6,07 & 2,20 & 0,10 & 0,80 & 1,63 & 4,98 \\
Cimento CPIII 30RS & 54,1 & 5,69 & 25,3 & 7,37 & 1,76 & 0,11 & 0,76 & 1,26 & 2,72 \\
\hline
\end{tabular}

Tabela 3 - Composição química do calcário em \% massa

\begin{tabular}{cccccccccccc}
\hline Amostra & $\mathrm{CaO}$ & $\mathrm{MgO}$ & $\mathrm{SiO}_{2}$ & $\mathrm{Al}_{2} \mathrm{O}_{3}$ & $\mathrm{Fe}_{2} \mathrm{O}_{3}$ & $\mathrm{MnO}$ & $\mathrm{Na}_{2} \mathrm{O}$ & $\mathrm{K}_{2} \mathrm{O}$ & $\mathrm{P}_{2} \mathrm{O}_{5}$ & $\mathrm{TiO}_{2}$ & $\mathrm{PF}$ \\
\hline Calcário Itaú & 39,1 & 8,90 & 9,04 & 2,16 & 2,30 & $<0,10$ & 0,15 & 0,41 & 0,16 & 0,15 & 39,2 \\
\hline
\end{tabular}

Como é de se esperar, a sílica ativa apresenta predominante concentração de dióxido de silício, o qual vai reagir com o hidróxido de cálcio livre.

Tabela 4 - Composição química da sílica ativa em \% massa

\begin{tabular}{lccccccccccc}
\hline Amostra & $\mathrm{SiO}_{2}$ & $\mathrm{Al}_{2} \mathrm{O}_{3}$ & $\mathrm{Fe}_{2} \mathrm{O}_{3}$ & $\mathrm{MnO}$ & $\mathrm{MgO}$ & $\mathrm{CaO}$ & $\mathrm{Na}_{2} \mathrm{O}$ & $\mathrm{K}_{2} \mathrm{O}$ & $\mathrm{TiO}_{2}$ & $\mathrm{P}_{2} \mathrm{O}_{5}$ & $\mathrm{PF}$ \\
\hline Sílica Ativa & 84,5 & 0,97 & 2,62 & 0,27 & 0,60 & 2,93 & 0,15 & 1,04 & $<0,10$ & 0,14 & 7,53 \\
\hline
\end{tabular}

\subsection{4 Área superficial (BET)}

Os equipamentos utilizados para a preparação das amostras e para a análise foram, respectivamente, o VacPrep 061 e o Gemini III 2375. O gás usado na adsorção foi o nitrogênio e os ensaios foram efetuados na temperatura de 77K. A amostra foi tratada em vácuo $(100 \mu \mathrm{m}$ de $\mathrm{Hg})$ e aquecida à temperatura de $300^{\circ} \mathrm{C}$ durante no mínimo $8 \mathrm{~h}$ para desgaseificação e eliminação de possíveis contaminantes superficiais.

O resultado das áreas específicas é apresentado na Tabela 5. O cimento CPV ARI de alta resistência inicial apresenta a área superficial superior aos demais cimentos, tornando-o mais reativo, o que é coerente em relação a esse cimento, uma vez que parte de sua alta resistência inicial está associada a sua alta reatividade (TAYLOR, 1997). Ainda, apresenta 90\% das partículas com tamanho 
inferior a $16,15 \mu \mathrm{m}$, enquanto os outros dois cimentos apresentam $90 \%$ das partículas inferiores de $43,08 \mu \mathrm{m}$ a $46,00 \mu \mathrm{m}$, o que pode ser constatado no Gráfico 8. Os cimentos CPIIE e CPIII 30 RS apresentam área superficial semelhante. Isso era esperado, uma vez que suas distribuições granulométricas apresentam perfis próximos, como observado no Gráfico 8. A sílica ativa, embora com uma distribuição de perfil granulométrico não distante à das outras matérias-primas, apresenta área superficial elevada, da ordem de 16 vezes maior que as demais. Isso se apresenta coerente com a hipótese de que a distribuição granulométrica registrada nada mais é do que a distribuição de aglomerados de sílica ativa. Dessa forma, quando quantificada a superfície específica registra-se a área real das partículas primárias e não a área de aglomerados.

Tabela 5 - Área de superfície específica das matérias-primas

\begin{tabular}{lcc}
\hline Amostra & $\begin{array}{c}\text { Área de superfície específica BET }\left(\mathbf{m}^{2} \mathbf{~ g )}\right. \\
\text { "Multi-point" } \\
\text { "Single-point" }\end{array}$ \\
\hline Cimento CPV & 1,57 & 1,68 \\
Cimento CPIIE & 1,07 & 0,95 \\
Cimento CPIII 30RS & 1,07 & 0,95 \\
Sílica ativa & 16,1 & 15,3 \\
Calcário Itaú & 1,47 & 1,14 \\
\hline
\end{tabular}

\subsubsection{Composição mineralógica}

O estudo foi efetuado através do método do pó, mediante o emprego de difractômetro de raios x, marca Philips, modelo MPD 1880 .

A identificação das fases cristalinas, descritas a seguir, foi obtida por comparação do difractograma da amostra com os bancos de dados do ICDD Internacional Centre for Diffraction Data (2003) e PAN-ICSD - PAN Analytical Inorganic Crystal Structure Database (2007).

As fases determinadas são apresentadas na Tabela 6 para a sílica ativa, na Tabela 7 para o calcário, na Tabela 8 para o cimento CPV, na Tabela 9 para o cimento CPIIE e na Tabela 10 para o cimento CPIII. 
Tabela 6 - Composição mineralógica da sílica ativa

\begin{tabular}{lccc}
\hline Nome do composto & Fórmula química & Mineral & Obs \\
\hline Moissanita & $\mathrm{SiC}$ & Moissanita & \\
Silício & $\mathrm{Si}$ & & \\
Quartzo & $\mathrm{SiO}_{2}$ & Quartzo & $\mathrm{pp}$ \\
Tridimita & $\mathrm{SiO}_{2}$ & Tridimita & $\mathrm{pp}$ \\
Gupeita & $\mathrm{Fe}_{3} \mathrm{Si}$ & Gupeita & $\mathrm{pp}$ \\
\hline
\end{tabular}

Nota: $\mathrm{pp}=$ possível presença

Tabela 7 - Composição mineralógica do calcário

\begin{tabular}{lccc}
\hline Nome do composto & Fórmula química & Mineral & Obs \\
\hline Calcita & $\mathrm{CaCO}_{3}$ & Calcita & \\
Dolomita & $\mathrm{CaMg}\left(\mathrm{CO}_{3}\right)_{2}$ & Dolomita & \\
Quartzo & $\mathrm{SiO}_{2}$ & Quartzo & \\
Clinocloro & $(\mathrm{Mg}, \mathrm{Fe})_{6}\left(\mathrm{Si}_{1} \mathrm{Al}_{4} \mathrm{O}_{10}(\mathrm{OH})_{8}\right.$ & Clinocloro & \\
Illita & $\left(\mathrm{K}, \mathrm{H}_{3} \mathrm{O}\right) \mathrm{Al}_{2} \mathrm{Si}_{3} \mathrm{AlO}_{10}(\mathrm{OH})_{2}$ & Illita & \\
Flogopita & $\mathrm{KMg}_{3}\left(\mathrm{Si}_{3} \mathrm{AlO}_{10}\right) \mathrm{F}_{2}$ & Flogopita & pp \\
\hline
\end{tabular}

Nota: $\mathrm{pp}=$ possível presença

\subsubsection{Morfologia}

O presente item apresenta caracterizações apenas qualitativas da forma das partículas.

A Figura 13 apresenta as micrografias realizadas para a sílica ativa. Nessas a escala de referência apresentada é de $1 \mu \mathrm{m}$ para ambas as micrografias. $\mathrm{Na}$ micrografia 13(a), assim como na micrografia 13(b), é possível observar que não se apresenta configuração de partículas definidas e isoladas e sim aglomerados de partículas. Isso se mostra coerente com a hipótese de uma distribuição granulométrica de aglomerados de sílica ativa, que promove uma área específica 16 vezes maior a distribuições próximas, uma vez que a área medida é das partículas primárias e não de áreas de aglomerados. 


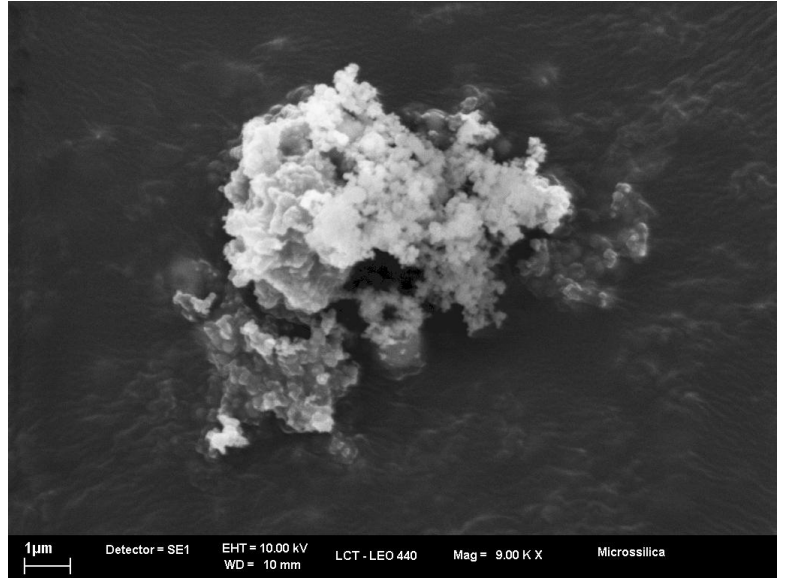

(a)

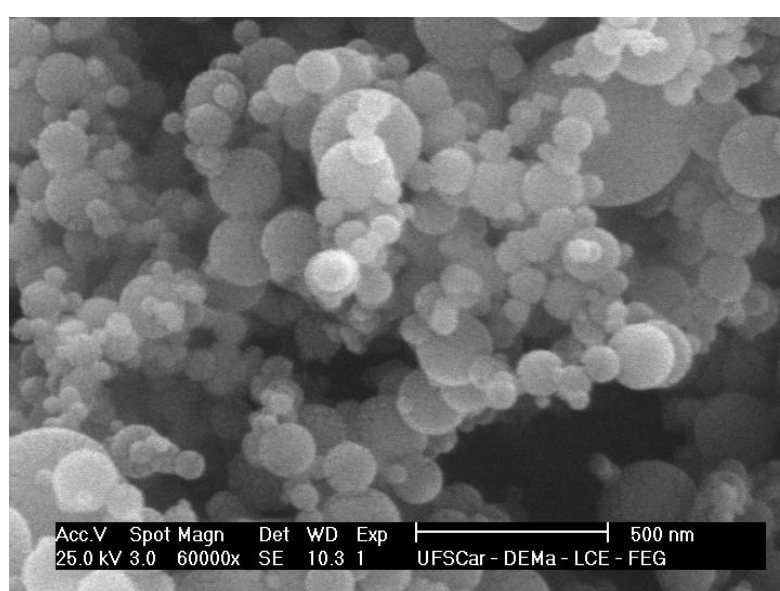

(b)

Figura 13 - Micrografias de partículas de sílica ativa aglomerada (a) e esfericidade das partículas (b)

O Gráfico 9 correspondente ao EDS do MEV de sílica ativa, confirma a presença de Si no material particulado.

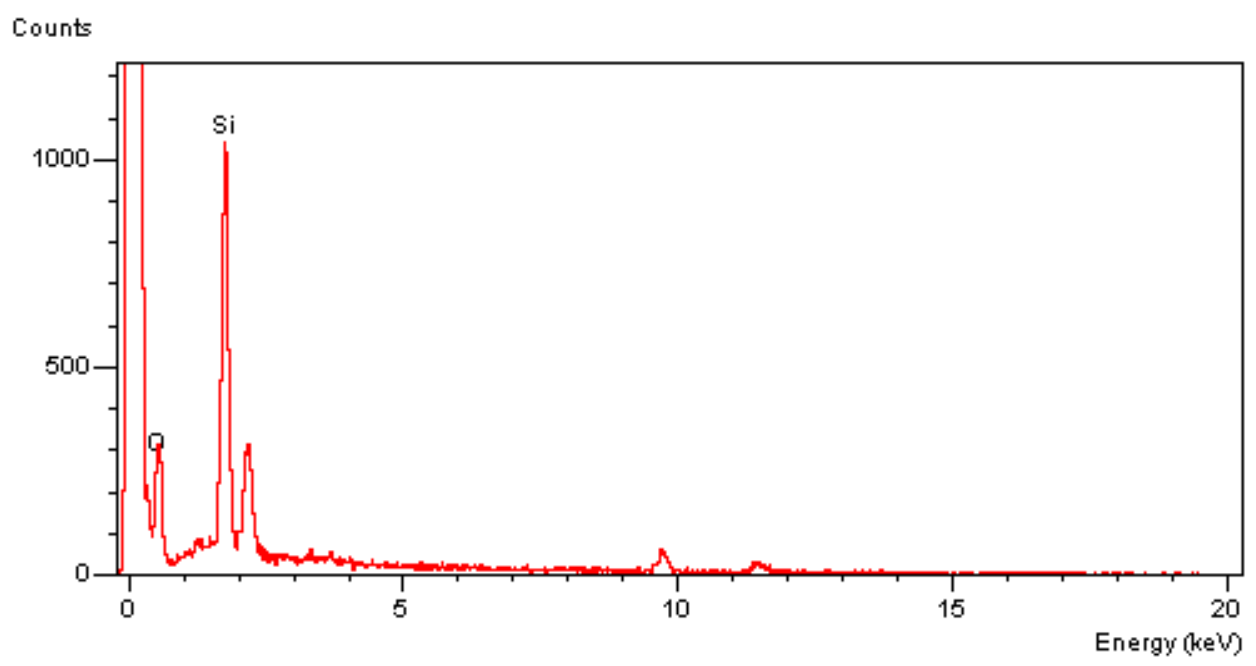

Gráfico 9 - EDS da sílica ativa

As micrografias da Figura 14 (a) e (b) apresentam escala de referência de $100 \mu \mathrm{m}$ e $10 \mu \mathrm{m}$, respectivamente. Como observado na imagem 14 (b), as partículas apresentam forma irregular com arestas vivas com baixa quantidade de partículas aglomeradas nas suas faces. 


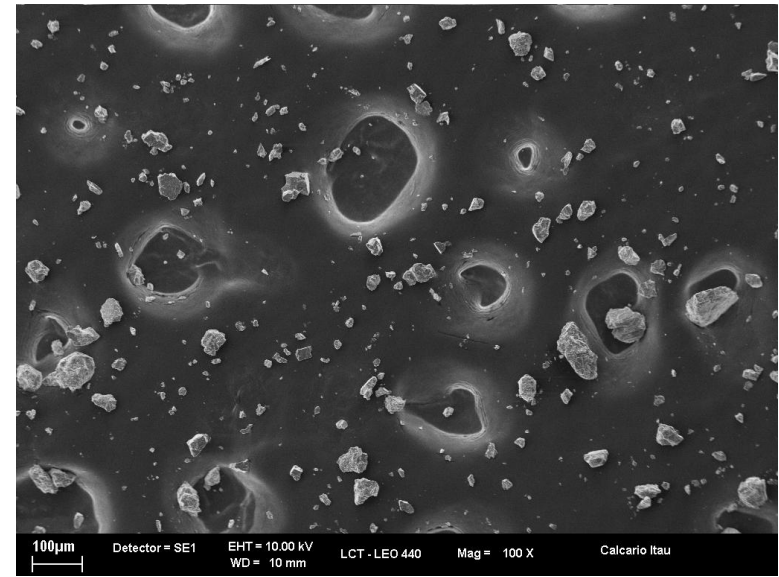

(a)

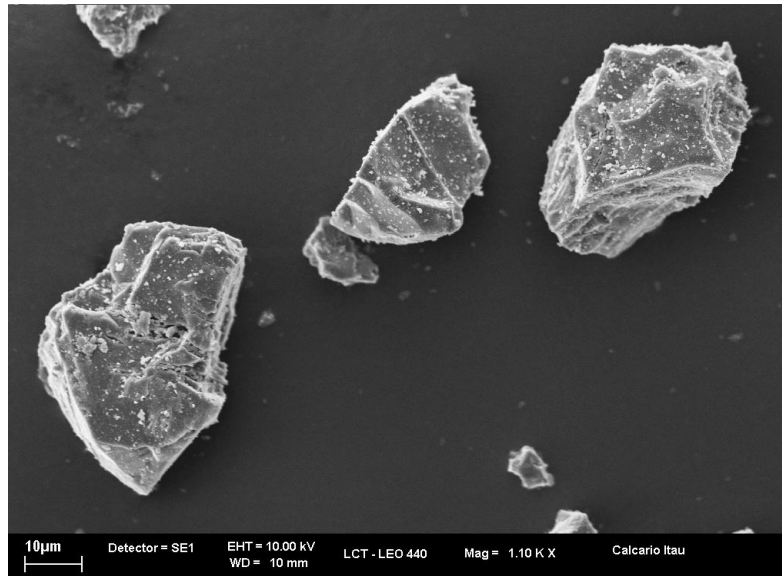

(b)

Figura 14 - Micrografias de partículas de calcário sem aglomeração (a) e com configuração irregular (b)

O Gráfico 10, correspondente ao EDS do MEV do pó calcário, confirma a presença de Ca no material particulado.

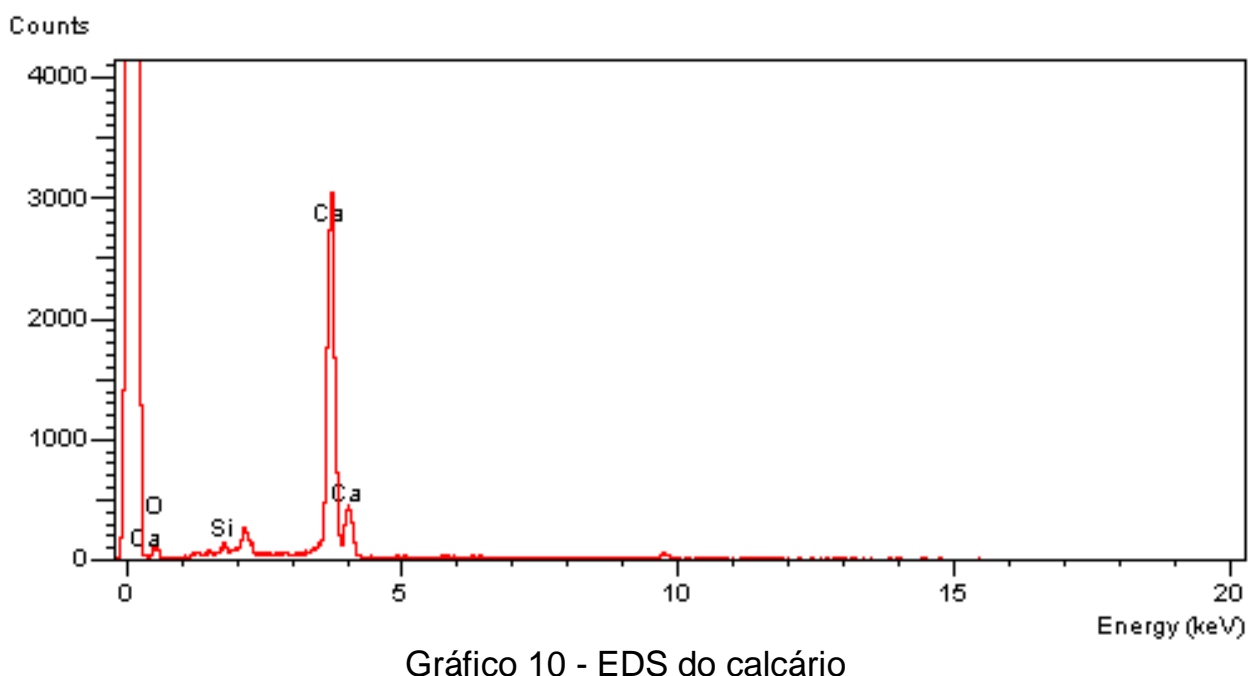

A Figura 15 (a) e (b) apresenta micrografias das partículas de cimento CPV, com escalas de referência de $100 \mu \mathrm{m}$ e $3 \mu \mathrm{m}$ respectivamente. As partículas apresentam configuração irregular sem dimensão predominante definida, com algumas partículas de dimensões menores aglomeradas nas suas fases. 


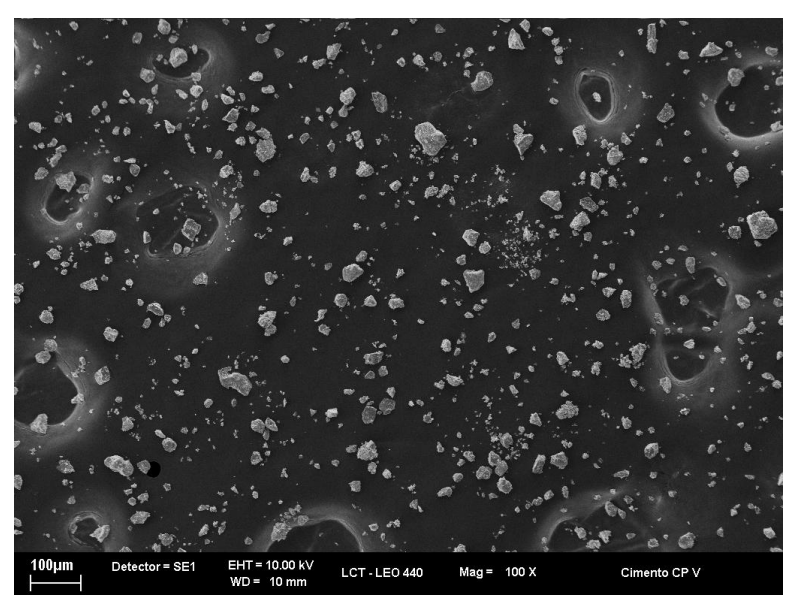

(a)

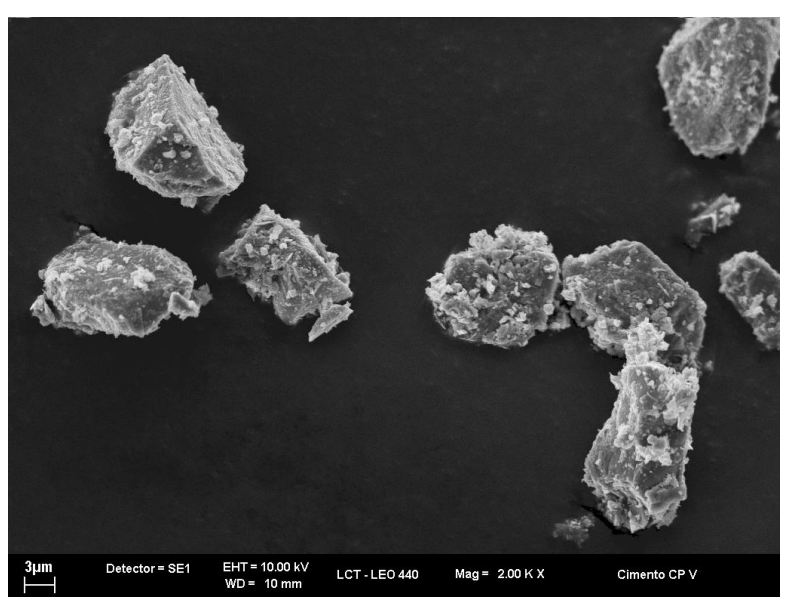

(b)

Figura 15 - Micrografias de partículas de cimento CPV sem aglomeração (a) e com configuração irregular (b)

A Figura 16 (a) e (b) apresenta micrografias de partículas de cimento CPII E, com escala de referência de $100 \mu \mathrm{m}$ e $10 \mu \mathrm{m}$ respectivamente. As partículas apresentam configuração irregular variando de partícula a partícula com arestas vivas. É possível apreciar pequenas quantidades de partículas menores aglomeradas às maiores.

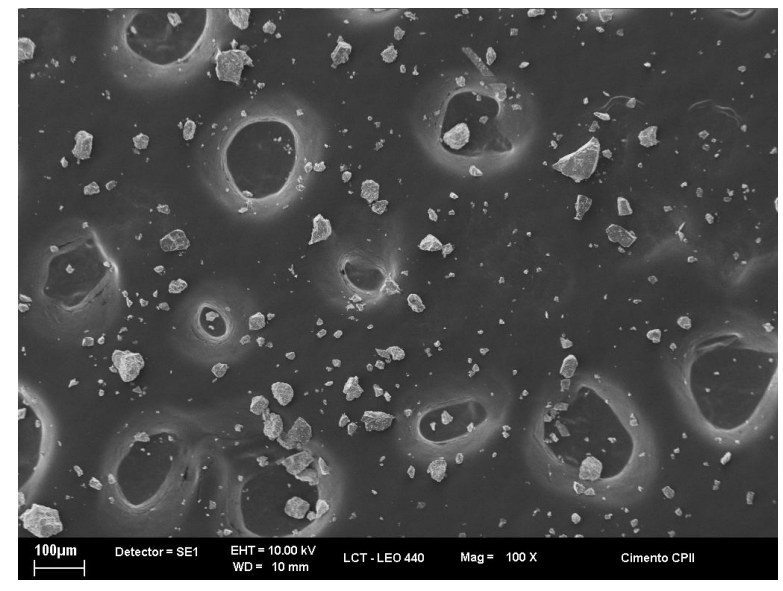

(a)

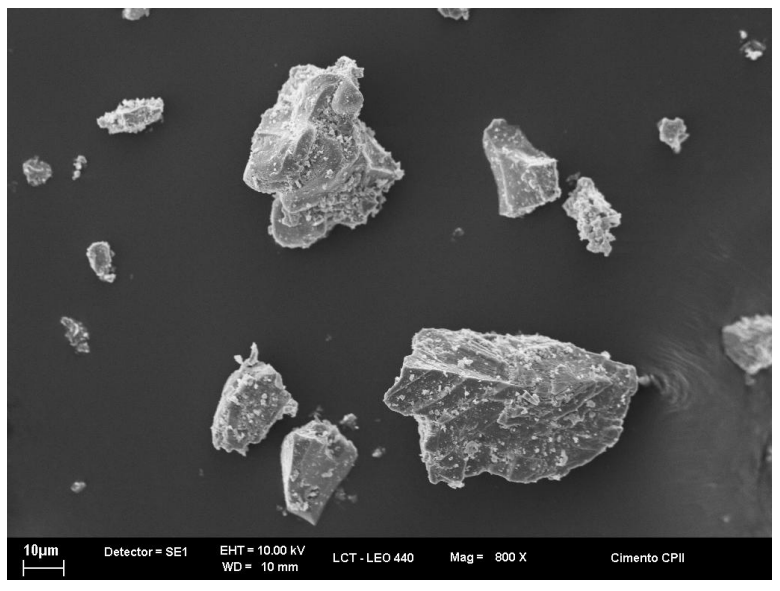

(b)

Figura 16 - Micrografias de partículas de cimento CPII E sem aglomeração (a) e com configuração irregular (b)

A Figura 17 (a) e (b) apresenta micrografias de partículas de cimento CPIII, com escalas de referência de $100 \mu \mathrm{m}$ e $10 \mu \mathrm{m}$ respectivamente. As partículas apresentam configurações morfológicas desde uma direção predominante sobre as outras até partículas onde nenhuma dimensão predomina sobre as outras. As morfologias destas partículas também se apresentam irregulares. 


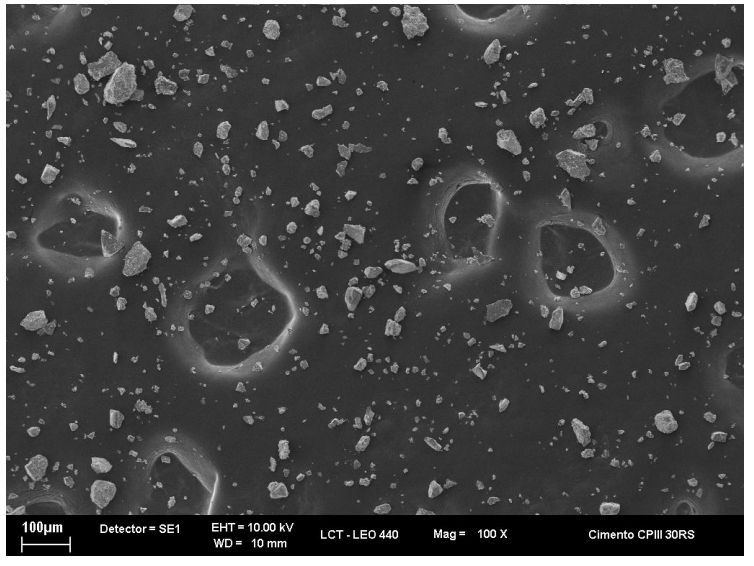

(a)

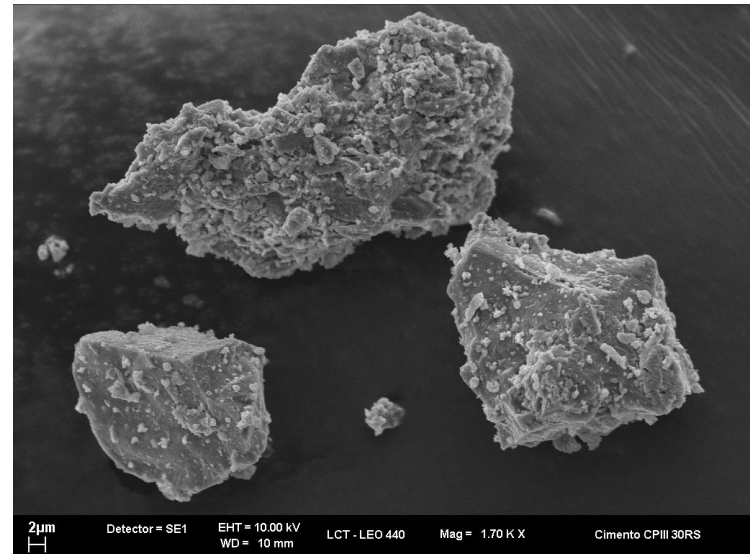

(b)

Figura 17 - Micrografias de partículas de cimento CPIII sem aglomeração (a) e com configuração irregular (b)

\subsection{PROPRIEDADES DAS FIBRAS DE REFORÇO}

\subsubsection{Fibra celulósica}

3.3.1.1 Características morfológicas das fibras celulósicas de eucalipto

Os principais atributos morfológicos da polpa de eucalipto branqueada foram determinados através do analisador de partículas Kajaani. A análise com Kajaani consiste na avaliação dos atributos (comprimento, largura, número de fibras por grama, "coarseness", entre outros) de todo o material fibroso presente na polpa. Os finos são definidos como fibras muito curtas ou fragmentos de fibras, que tipicamente é todo material fibroso menor que $75 \mu \mathrm{m}$ (SAARELA et al., 2003).

O método "Canadian Standard Freeness" (CSF) é uma estimativa da intensidade de refino da polpa e é uma mensuração arbitrária das propriedades de drenagem ou drenabilidade da polpa. Esse método se correlaciona bem com a taxa inicial de drenagem da polpa úmida durante o processo de retirada da água por aplicação de pressão negativa. Baixos valores de CSF (menores que $300 \mathrm{~mL}$ ) são um indicativo de altos graus de fibrilação externa das fibras e provocam longos 
períodos de drenagem durante a realização desse procedimento. Os valores de CSF para a polpa foram determinados de acordo com a norma brasileira NBR 14344 (2003). As propriedades das fibras celulósicas mencionadas anteriormente são apresentadas na Tabela 8 a seguir.

Tabela 8 - Propriedades das fibras celulósicas

\begin{tabular}{lc}
\hline \multicolumn{2}{c}{ Polpa de Eucalipto CSF $\mathbf{6 0 0} \mathbf{~ m L}$ (não refinada) } \\
\hline Comprimento médio $(\mathrm{mm})$ & $0,87 \pm 0,06$ \\
Largura média $(\mu \mathrm{m})$ & $17,1 \pm 0,4$ \\
Razão de aspecto & 51 \\
Diâmetro de lumen $(\mu \mathrm{m})$ & $11,7 \pm 7,2$ \\
Espessura parede celular $(\mu \mathrm{m})$ & $2,7 \pm 0,2$ \\
Coarseness $(\mathrm{mg} / 100 \mathrm{~m})$ & $6,5 \pm 0,5$ \\
Número de fibras $\left(10^{6}\right.$ fibers/g) & $20,6 \pm 0,1$ \\
Finos $(\%)$ & $11,1 \pm 0,8$ \\
\hline
\end{tabular}

\subsubsection{Umidade das fibras celulósicas de eucalipto}

Para obter a capacidade de absorção de água da fibra celulósica, as fibras foram saturadas de água e colocadas em refrigeração na temperatura de $5^{\circ} \mathrm{C}$ durante $24 \mathrm{~h}$, e posteriormente foram colocadas em forno a temperatura de $105^{\circ} \mathrm{C}$ durante $24 \mathrm{~h}$. Realizaram-se três leituras de massa saturada, e três leituras de massa seca, obtendo-se o teor da umidade por diferença de massa. Assim foi obtida a umidade para a celulose de eucalipto de $73 \%$ em massa com desvio padrão de $0,21 \%$. 


\subsubsection{Fibra sintética}

3.3.2.1 Fibras de polivinil-álcool

As fibras de reforço utilizadas no presente trabalho são de polivinil-álcool (PVA) elaboradas pela firma KURARAY CO Ltda., com o nome comercial de Kuralon KII, do Japão. As suas propriedades são apresentadas na Tabela 9.

\begin{tabular}{lc} 
Tabela 9 - Propriedades das fibras de PVA Kuralon KII \\
\hline Diâmetro (mm) & 0,027 \\
Comprimento (mm) & 6 \\
Elongação (\%) & 6,5 \\
Modulo de elasticidade $(\mathrm{GPa})$ & 39 \\
Resistência a tração $(\mathrm{MPa})$ & 1600 \\
Densidade específica $\left(\mathrm{g} / \mathrm{cm}^{3}\right)$ & 1,3 \\
\hline
\end{tabular}

\subsubsection{Fibras de polipropileno}

As fibras utilizadas neste trabalho são fornecidas pela empresa BRASILIT Ltda., Brasil, e são obtidas a partir do processo de fiação de um homopolímero de polipropileno, submetendo-se posteriormente a um processo de estiramento controlado até as propriedades físico-mecânicas finais desejadas.

Os fios cortados de polipropileno (PP) são cobertos por encimagem que, segundo o fabricante, permite obter uma dispersão adequada dos fios e uma melhor adesão à massa cimentícia. A Tabela 10 apresenta as propriedades do PP. 


\begin{tabular}{lc} 
Tabela 10 - Propriedades das fibras de Polipropileno \\
\hline Diâmetro (dtex)* & 0,8 a 1,2 \\
Comprimento (mm) & 6 \\
Elongação na ruptura (\%) & 20 a 22 \\
Módulo de elasticidade (GPa) & 6 \\
Tenacidade (cN/dtex) & 9 a 9,5 \\
Resistência a tração $\left(\mathrm{N} / \mathrm{mm}^{2}\right)$ & $\mathrm{nf}^{* *}$ \\
Densidade $\left(\mathrm{g} / \mathrm{cm}^{3}\right)$ & 0,98 \\
\hline
\end{tabular}

*1dtex $(\sim 12 \mu \mathrm{m}),{ }^{* *}$ não fornecido pelo fabricante

\subsection{ELABORAÇÃO DE COMPÓSITOS CIMENTÍCIOS}

\subsubsection{Equipamentos utilizados para a extrusão de compósitos}

No desenvolvimento do presente trabalho foram utilizados dois misturadores planetários um de $20 \mathrm{~L}$ de capacidade com velocidade de $150 \mathrm{rpm}$ e outro de $6 \mathrm{~L}$ de capacidade com duas velocidades de mistura $140 \mathrm{rpm}$ e $285 \mathrm{rpm}$. Esses equipamentos são mostrados na Figura 18 e 19 respectivamente.

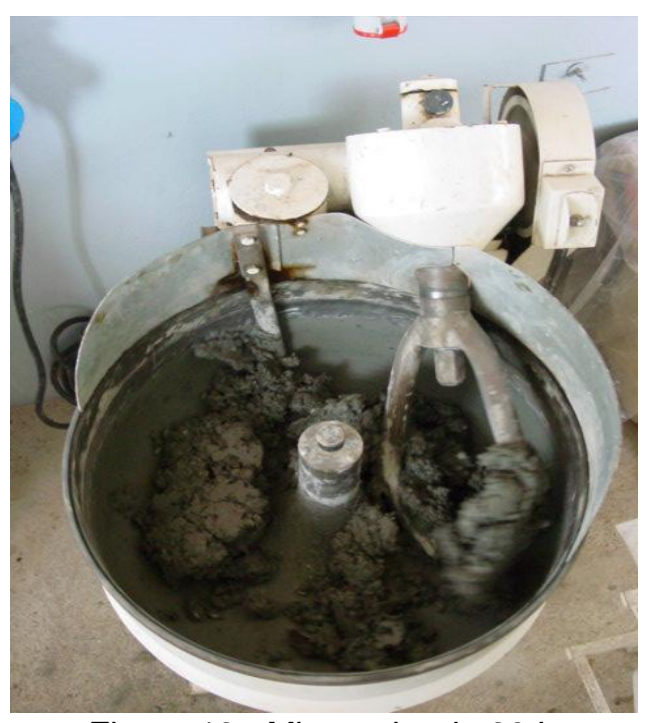

Figura 18 - Misturador de $20 \mathrm{~L}$

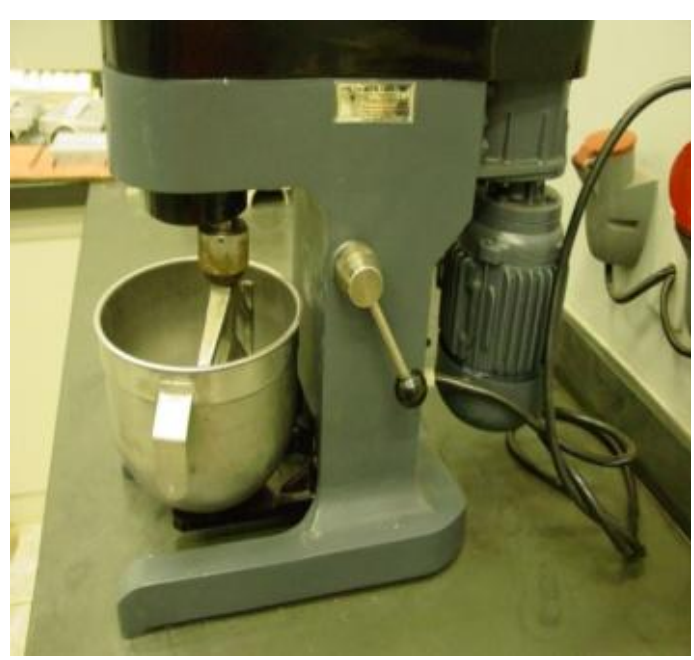

Figura 19 - Misturador de $6 \mathrm{~L}$ 
Também foram utilizadas duas extrusoras, uma de pequena capacidade, Figura 20, e outra de maior capacidade, Figura 21. A extrusora pequena com capacidade de processamento de até $100 \mathrm{~kg} / \mathrm{h}$, sem vácuo, com diâmetro de barril de $45 \mathrm{~mm}$ e comprimento de rosca de $250 \mathrm{~mm}$. A maior tem capacidade de processamento de até $500 \mathrm{~kg} / \mathrm{h}$ com diâmetro de barril de $75 \mathrm{~mm}$ e comprimento de rosca de $750 \mathrm{~mm}$, com vácuo.

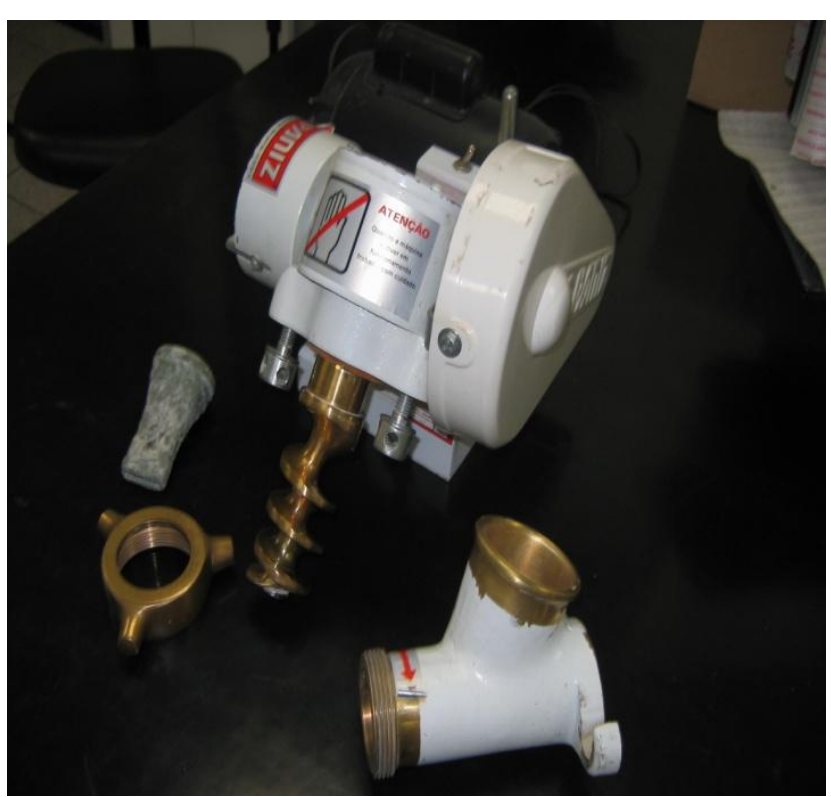

Figura 20 - Extrusora de rosca sem vácuo

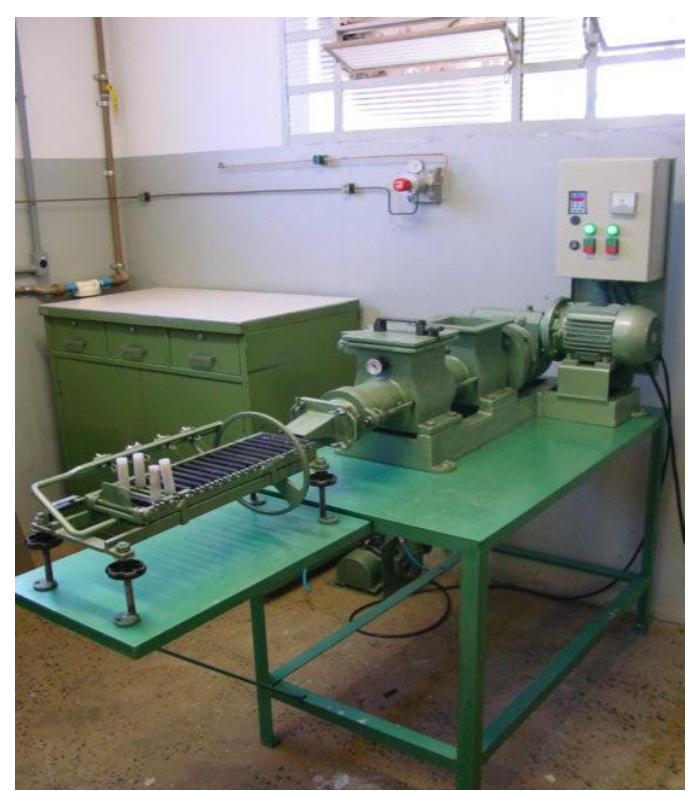

Figura 21 - Extrusora de rosca com vácuo

\subsubsection{Elaboração de corpos-de-prova por extrusão}

A elaboração dos corpos-de-prova são realizadas seguindo as etapas de mistura, extrusão e curado.

Antes de iniciar a extrusão, a mistura cimentícia é misturada a seco em 140 rpm (mistura distributiva) com a finalidade de promover a distribuição homogênea dos particulados onde o tempo de mistura é de 5 min. Posteriormente adiciona a água e as fibras de acordo com a formulação, continuando a mistura por mais 5 min a $285 \mathrm{rpm}$. Finalmente inicia-se a extrusão alimentando a extrusora com a pasta cimentícia para obter as placas com seção transversal de $40 \mathrm{~mm} \times 6 \mathrm{~mm}$. A mistura é realizada seguindo o mesmo procedimento em ambos misturadores planetários no de $20 \mathrm{~L}$ e no de $6 \mathrm{~L}$, porém, na misturadora maior, utiliza-se unicamente a 
velocidade de $150 \mathrm{rpm}$ em todo o processo. As extrusoras são utilizadas, durante o processamento, com a taxa de extrusão de $2400 \mathrm{~mm}^{3} / \mathrm{s}$.

As placas são curadas por 2 dias, em pacotes plásticos selados, para posteriormente serem submersas em água saturada de hidróxido de cálcio por 26 dias. A seguir são cortadas em comprimentos de $160 \mathrm{~mm}$ obtendo assim os corposde-prova (CPs).

Após 28 dias de cura, são realizados ensaios mecânicos de flexão com quatro cutelos e ensaios físicos, de acordo ao descrito no item 3.1.1.

A cura acelerada dos compósitos, quando necessária, é realizada seguindo o método utilizado por Shah et al. (1998). Onde menciona que, em relação às suas propriedades, a cura realizada em ambiente úmido por 28 dias ou em cura a vapor a $90^{\circ} \mathrm{C}$ por 2 dias apresentam resultados semelhantes em ambos os compósitos.

\subsection{COMENTÁRIOS ADICIONAIS}

A metodologia utilizada para a determinação dos módulos de Weibull correspondem a linearização da eq. (25) a partir da regressão linear utilizando pelo menos 30 corpos-de-provas, conforme descrito com maior detalhes em Zanotto e Migliore (1991).

A modelagem estatística de misturas é realizada utilizando os modelos linear, quadrático, cúbico e cúbico completo com delineamento experimental seguindo as diretrizes expostas por Cornell (2002). Todas as formulações utilizadas nas modelagens são realizadas com pelo menos 6 CPs. 


\section{ESTUDO REOLÓGICO}

\subsection{REÔMETRO EXTRUSOR}

O equipamento extrusor foi construído especialmente para o presente trabalho, baseado nos modelos elaborados por SHEN (2003). As dimensões do equipamento são apresentadas na Tabela 11.

Tabela 11 - Dimensões do reômetro extrusor

\begin{tabular}{cccccc}
\hline $\begin{array}{c}\text { Diâmetro do } \\
\text { Barril } D_{0} \\
(\mathrm{~mm})\end{array}$ & $\begin{array}{c}\text { Comprimento } \\
\text { do Barril } L_{0} \\
(\mathrm{~mm})\end{array}$ & $\begin{array}{c}\text { Diâmetro da } \\
\text { Boquilha } \boldsymbol{D} \\
(\mathrm{mm})\end{array}$ & $\begin{array}{c}\text { Comprimento } \\
\text { do corpo da } \\
\text { Boquilha } L_{1} \\
(\mathrm{~mm})\end{array}$ & $\begin{array}{c}\text { Comprimento } \\
\text { do corpo da } \\
\text { Boquilha } L_{2} \\
(\mathrm{~mm})\end{array}$ & $\begin{array}{c}\text { Comprimento } \\
\text { do corpo da } \\
\text { Boquilha } L_{3} \\
(\mathrm{~mm})\end{array}$ \\
\hline 38,10 & 142,20 & 12,70 & 12,70 & 50,80 & 101,60 \\
\hline
\end{tabular}

A Figura 22 (a) e (b) apresenta do lado esquerdo as boquilhas e do lado direito o barril do reômetro extrusor.

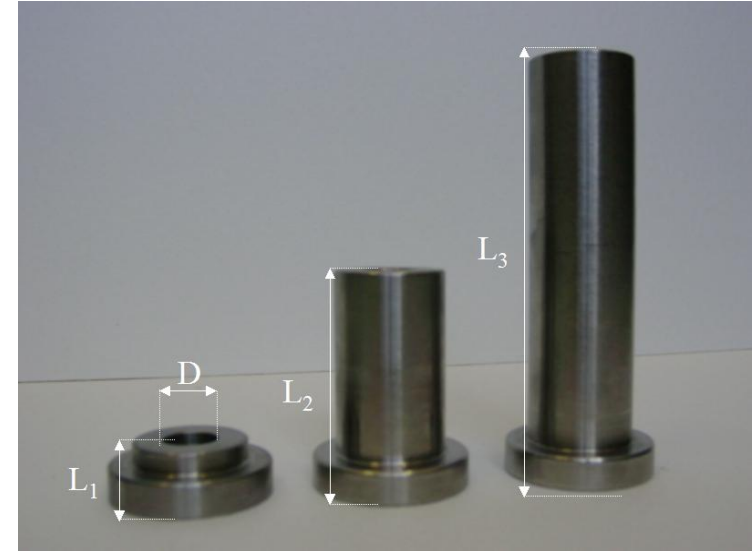

(a)

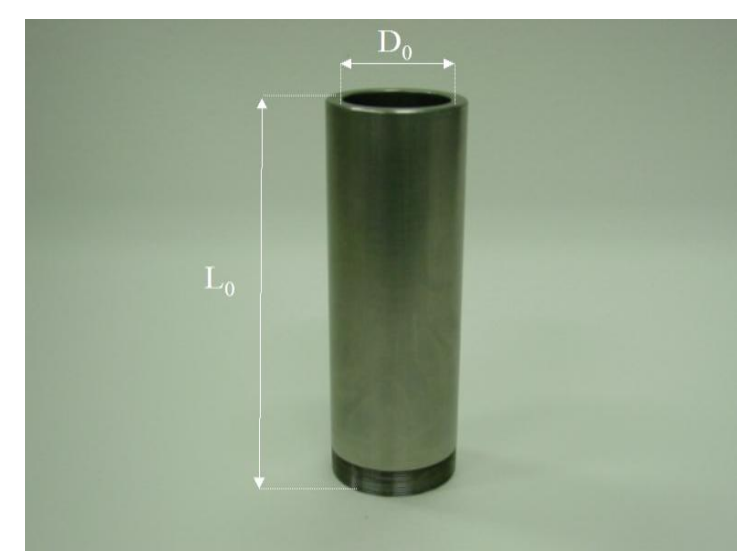

(b)

Figura 22 - Elementos do reômetro extrusor, boquilhas (a) e barril (b)

O equipamento é acoplado à máquina de ensaios mecânicos modelo Emic para posteriormente serem realizados ensaios em cinco velocidades, sendo a última velocidade idêntica à inicial. O motivo de a última velocidade repetir a velocidade 
inicial se deve à necessidade de constatar se foi atingida a pressão de fluxo estável. Caso isso não ocorra, realiza-se novamente o ensaio com um maior percurso inicial até se atingir a região de pressão de fluxo estável. Esse procedimento é uma forma de economia de tempo de ensaio uma vez que seria desnecessário rodar uma batelada completa em uma única velocidade, já que, uma vez atingida a pressão estável, essa tem uma variação insignificante em todo o restante do percurso.

A Figura 23 exibe o reômetro extrusor acoplado à máquina de ensaios mecânicos marca Emic. As características da máquina de ensaios mecânicos são descrita no item 3.1.1.

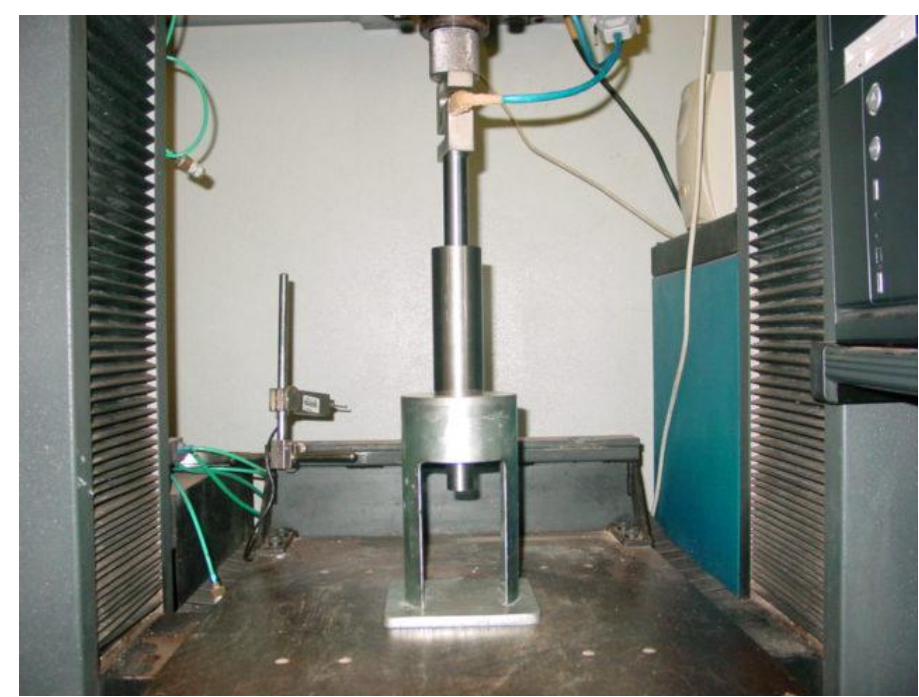

Figura 23 - Reômetro acoplado à maquina de ensaios mecânicos

\subsubsection{Análise da repetitividade dos dados do equipamento}

Para análise da repetitividade das leituras realizadas por esse equipamento, foram realizados testes utilizando uma mistura composta de água, carboidratos de cereais, cloreto de sódio, hidrocarbonetos alifáticos, aroma, metil e pigmentos. Essa mistura é comercializada como massa de modelar com nome comercial de UTI GUTI em quantidade de $500 \mathrm{~g}$. Optou-se por utilizar essa mistura como referência, pois o cimento, uma vez em contato com a água, entra em reação de hidratação tendo sua microestrutura modificada rapidamente. Esse fato traz consequências no comportamento reológico podendo com isso tornar mais trabalhosa a verificação da repetitividade do ensaio. 
A boquilha utilizada no presente ensaio foi a de L/D igual a 4 (L2=50,80 $\mathrm{mm}$ e $\mathrm{D}=12,70 \mathrm{~mm})$.

A massa foi alimentada no reômetro extrusor mediante pequenos fragmentos e consolidada por percução direta com a finalidade de eliminar vazios.

Uma vez alimentado o barril do reômetro até o topo, foi acoplado a máquina de ensaios mecânicos. Posteriormente o pistão foi alinhado na entrada do barril e foi dado início ao ensaio com velocidade inicial de extrusão de $20 \mathrm{~mm} / \mathrm{s}$ pelo percurso de $40 \mathrm{~mm}$. Em seguida, a velocidade de extrusão foi reduzida a cada trecho de $20 \mathrm{~mm}$, para $13,33 \mathrm{~mm} / \mathrm{s}, 8,89 \mathrm{~mm} / \mathrm{s}$ e $5,56 \mathrm{~mm} / \mathrm{s}$ e finalmente ajustada à velocidade inicial de 20 mm/s. Na Figura 24 (a) é possível observar a plasticidade da massa uma vez que submetida a tensões com a mão ela flui, e retirada as tensões, mantém a configuração atribuída. Na Figura 24, (a) (b) (c) e (d), é possível observar a alimentação e a compactação da massa no barril e o alinhamento do barril com o pistão.

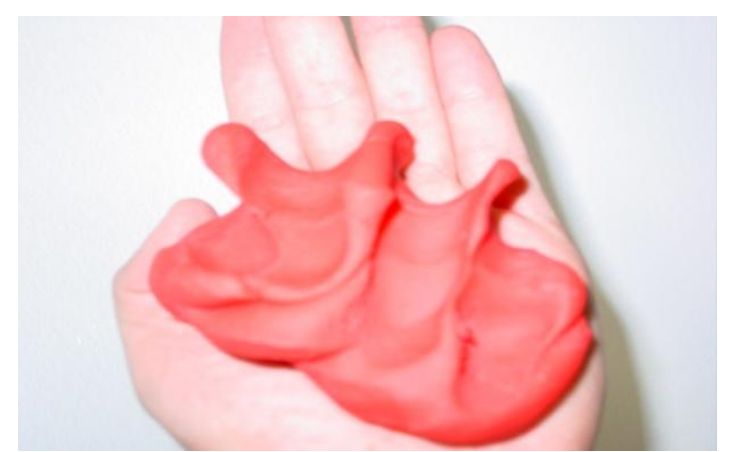

(a)

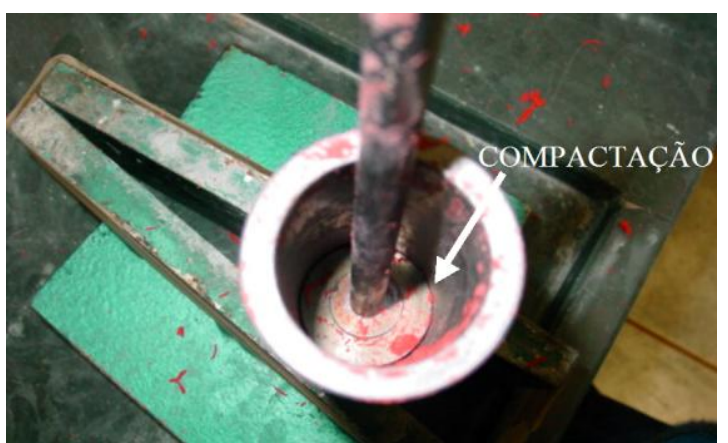

(c)

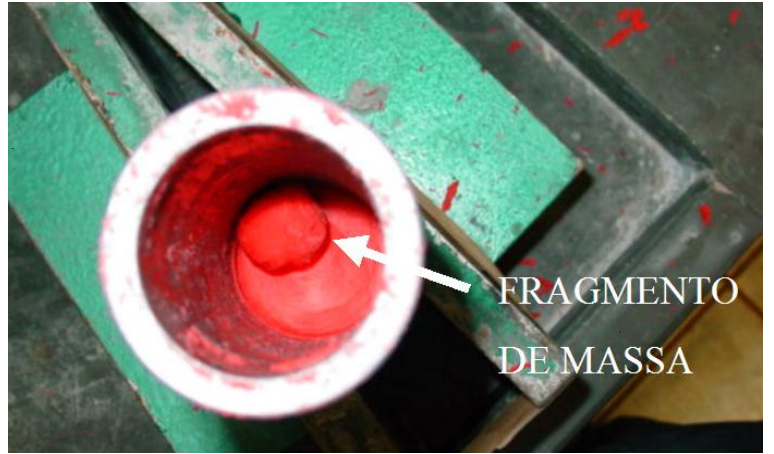

(b)

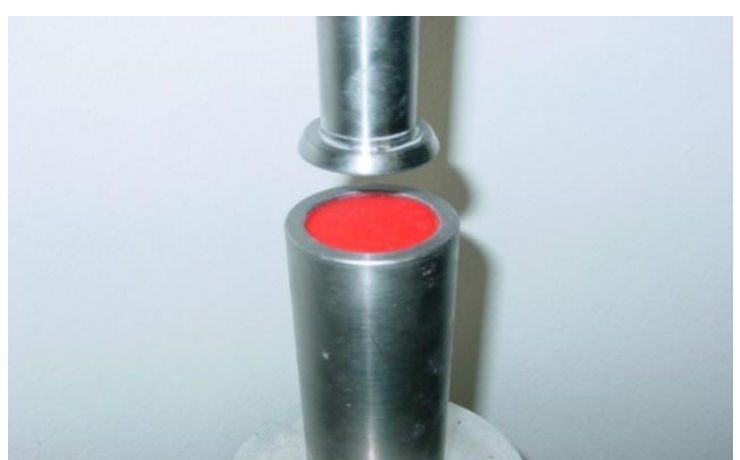

(d)

Figura 24 - Preparação do reômetro extrusor para ensaio

$\mathrm{Na}$ Figura 25 pode se observar o reômetro extrusor durante o alinhamento e a execução do ensaio. 

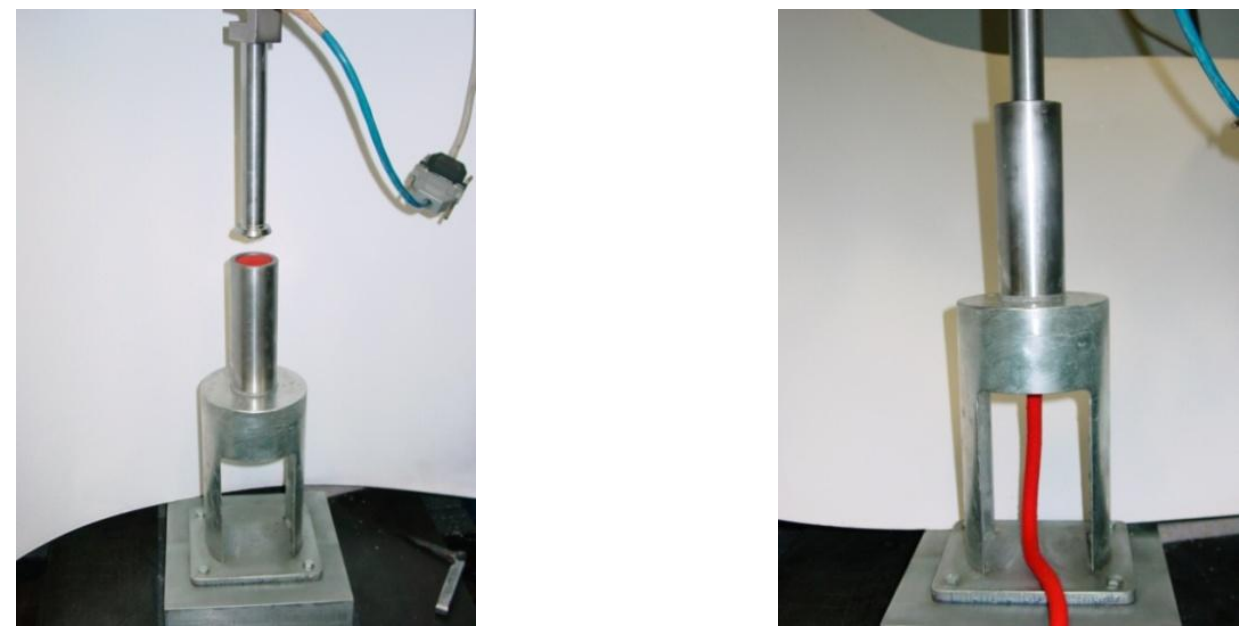

Figura 25 - Reômetro extrusor durante ensaio

Desse ensaio são obtidas as curvas apresentadas no Gráfico 11. A curva da primeira rodada apresenta uma pressão elevada, pelo fato de que toda a parte interna estar-se impregnando pela primeira vez do material ensaiado. As curvas da segunda rodada e da terceira apresentam uma redução de pressão de extrusão, pois, nesse estágio o material já impregnou a parte interna do equipamento, lubrificando as paredes. A curva da terceira rodada apresenta um perfil semelhante com valores próximos à curva da segunda, isso evidenciando uma boa repetitividade do ensaio.

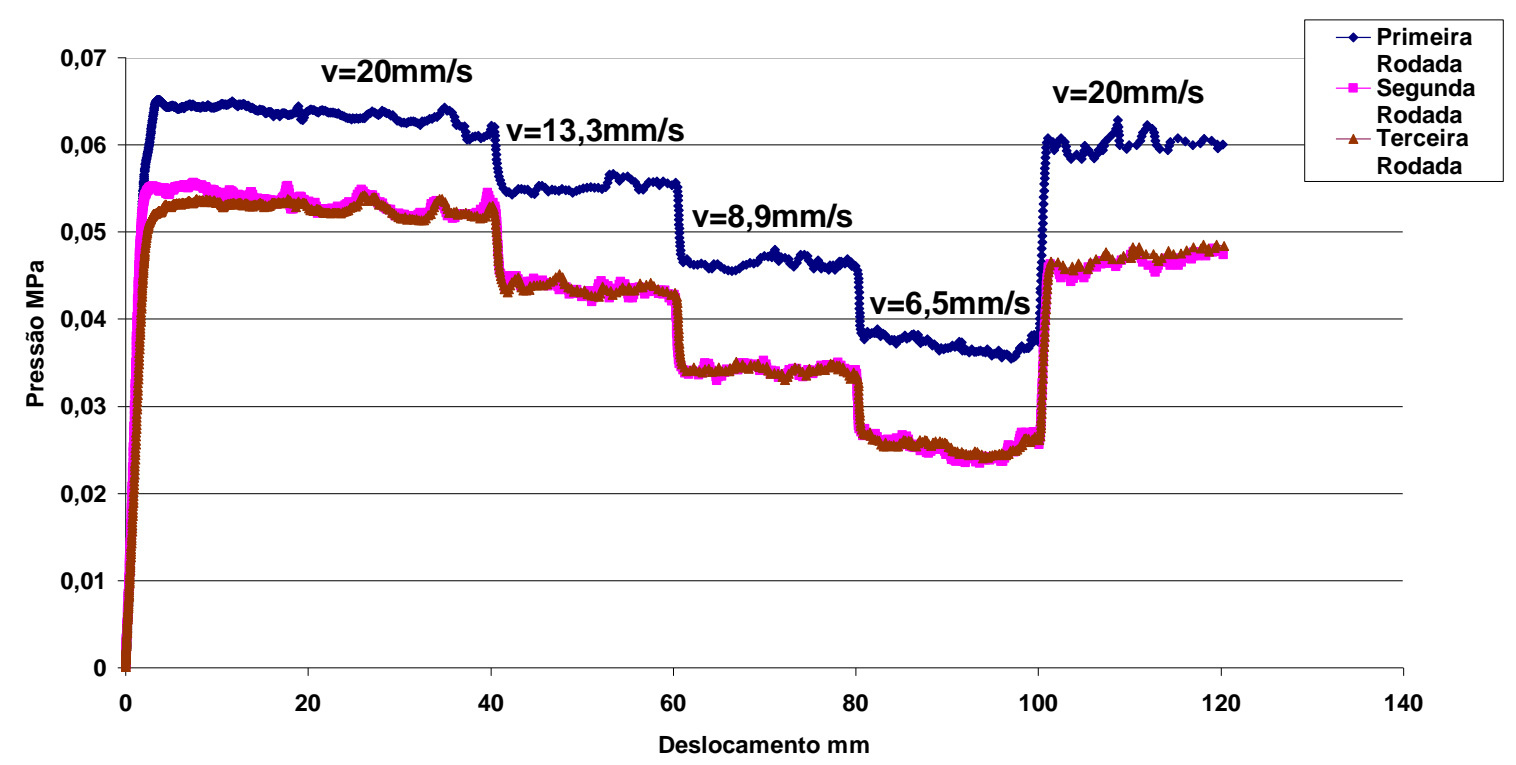

Gráfico 11 - Ensaio de repetitividade da pressão de extrusão em diferentes velocidades 


\subsection{EFEITO DA CONFIGURAÇÃO DA BOQUILHA}

Para estudo do efeito da configuração da boquilha, foram rodados ensaios com mistura cimentícia de $100 \%$ de cimento CPV, utilizando 0,5\% de HPMC e 0,5\% de dispersante ADVA FLOW em relação à massa do cimento. $O$ ensaio foi realizado com relações comprimento/diâmetro de boquilha (L/D) de 1, 4 e 8, e utilizando as velocidades de extrusão de $20 \mathrm{~mm} / \mathrm{s}, 13,3 \mathrm{~mm} / \mathrm{s}, 8,9 \mathrm{~mm} / \mathrm{s}, 5,6 \mathrm{~mm} / \mathrm{s}$ e $20 \mathrm{~mm} / \mathrm{s}$. Os resultados desse ensaio são apresentados no Gráfico 12, no qual se observa que a pressão de extrusão aumenta com o aumento da relação $L / D$, pois se desenvolve uma força resultante maior, em razão da influência da maior superfície de contato entre a mistura e o corpo da boquilha. Esse desenvolvimento de maior força resultante acontece em todas as velocidades para a configuração de boquilha com maior relação L/D.

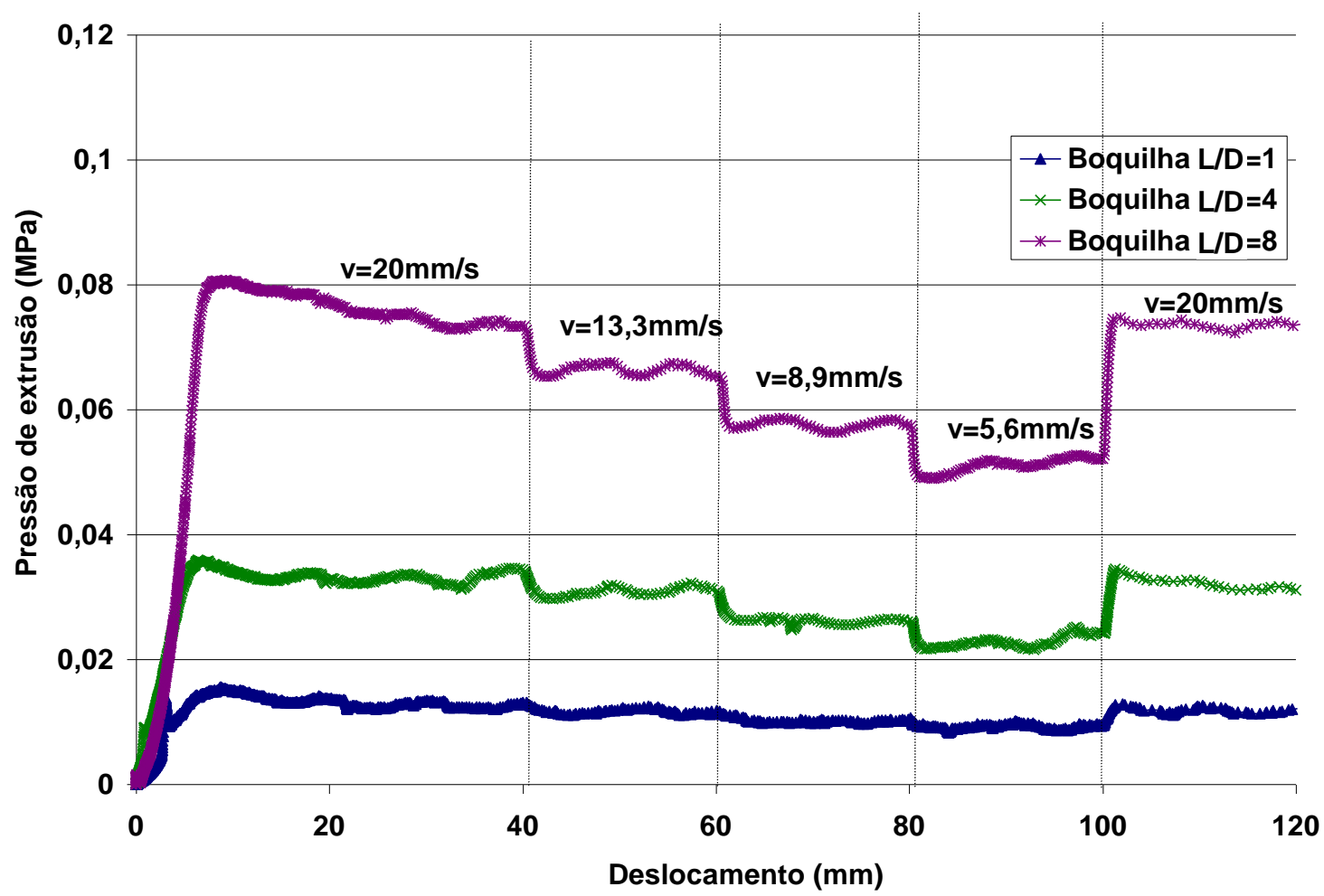

Gráfico 12 - Efeito da configuração da boquilha na pressão de extrusão em diferentes velocidades 


\subsection{CÁLCULO DOS PARÂMETROS DE EXTRUSÃO}

Cada batelada de mistura foi submetida a cinco forças de extrusão correspondentes a quatro velocidades de extrusão com L/D fixo. A pressão de extrusão é igual à força de extrusão dividida pela área da seção transversal do barril. Logo a pressão de extrusão $(p)$ é plotado com o correspondente L/D (1, 4 e 8) para as quatro diferentes velocidades. Para uma dada velocidade de extrusão, a relação entre a pressão de extrusão e L/D tende à linearidade. Assim, a partir da curva ajustada de $p x \mathrm{~L} / \mathrm{D}$, é possível determinar a pressão $p$ para um comprimento de boquilha igual a zero. Utilizando-se esses dados posteriormente é realizado o cálculo dos quatros parâmetros reológicos da mistura seguindo o procedimento descrito no item 3.1.3.

\subsection{PROCEDIMENTO DE ENSAIO}

Inicialmente o material particulado (calcário, cimento e sílica), a fibra (quando for o caso) e o modificador reológico (Methocel F4M) foram misturados a baixa rotação. O misturador é do tipo planetário, fabricado pela EMIC com velocidades de baixa e alta rotação, de $140 \mathrm{rpm}$ e $285 \mathrm{rpm}$, respectivamente. O processo de mistura é um complexo procedimento que pode ser subdividido em duas etapas. A primeira consiste em redistribuir em seco a posição do material particulado procurando a distribuição homogênea das partículas. Nessa mistura, aqui chamada de "mistura distributiva", o reposicionamento das partículas é realizado em baixa rotação, ou "baixa velocidade de cisalhamento", evitando-se a elevação das partículas no ambiente. A segunda etapa consiste na quebra das aglomerações da mistura e na dispersão das fibras e é realizada em alta rotação. Chamaremos essa mistura de "mistura dispersiva". Essas duas etapas são esquematizadas no Gráfico 13. 


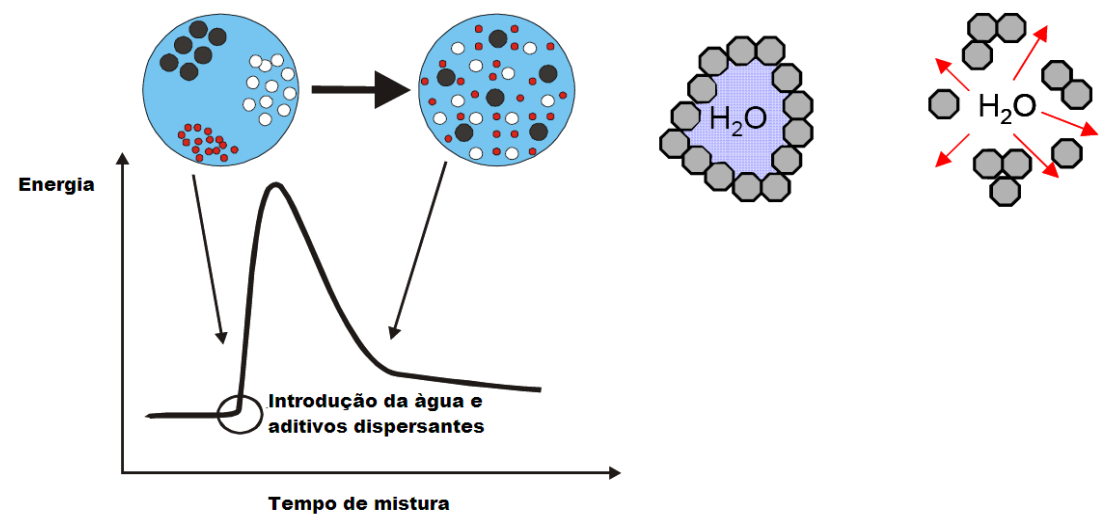

Gráfico 13 - Etapas do processo de mistura (autor anônimo)

O equipamento misturador utilizado é capaz de prover suficiente cisalhamento para pequenas quantidades de material $(2 \mathrm{~L})$. O material particulado é misturado por 2 min em regime de mistura distributiva. Posteriormente, a água é adicionada lentamente, com o superplastificante ADVA Flow, colocando-se o sistema em regime de mistura dispersiva por 5 min. Nessa etapa adicionam-se as fibras (quando aplicável).

A seguir, a pasta misturada é alimentada manualmente no barril. O pistão é posicionado na entrada do barril para dar início ao processo. Logo se aplica um deslocamento constante pelo percurso de $80 \mathrm{~mm}$, o qual é suficiente para obter uma pressão constante. Nessa série de testes, cada comprimento de boquilha foi testado em cinco velocidades: $1,8 \mathrm{~mm} / \mathrm{s}, 1,2 \mathrm{~mm} / \mathrm{s}, 0,8 \mathrm{~mm} / \mathrm{s}, 0,5 \mathrm{~mm} / \mathrm{s}$ e novamente 1,8 $\mathrm{mm} / \mathrm{s}$. Assumindo fluxo incompressível, e tomando a relação da continuidade $v_{0} A_{0}=v A$ como válida (onde $v_{0}$ é a velocidade do pistão ou velocidade média do material no barril, $v$ é a velocidade do extrudado, e $A_{0}$ e $A$ são as seções transversais do barril e da boquilha respectivamente), é possível determinar as velocidades do extrudado como sendo: $20 \mathrm{~mm} / \mathrm{s}, 13,33 \mathrm{~mm} / \mathrm{s} 8,89 \mathrm{~mm} / \mathrm{s}, 5,56 \mathrm{~mm} / \mathrm{s}$ e novamente $20 \mathrm{~mm} / \mathrm{s}$.

Os dados coletados do ensaio foram os valores da carga e do deslocamento. Os parâmetros reológicos foram calculados de acordo com os mecanismos de extrusão descritos no item 2.7.3 e ao procedimento de cálculo descrito no item 3.1.3. Para efeito de comparação $\sigma, \tau$ e $p$ foram calculados utilizando a velocidade de extrusão de 20 mm/s, com L/D=8. 


\subsection{INFLUÊNCIA DOS COMPONENTES DA FORMULAÇÃO NA REOLOGIA DO SISTEMA}

Para identificar a influência dos componentes na formulação cimentícia foram elaboradas 12 formulações cimentícias como apresentadas na Tabela 12 e 13. As formulações foram preparadas em 3 níveis para cada matéria-prima, com diferença de $5 \%$ em massa, escalonado sistematicamente com exceção das formulações contendo PP, onde a diferença adotada foi de $0,5 \%$ em massa. Os níveis e os teores foram escolhidos com o propósito de obter o efeito na reologia das diferentes matérias-primas em relação ao sistema em estudo. Nessas formulações foi utilizada uma quantidade de aditivos, ponderada em porcentagem em relação à massa dos sólidos, fixada para todas as formulações em 3\% de Hidroxipropilmetilcelulose (HPMC), $2 \%$ de ADVA e $0,2 \%$ de propilenoglicol (PGL) em relação à massa do material cimentício. A relação a/c utilizada em todas as formulações foi fixa em 0,2. As propriedades das matérias-primas utilizadas encontram-se descritas no item 3.2.

Tabela 12 - Formulações com variações dos componentes em porcentagem

\begin{tabular}{lccccc}
\hline & Cimento & Sílica & & Celulose & Fibras \\
Formulação & CPV & Ativa & Calcário & de & (\%massa) \\
(\%massa) & $\begin{array}{c}\text { Eucalipto } \\
\text { (\%massa) }\end{array}$ & $\begin{array}{c}\text { PP } \\
\text { (\%massa) }\end{array}$ \\
\hline CPV95S5 & 95 & 5 & - & - & - \\
CPV90S10 & 90 & 10 & - & - & - \\
CPV85S15 & 85 & 15 & - & - & - \\
CPV95CC5 & 95 & - & 5 & - & - \\
CPV90CC10 & 90 & - & 10 & - & - \\
CPV85CC15 & 85 & - & 15 & - & - \\
CPV95C5 & 95 & - & - & 5 & - \\
CPV90C10 & 90 & - & - & 10 & - \\
CPV85C15 & 85 & - & - & 15 & - \\
CPV99,5PP0,5 & 99,5 & - & - & - & 0,5 \\
CPV99PP1 & 99 & - & - & - & 1,0 \\
CPV985PP1,5 & 98,5 & - & - & - & 1,5 \\
\hline
\end{tabular}


As formulações utilizadas descritas em massa são apresentadas na Tabela 13 a seguir.

Tabela 13 - Formulações com variações dos componentes em massa

\begin{tabular}{|c|c|c|c|c|c|c|c|c|}
\hline Formulação & $\begin{array}{c}\text { Cimento } \\
\text { CPV } \\
\text { (g) }\end{array}$ & $\begin{array}{c}\text { Sílica } \\
\text { Ativa } \\
(\mathrm{g})\end{array}$ & $\begin{array}{c}\text { Calcário } \\
\text { (g) }\end{array}$ & $\begin{array}{c}\text { Celulose } \\
\text { (g) }\end{array}$ & $\begin{array}{c}\text { Fibras } \\
\text { (g) }\end{array}$ & $\begin{array}{l}\text { HPMC } \\
\text { (g) }\end{array}$ & $\begin{array}{l}\text { ADVA } \\
\text { (g) }\end{array}$ & $\begin{array}{l}\text { Lubr. } \\
\text { (g) }\end{array}$ \\
\hline CPV95S5 & 380 & 20 & - & - & - & 12 & 8 & 0,8 \\
\hline CPV90S10 & 360 & 40 & - & - & - & 12 & 8 & 0,8 \\
\hline CPV85S15 & 340 & 60 & - & - & - & 12 & 8 & 0,8 \\
\hline CPV95CC5 & 380 & - & 20 & - & - & 12 & 8 & 0,8 \\
\hline CPV90CC10 & 360 & - & 40 & - & - & 12 & 8 & 0,8 \\
\hline CPV85CC15 & 340 & - & 60 & - & - & 12 & 8 & 0,8 \\
\hline CPV95C5 & 380 & - & - & 20 & - & 12 & 8 & 0,8 \\
\hline CPV90C10 & 360 & - & - & 40 & - & 12 & 8 & 0,8 \\
\hline CPV85C15 & 340 & - & - & 60 & - & 12 & 8 & 0,8 \\
\hline CPV99,5PP0,5 & 398 & - & - & - & 2 & 12 & 8 & 0,8 \\
\hline CPV99PP1 & 396 & - & - & - & 4 & 12 & 8 & 0,8 \\
\hline CPV985PP1,5 & 394 & - & - & - & 6 & 12 & 8 & 0,8 \\
\hline
\end{tabular}

A Tabela 14 apresenta os parâmetros de Benbow calculados para as formulações da Tabela 13. 
Tabela 14 - Parâmetros reológicos de Benbow para as componentes

\begin{tabular}{lccccccc}
\hline Formulação & $\begin{array}{c}\sigma_{0} \\
(\mathbf{k P a})\end{array}$ & $\begin{array}{c}\tau_{0} \\
(\mathbf{k P a})\end{array}$ & $\begin{array}{c}\boldsymbol{\alpha} \\
(\mathbf{k P a . s} / \mathbf{m m})\end{array}$ & $\begin{array}{c}\boldsymbol{\beta} \\
(\mathbf{k P a . s} / \mathbf{m m})\end{array}$ & $\begin{array}{c}\sigma=20 \mathrm{em} / \mathbf{s} \\
\mathbf{( k P a )}\end{array}$ & $\begin{array}{c}\tau \text { em } \\
\mathbf{v = 2 0 m m / s} \\
(\mathbf{k P a})\end{array}$ & $\begin{array}{c}\text { Pressão de } \\
\text { extrusão } \\
(\mathbf{k P a})\end{array}$ \\
\hline CPV95S5 & 44,8 & 2,6 & 2,68 & 0,11 & 98,4 & 4,8 & 370,4 \\
CPV90S10 & 23,3 & 5,3 & 1,19 & 0,28 & 47,3 & 10,1 & 454,0 \\
CPV85S15 & 26,9 & 7,2 & 1,29 & 0,34 & 52,6 & 13,8 & 558,5 \\
CPV95CC5 & 14,2 & 5,5 & 0,90 & 0,31 & 32,1 & 11,7 & 445,0 \\
CPV90CC10 & 21,0 & 5,3 & 1,11 & 0,35 & 43,2 & 12,3 & 489,0 \\
CPV85CC15 & 26,0 & 6,4 & 1,36 & 0,43 & 53,0 & 15,0 & 600,0 \\
CPV95C5 & 48,9 & 3,6 & 1,85 & 0,26 & 85,8 & 8,8 & 469,8 \\
CPV90C10 & 71,1 & 3,9 & 2,42 & 0,13 & 119,0 & 6,5 & 472,0 \\
CPV85C15 & 79,5 & 3,8 & 1,78 & 0,15 & 114,9 & 6,8 & 469,9 \\
CPV99,5PP0,5 & 52,5 & 4,1 & 2,72 & 0,09 & 106,8 & 5,9 & 425,4 \\
CPV99PP1 & 70,5 & 5,1 & 3,67 & 0,31 & 143,9 & 11,3 & 676,3 \\
CPV985PP1,5 & 84,2 & 6,2 & 4,90 & 0,39 & 183,3 & 14,0 & 851,9 \\
\hline
\end{tabular}

\subsubsection{Efeito da sílica ativa}

Comparando-se formulações CPV95S5, CPV90S10 e CPV85S5, é possível observar um decréscimo em $\sigma_{0}$ com o uso de teores de $10 \%$ e $15 \%$ de sílica ativa em relação ao teor de 5\%. Esse decréscimo pode ser observado no Gráfico 14. De acordo a CLARKE (1976) a configuração esférica das partículas favorece ao fluxo da mistura, assim promovendo a redução do $\sigma_{0}$ e $\alpha$. Isso pode ser observado nos Gráficos 14 e 16.

O acréscimo de sílica ativa aumenta a superfície total das partículas do sistema, uma vez a que a sílica possui área superficial de $16,10 \mathrm{~m}^{2} / \mathrm{g}$ enquanto 0 cimento possui área superficial de $1,57 \mathrm{~m}^{2} / \mathrm{g}$, assim incrementando a água necessária para o molhamento da superfície da partícula. Isso condiz com o argumentado por Hunger e Brouwers (2009), no referente à demanda de água das partículas. A sílica ativa apresenta tamanhos inferiores de partículas comparados aos do cimento, o que pode promover um coeficiente de empacotamento maior ao 
que de um sistema utilizando unicamente cimento. Um coeficiente de empacotamento incrementado tende a reduzir a quantidade de água necessária para preencher os espaços vazios, assim como o número de coordenação da mistura (contato entre partículas). A quantidade de água demandada pelo aumento da área superficial do material parece ser maior que a quantidade de água liberada pelo aumento da densificação do sistema de partículas. Assim o sistema pode estar demandando uma maior quantidade de água requerida para preencher os espaços vazios e molhar a área superficial das partículas do sistema, levando isso a um acréscimo de $\beta$ e $\tau_{0}$, como observado nos Gráficos 15 e 17. Esse sistema bem compacto apresenta maior dificuldade para fluir quando submetido a tensões associadas a maior friç̧ão e travamento das partículas. Não e possível chegar a conclusões definitivas sem uma pesquisa extensiva incluindo análise de empacotamento de partículas para o sistema em questão.

A pressão do total do sistema apresenta incremento com o aumento das adições de sílica ativa conforme observado no Gráfico 18. Isso pode estar sendo promovido pelo aumento da demanda de água, como também pela dispersão inadequada da sílica ativa, formando aglomerados que tem maior dificuldade em fluir, como argumentado por Castro e Pandofelli (2009).

\subsubsection{Efeito do calcário.}

A influência do calcário pode ser observada nas formulações CPV95CC5, CPV90CC10 e CPV85C15 descritas em detalhe nas Tabelas 15 e 16 com os respectivos efeitos nos Gráficos de 14 a 18. A área superficial do calcário de 1,47 $\mathrm{m}^{2} / \mathrm{g}$ e a do cimento CPV de $1,57 \mathrm{~m}^{2} / \mathrm{g}$ não apresentam grande diferença, o qual nos leva a refletir que a demanda de água associada à necessidade de molhamento da superfície da partícula não sofre expressiva alteração, podendo apresentar assim uma influência baixa na reologia do sistema.

As arestas vivas das partículas de calcário não facilitam o fluxo da mistura, aumentando, dessa forma, a viscosidade do sistema, como pode ser observado pelos parâmetros $\sigma_{0}$ e $\alpha$ nos teores de $10 \%$ e $15 \%$ nos Gráficos 14 e 16 . O 
acréscimo dos parâmetros $\beta$ e $\tau_{0}$ pode ser também atribuído à configuração das partículas do calcário, uma vez que estas promovem uma maior fricção quando atravessam o corpo da boquilha, isso observado nos Gráficos 15 e 17.

A densidade de empacotamento pode não estar sendo modificada significativamente, com a adição de calcário, já que a área superficial e a distribuição granulométrica do material apresentam-se próximos.

As formulações com adições de calcário apresentam pressão total de extrusão maior, quando comparadas as de sílica ativa, com teores de 5\% e 10\%. Isso mostra que o parâmetro $\beta$ é o de destacada diferença em relação aos demais materiais, levando a obter-se uma pressão total de extrusão da formulação CPV85C15 maior que as demais, como pode ser observado no Gráfico 18 e na Tabela 16.

\subsubsection{Efeito da polpa de celulose de eucalipto}

O efeito da polpa de celulose pode ser observado das formulações CPV95C5, CPV90C10 e CPV85C15, nos Gráficos 14, 15, 16, 17 e 18, e sua composição assim como dados reológicos nas Tabelas 15 e 16. As fibras celulósicas apresentam formas semelhantes a canudos, os quais têm a capacidade de absorver água. Essa configuração promove o aumento da viscosidade interna do material, o que pode ser apreciado pelo aumento dos valores do parâmetro $\sigma_{0}$ no Gráfico 14. Clarke (1967) menciona que a viscosidade de suspensões de partículas geralmente aumenta à medida do desvio da forma esférica, as fibras de eucalipto apresentam razão de aspecto igual a 51, contribuindo para o aumento da viscosidade.

Durante a extrusão, as fibras de celulose, em razão das tensões tangenciais e normais que sofrem, liberam ao sistema grande parte da água absorvida. Por causa desse fenômeno, o parâmetro $\beta$ mostra-se afetado pela água adicional, já que essa tende a lubrificar o corpo da boquilha e o material extrudado. Porém, essa liberação de água parece não afetar a $\tau_{0}$, provavelmente pelo fato que a água livrada se torna efetiva durante a execução da extrusão, não ocorrendo isso no seu inicio. 
As pressões totais de extrusão apresentadas, pelos diferentes teores de celulose, não variam significativamente. Isso provavelmente porque a água liberada pela celulose reduz o efeito da configuração da fibra na viscosidade da mistura, reduz também a friç̧ão entre a massa e a boquilha quando o sistema está em movimento, influenciando os parâmetros $\alpha$ e $\beta$. Porém, a água liberada não tem efeito significativo nos parâmetros $\tau_{0}$ e $\sigma_{0}$, quando o sistema começa a entrar em movimento, já que a água não foi efetivamente liberada.

\subsubsection{Efeito do conteúdo de fibras de polipropileno}

$O$ efeito das fibras de polipropileno de $6 \mathrm{~mm}$ pode ser observado das formulações CPV99,5PP0,5, CPV99PP1, CPV985PP1,5 e nos Gráficos de 19 a 23. A configuração cilíndrica das fibras com razão de aspecto de 231, bastante distante da forma de uma esfera, promove a elevação da viscosidade do material à medida que o aumenta o teor. Essa dificuldade de movimentação da mistura ocasiona aumento do parâmetro $\sigma_{0}$ e $\alpha$. O incremento da área superficial do sistema provavelmente torna ainda mais abrasiva a mistura elevando também os parâmetros $\tau_{0}$ e $\beta$.

Em consequência da elevação de todos os parâmetros reológicos de Benbow, obtém-se pressão total de extrusão pronunciadamente crescente com o aumento do teor de fibras de polipropileno. Isso pode ser observado no Gráfico 19. 


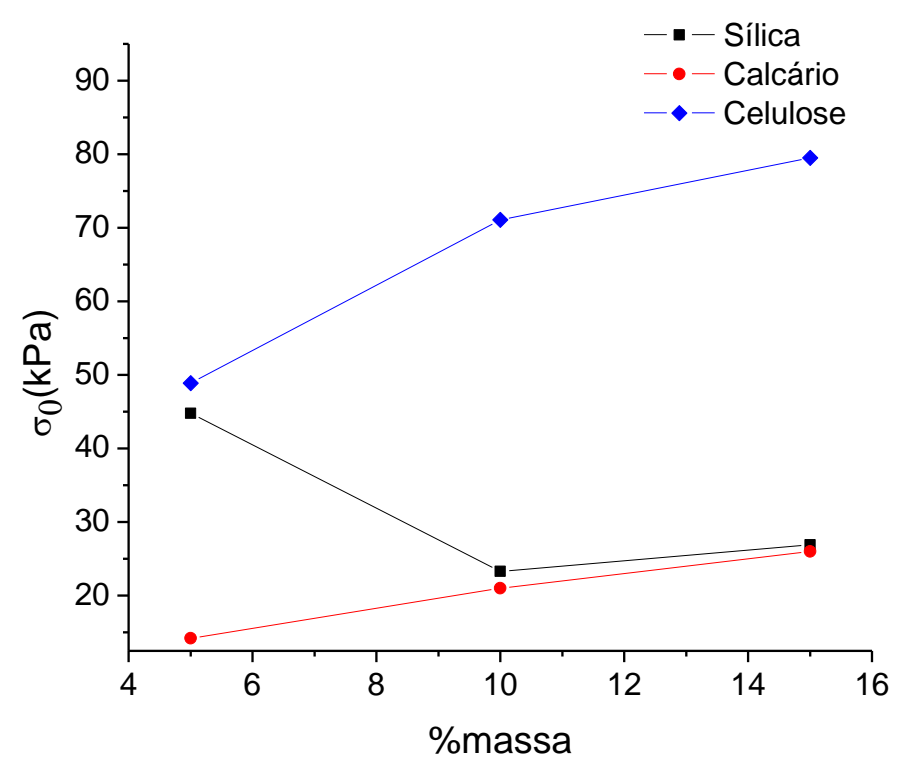

Gráfico 14 - Tensão de escoamento inicial dos componentes vs. \% massa das adições

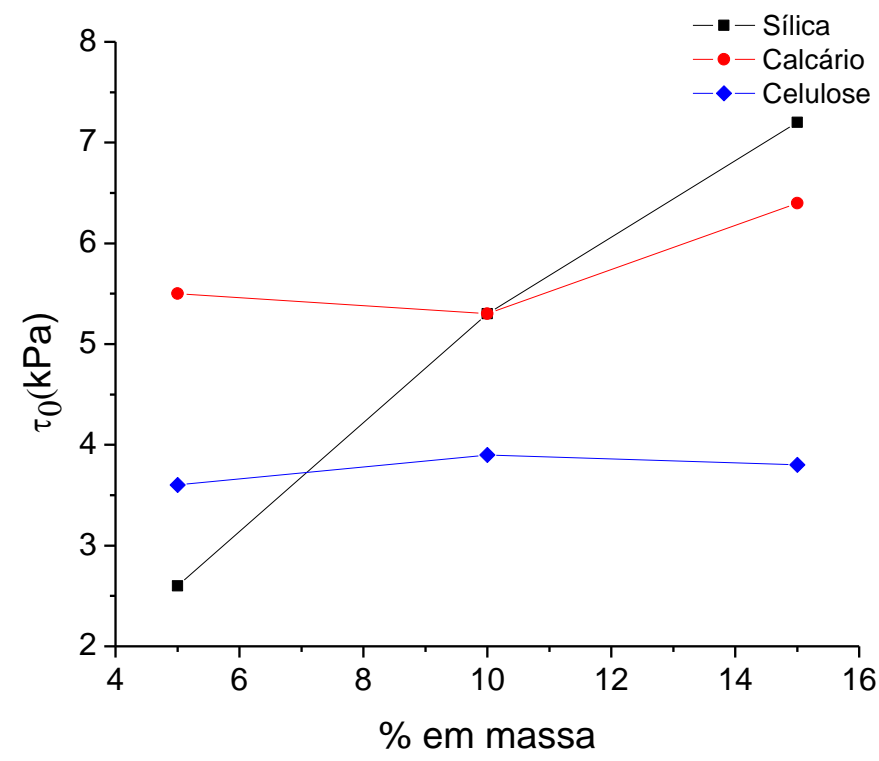

Gráfico 15 - Tensão de cisalhamento inicial dos componentes vs. \% massa das adições 


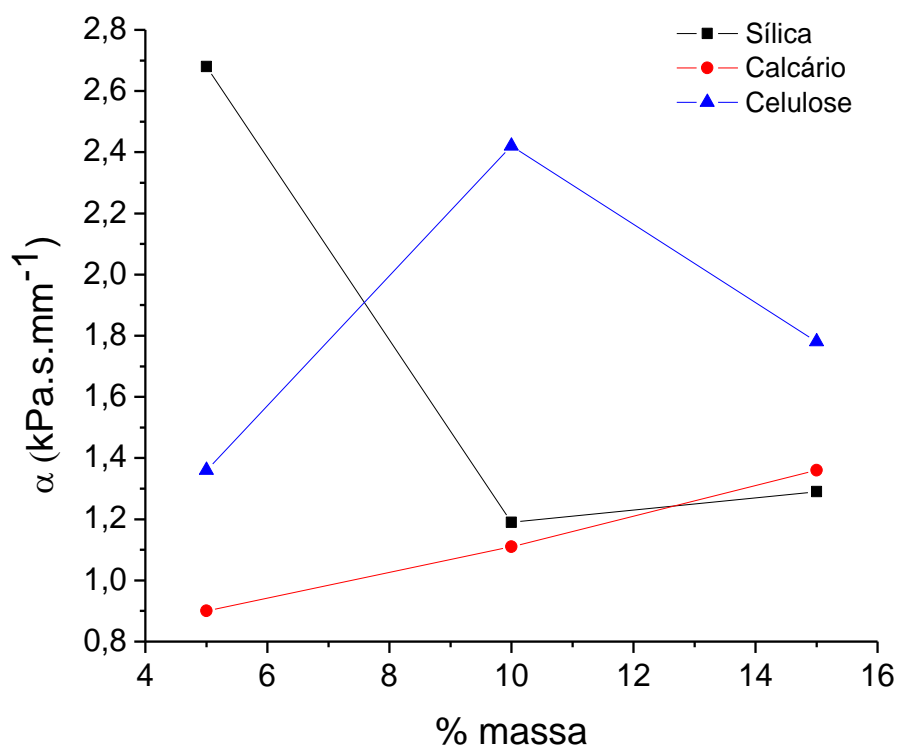

Gráfico 16 - Influência da velocidade na tensão de escoamento vs. \% massa das adições

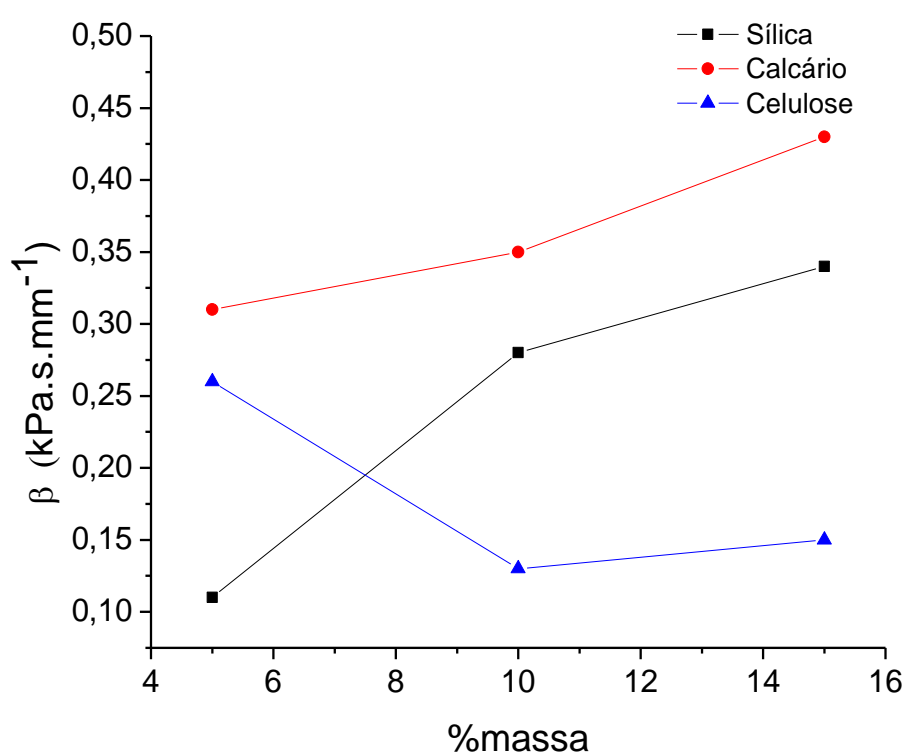

Gráfico 17 - Influência da velocidade na tensão de cisalhamento vs. \% massa das adições 


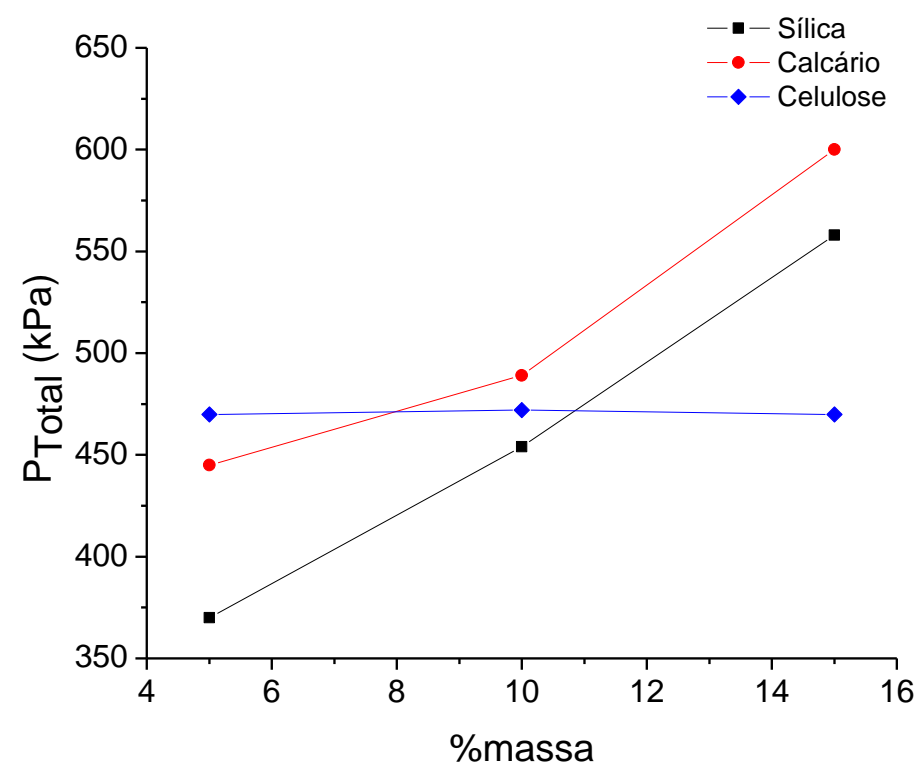

Gráfico 18 - Pressão total de extrusão para os teores de adições

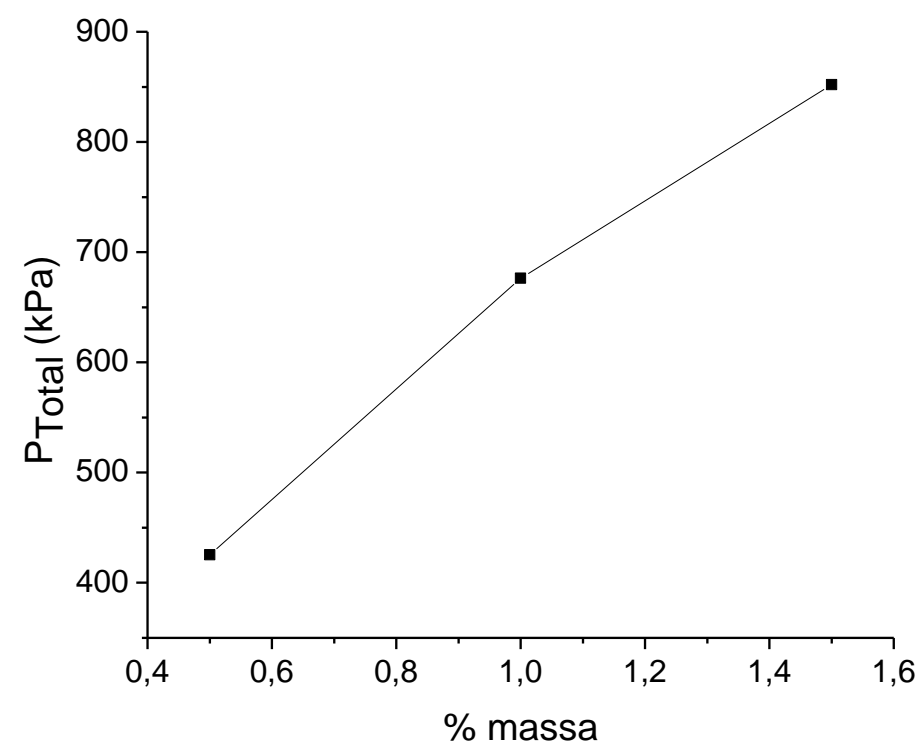

Gráfico 19 - Pressão total para teores de polipropileno 


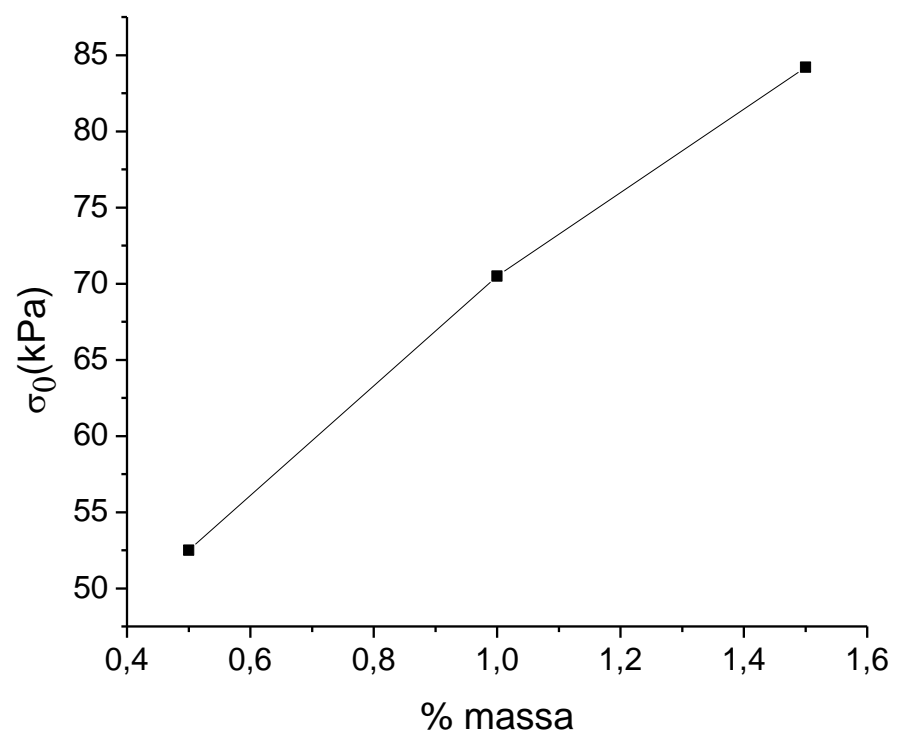

Gráfico 20 - Tensão de escoamento inicial vs. adições de polipropileno

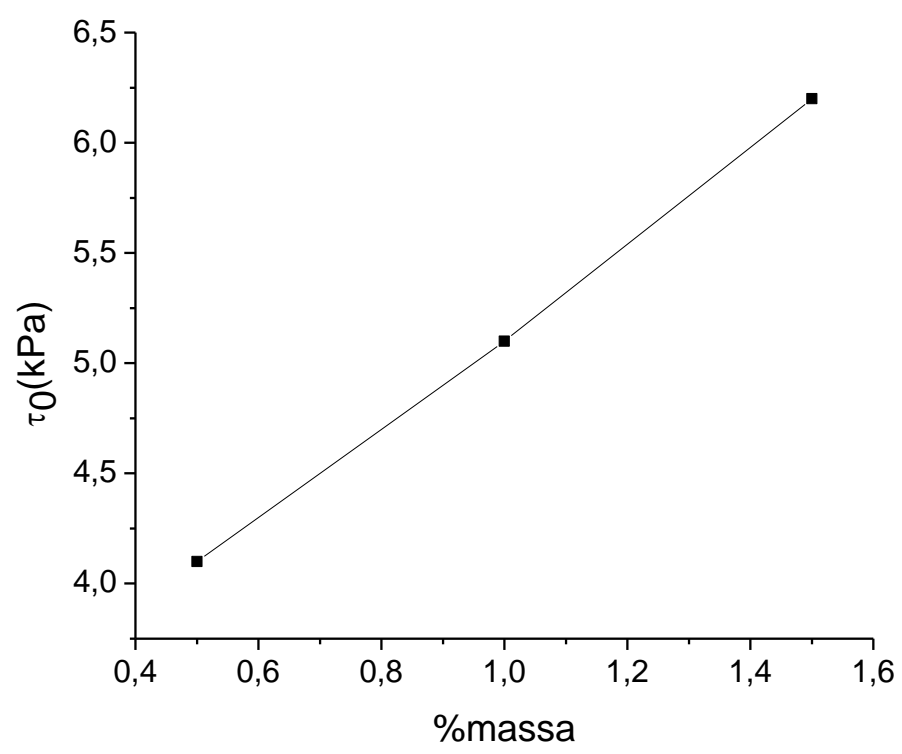

Gráfico 21 - Tensão de cisalhamento inicial vs adições de polipropileno 


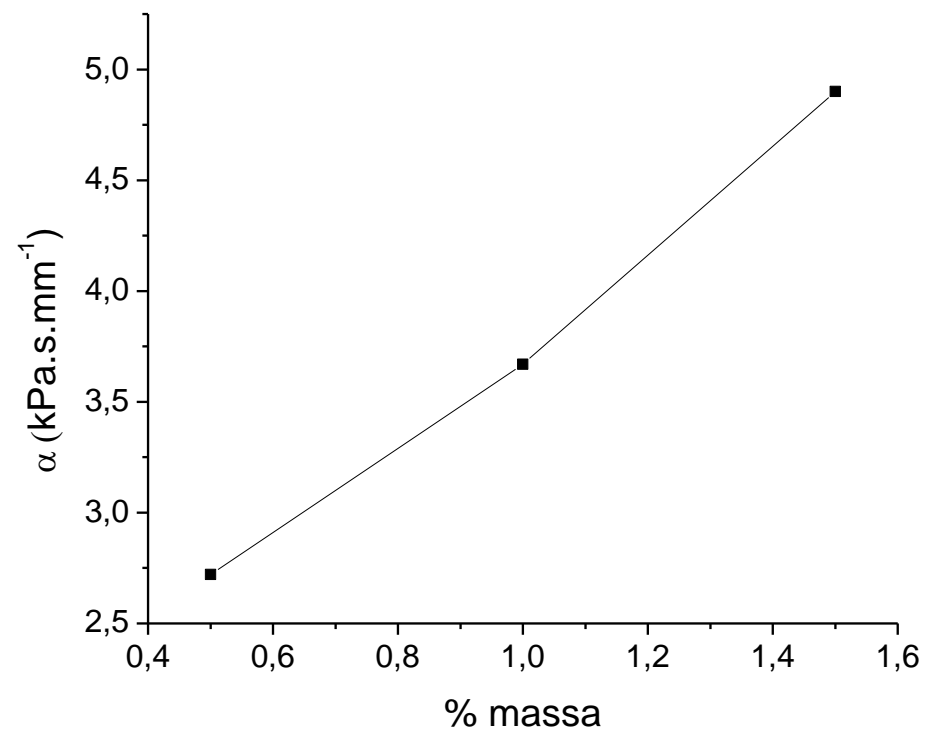

Gráfico 22 - Influência da velocidade na tensão de escoamento vs. \%massa de fibras de polipropileno

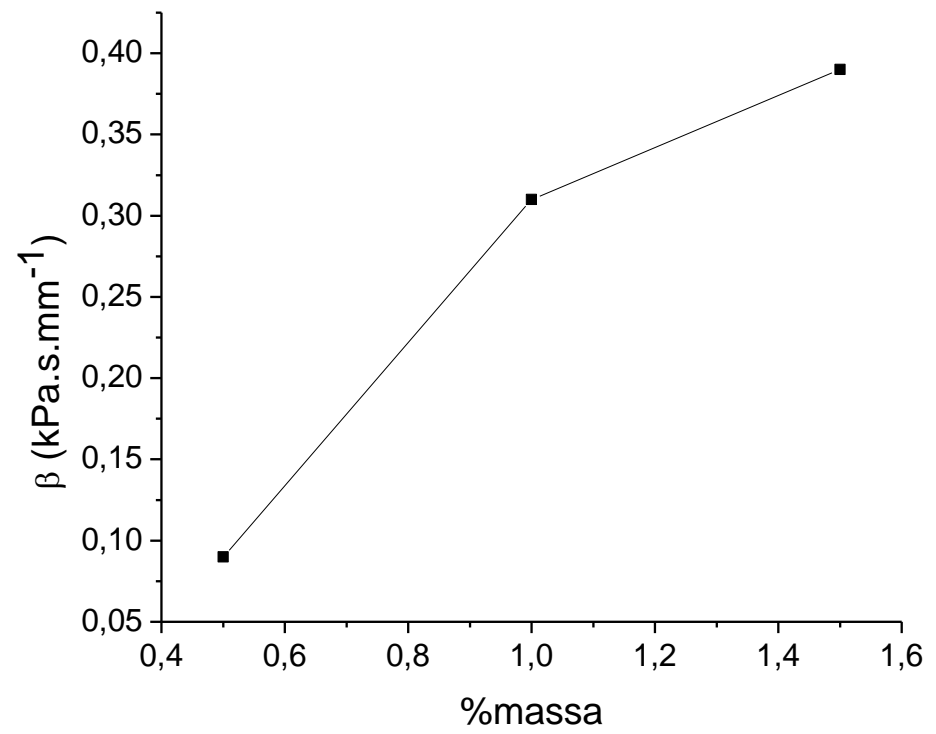

Gráfico 23 - Influência da velocidade na tensão de cisalhamento vs. \%massa de fibras de polipropileno 


\subsection{INFLUÊNCIA DOS ADITIVOS NA REOLOGIA DO SISTEMA}

Para avaliar o efeito dos aditivos no comportamento reológico da mistura cimentícia foram elaboradas oito formulações cimentícias como apresentado na Tabela 15 e 16. Nessas formulações foram realizadas três variações de níveis de aditivos para HPMC, ADVA e lubrificante propilenoglicol (PGL). Assim como também foi elaborado um nível adicional de água/cimento, variando de 0,8 para 0,9 com a finalidade de constatar o efeito desse na reologia.

Tabela 15 - Formulações com variação dos aditivos em \% massa

\begin{tabular}{lccccc}
\hline Formulação & $\begin{array}{c}\text { Cimento } \\
\text { CPV } \\
\text { (\%massa) }\end{array}$ & a/c & $\begin{array}{c}\text { HPMC } \\
\text { (\%massa) }\end{array}$ & $\begin{array}{c}\text { ADVA } \\
\text { (\%massa) }\end{array}$ & $\begin{array}{c}\text { Lubr. } \\
\text { (\%massa) }\end{array}$ \\
\hline CPV100H3D2L0,2 & 100 & 0,200 & 3 & 2 & 0,2 \\
CPV100H2D2L0,2 & 100 & 0,200 & 2 & 2 & 0,2 \\
CPV100H1D2L0,2 & 100 & 0,200 & 1 & 2 & 0,2 \\
CPV100H1D1L0,2 & 100 & 0,200 & 1 & 1 & 0,2 \\
CPV100H1D3L0,2 & 100 & 0,200 & 1 & 3 & 0,2 \\
CPV100H1D2L0,7 & 100 & 0,200 & 1 & 2 & 0,7 \\
CPV100H1D2L1,2 & 100 & 0,200 & 1 & 2 & 1,2 \\
CPV100H3D1L0,2A80 & 100 & 0,200 & 3 & 1 & 0,2 \\
CPV100H3D1L0,2A90 & 100 & 0,225 & 3 & 1 & 0,2 \\
\hline
\end{tabular}




\begin{tabular}{|c|c|c|c|c|c|}
\hline Formulação & $\begin{array}{l}\text { Cimento } \\
\text { CPV } \\
\text { (g) }\end{array}$ & $a / c$ & $\begin{array}{c}\text { HPMC } \\
(\mathrm{g})\end{array}$ & $\begin{array}{c}\text { ADVA } \\
\text { (g) }\end{array}$ & $\begin{array}{l}\text { Lubr. } \\
\text { (g) }\end{array}$ \\
\hline CPV100H3D2L0,2 & 400 & 0,200 & 12 & 8 & 0,8 \\
\hline CPV100H2D2L0,2 & 400 & 0,200 & 8 & 8 & 0,8 \\
\hline CPV100H1D2L0,2 & 400 & 0,200 & 4 & 8 & 0,8 \\
\hline CPV100H1D1L0,2 & 400 & 0,200 & 1 & 4 & 0,8 \\
\hline CPV100H1D3L0,2 & 400 & 0,200 & 1 & 12 & 0,8 \\
\hline CPV100H1D2L0,7 & 400 & 0,200 & 1 & 8 & 2,8 \\
\hline CPV100H1D2L1,2 & 400 & 0,200 & 1 & 8 & 4,8 \\
\hline CPV100H3D1L0,2 ${ }^{A} 80$ & 400 & 0,200 & 12 & 4 & 0,8 \\
\hline CPV100H3D1L0,2 ${ }^{A} 90$ & 400 & 0,225 & 12 & 4 & 0,8 \\
\hline
\end{tabular}

A Tabela 17 apresenta os valores dos parâmetros reolôgicos de Benbow para as variações de aditivos. 
Tabela 17 - Parâmetro reológicos de Benbow para as formulações variando os aditivos

\begin{tabular}{|c|c|c|c|c|c|c|c|}
\hline Formulação & $\begin{array}{c}\sigma_{0} \\
(k P a)\end{array}$ & $\begin{array}{c}\tau_{0} \\
(k P a)\end{array}$ & $\begin{array}{c}\alpha \\
(k P a * s / m m)\end{array}$ & $\begin{array}{c}\boldsymbol{\beta} \\
(k P a * s / \mathbf{m m})\end{array}$ & $\begin{array}{c}\sigma \\
v=20 \mathrm{~mm} / \mathrm{s} \\
(k P a)\end{array}$ & $\begin{array}{c}\tau \\
v=20 \mathrm{~mm} / \mathrm{s} \\
(k P a)\end{array}$ & $\begin{array}{c}\text { Pressão de } \\
\text { extrusão } \\
(k P a)\end{array}$ \\
\hline CPV100H3D2L0,2 & 221,7 & 14,4 & 2,69 & 1,20 & 275 & 38,40 & 1832 \\
\hline CPV100H2D2L0,2 & 31,8 & 1,9 & 1,82 & 0,17 & 68,3 & 5,20 & 317,3 \\
\hline CPV100H1D2L0,2 & 31,7 & 1,47 & 1,41 & 0,17 & 59,9 & 4,94 & 290,0 \\
\hline CPV100H1D1L0,2 & 129,3 & 6,22 & 5,31 & 0,59 & 235,6 & 18,13 & 1097,7 \\
\hline CPV100H1D3L0,2 & 18,5 & 1,68 & 1,05 & 0,14 & 39,6 & 4,64 & 235,7 \\
\hline CPV100H1D2L1,2 & 21,7 & 1,01 & 0,94 & 0,15 & 40,5 & 4 & 216 \\
\hline CPV100H3D1L0,2A80 & 332,2 & 24,36 & 7,37 & 1,19 & 479,6 & 48,2 & 2597 \\
\hline CPV100H3D1L0,2A90 & 139,9 & 19,4 & 4,72 & 0,64 & 234,3 & 32,36 & 1550 \\
\hline
\end{tabular}




\subsubsection{Efeito do teor de água}

Comparando os resultados das fórmulas CPV100H3D1L0,2A80 e CPV100H3D1L0,2A90, é possível observar que esses resultados estão conforme com o que se pode antecipar. Com o aumento da quantidade de água obtém-se um decréscimo tanto na fricção interna como na fricção externa da mistura, isto é, em todos os parâmetros de Benbow. Esse efeito foi observado por Benbow et al. (1987), sendo atribuído ao excedente de líquido necessário para preencher os espaços intersticiais das partículas aumentando o espaçamento entre as partículas e facilitando o fluxo. A pressão total de extrusão calculada na velocidade de $20 \mathrm{~mm} / \mathrm{s}$ e L/D=8 para a formulação CPV100H3D1L0,2A80 mostra ser 67\% maior em relação à formulação com $10 \mathrm{~g}$ a mais de água, evidenciando que uma redução ligeira da relação a/c, como nesse caso de 0,025, apresenta um significativo aumento generalizado nos parâmetros reológicos de Benbow, conforme expostos na Tabela 17.

\subsubsection{Efeito do teor de HPMC}

As formulações, CPV100H1D2L0,2, CPV100H2D2L0,2, CPV100H3D2L0,2, apresentadas na Tabela 15 e 16, foram elaboradas utilizando teores de HPMC de $1 \%, 2 \%$ e $3 \%$ em relação à massa, respectivamente, com a finalidade de observar 0 efeito na mistura cimentícia. O efeito do aumento do teor de HPMC introduz um aumento dos parâmetros $\sigma_{0}, \alpha, \tau_{0}$ e $\beta$. Esse aumento mostra ser efetivo a partir de 2\% de HPMC como pode ser observado nos Gráficos 24, 25, 26 e 27. O Gráfico 28 mostra que o aumento da pressão total de extrusão para 3\% de HPMC é incrementado 531\% em relação à pressão total de extrusão para 1\% de HPMC. 


\subsubsection{Efeito do teor do dispersante}

As formulações CPV100H1D1L0,2, CPV100H1D2L0,2 e CPV100H1D3L0,2 foram elaboradas, com o propósito de analisar o efeito do dispersante no sistema, utilizando teores de dispersante de $1 \%, 2 \%$ e $3 \%$ em relação à massa dos sólidos. $\mathrm{A}$ sua descrição completa pode ser observada nas Tabelas 15 e 16. A utilização do dispersante, como mostrado nos Gráficos de 24, 25, 26 e 27, leva à redução generalizada de todos os parâmetros de Benbow. A queda na pressão total de extrusão é de $78,5 \%$ entre os teores de $1 \%$ e $3 \%$, mostrando alta efetividade em reduzir a pressão de extrusão, como mostrado no Gráfico 28.

\subsubsection{Efeito do teor de lubrificante}

Para analisar o efeito do lubrificante propilenoglicol, foram elaboradas as formulações CPV100H1D2L0,2, CPV100H1D2L0,7 e CPV100H1D2L1,2 utilizando os teores de $0,2 \%, 0,7 \%$ e 1,2\% em relação à massa dos sólidos, como pode ser observado nas Tabelas 15 e 16. Os Gráficos 24 a 28 mostram que o propileno glicol, com os teores utilizados, exerce um efeito pouco significativo nos parâmetros de Benbow. É possível evidenciar que a efetividade do aditivo lubrificante, em reduzir as tensões na boquilha e a massa não é da magnitude esperada em teores aceitáveis para o processo.

\subsection{CONSIDERAÇÕES ADICIONAIS}

Os resultados apresentados na Tabela 17 para as pressões de extrusão exibem boa correlação entre as pressões medidas e calculadas. Benbow et al. (1993) conclui que, uma vez calculados os parâmetros da eq.(18), eles podem ser utilizados para prever o comportamento da pressão x velocidade para outros tipos de secções transversais. Com o conhecimento desses parâmetros, é possível realizar 
julgamentos de composições e condições de processamento que resultem em melhores extrudados em termos de reologia e estética.

A extrudabilidade está relacionada à velocidade e a configuração geométrica do elemento a ser extrudado. Assim que a velocidade é incrementada a extrudabilidade pode ser melhorada (BENBOW e BRIDGEWATER, 1993). Se a velocidade for aumentada é possível que sejam necessárias pequenas quantidades de modificador reológico. Adicionalmente, se uma configuração de boquilha com maior complexidade for utilizada, a extrudabilidade pode piorar, por outro lado, com uma boquilha de simples configuração a extrudabilidade pode ser melhorada. Assim, qualquer mínima quantidade de modificador reológico definida está vinculada a velocidade e a configuração da boquilha utilizada.

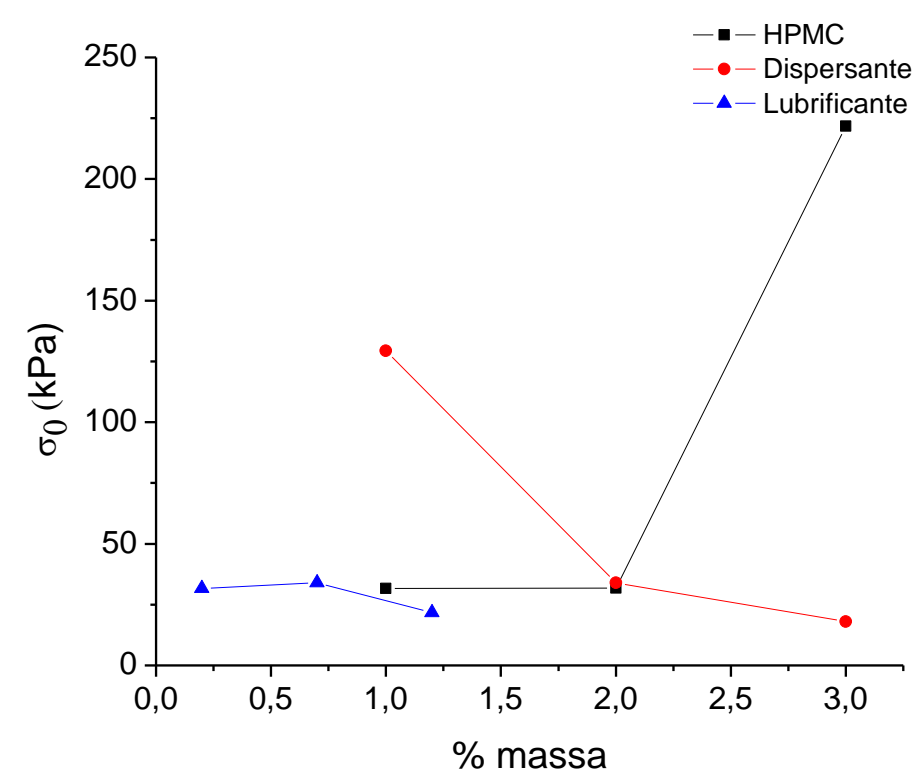

Gráfico 24 - Tensão de escoamento inicial vs. teor de aditivos 


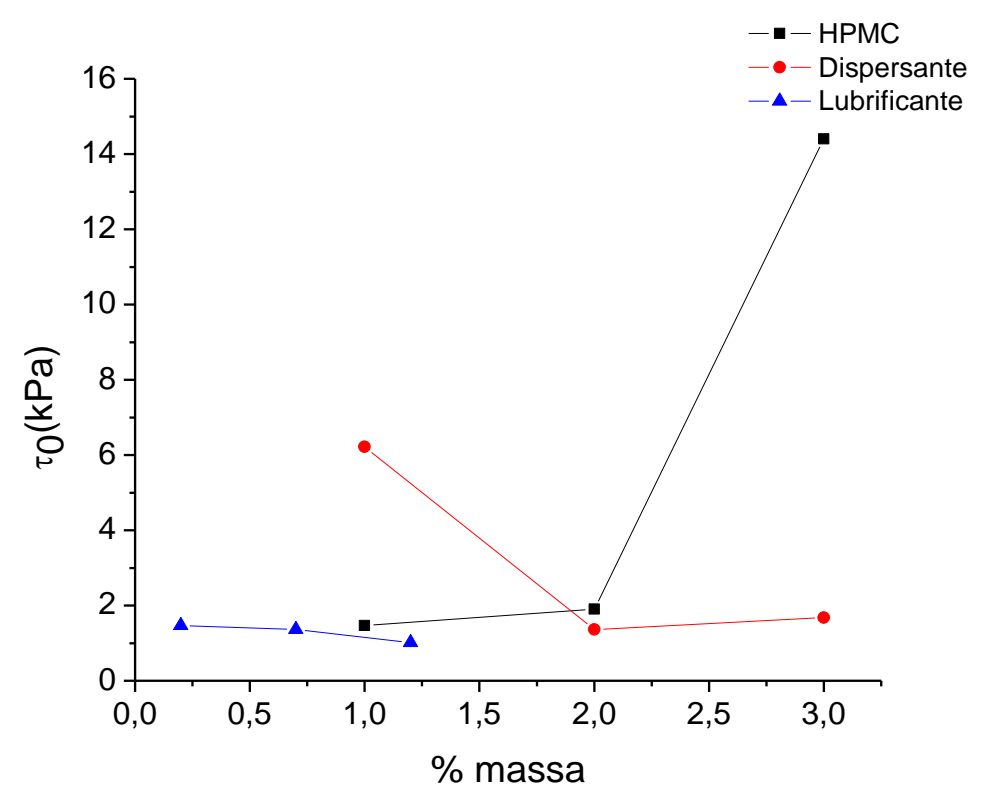

Gráfico 25 - Tensão de cisalhamento inicial vs. teor de aditivos

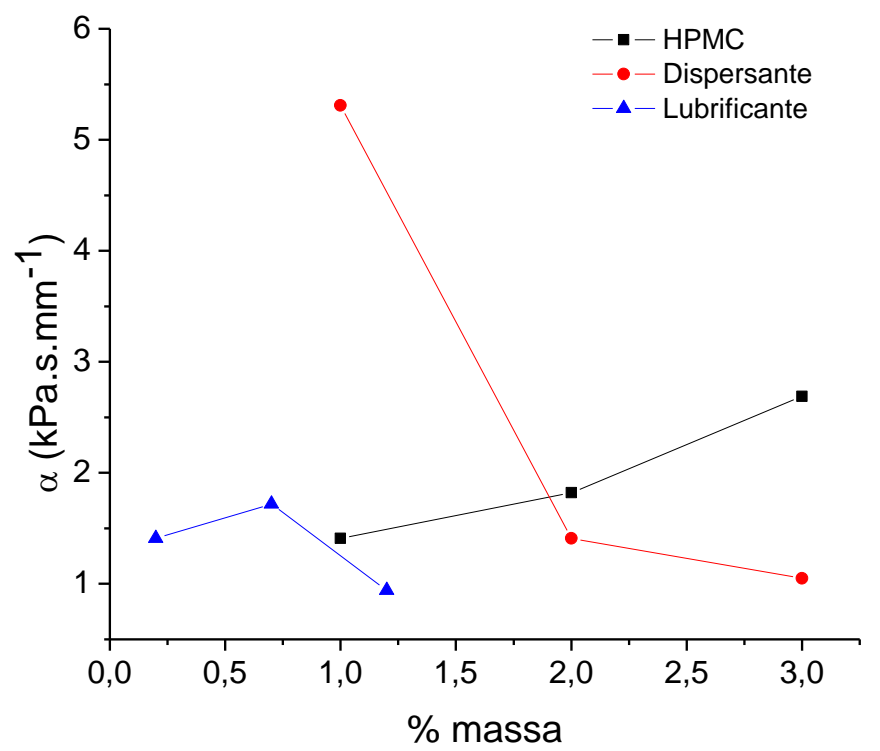

Gráfico 26 - Efeito da velocidade na tensão de escoamento vs. teor de aditivos 


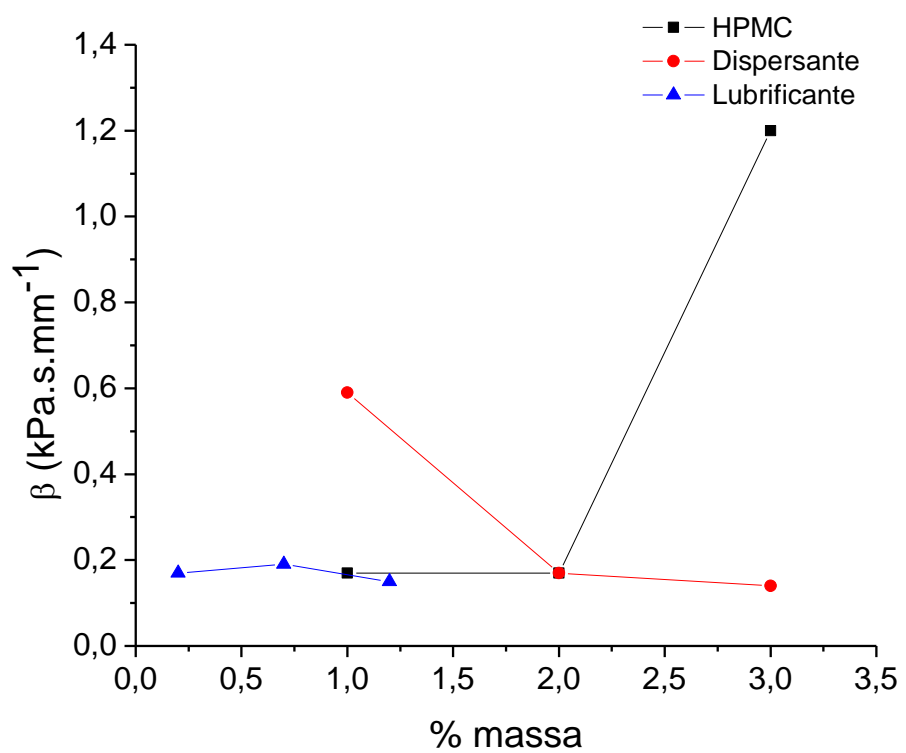

Gráfico 27 - Efeito da velocidade na tensão de cisalhamento para os aditivos

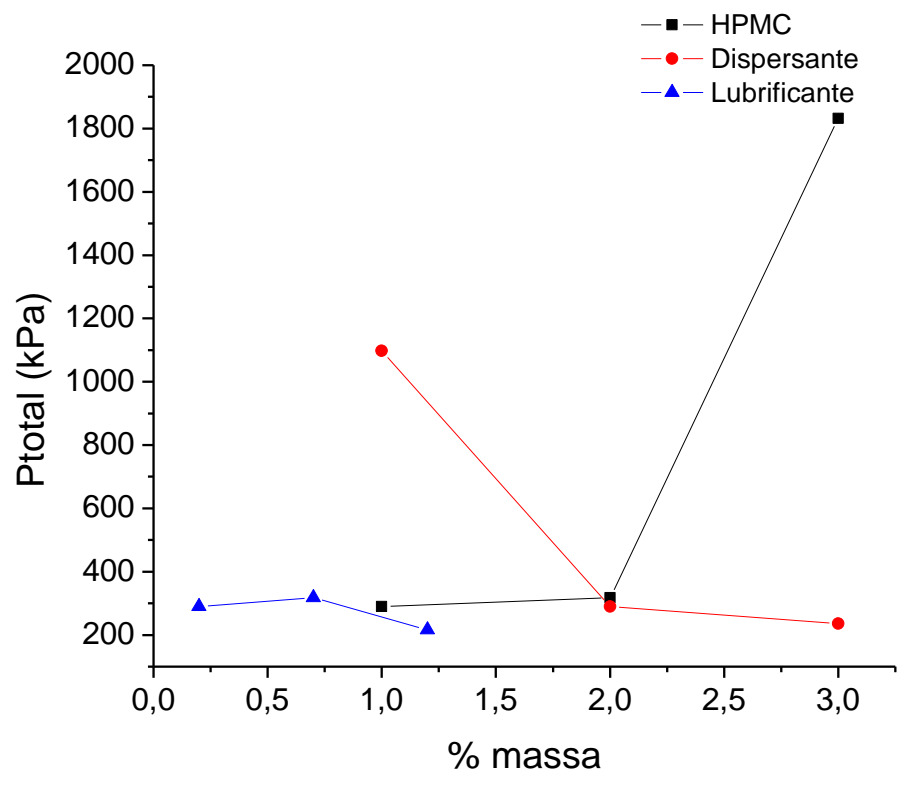

Gráfico 28 - Pressão total de extrusão 


\section{COMPÓSITOS ELABORADOS POR EXTRUSÃO}

Com o propósito de avaliar a influência do modificador reológico (HPMC) e do dispersante (Adva Flow) no compósito endurecido aos 28 dias foi realizado o estudo das propriedades mecânicas e físicas dos compósitos em três níveis de teor para cada aditivo. O lubrificante não foi considerado no estudo uma vez que constatado, no item 4.6.4, sua ineficiência em reduzir as tensões de cisalhamento na boquilha.

A elaboração dos corpos-de-prova para avaliação do modificador reológico HPMC e do dispersante Adva Flow, foram realizadas segundo os procedimentos descritos no item 3.4.2, utilizando o misturador planetário de volume de $6 \mathrm{~L}$, extrusora sem vácuo de rosca e processo de cura úmida de 28 dias. Foram utilizados no estudo de cada formulação séries de pelo menos 12 corpos-de-prova.

As matérias-primas utilizadas seguem as propriedades descritas no item 3.2

\subsection{EFEITO DO HPMC NO COMPÓSITO DE CIMENTO ELABORADO POR EXTRUSÃO}

Com a finalidade de avaliar 0 efeito do modificador reológico hidroxipropilmetilcelulose F4M (HPMC), foram elaborados compósitos com teores de HPMC de $0,7 \%, 1,1 \%$ e $1,5 \%$ em relação à massa do cimento (CPV), e com $a / c=0,28$. A matriz foi constituída de cimento CPV utilizando teor de $0,75 \%$ de dispersante.

Para avaliar o desempenho mecânico e físico, foram testados pelo menos 12 copos-de-prova para cada série. As propriedades mecânicas desenvolvidas pelos corpos-de-prova são apresentadas na Tabela 18. 
Tabela 18- Propriedades mecânicas dos compósitos com diferentes teores de HPMC

\begin{tabular}{lllllcccc}
\hline Formulação & $\begin{array}{c}\text { MOR } \\
(\mathbf{M P a})\end{array}$ & DVP & $\begin{array}{c}\text { LOP } \\
(\mathrm{MPa})\end{array}$ & $\begin{array}{c}\text { DVP } \\
\text { (MPa) }\end{array}$ & $\begin{array}{c}\text { MOE } \\
\text { DVP }\end{array}$ & $\begin{array}{c}\text { EE } \\
\left(\mathrm{kJ} / \mathbf{m}^{2}\right)\end{array}$ & DVP \\
\hline HPMC_0,7\% & 9,36 & 0,91 & 8,96 & 0,87 & 16567 & 1389 & 0,50 & 0,14 \\
HPMC_1,1\% & 7,23 & 0,91 & 6,86 & 0,89 & 13708 & 996 & 0,45 & 0,11 \\
HPMC_1,5\% & 8,51 & 0,75 & 6,39 & 0,97 & 22705 & 2153 & 0,28 & 0,04 \\
\hline
\end{tabular}

Os éteres celulósicos (HPMC), embora tenham a capacidade de reter água melhorando a hidratação em longo prazo, também se decompõem em meio alcalino gerando produtos como ácidos hidroxi-carboxílicos, que tem efeito de retardo na hidratação do cimento (POURCHEZ et al., 2006; WEYER et al., 2005). Além disso, os éteres celulósicos têm a capacidade de incorporar ar no compósito conforme constatado por Srinivasan, Deford e Shah (1999). Embora a pressão da extrusão aumente com o acréscimo de HPMC, como observado no item 4.6.2, a incorporação de ar pode ser o que promove a redução do desempenho mecânico do compósito com o aumento do teor do éter celulósico, como observado na Gráfico 29 para MOR e Gráfico 30 para EE.

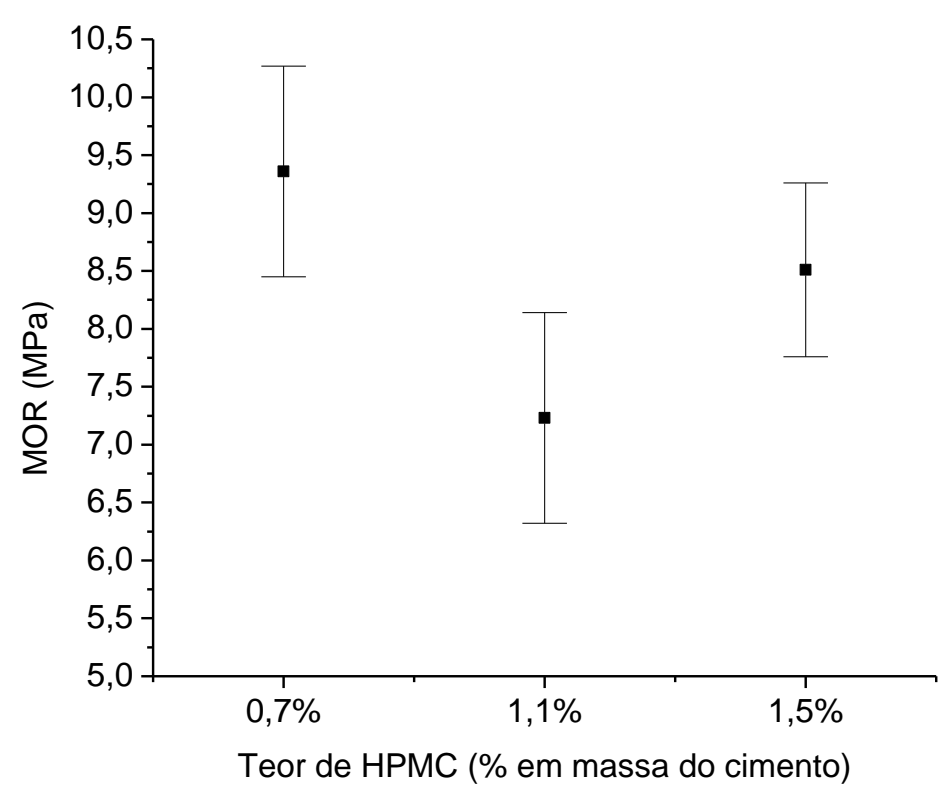

Gráfico 29 - Módulo de ruptura do compósito com diferentes teores de HPMC 


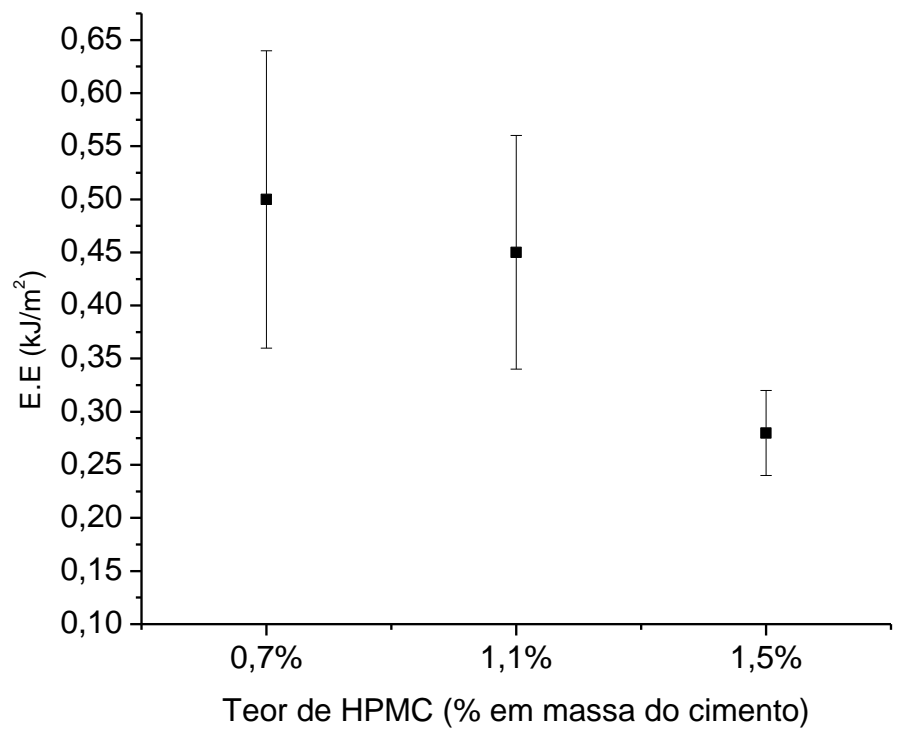

Gráfico 30 - Energia específica do compósito com diferentes teores de HPMC

A Tabela 19 apresenta as propriedades físicas dos corpos elaborados com os diferentes teores de HPMC. Essas propriedades são afetadas pelo éter celulósico HPMC devido à capacidade de incorporar ar na mistura aumentando assim, com o aumento do teor do mesmo, a AA e a PA e reduzindo a DA, isso pode ser apreciado nos Gráficos 31, 32 e 33.

Tabela 19- Propriedades físicas dos compósitos com adição de HPMC

\begin{tabular}{lcccccc}
\hline Formulações & $\begin{array}{c}\text { AA } \\
(\%)\end{array}$ & DVP & $\begin{array}{c}\text { DA } \\
\left(\mathbf{g} / \mathbf{c m}^{3}\right)\end{array}$ & DVP & $\begin{array}{c}\text { PA } \\
(\%)\end{array}$ & DVP \\
\hline HPMC_0,7 & 15,15 & 0,49 & 1,922 & 0,013 & 29,12 & 0,77 \\
HPMC_1,10 & 16,29 & 0,19 & 1,848 & 0,018 & 30,10 & 0,19 \\
HPMC_1,50 & 16,42 & 0,33 & 1,855 & 0,011 & 30,44 & 0,48 \\
\hline
\end{tabular}




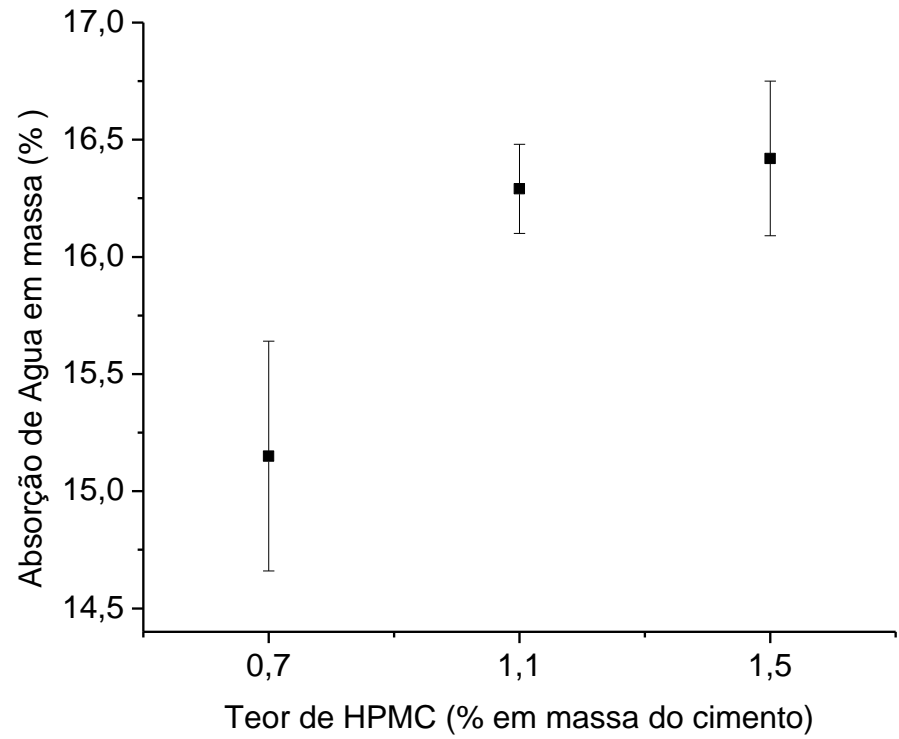

Gráfico 31 - Absorção de água do compósito com diferentes teores de HPMC

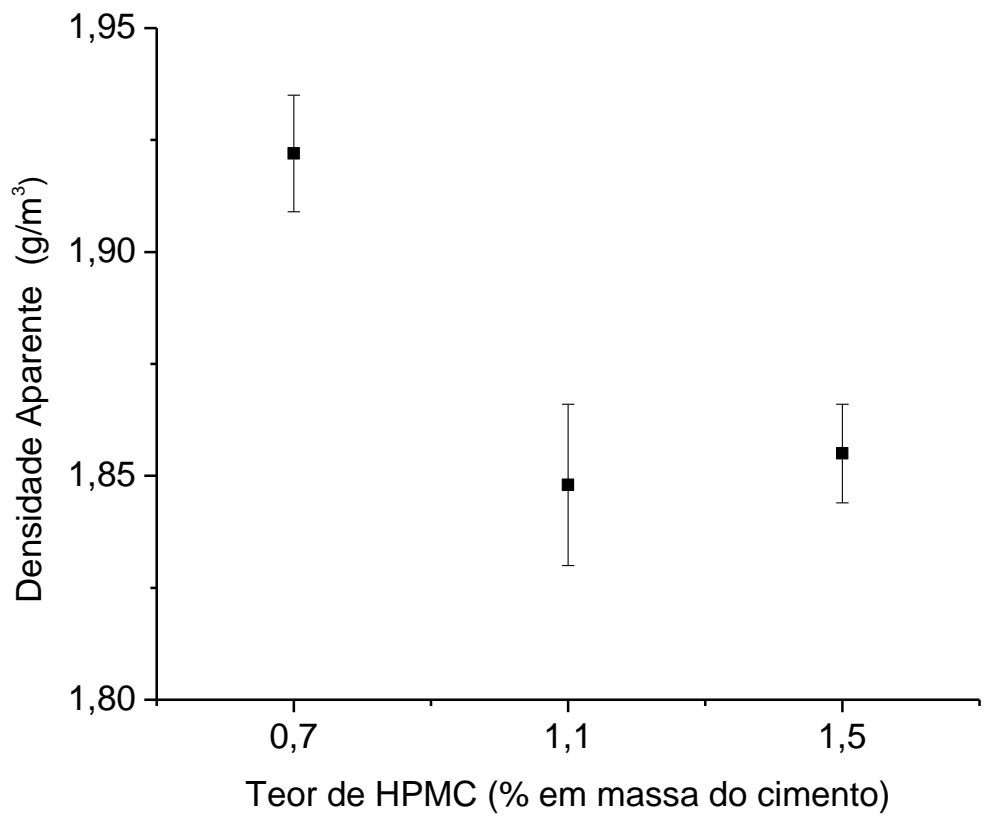

Gráfico 32 - Densidade aparente de compósitos com diferentes teores de HPMC 


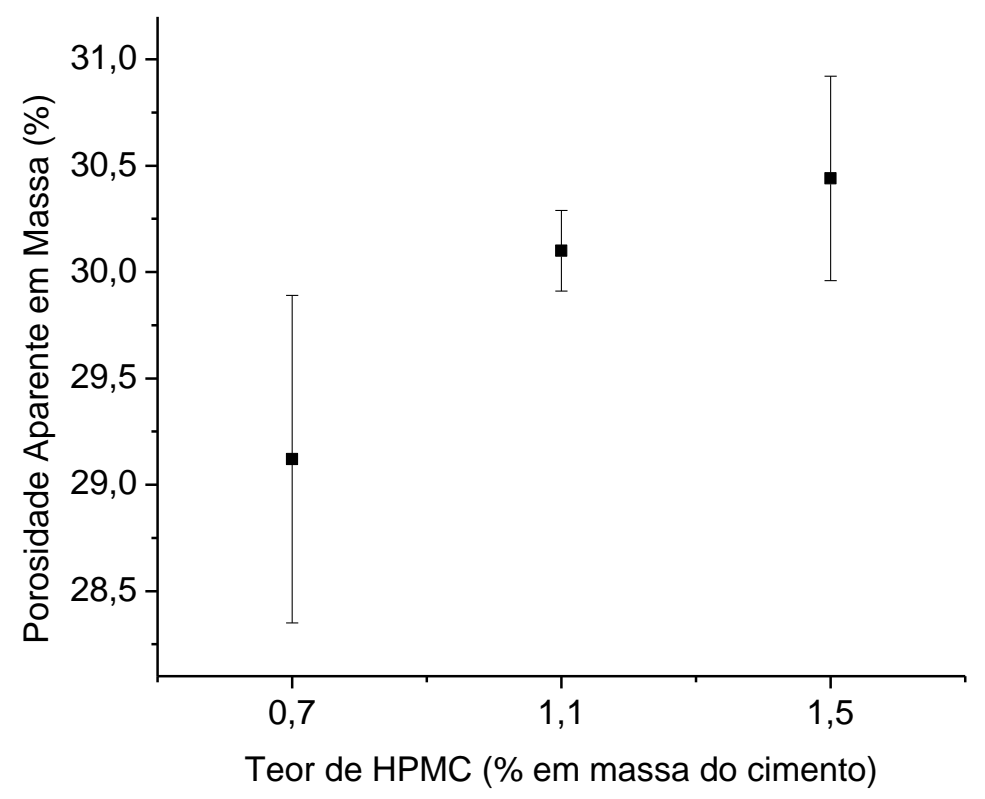

Gráfico 33 - Porosidade aparente de compósitos com diferentes teores de HPMC

\subsection{EFEITO DO DISPERSANTE NO COMPÓSITO DE CIMENTO ELABORADO POR EXTRUSÃO}

Com a finalidade de avaliar o efeito do dispersante no compósito foram elaboradas formulações em três níveis de teor. O dispersante utilizado foi um poliéter carboxílico com nome comercial ADVA FLOW, fabricado pela Grace, com teores em relação à massa de cimento de $0,25 \%, 0,50 \%$ e $0,75 \%$. A matriz foi constituída de cimento CPV utilizando modificador reológico HPMC em teor de 1,1\% e relação a/c de 0,2 .

A Tabela 20 apresenta os resultados dos ensaios mecânicos realizados para os diferentes teores de dispersante. O dispersante utilizado é de efeito eletro estérico o qual tem capacidade de dispersão de alta eficiência conseqüentemente gerando uma necessidade de menor quantidade de água na mistura. Logo, uma mesma mistura com teores adicionais de dispersante exibirá fluidez maior uma vez que a superfície das partículas são efetivamente molhadas com menor quantidade de água, ficando disponível uma porção adicional para aumentar a distancia entre as partículas (OLIVEIRA et al., 2000). Senff, Hotza e Repette (2010), em estudos realizados utilizando cimento $\mathrm{CPV}$ e diferentes teores de dispersante poliéter 
carboxílico, constataram a diminuição da viscosidade e da tensão de escoamento da mistura, na medida em que é aumentado o teor de dispersante. Como observado no estudo do efeito do dispersante nos parâmetros de Benbow, no item 4.6.3, a pressão total de extrusão é diminuída com a utilização do aditivo dispersante, o que leva a assumir que os compósitos gerados terão menor compactação à medida que for aumentado o teor de aditivo dispersante. Os efeitos anteriormente mencionados justificam a queda do MOR, conforme apresentado no Gráfico 34, e da EE, apresentado no Gráfico 35. É coerente proceder de forma que, à medida que for aumentando o teor de aditivo, se diminua a quantidade de água na mistura, pois devido a que $o$ aditivo utilizado tem esta finalidade.

Tabela 20 - Propriedades mecânicas dos compósitos com variações de teor de dispersante

\begin{tabular}{lcccccccc}
\hline Formulações & $\begin{array}{c}\text { MOR } \\
\text { (MPa) }\end{array}$ & DVP & $\begin{array}{c}\text { LOP } \\
\text { (MPa) }\end{array}$ & $\begin{array}{c}\text { DVP } \\
\text { MOE }\end{array}$ & $\begin{array}{c}\text { DVP } \\
(\mathbf{M P a})\end{array}$ & $\begin{array}{c}\text { EE } \\
\left(\mathbf{k J} / \mathbf{m}^{2}\right)\end{array}$ & DVP \\
\hline Dispersante_0,25 & 9,77 & 0,80 & 9,43 & 0,80 & 16558 & 741 & 0,47 & 0,10 \\
Dispersante_0,50 & 8,28 & 0,64 & 7,96 & 0,69 & 17272 & 1111 & 0,32 & 0,09 \\
Dispersante_0,75 & 6,29 & 0,87 & 5,97 & 0,77 & 17998 & 1646 & 0,15 & 0,07 \\
\hline
\end{tabular}

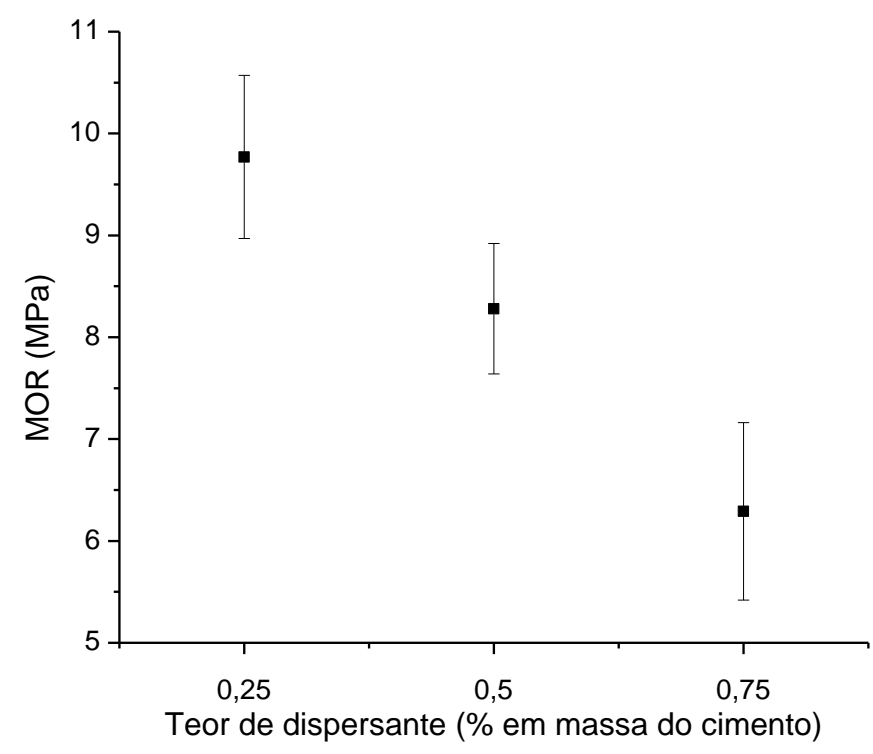

Gráfico 34 - Módulo de ruptura do compósito com diferentes teores de dispersantes 


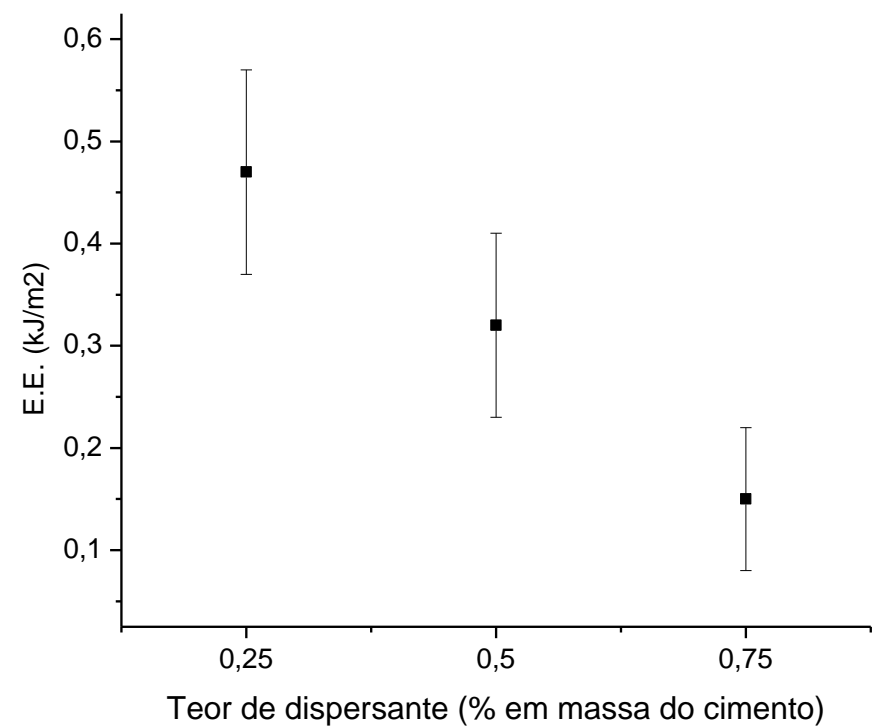

Gráfico 35 - Energia específica do compósito com diferentes teores de dispersante

A Tabela 21 apresenta as propriedades físicas para os diferentes teores de dispersante. Como mencionado anteriormente, o excedente de água provoca redução no desempenho das propriedades mecânicas. Esse excedente de água provoca um aumento na PA, como mostrado no Gráfico 36, sem grandes variações nas propriedades de DA e AA, como apresentado no Gráfico 37.

Tabela 21- Propriedades físicas dos compósitos com diferentes teores de dispersante

\begin{tabular}{lcccccc}
\hline Formulações & $\begin{array}{c}\text { AA } \\
(\%)\end{array}$ & DVP & $\begin{array}{c}\text { DA } \\
\left(\mathrm{g} / \mathrm{cm}^{3}\right)\end{array}$ & DVP & $\begin{array}{c}\text { PA } \\
(\%)\end{array}$ & DVP \\
\hline Dispersante_0,25 & 14,35 & 0,36 & 1,930 & 0,010 & 27,10 & 0,57 \\
Dispersante_0,50 & 14,69 & 0,21 & 1,937 & 0,016 & 28,45 & 0,25 \\
Dispersante_0,75 & 14,18 & 0,18 & 1,934 & 0,004 & 27,97 & 0,31 \\
\hline
\end{tabular}




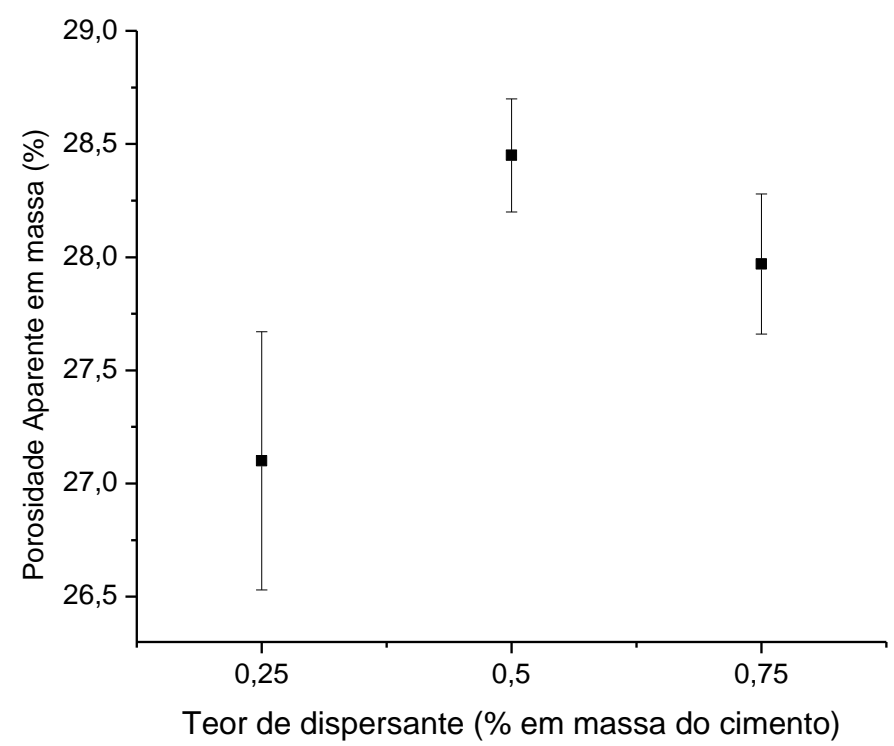

Gráfico 36 - Porosidade aparente do compósito com diferentes teores de dispersante

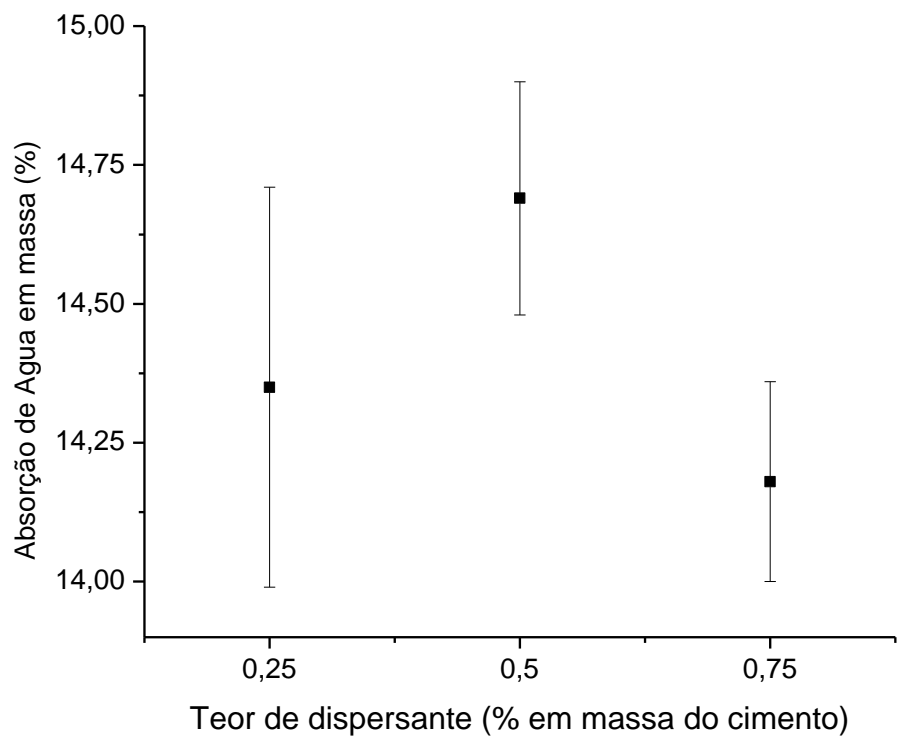

Gráfico 37 - Absorção de água do compósito com diferentes teores de dispersante

\subsection{DISCUSSÃO COMPLEMENTAR}

O quando há incremento do HPMC na mistura, o valor dos parâmetros reológicos se eleva, incrementando a pressão de extrusão, como pode ser 
constatado no item 4.6.2. Esse efeito favorece a conformação do compósito por extrusão, sempre que não seja excedida a capacidade de gerar pressão do extrusor. Porém, o incremento do HPMC reduz o MOR do compósito, isto provavelmente ocorre em razão ao incremento dos poros não conectados, induzidos pelo HPMC. Existe a necessidade de selecionar um teor de HPMC que possibilite a extrusão sem comprometer o desempenho mecânico da matriz e a homogeneização do sistema que é outro fator que se agrava com o incremento do aditivo.

$O$ incremento do dispersante na mistura apresenta efetiva capacidade de reduzir os parâmetros reológicos de Benbow como constatado no item 4.6.3 reduzindo a pressão de extrusão. Esses efeitos são atribuíveis à capacidade de dispersar, reduzindo a presença de aglomerados no material cimentício, liberando água no sistema. Por outro lado, o compósito endurecido com incrementos de dispersante, tende a reduzir o MOR, isso devido ao fato de a pressão de extrusão também ser reduzida e a água disponível no sistema sofrer incremento. $\mathrm{O}$ uso desse aditivo encontra-se vinculado a redução da relação a/c do sistema cimentício. 


\section{MODELAGEM ESTATÍSTICA DO COMPÓSITO}

A modelagem é desenvolvida em duas etapas. Na etapa I, é realizada a modelagem de matrizes e, na etapa II, a modelagem dos reforços. De acordo com o desempenho mecânico desejado, escolhe-se a matriz utilizando o modelo gerado na etapa I. Posteriormente realiza-se a etapa II, utilizando a matriz selecionada, os reforços de polipropileno e a polpa de celulose, para gerar um modelo correspondente ao reforço. Na segunda fase, é selecionada, a partir do modelo do reforço, a mistura que satisfaça o requerimento mecânico e físico do compósito desejado (placa).

Para a implantação dos modelos foram elaborados corpos-de-prova segundo os procedimentos descritos no item 3.4.2, utilizando o misturador planetário de volume de $6 \mathrm{~L}$, extrusora sem vácuo de rosca e o processo de cura acelerada. Cada formulação foi estudada considerando séries de pelo menos seis corpos-de-prova.

As matérias-primas utilizadas, de ampla disponibilidade no mercado nacional, seguem as propriedades descritas no item 3.2

\subsection{MODELAGEM DA MATRIZ}

As matérias-primas utilizadas na matriz e suas propriedades estão descritas no item 3.2. Para cada componente da matriz foram utilizadas as seguintes abreviações: Cimento Portland V ARI (CPV), Sílica ativa (S), Calcário (CC).

A utilização das matrizes $100 \%$ CC ou $100 \%$ S tiveram apenas o propósito de base de dados para a modelagem teórica para as matrizes.

O teor de HPMC utilizado em todas as formulações foi de $2 \%$ em massa. Esse elevado teor é adotado em razão de serem utilizadas diferentes combinações de matéria-prima na matriz, em elevado teor, acarreta variação nos parâmetros reológicos como constatado no item 4.5 podendo comprometer a extrudabilidade. Assim, adotando um teor de HPMC elevado, possibilita a extrudabilidade de uma ampla combinação das matérias-primas. 
O dispersante Adva Flow foi adotado em teor de $2 \%$ para todas as formulações. Esse valor foi utilizado em razão da ampla variação da área específica das matérias-primas, constatado no item 3.2.4, o que influência na dispersão do material cimentício. Dessa forma procura-se tornar efetiva a dispersão da pasta cimentícia.

O delineamento experimental foi realizado com a finalidade de determinar os coeficientes dos modelos implantados utilizando o programa estatístico Minitab versão 16. A Tabela 22 descreve as formulações utilizadas para determinar os coeficientes dos modelos.

Tabela 22 - Formulações para determinação de coeficientes dos modelos

\begin{tabular}{lccc}
\hline Formulação & $\begin{array}{c}\text { Cimento } \\
\text { (\%massa) }\end{array}$ & $\begin{array}{c}\text { Sílica Ativa } \\
\text { (\%massa) }\end{array}$ & $\begin{array}{c}\text { Calcário } \\
\text { (\%massa) }\end{array}$ \\
\hline CPV100 & 100 & - & - \\
S100 & - & 100 & - \\
C100 & - & - & 100 \\
CPV50S50 & 5 & 1 & - \\
S50C50 & - & 50 & 50 \\
CPV50C50 & 50 & - & 50 \\
CPV33S33C33 & 33,3 & 33,3 & 33,3 \\
CPV66S16C16 & 66,7 & 16,7 & 16,6 \\
CPV16S66C16 & 16,7 & 66,7 & 16,6 \\
CPV16S16C66 & 16,7 & 16,7 & 66,7 \\
\hline
\end{tabular}

Para cada formulação obtida através do planejamento experimental foram realizados ensaios com séries de pelo menos seis CPs.

\subsubsection{Modelagem das propriedades mecânicas}

As propriedades mecânicas de MOR, LOP, MOE e EE são modeladas utilizando o delineamento experimental apresentado na Tabela 22. Os ajustes do modelo linear, quadrático e cúbico são apresentados na Tabela 23. 
Tabela 23 - Análise dos modelos para as propriedades mecânicas da matriz

\begin{tabular}{lcccc}
\hline Modelo & MOR & LOP & MOE & EE \\
\hline Linear & & & & \\
$\mathrm{R}^{2}$ & 0,5781 & 0,5516 & 0,9390 & 0,0568 \\
Adj- ${ }^{2}$ & 0,5633 & 0,5359 & 0,9369 & 0,0237 \\
F & 39,06 & 35,06 & 438,85 & 1,72 \\
Quadrático & & & & \\
$\mathrm{R}^{2}$ & 0,7451 & 0,7388 & 0,9557 & 0,4029 \\
Adj-R & 0,7215 & 0,7146 & 0,9516 & 0,3477 \\
F & 31.56 & 30,55 & 232,94 & 7,29 \\
Cúbico & & & & \\
$\mathrm{R}^{2}$ & 0,9131 & 0,9032 & 0,9684 & 0,6556 \\
Adj- $R^{2}$ & 0,9032 & 0,8923 & 0,9648 & 0,6266 \\
F & 92,77 & 89,23 & 270,52 & 16,82 \\
\hline
\end{tabular}

Adota-se $60 \%$ como satisfatório para a porcentagem do coeficiente de determinação $R^{2}$ e de $95 \%$ na significância estatística. Nessas condições, apresentam-se satisfatórios o modelo Linear para o MOE, modelo quadrático para o MOR, LOP e o modelo cúbico para a EE. As equações com os respectivos coeficientes são apresentados na Tabela 24.

Tabela 24 - Modelos ajustados para a modelagem das propriedades mecânicas da matriz

\begin{tabular}{|c|c|c|c|}
\hline Propriedade & Equação & Modelo & $\mathbf{R}^{2}$ \\
\hline MOR & $\begin{array}{c}M O R=10,1135 * C P V+0,6981 * S+1,3475 * C C+ \\
7,4306 * C P V * S+19,5160 * C P V * C C+9,9451 * S * C C\end{array}$ & Quadrático & 0,7451 \\
\hline LOP & $\begin{array}{c}\mathrm{LOP}=9,5127 * \mathrm{CPV}+0,7098 * \mathrm{~S}+1,3558 * \mathrm{CC}+8,1540 * \\
\quad \mathrm{CPV} * \mathrm{~S}+20,2395 * \mathrm{CPV} * \mathrm{CC}+9,5604 * \mathrm{~S} * \mathrm{CC}\end{array}$ & Quadrático & 0,7388 \\
\hline MOE & $M O E=23813,8 * \mathrm{CPV}+890,6 * \mathrm{~S}+1856,9 * \mathrm{CC}$ & Linear & 0,9390 \\
\hline EE & $\begin{array}{c}E E=0,05469 * \mathrm{CPV}+0,01972 * \mathrm{~S}+0,03635 * \mathrm{CC}- \\
0,05853 * \mathrm{CPV} * \mathrm{~S}+0,43474 * \mathrm{CPV} * \mathrm{CC}-0,01453 * \mathrm{~S} * \\
\mathrm{CC}+5,34565 * \mathrm{CPV} * \mathrm{~S} * \mathrm{CC}\end{array}$ & Cúbico & 0,6556 \\
\hline
\end{tabular}


Os Gráficos 38, 39, 40 e 41 apresentam o comportamento das propriedades mecânicas de acordo com os respectivos modelos implementados.

O Gráfico 38, correspondente ao módulo de ruptura, apresenta valores de módulo de ruptura maiores para as combinações onde predomina o conteúdo de CPV, o que era previsto, uma vez que o CPV é o ligante das matrizes. O hidróxido de cálcio liberado, durante a hidratação do CPV, reage pozolanicamente com o S para formar C-S-H adicional. Por outro lado, o CC unicamente cumpre a função de filler inerte nas matrizes.

É evidente que matrizes formadas com predominância de CC ou S não iriam apresentar valores de MOR maiores se comparadas às matrizes com predominância de CPV, porém esperava-se uma melhora do MOR em matrizes predominantes de CPV com pequenas adições de S. Esse incremento esperado do MOR não acontece em razão de uma provável dispersão ineficiente da $S$, que, em vez de preencher os espaços entre as partículas de cimento introduz vazios promovidos por aglomerados de partículas de S. O mesmo problema foi constatado por Dias et al. (2010) em compósitos elaborados por drenagem e prensagem. A dificuldade de se obter uma $S$ dispersa foi observada por Romano et al. (2008) em estudo de dispersões com elevado teor de água. Por outro lado, Iveson et al. (2001) ressalta que a dificuldade de dispersão aumenta para teores baixos de líquido.

As matrizes com tendência predominante de CC exibem uma menor redução do MOR quando comparadas com as de predominância de S. Isso pode ser atribuído à menor dificuldade de dispersão, por causa da presença de tamanhos de partículas maiores e área superficial menor, quando comparadas às partículas da $\mathrm{S}$. Outro fator que pode estar influenciando essas tendências são as maiores pressões de compactação durante o processamento, que predominam nas matrizes de CC, como evidenciado no item 4.5, em estudo reológico, onde são determinadas as pressões de extrusão devido à variação da adição de CC e S. Mais um fator que pode explicar essa tendência é a maior demanda de água das matrizes com predominância de $\mathrm{S}$, quando comparadas às de predominância de $\mathrm{CC}$, como pode ser constatado no item demanda de água do particulado. Isso pode estar levando a uma maior quantidade de poros na matriz, de acordo com a tendência de menor fração volumétrica de sólidos da mistura em matrizes com predominância de $S$. 

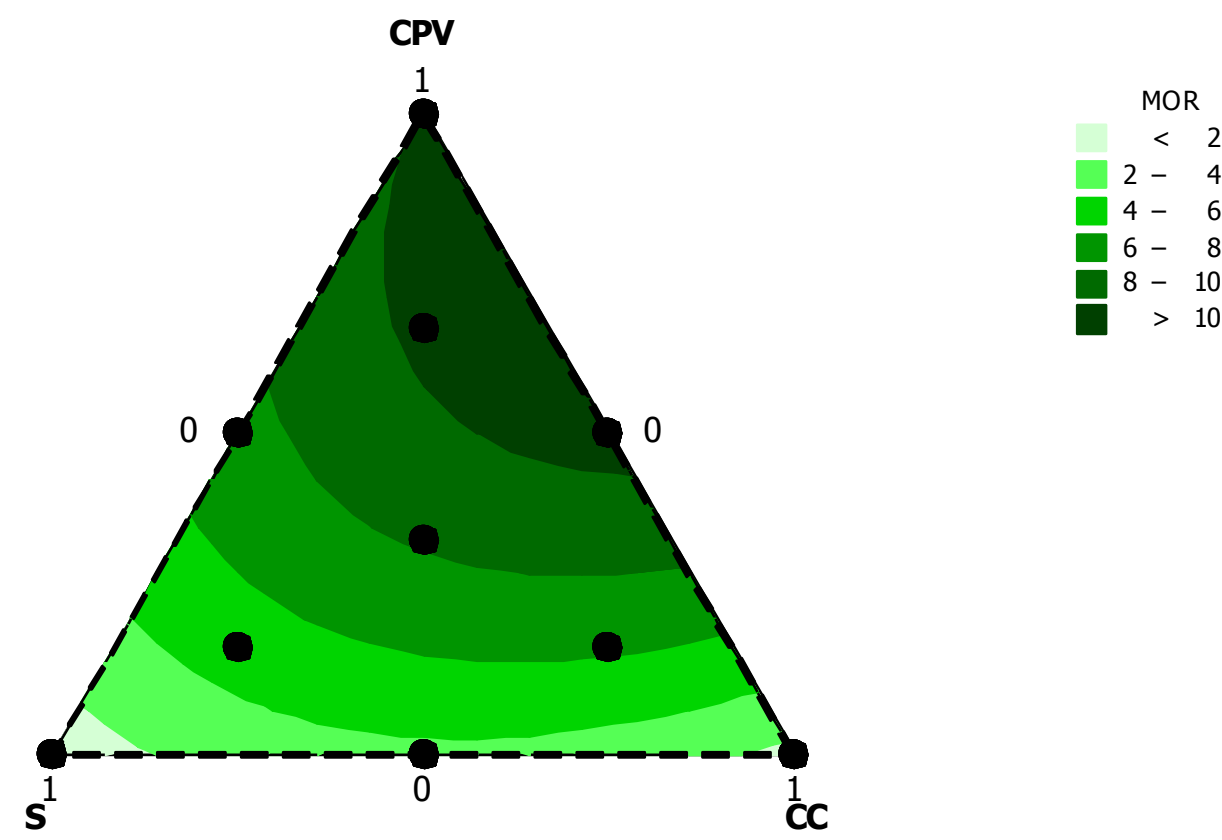

Gráfico 38 - Valores de MOR estimados com o modelo quadrático para as matrizes

O Gráfico 39 corresponde ao LOP das matrizes. Os efeitos sugeridos como influencia no comportamento de MOR para as matrizes são sugestões validas para o comportamento do LOP. As tendências apresentadas pelas matrizes, no que se refere ao MOR, permanecem no caso do LOP.
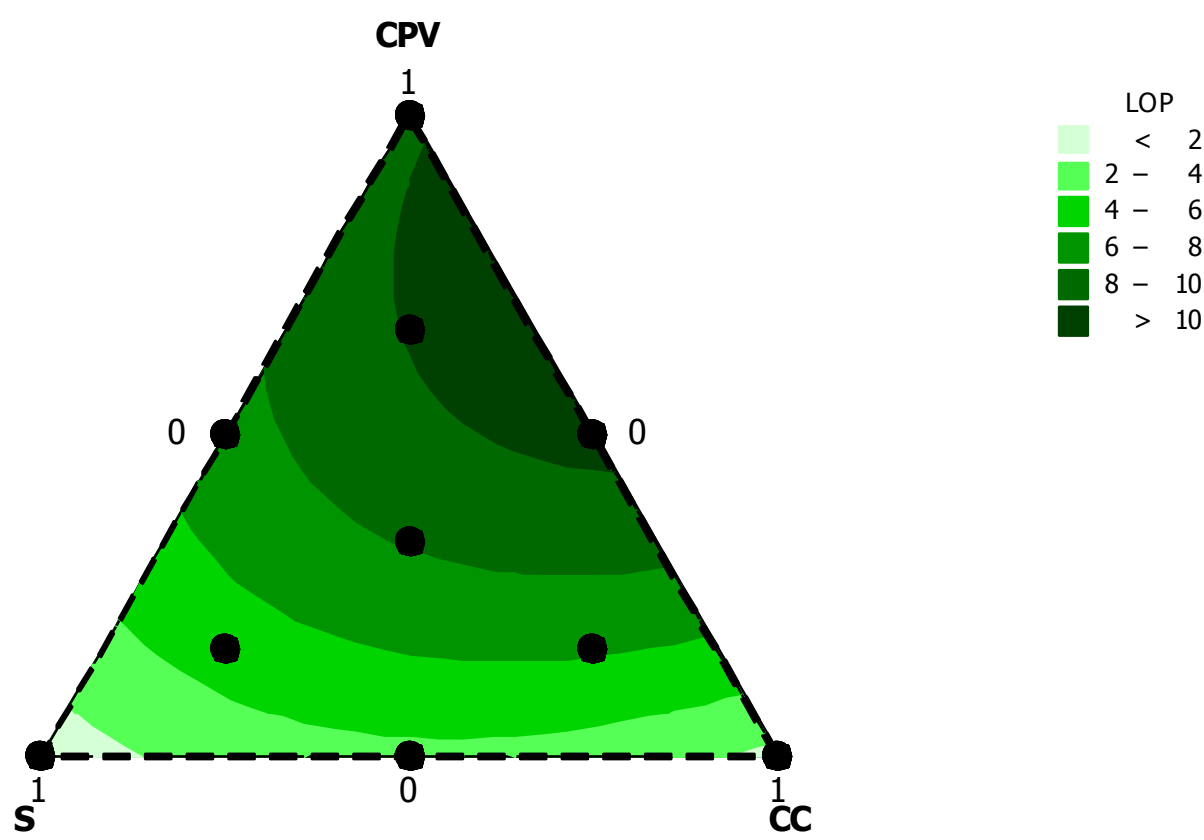

Gráfico 39 - Valores de LOP estimado com o modelo quadrático para as matizes

O Gráfico 40, referente ao MOE das matrizes, mostra a tendência de maiores valores na região onde predomina o componente CPV. O declínio dessa propriedade 
manifesta-se constante tanto para adições de $\mathrm{S}$ ou CC, mostrando a preponderância do ligante na obtenção de valores elevados de MOE. Por outro lado, as adições de $S$ e CC, pelo seu caráter inerte ou reatividade pozolânica, exibem uma tendência constante de redução do MOE para ambos os casos.
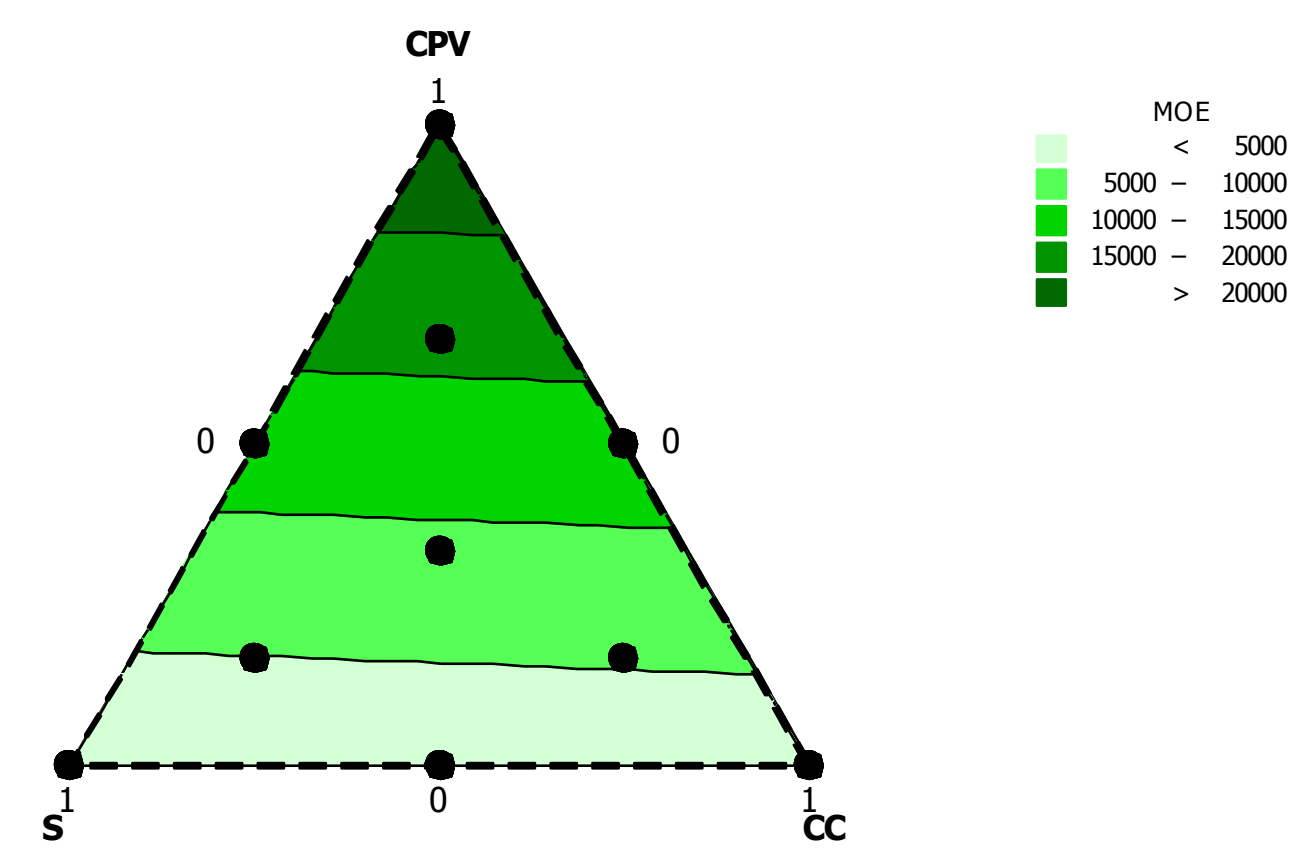

Gráfico 40 - Valores de MOE estimado com o modelo quadrático para as matrizes

O Gráfico 41 exibe os valores de EE para as respectivas matrizes. Como esperado as matrizes não apresentam grande absorção de energia, variando entre 0,03 a 0,28 . Essa propriedade exibe os maiores valores na parte central do gráfico simplex. As matrizes apresentam baixa absorção de energia, pois a ruptura durante a solicitação, é de caráter frágil. 

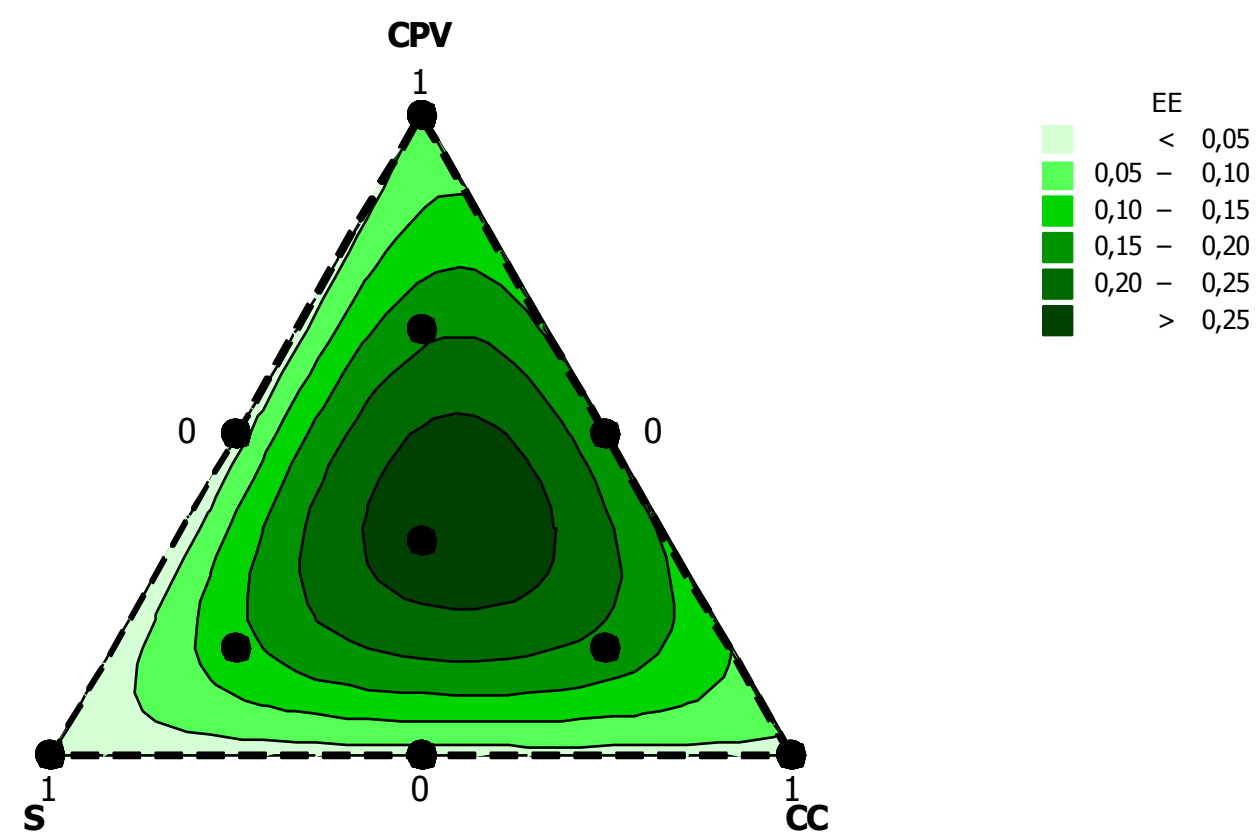

Gráfico 41 - Valores de EE estimado com o modelo cúbico para as matrizes

\subsubsection{Modelagem das propriedades físicas}

As propriedades físicas de absorção de água (AA), densidade aparente (DA) e porosidade aparente (PA) são modeladas para as matrizes utilizando o delineamento experimental apresentado na Tabela 25. Os resultados dos ensaios, utilizados nos ajustes dos modelos, são apresentados no Apêndice B.

Os ajustes dos modelos, linear, quadrático e cúbico, são apresentados na Tabela 25. 
Tabela 25 - Análise dos modelos para as propriedades físicas da matriz

\begin{tabular}{lccc}
\hline Modelo & AA & DA & PA \\
\hline Linear & & & \\
$\mathrm{R}^{2}$ & 0,5168 & 0,8787 & 0,3142 \\
Adj- ${ }^{2}$ & 0,40998 & 0,8784 & 0,2902 \\
F & 30,48 & 206,43 & 13,06 \\
Quadrático & & & \\
$\mathrm{R}^{2}$ & 0,8133 & 0,8836 & 0,7212 \\
Adj- ${ }^{2}$ & 0,7961 & 0,8729 & 0,6954 \\
F & 47,06 & 82,02 & 27,94 \\
Cúbico & & & \\
$\mathrm{R}^{2}$ & 0,8471 & 0,8839 & 0,8236 \\
Adj- $R^{2}$ & 0,8297 & 0,8707 & 0,8036 \\
F & 48,92 & 67,23 & 41,25 \\
\hline
\end{tabular}

Adota-se $60 \%$ como satisfatório para a porcentagem do coeficiente de determinação $R^{2}$ e de $95 \%$ para a significância estatística. Nessas condições, apresentam-se satisfatórios o modelo linear para a DA e os modelos quadráticos para a AA e a PA. As equações com os respectivos coeficientes são apresentados na Tabela 26.

Tabela 26 - Modelos implementados para o comportamento físico das matrizes

\begin{tabular}{cccc}
\hline Propriedade & Equação & Modelo & $\mathbf{R}^{2}$ \\
\hline $\mathrm{AA}$ & $\begin{array}{c}A A=13,89 * \mathrm{CPV}+40,66 * \mathrm{~S}+16,20 * \mathrm{CC}-53,29 * \\
\mathrm{CPV} * \mathrm{~S}-6,90 * \mathrm{CPV} * \mathrm{CC}-27,77 * \mathrm{~S} * \mathrm{CC}\end{array}$ & Quadrático & 0,9469 \\
& & & \\
$\mathrm{DA}$ & $D A=1,965 * \mathrm{CPV}+1,159 * \mathrm{~S}+1,758 * \mathrm{CC}$ & Linear & 0,9687 \\
& & & \\
$\mathrm{PA}$ & $P A=26,98 * \mathrm{CPV}+47,33 * \mathrm{~S}+28,25 * \mathrm{CC}-62,30 *$ \\
& $\mathrm{CPV} * \mathrm{~S}-14,89 * \mathrm{CPV} * \mathrm{CC}-23,77 * \mathrm{~S} * \mathrm{CC}$ & Quadrático & 0,8764 \\
\hline
\end{tabular}

Os Gráficos 42, 43 e 44 apresentam o comportamento das propriedades físicas, de acordo com os respectivos modelos implantados. 
O Gráfico 42 apresenta pouca variabilidade da AA em combinações de CPV e $\mathrm{CC}$, se comparadas com as de CPV e S. A explicação para esse fato pode ser atribuída à dificuldade de dispersão dos aglomerados de S. Por outro lado, a baixa variabilidade apresentada em combinações de matrizes com predominância de CPV e CC pode ser atribuída a baixas forças de superfície atuantes, já que a área superficial dessas duas componentes é inferior ao da $S$, facilitando assim a dispersão dos aglomerados.
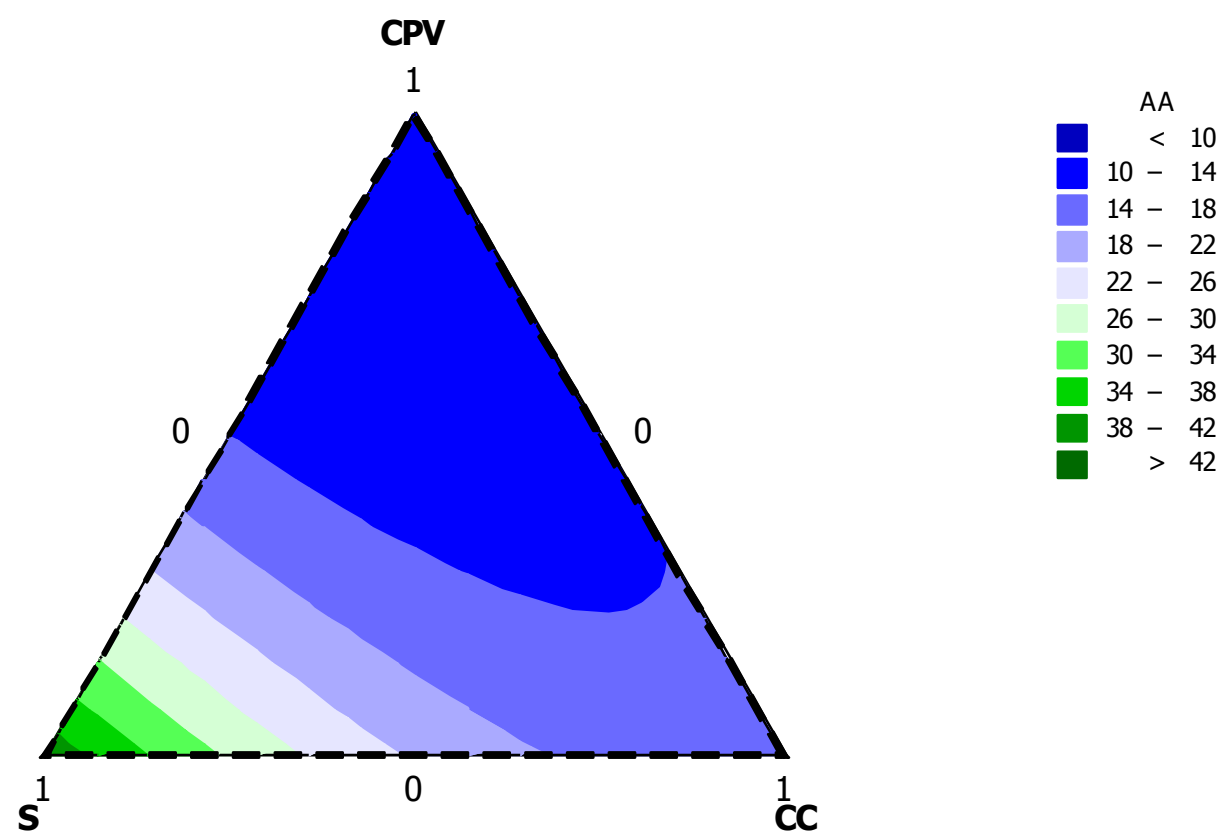

Gráfico 42 - Valores de AA estimado com o modelo quadrático para as matrizes

O Gráfico 43 apresenta as densidades das matrizes, exibindo a tendência de maiores densidades para as formulações com predominância de CPV. A adição de CC apresenta menor variação do valor de DA quando comparado com os valores correspondentes às matrizes com predominância de $S$. Essa maior variação pode ser atribuída à dificuldade de dispersão da $\mathrm{S}$ em comparação ao $\mathrm{CC}$. Além disso, a maior demanda de água apresentada pelas matrizes com predominância de $\mathrm{S}$, se comparadas às matrizes com predominância de CC, pode estar contribuindo para a redução acentuada da densidade. 


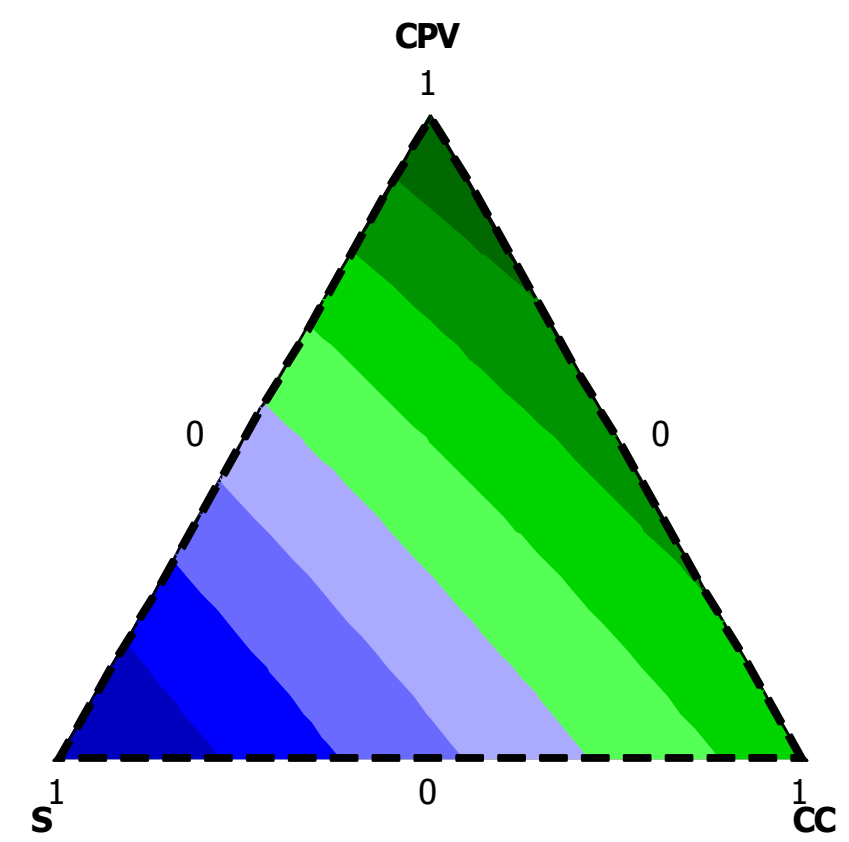

Gráfico 43 - Valores de DA estimado com o modelo linear para as matrizes

O Gráfico 44 referente à PA mostra a maior variabilidade dessa propriedade na predominância de $\mathrm{S}$ se comparada com matrizes com predominância de CC. As prováveis causas para essas tendências podem ser atribuídas às diretrizes de dispersão e de demanda de água citadas anteriormente, enfatizando a dificuldade de dispersar a $S$ em razão das elevadas forças de superfícies. Por outro lado, a elevada demanda de água de S quando comparada ao CC pode estar propiciando um maior conteúdo de poros nas matrizes com predominância de $S$. Porém existe uma região dentro da área de predominância de CPV e S em que a PA chega a ter o menor valor, o que condiz com o descrito por Gutierrez, Díaz e Delvasto (2005). Esses autores destacam que, em geral, a adição de $S$ reduz o conteúdo de poros do compósito. 


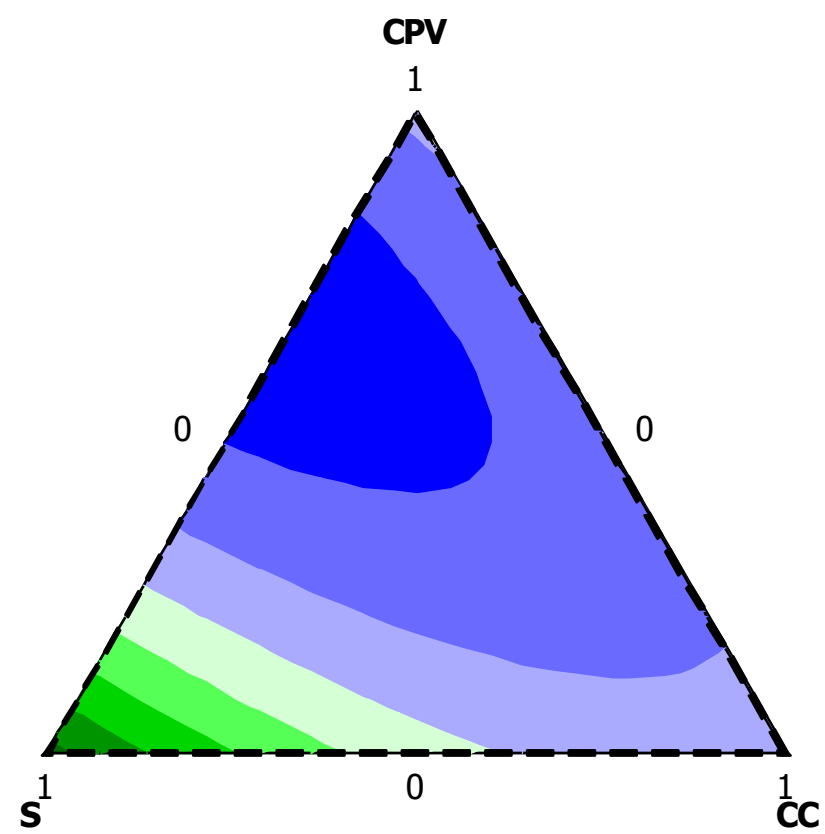

Gráfico 44 - Valores de PA estimado com o modelo quadrático para as matrizes

\subsubsection{Modelagem da demanda de água do particulado}

A Tabela 27 apresenta as demandas de águas determinadas para os diferentes sistemas de particulados, foram determinadas de acordo ao descrito no item 3.1.4. Para cada formulação é apresentada a fração volumétrica de sólidos (FVS) correspondente na Tabela 30. 
Tabela 27 - Demanda de água e fração volumétrica de sólidos (FVS) para as matrizes

\begin{tabular}{lcc}
\hline Formulação & $\begin{array}{c}\text { Demanda de água } \\
(\mathbf{a} / \mathbf{s})\end{array}$ & $\begin{array}{c}\text { FVS } \\
(\%)\end{array}$ \\
\hline CPV100 & 0,180 & 64,1 \\
S100 & 0,360 & 53,8 \\
C100 & 0,130 & 70,6 \\
CPV50S50 & 0,194 & 64,1 \\
CPV50C50 & 0,125 & 0,70 \\
S50CC50 & 0,210 & 63,6 \\
CPV33S33C33 & 0,126 & 72,0 \\
CPV66S16CC16 & 0,118 & 71,8 \\
CPV16S66CC16 & 0,240 & 61,1 \\
CPV16S16CC66 & 0,100 & 75,5
\end{tabular}

A partir dos resultados correspondentes ao delineamento experimental apresentado na Tabela 27 obtêm-se os modelos quadráticos contidos na Tabela 29, e a respectiva análise dos modelos na Tabela 28.

Tabela 28 - Análise dos modelos linear e quadrático para a/s e FVS das matrizes

\begin{tabular}{lcc}
\hline Modelo & $\mathbf{a} / \mathbf{s}$ & FVS \\
\hline Linear & & \\
$\mathrm{R}^{2}$ & 0,777 & 0,6735 \\
Adj- $\mathrm{R}^{2}$ & 0,7141 & 0,5802 \\
$\mathrm{~F}$ & 12,24 & 7,22 \\
Quadrático & & \\
$\mathrm{R}^{2}$ & 0,9672 & 0,8804 \\
Adj- $^{2}$ & 0,9263 & 0,7310 \\
$\mathrm{~F}$ & 23,63 & 5,89 \\
\hline
\end{tabular}


Tabela 29 - Modelos quadráticos implementados para a/s e FVS das matrizes

\begin{tabular}{|c|c|c|c|}
\hline Propriedade & Equação & Modelo & $\mathbf{R}^{2}$ \\
\hline $\begin{array}{l}\text { Demanda de } \\
\text { àgua }\end{array}$ & $\begin{array}{c}\text { Demanda de água }=0,1791 * \mathrm{CPV}+0,3682 * \mathrm{~S}+ \\
0,1273 * \mathrm{CC}-0,3608 * \mathrm{CPV} * \mathrm{~S}-0,2027 \mathrm{CPV} * \mathrm{CC}- \\
0,2005 * \mathrm{~S} * \mathrm{CC}\end{array}$ & Quadrático & 0,9672 \\
\hline $\begin{array}{l}\text { Fração } \\
\text { Volumétrica de } \\
\text { sólidos }\end{array}$ & $\begin{array}{c}F V S=64,19 * \mathrm{CPV}+52 * \mathrm{~S}+71,15 * \mathrm{CC}+28,88 * \\
\quad \mathrm{CPV} * \mathrm{~S}+22,61 * \mathrm{CPV} * \mathrm{CC}+14,81 * \mathrm{~S} * \mathrm{CC}\end{array}$ & Quadrático & 0,8804 \\
\hline
\end{tabular}

O Gráfico 45 apresenta o comportamento da demanda de água para composições de CPV, S e CC de acordo com previsto pelo modelo quadrático.
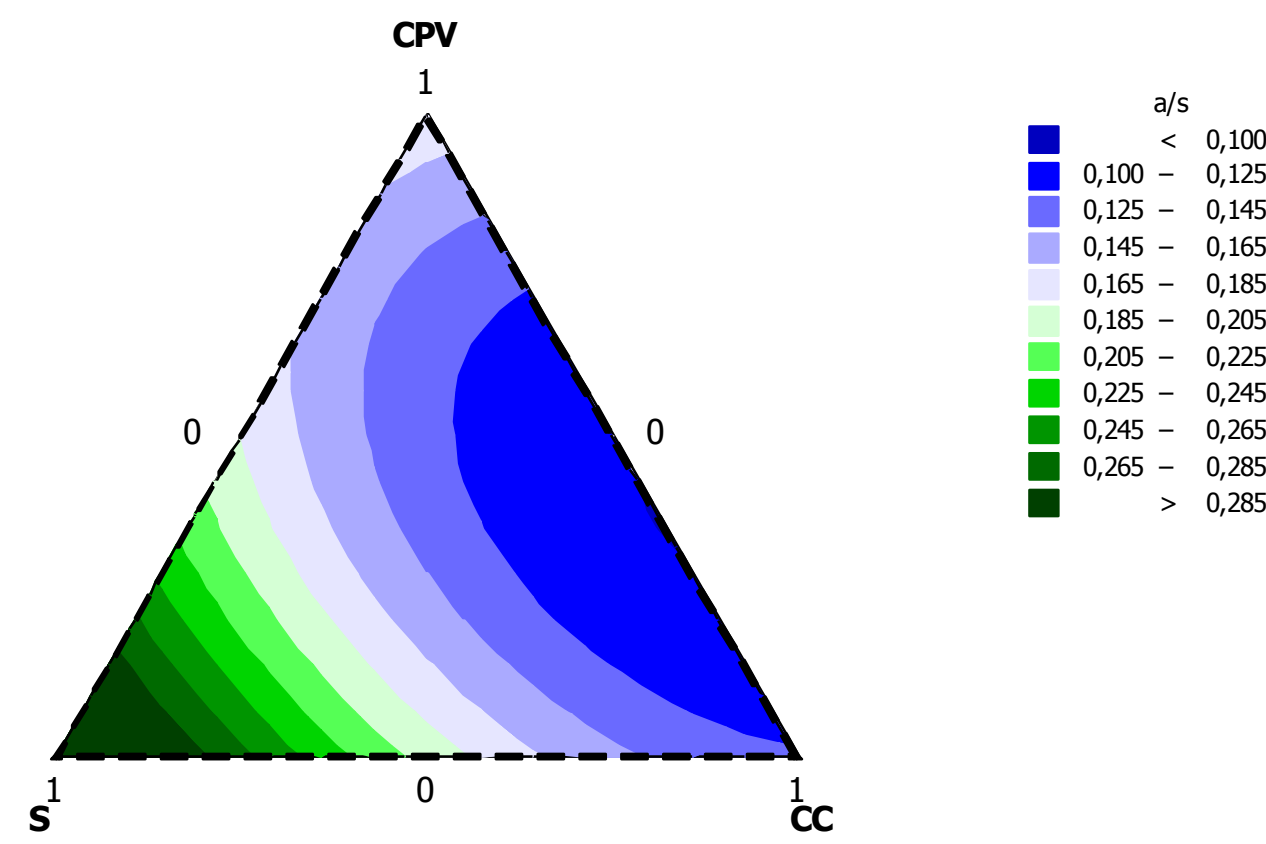

Gráfico 45 - Comportamento da demanda de água nas formulações cimenticias

A demanda de água de composições únicas de CPV100, C100 ou $\$ 100$ apresentam valores de a/s iguais a 0,180, 0,360 e 1,30 respectivamente. Embora formulações com composições únicas de $S$ e CC não sejam viáveis na prática, são importantes para detalhar o comportamento da demanda de água do particulado e para a determinação dos coeficientes do modelo. A composição única de $S$ exibe uma maior demanda de água em comparação às outras duas composições únicas de CPV e CC, isso devido, provavelmente, a sua elevada área superficial. Tal constatação está de acordo com o descrito por Ferraris et al. (2001), que ressaltam a relevância da demanda de água influenciada pela área superficial das partículas. 
Por outro lado, Gallias et al. (2000) destacam que a morfologia das partículas tem relevância na demanda de água, relacionando que uma partícula de forma irregular pode representar um aumento de duas a quatro vezes na demanda de água quando comparada a uma partícula esférica. As partículas de $\mathrm{S}$, mesmo tendo morfologia esférica, conforme constatado na Figura 19, superam amplamente a quantidade de água requerida para as partículas de CPV e CC, prevalecendo a área superficial.

Mesmo que a área superficial específica, morfologia e tamanho médio de partículas do CPV e CC sejam próximas, as demandas de água diferem na ordem de 0,05 , a qual pode estar sendo promovida pela reatividade das partículas de cimento, ocasionando dissolução rápida de certos constituintes. A partícula de cimento perde substâncias e, ao mesmo, tempo adquire pequena quantidade de água, devido a combinações químicas na superfície (POWERS, 1968).

As partículas de $\mathrm{CC}$, por serem inertes, utilizam a demanda de água exclusivamente para cobrir as superfícies e preencher os espaços intersticiais das partículas. Além disso, as partículas de CC apresentam área superficial muito inferior a $S$ e, conseqüentemente, têm potencial de aglomeração menor. O CC, como discutido por Vikan e Justnes (2007), tem uma melhor dispersão das partículas, o que pode ser uma explicação coerente para a tendência de formulações com predominância de CC e com menor demanda de água.

O Gráfico 46, apresenta-se o comportamento da FVS dos sistemas particulados, onde é possível observar que, conforme o aumento do teor de S a FVS diminui, mesmo existindo uma região de ligeira redução da demanda de água. Embora o tamanho médio das partículas de $\mathrm{S}$ seja muito inferior ao tamanho médio das partículas de CPV e CC, elas não apresentam, em nenhum teor utilizado, a capacidade de aumentar a FVS. Isso ocorre, provavelmente, pelo fato das partículas de $S$ ainda encontrarem-se parcialmente aglomeradas, assim impossibilitando um empacotamento efetivo que possa promover aumento na FVS. A dispersão das partículas de sílica ativa, como discutido por Romano et al. (2008) e por Vikan e Justnes (2007), está vinculada não unicamente ao uso de dispersante, em quantidades suficiente para neutralizar as forças de superfície, mas também à energia de dispersão utilizada. 


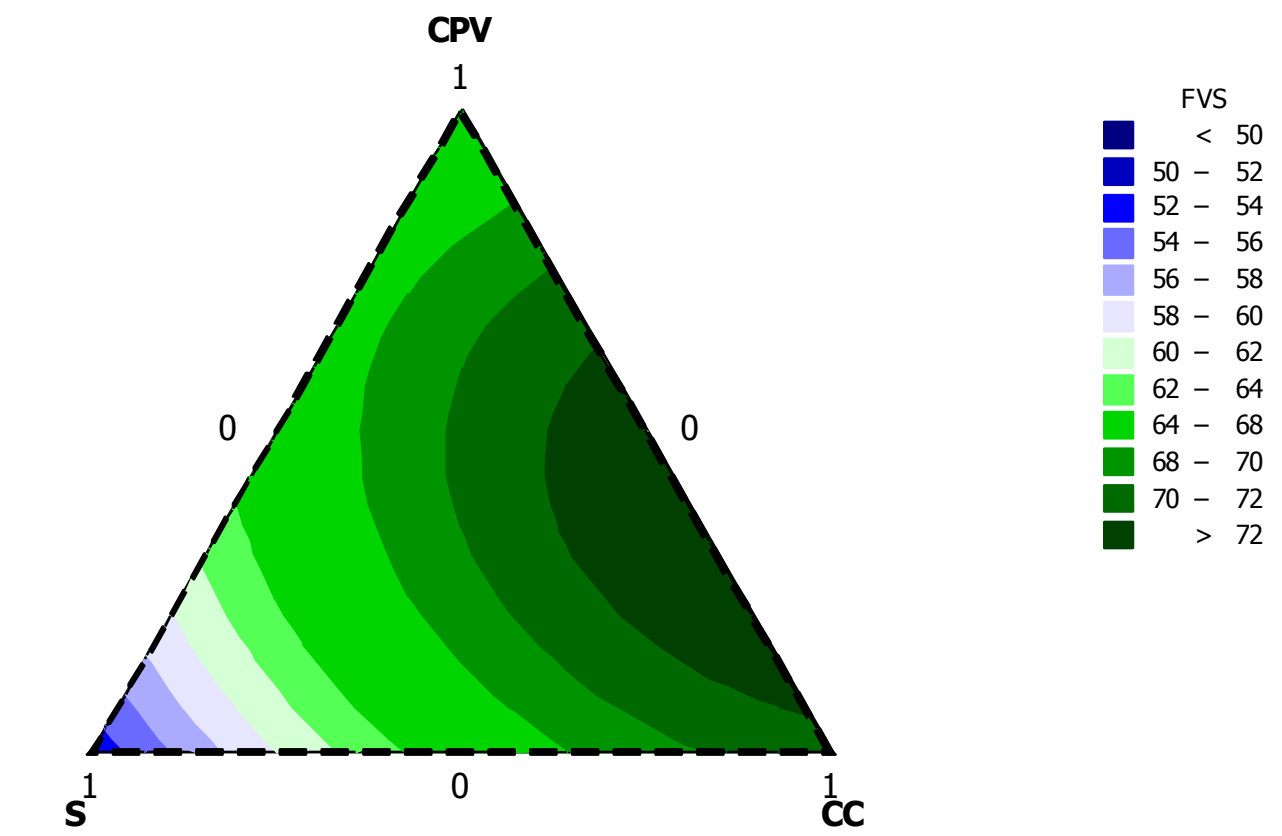

Gráfico 46 - Comportamento da FVS dos sistemas particulados

\subsection{MODELAGEM DO REFORÇO DE PLACAS}

A partir dos modelos mecânicos e físicos, elaborados na etapa I, escolheu-se a matriz com a formulação CPV33S33CC33 de desempenho mecânico na área de intervalos de 8 a $10 \mathrm{MPa}$ de MOR e com densidade aparente dentro do intervalo de 1,6 a $1,7 \mathrm{~g} / \mathrm{cm}^{3}$.

Os intervalos de teores da matriz (M), fibras de polipropileno (PP) e polpa de celulose de eucalipto $(C)$ são delimitados de acordo a intervalos com os quais é possível executar a mistura, sendo estes:

$$
\begin{aligned}
& 0,88 \leq M \leq 1,000 \\
& 0,00 \leq C \leq 0,1200 \\
& 0,00 \leq P P \leq 0,015
\end{aligned}
$$

O delineamento experimental da Tabela 30 foi realizado estrategicamente com a finalidade de determinar os coeficientes dos modelos mostrados na Tabela 32. 
Tabela 30 - Delineamento experimental para determinação dos coeficientes dos modelos para a matriz reforçada

\begin{tabular}{lccc}
\hline Compósito & $\begin{array}{c}\text { Matriz } \\
\text { (\% em massa) }\end{array}$ & $\begin{array}{c}\text { Celulose } \\
\text { (\% em massa) }\end{array}$ & $\begin{array}{c}\text { Polipropileno } \\
\text { (\% em massa) }\end{array}$ \\
\hline M88C12 & 88 & 12 & - \\
M88C10,5PP1,50 & 88 & 10,5 & 1,5 \\
M100 & 100 & - & - \\
M98,5PP1,50 & 98,5 & - & 1,5 \\
M88C11,3PP0,75 & 88 & 11,25 & 0,75 \\
M99,3PP0,75 & 99,25 & - & 0,75 \\
M94C6 & 94 & 6 & - \\
M93,3C5,3PP1,5 & 93,25 & 5,25 & 1,5 \\
M93,6C5,6PP0,75 & 93,6 & 5,6 & 0,75 \\
M90,8C8,8PP0,38 & 90,813 & 8,813 & 0,375 \\
M90,8C8PP1,11 & 90,813 & 8,0625 & 1,125 \\
M96,813C2,8PP0,375 & 96,813 & 2,8125 & 0,375 \\
M96,1C2,81PP1,125 & 96,063 & 2,8125 & 1,125 \\
\hline
\end{tabular}

\subsubsection{Modelagem das propriedades mecânicas}

As propriedades mecânicas de MOR, LOP, MOE e EE, obtidas do ensaio de tração na flexão, são modeladas utilizando o delineamento experimental apresentado na Tabela 30.

Os ajustes dos modelos linear, quadrático, cúbico e cúbico completo são apresentados na Tabela 31. 
Tabela 31 - Análise dos modelos para as propriedades mecânicas da matriz reforçada

\begin{tabular}{|c|c|c|c|c|}
\hline Modelo & MOR & LOP & MOE & EE \\
\hline \multicolumn{5}{|l|}{ Linear } \\
\hline $\mathrm{R}^{2}$ & 0,2333 & 0,2072 & 0,5086 & 0,1740 \\
\hline Adj- $R^{2}$ & 0,2129 & 0,1871 & 0,4985 & 0,1519 \\
\hline$F$ & 11,41 & 9,80 & 0,3882 & 7,90 \\
\hline \multicolumn{5}{|c|}{ Quadrático } \\
\hline $\mathrm{R}^{2}$ & 0,5229 & 0,3048 & 0,6502 & 0,4171 \\
\hline $\operatorname{Adj}-R^{2}$ & 0,4898 & 0,2566 & 0,6259 & 0,3766 \\
\hline $\mathrm{F}$ & 15,78 & 6,31 & 26,77 & 10,31 \\
\hline \multicolumn{5}{|l|}{ Cúbico } \\
\hline $\mathrm{R}^{2}$ & 0,6381 & 58,87 & 66,20 & 0,4778 \\
\hline $\operatorname{Adj}-R^{2}$ & 0,6076 & 0,5540 & 66,34 & 0,4337 \\
\hline $\mathrm{F}$ & 20,87 & 16,94 & 23,17 & 10,83 \\
\hline \multicolumn{5}{|c|}{ Cúbico completo } \\
\hline $\mathrm{R}^{2}$ & - & - & - & 0,5844 \\
\hline $\operatorname{Adj}-R^{2}$ & - & - & - & 0,5294 \\
\hline $\mathrm{F}$ & - & - & - & 10,63 \\
\hline
\end{tabular}

Adota-se $55 \%$ como satisfatório para a porcentagem do coeficiente de determinação $R^{2}$ e 95\% na significância estatística. Nessas condições, apresentamse satisfatórios o modelo cúbico para MOR, LOP e MOE e o modelo cúbico completo para EE. As equações com os respectivos coeficientes são apresentadas na Tabela 32. 
Tabela 32 - Modelos implantados para o comportamento mecânico da matriz reforçada

\begin{tabular}{|c|c|c|c|}
\hline Propriedade & Equação & Modelo & $\mathbf{R}^{2}$ \\
\hline MOR & $\begin{aligned} M O R= & 12 * \mathrm{M}+235 * \mathrm{C}+45840 * \mathrm{PP}-247 * \mathrm{M} * \mathrm{C}- \\
& 209458 * \mathrm{C} * \mathrm{PP}+177593 * \mathrm{M} * \mathrm{C} * \mathrm{PP}\end{aligned}$ & Cúbico & 0,6381 \\
\hline LOP & $\begin{aligned} L O P= & 12 * \mathrm{M}+235 * \mathrm{C}+45840 * \mathrm{PP}-247 * \mathrm{M} * \mathrm{C}- \\
& 209458 * \mathrm{C} * \mathrm{PP}+177593 * \mathrm{M} * \mathrm{C} * \mathrm{PP}\end{aligned}$ & Cúbico & 0,5887 \\
\hline MOE & $\begin{array}{c}M O E=40611274 * \mathrm{PP}+264801 * \mathrm{M} * \mathrm{C}+ \\
41880587 * \mathrm{M} * \mathrm{PP}+97575370 * \mathrm{PP} * \mathrm{C}-71676619 * \\
\mathrm{M} * \mathrm{C} * \mathrm{PP}\end{array}$ & Cúbico & 0,6620 \\
\hline EE & $\begin{array}{c}E E=0 * \mathrm{M}-4981 * \mathrm{C}+5687464 * \mathrm{PP}+7873 * \mathrm{M} * \\
\mathrm{C}-8585654 * \mathrm{M} * \mathrm{PP}-8649889 * \mathrm{C} * \mathrm{PP}+ \\
5860012 * \mathrm{M} * \mathrm{C} * \mathrm{PP}\end{array}$ & $\begin{array}{l}\text { Cúbico } \\
\text { Completo }\end{array}$ & 0,5844 \\
\hline
\end{tabular}

Os Gráficos 47, 48, 49 e 50 apresentam o comportamento das propriedades mecânicas de acordo com os respectivos modelos implantados.

O Gráfico 47 exibe o comportamento de MOR para a matriz reforçada com PP e C. Os maiores valores de MORs são alcançados com reforços de PP o qual pode ser atribuído, em parte, à elevada razão de forma do reforço de PP em relação ao reforço de $\mathrm{C}$, isso é de 231 para o $\mathrm{PP}$ e 51 para a $\mathrm{C}$.

O PP eleva a pressão de extrusão à medida que os teores são incrementados, como visto no item 4.5.4 nas pressões de extrusão, gerando compósitos submetidos à maior pressão, se extrusão comparados aos compósitos reforçados com $\mathrm{C}$.

A tendência de manter ou mesmo reduzir o MOR nas matrizes reforçadas com $C$ pode ser atribuída a quase estável pressão de extrusão mesmo com o incremento do teor de $\mathrm{C}$. Durante a extrusão a mistura ganha um adicional de água liberada pela fibra durante o processamento, a qual neutraliza, em termos de pressão de extrusão, o obstáculo ao fluxo que a fibra representa na mistura. Essa manutenção das pressões de extrusão com adição das fibras de $C$ foi constatado no estudo reológico das fibras no item 4.5.3. Além disso, a forma tubular das fibras aumenta a quantidade de defeitos nos compósitos, acarretando a queda do MOR como observado na região de predominância de fibras de C. Shao et al. (2000), em estudo realizado utilizando fibras curtas e longas, obteve resultados onde um ligeiro 
incremento de MOR foi constatado, com o aumento do conteúdo de fibras curtas de até $8 \%$ em massa.

Os maiores incrementos de MOR acontecem com reforços de PP próximos a $1,5 \%$, assim como, em combinações de reforços de PP em torno de 1,5\% e C próximo de $6 \%$.
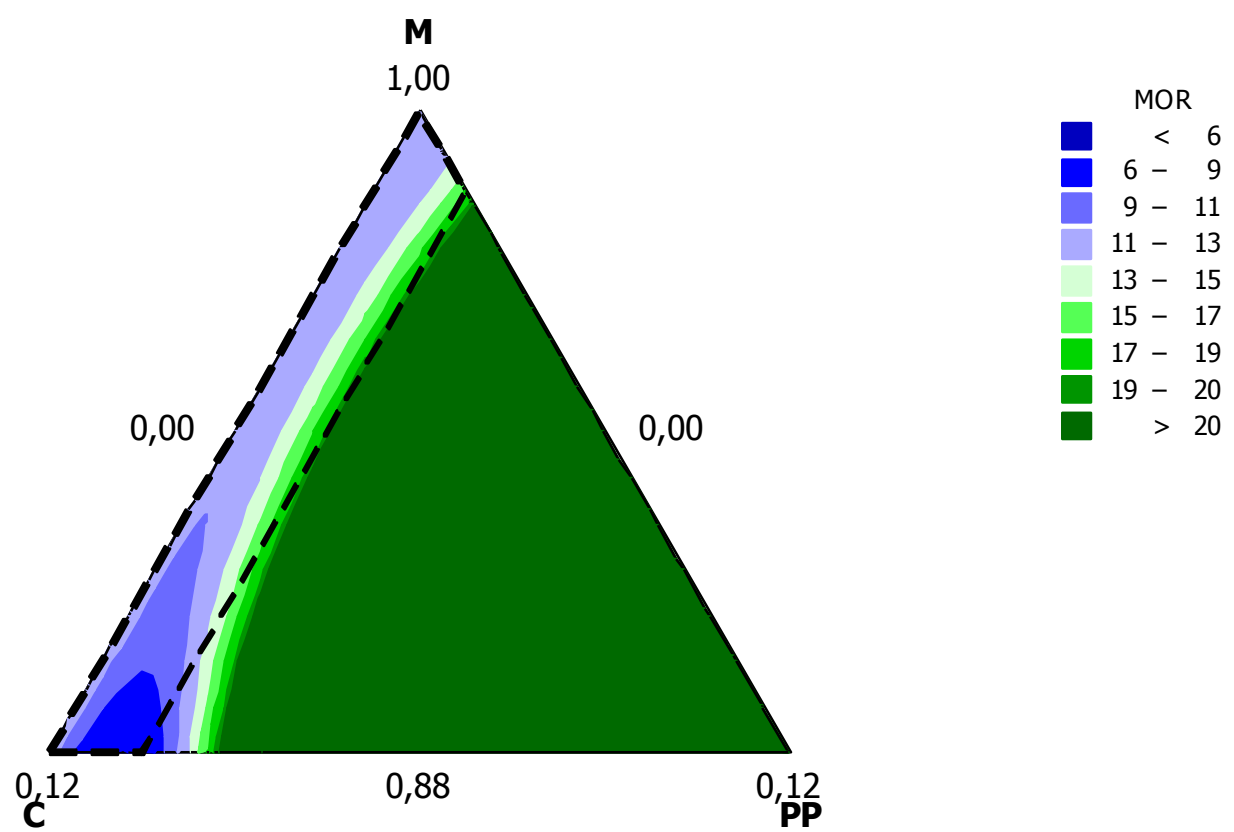

Gráfico 47 - Valores de MOR estimado com modelo cúbico para o reforço

O Gráfico 48, referente ao LOP dos compósitos reforçados, apresenta redução do valor com aumento do reforço de PP ou de C. Porém, para reforços combinados com teores de PP próximos a 1,5\% e C em torno de $6 \%$, são atingidos os maiores valores de LOP. 


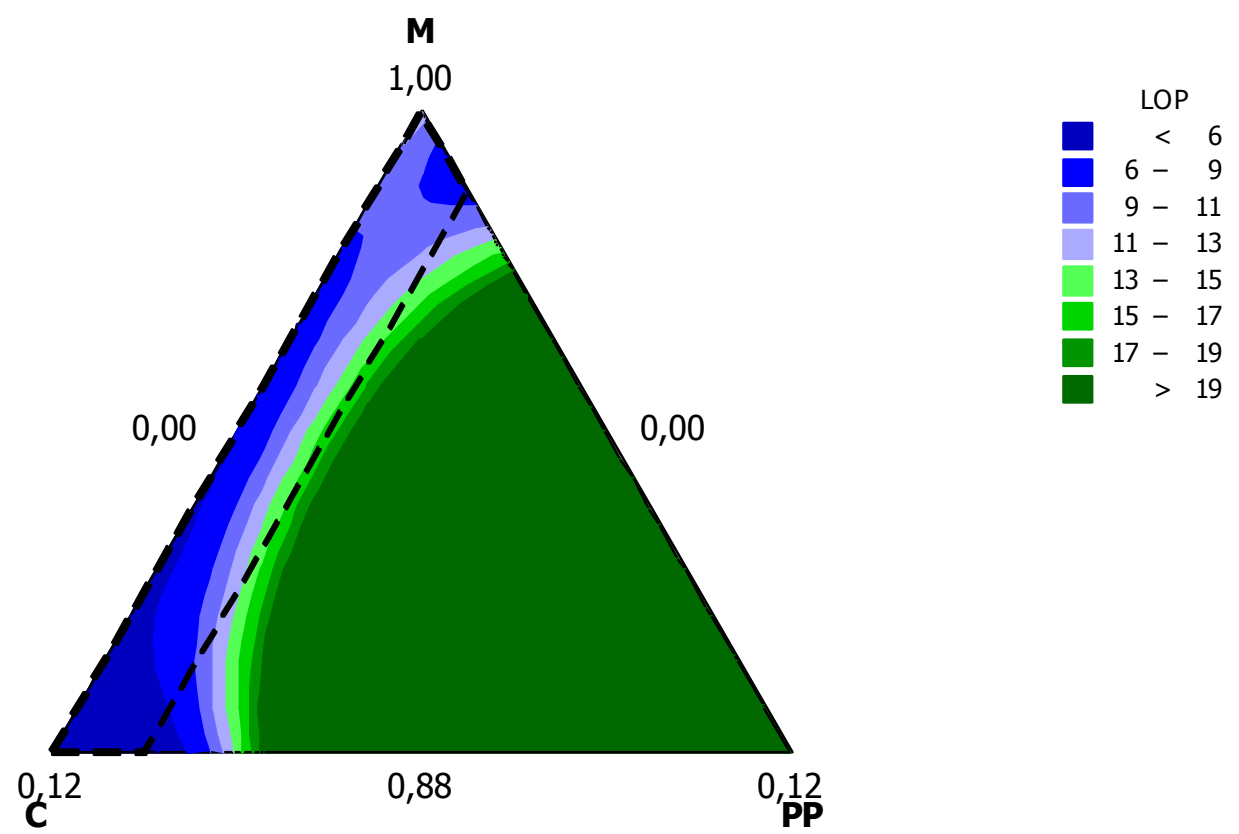

Gráfico 48 - Valores de LOP estimado com modelo cúbico para o reforço

O Gráfico 49, referente à MOE, apresenta a tendência de redução do valor com o aumento dos reforços de $\mathrm{C}$, por outro lado a região com reforços de PP próximos de 1,5\% exibem aumento nos valores. Essas tendências podem estar sendo ocasionadas pela introdução de imperfeições no compósito pelas fibras de $C$, assim como pela configuração tubular dessas fibras. A região correspondente ao incremento de MOE pode estar relacionada ao incremento da pressão de extrusão ocasionada pelas fibras de PP, por causa da razão de aspecto de 231 o que representa um obstáculo ao fluxo da mistura. 


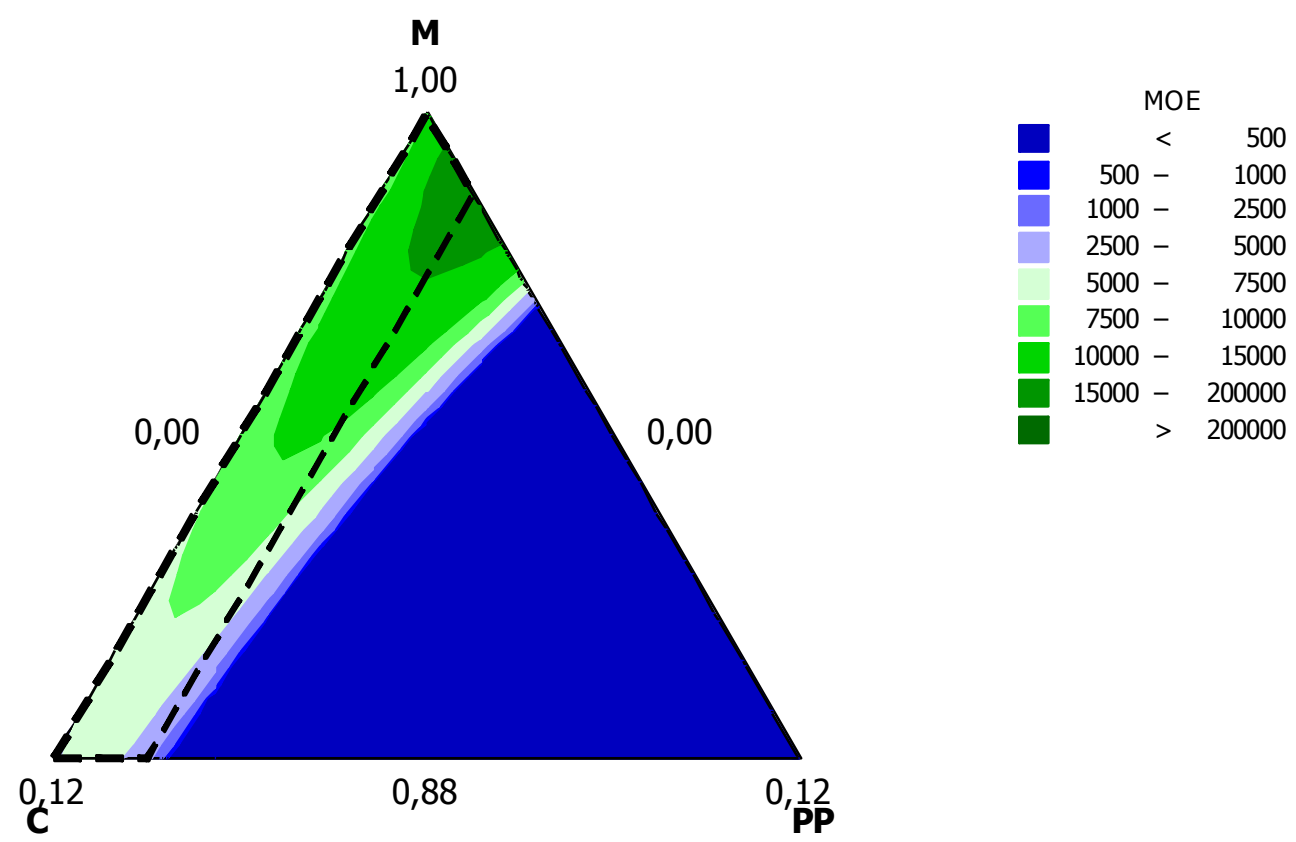

Gráfico 49 - Valores de MOE estimado com modelo cúbico para o reforço

O Gráfico 50, referente ao EE das matrizes, exibe um aumento da absorção de energia tanto com reforços de PP como com C. O aumento da absorção de energia devido ao aumento de reforço de PP é mais acentuado se comparado ao aumento do reforço de $\mathrm{C}$. $\mathrm{O}$ incremento da absorção de energia é expressivo com o aumento do reforço de $\mathrm{C}$, o que não ocorre quando o MOR é observado. Por outro lado o aumento do reforço de PP tem a capacidade de incrementar não unicamente a EE do compósito, mas também o MOR, conforme observado no Gráfico 47.
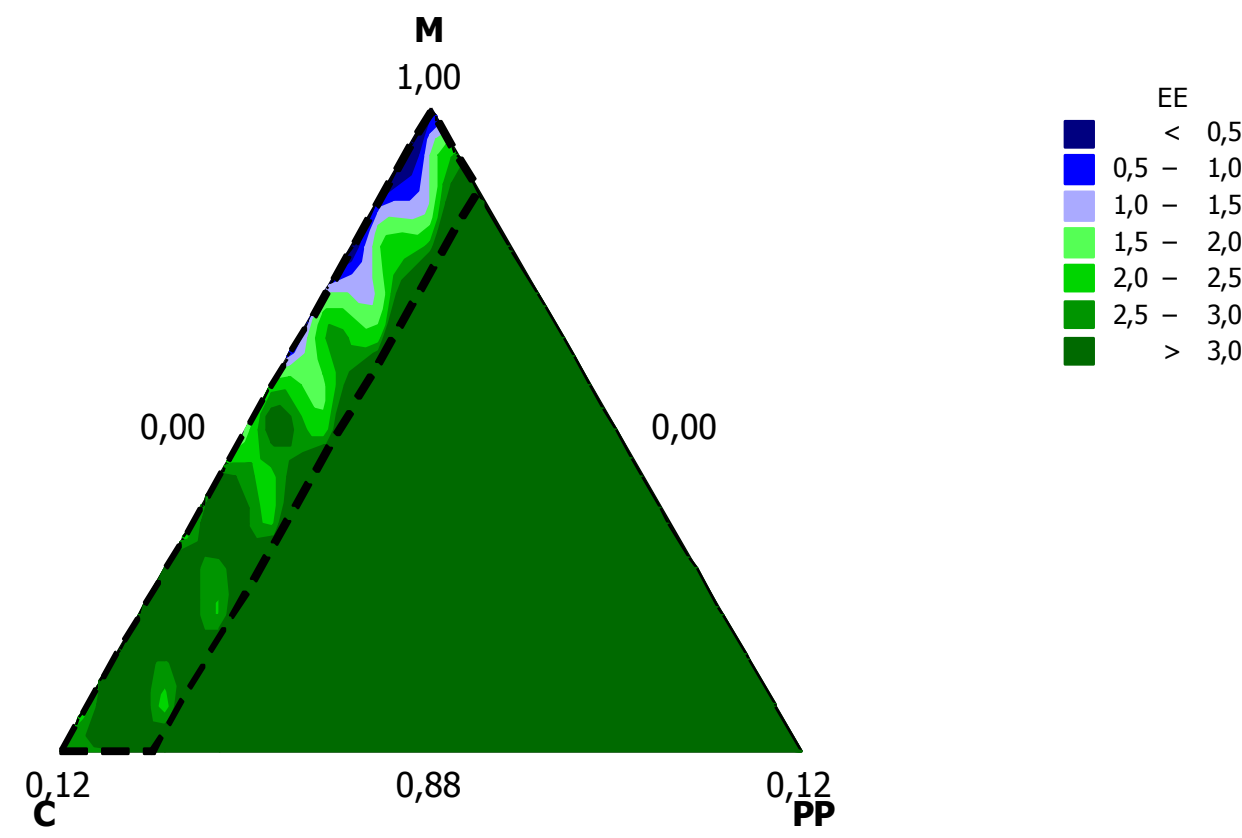

Gráfico 50 - Valores de EE estimado com modelo cúbico completo para o reforço 


\subsubsection{Modelagem das propriedades físicas}

As propriedades físicas de absorção aparente de água (AA), densidade aparente (DA) e porosidade aparente (PA) são modeladas utilizando o delineamento experimental apresentado na Tabela 30. Os ajustes dos modelos, linear e quadrático são apresentados na Tabela 33.

Tabela 33 - Análise dos modelos para as propriedades físicas da matriz reforçada

\begin{tabular}{lccc}
\hline Modelo & AA & DA & PA \\
\hline Linear & & & \\
$\mathrm{R}^{2}$ & 0,7804 & 0,7325 & 0,8694 \\
Adj- $^{2}$ & 0,7746 & 0,7254 & 0,8659 \\
F & 133,28 & 102,70 & 249,70 \\
Quadrático & & & \\
$\mathrm{R}^{2}$ & 0,8192 & 8422 & 92,48 \\
Adj- $^{2}$ & 0,8066 & 8313 & 91,96 \\
F & 65,27 & 76,88 & 177,20 \\
\hline
\end{tabular}

Adota-se 55\% como satisfatório para a porcentagem do coeficiente de determinação $\mathrm{R}^{2}$ e de $95 \%$ para a significância estatística. Nessas condições, apresentam-se satisfatórios os modelos lineares para todas as propriedades físicas. As equações com os respectivos coeficientes são apresentados na Tabela 34. 
Tabela 34 - Modelos implementados para o comportamento físico da matriz reforçada

\begin{tabular}{cccc} 
Propriedade & Equação & Modelo & $\mathbf{R}^{2}$ \\
\hline AA & $A A=11,62 * \mathrm{M}+183,21 * \mathrm{C}+181,76 * \mathrm{PP}$ & Linear & 0,7804 \\
& & & \\
DA & $D A=1,687 * \mathrm{M}-2,372 * \mathrm{C}-0,840 * \mathrm{PP}$ & Linear & 0,7325 \\
& & & \\
PA & $P A=20,8 * \mathrm{M}+184,25 * \mathrm{C}+145,24 * \mathrm{PP}$ & Linear & 0,8694 \\
& & & \\
\hline
\end{tabular}

Os Gráficos 51, 52 e 53 apresentam o comportamento das propriedades físicas da matriz reforçada de acordo com os respectivos modelos implantados.

O Gráfico 51, correspondente aos resultados de AA, mostra a tendência de aumento desses valores na direção dos compósitos reforçados por $\mathrm{C}$. Isso era de se esperar, pois as fibras de $\mathrm{C}$ apresentam configuração tubular e a capacidade de absorver água. O reforço dos compósitos com fibras de PP não exibe incremento de AA quando utilizadas sem as fibras de $C$. Isso pode ser explicado pela incapacidade de absorção de água dessas fibras poliméricas, que, por sua vez, introduzem defeitos na matriz, mas não em quantidade suficiente para induzir a um aumento na AA.

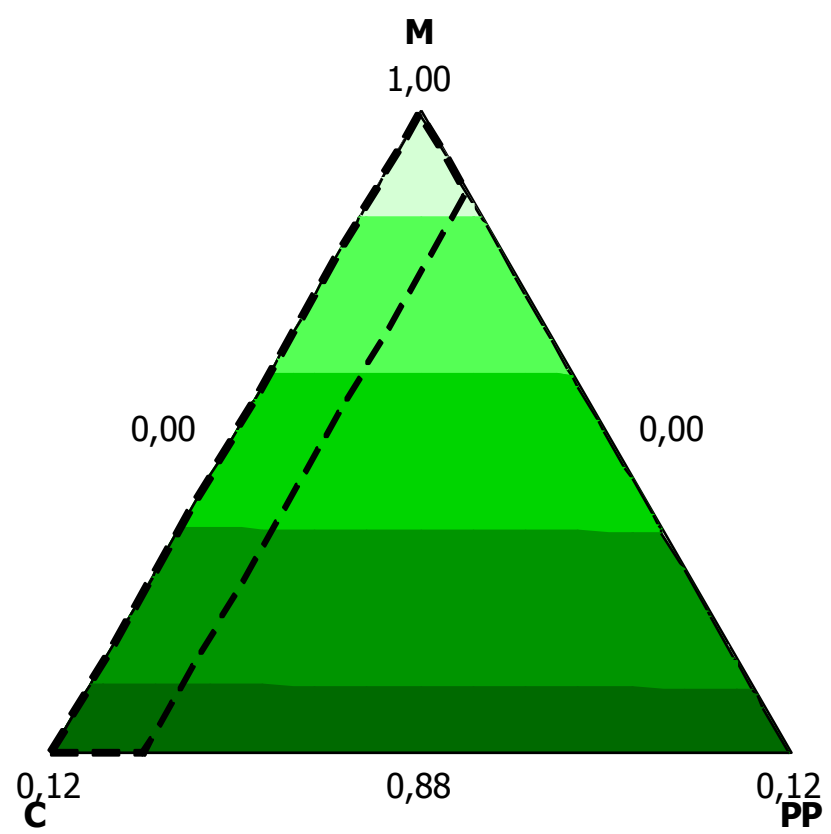


O Gráfico 52, referente à $\mathrm{PA}$, exibe tendência semelhante à $\mathrm{AA}$. Essa tendência de aumentar a PA é decorrente, em parte, do aumento do reforço de $\mathrm{C}$, o que pode ser atribuído às características próprias de configuração geométrica e absorção de água dessas fibras.

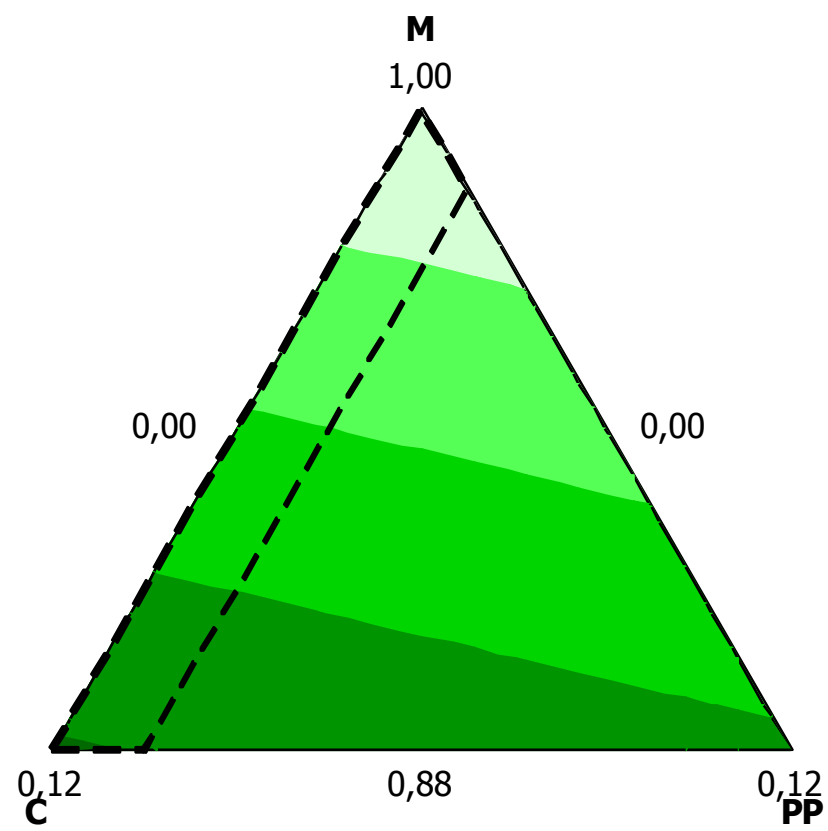

Gráfico 52 - Valores de PA estimado com modelo linear para o reforço

O Gráfico 53, referente à DA, mostra a maior densidade na região onde predomina $\mathrm{M}$. O reforço de PP na matriz, nos teores utilizados, não exibe influência nessa propriedade. Por outro lado, o aumento do reforço com $\mathrm{C}$ mostra redução na DA, o que pode ser atribuído aos mesmos fatores propostos em AA e PA. 


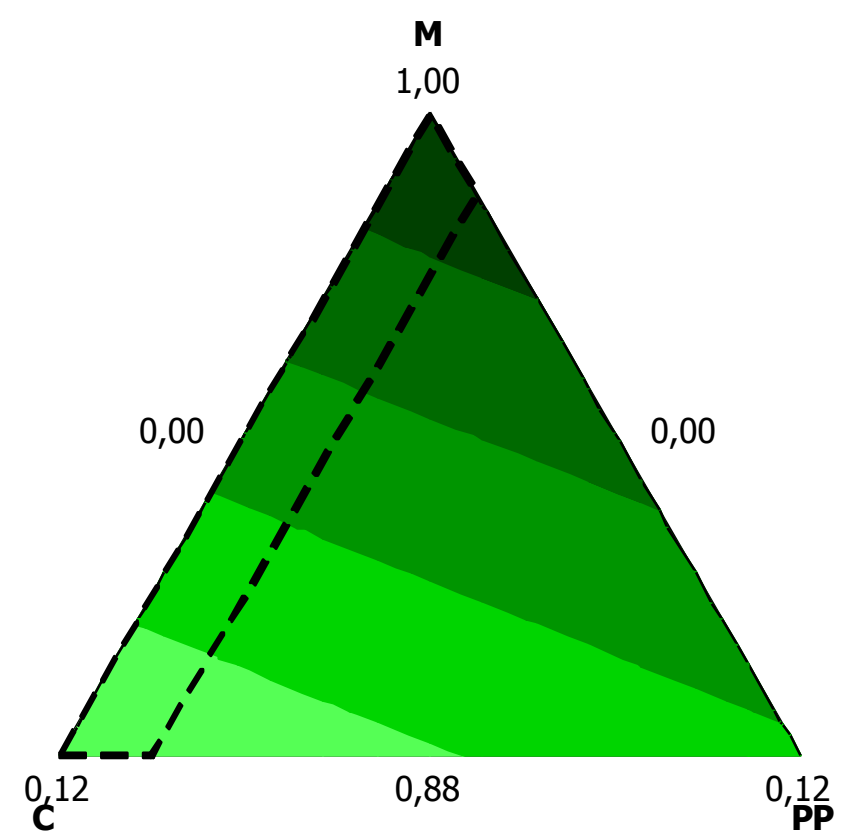

DA

\subsection{DISCUSSÃO COMPLEMENTAR}

Os modelos implantados para as propriedades mecânicas das matrizes utilizando CPV, S e CC mostram-se capazes de estimar as tendências utilizando diferentes combinações de matérias-primas. Esses modelos apresentam coeficientes de determinação inferiores quando comparados aos modelos implantados para as propriedades físicas. Isto é, variando de $R^{2}$ de 0,6556 para o EE com o modelo cúbico até $R^{2}$ de 0,9390 para o MOE com o modelo linear, enquanto os modelos das propriedades físicas variam de $R^{2}$ de 0,9687 para o DA com o modelo linear até $R^{2}$ de 0,8764 para a PA com o modelo quadrático. Isso evidencia um melhor ajuste dos modelos nas propriedades físicas do que nas mecânicas.

A metodologia utilizada para a determinação da demanda de água das matrizes cimentícias mostrou-se coerente aos materiais analisados, em respeito à água requerida para cobrir as partículas e preencher os espaços intersticiais.

Os modelos implantados para as propriedades mecânicas da matriz reforçada com PP e C são capazes de estimar a tendência do comportamento do compósito utilizando diferentes combinações de reforços. Esses modelos apresentam a mesma 
característica que os implantados na matriz, ou seja, coeficientes de determinação inferiores quando comparados aos modelos implantados para as propriedades físicas. Nesse caso variando de $R^{2}$ de 0,5887 para o $E E$ com o modelo cúbico completo até $R^{2}$ de 0,6620 para o MOE com o modelo cúbico, enquanto os modelos das propriedades físicas variam de $R^{2}$ de 0,7325 para o DA com o modelo linear até $\mathrm{R}^{2}$ de 0,8694 para a PA com o modelo linear. Apresentando também, como na matriz, um melhor ajuste dos modelos nas propriedades físicas do que nas mecânicas.

Geralmente, os modelos implantados nas matrizes apresentam maiores coeficiente de determinação, com modelos mais simples, se comparados aos modelos implantados na matriz reforçada. Isso acontece provavelmente em razão dos diferentes alinhamentos e imperfeições que a fibra assume e introduz respectivamente na matriz. 


\section{ESTUDOS COMPLEMENTARES}

As propriedades mecânicas e físicas dos compósitos nas primeiras idades podem diferir significativamente se comparadas com os compósitos envelhecidos. Essa degradação das propriedades é motivo para a sua avaliação por processos acelerados de envelhecimento como forma de anticipar o comportamento do compósito. Neste item, serão avaliadas formulações pelo envelhecimento acelerado de imersão/secagem.

A reprodutibilidade da propriedade mecânica de $M O R$, isto é o quanto os valores de MOR espalham-se ou convergem à média, é uma característica de relevante importância na produção de compósitos. As médias mecânicas e físicas são independentes da reprodutibilidade. É possível obter baixa média mecânica com elevada reprodutibilidade e elevadas médias mecânicas com baixa reprodutibilidade. Porém, baixas dispersões dos valores mecânicos e elevadas reprodutibilidade conduzirão a dimensionamentos de compósitos eficientes e de menor custo. Para poder avaliar essa reprodutibilidade o módulo de Weibull apresenta-se como ferramenta importante. A determinação dos módulos de Weibull para formulações de matriz pura e matriz reforçada, com teor de fibra considerado crítico, é realizado no presente item.

Os custos de produção de um compósito, vinculado ao processo de fabricação utilizado, são um dos aspectos de importância na competitividade no mercado. Uma avaliação aproximada de custos dos compósitos extrudados é realizada no presente item.

\subsection{ENVELHECIMENTO DE PLACAS CIMENTÍCIAS}

Foram envelhecidas placas com matriz cimenticia contendo um terço de CPV, um terço de sílica ativa e um terço de pó calcário. A matriz foi selecionada utilizando como diretriz os resultados obtidos por Morh, Biernacki e Kurtis (2007), os quais reportam que a substituição do CPV por sílica ativa, em teores de $30 \%$ ou $50 \%$ em 
massa, elimina a degradação das fibras ao envelhecimento acelerado por imersão/secagem. Adicionalmente, mencionam que com teores de $50 \%$ de sílica ativa, os compósitos sem envelhecer apresentam absorção de energia semelhante à matriz sem adição. Adições de 10\% e 30\% exibiram redução na absorção de energia de $35,4 \%$ e $27,4 \%$ respectivamente.

Neste estudo, a matriz foi estudada com reforços de celulose de eucalipto, focando no estudo de compósitos envelhecidos reforçados com celulose. De acordo com Hannant (1986) e Bentur e Mindess (2007), essas fibras apresentam maior efeito no envelhecimento desses compósitos se comparados aos compósitos reforçados com fibras sintéticas.

O envelhecimento acelerado aplicado nos corpos-de-prova foi o de ciclos de imersão e secagem, como descrito no item 3.1.5, sendo um dos mais abrangentes, pois considera o ataque alcalino, a mineralização, a densificação da zona de interface e os danos progressivos do compósito (DIAS, 2005).

As matérias-primas utilizadas têm as suas características descritas no item 3.2.

Os compósitos foram elaborados utilizando a matriz CPV33S33C33 descrita no item 6.1 reforçado com polpa de celulose de eucalipto com teores de $4 \%, 8 \%$ e $12 \%$ em massa do compósito.

Os corpos-de-prova foram produzidos segundo os procedimentos descritos no item 3.4.2, utilizando o misturador planetário de volume de $20 \mathrm{~L}$, extrusora a vácuo de rosca e o processo de cura acelerada a vapor. Cada formulação foi estudada considerando séries de pelo menos seis corpos-de-prova.

\subsubsection{Resultados do envelhecimento e discussão}

Os resultados mecânicos do envelhecimento acelerado de 200 ciclos (imersão/secagem) e sem envelhecimento da matriz $\mathrm{M}$ com reforços de 4, 8 e 12\% em massa de polpa celulose são apresentados na Tabela 35. 
Tabela 35 - Propriedades físicas e mecânicas das formulações com e sem envelhecimento

\begin{tabular}{|c|c|c|c|c|c|c|c|c|c|}
\hline Formulação & Ciclos & $\begin{array}{c}\text { MOR } \\
\text { (MPa) }\end{array}$ & DVP & $\begin{array}{l}\text { LOP } \\
\text { (MPa) }\end{array}$ & DVP & $\begin{array}{c}\text { MOE } \\
(\mathrm{MPa})\end{array}$ & DVP & $\begin{array}{c}\mathrm{EE} \\
\left(\mathbf{k J} / \mathbf{m}^{2}\right)\end{array}$ & DVP \\
\hline M96C4 & 0 & 6,97 & 0,78 & 5,21 & 0,96 & 4479 & 370 & 0,25 & 0,05 \\
\hline M96C4 & 200 & 6,98 & 0,27 & 5,16 & 0,41 & 7672 & 1077 & 0,56 & 0,10 \\
\hline M92C8 & 0 & 9,58 & 0,57 & 7,59 & 0,74 & 4253 & 289 & 0,76 & 0,07 \\
\hline M92C8 & 200 & 7,62 & 0,77 & 4,59 & 1,46 & 4449 & 872 & 1,44 & 0,22 \\
\hline M88C12 & 0 & 11,06 & 0,26 & 7,17 & 0,34 & 4049 & 279 & 2,40 & 0,42 \\
\hline M88C12 & 200 & 7,86 & 0,60 & 3,39 & 0,41 & 3217 & 344 & 2,39 & 0,25 \\
\hline
\end{tabular}

Como observado no Gráfico 54, com o aumento do teor do reforço de celulose o MOR melhora tenuemente. Por outro lado, após 200 ciclos de envelhecimento, os ganhos no MOR mostram-se nulos. Isso pode ser explicado por uma perda de aderência da fibra com a matriz ocorrida na zona de transição. Essa perda de aderência pode estar sendo promovida pela variação dimensional diferencial cíclica entre a matriz e a fibra. Essa variação dimensional submete a zona de transição a tensões, ocasionando colapso na região fraca usualmente situada a uma distância entre 10 a $40 \mu \mathrm{m}$ da interface.

Savastano, Warden e Coutts (2005) observaram enfaticamente a elevada capacidade de absorção de água das fibras, incrementando assim a relação a/c da pasta próxima à fibra, tendo como conseqüência a geração de fissuras na região próxima à interface matriz-fibra. Isso pode ser uma explicação da tênue melhora do MOR nos compósitos sem envelhecimento. Essas fissuras próximas à interface matriz-fibra são pontos de concentração de tensões para as solicitações devido à variação dimensional da matriz-fibra.

Mohr, Biernacki e Kurtis (2007) em estudo de envelhecimento por imersão/secagem de compósitos reforçados com 4\% em massa de fibras longas de pino slash, e adições de $30 \%$ e $50 \%$ em massa de sílica ativa concluem que não existe degradação da fibra nos teores de adição e reforço citados. O mesmo pode ter ocorrido no presente estudo com os resultados obtidos para os compósitos com reforço de 4\%, não sendo válido para os compósitos com reforços de $8 \%$ e 12\%. 


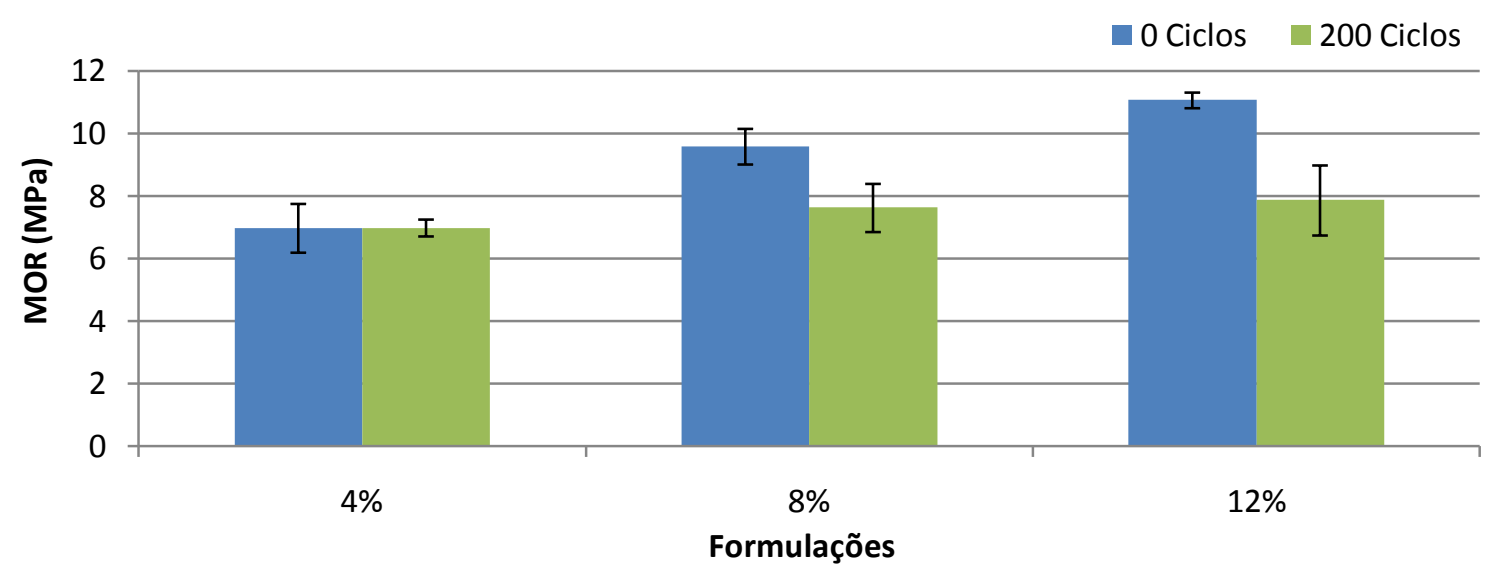

Gráfico 54 - MOR das formulações com teores de 4\%, 8\% e 12\% de polpa de celulose com e sem envelhecimento

Os valores de EE para as formulações em estudo são apresentados no Gráfico 55 onde se observa um aumento na absorção da energia à medida que o reforço é incrementado. Por outro lado, após o envelhecimento de 200 ciclos, constata-se que a EE tem a tendência de se manter ou de aumentar os desempenhos para essa propriedade. $\mathrm{O}$ fato de manter ou incrementar a EE é um indicador de que a fibra, após o envelhecimento, ainda mantém razoavelmente inalteradas as suas propriedades mecânicas. Isso se deve provavelmente ao efeito de pozolanicidade da sílica ativa, a qual foi utilizada em teores elevados, colaborando para a redução da degradação química da fibra pela alcalinidade da matriz.

A degradação da fibra em ambiente alcalino é detalhadamente descrita por Bentur e Mindess (2007) e a atividade pozolânica da S em presença do hidróxido de calcio é descrito por Neville (1997), evidenciando esses mecanismos como prováveis motivos da manutenção das propriedades mecânicas do reforço. Outro fator que promove o aumento da EE pode ser atribuído ao escorregamento das fibras pela redução da resistência da zona de transição, promovendo a transferência de tensões entre a matriz e a fibra pelo mecanismo de escorregamento friccional. 


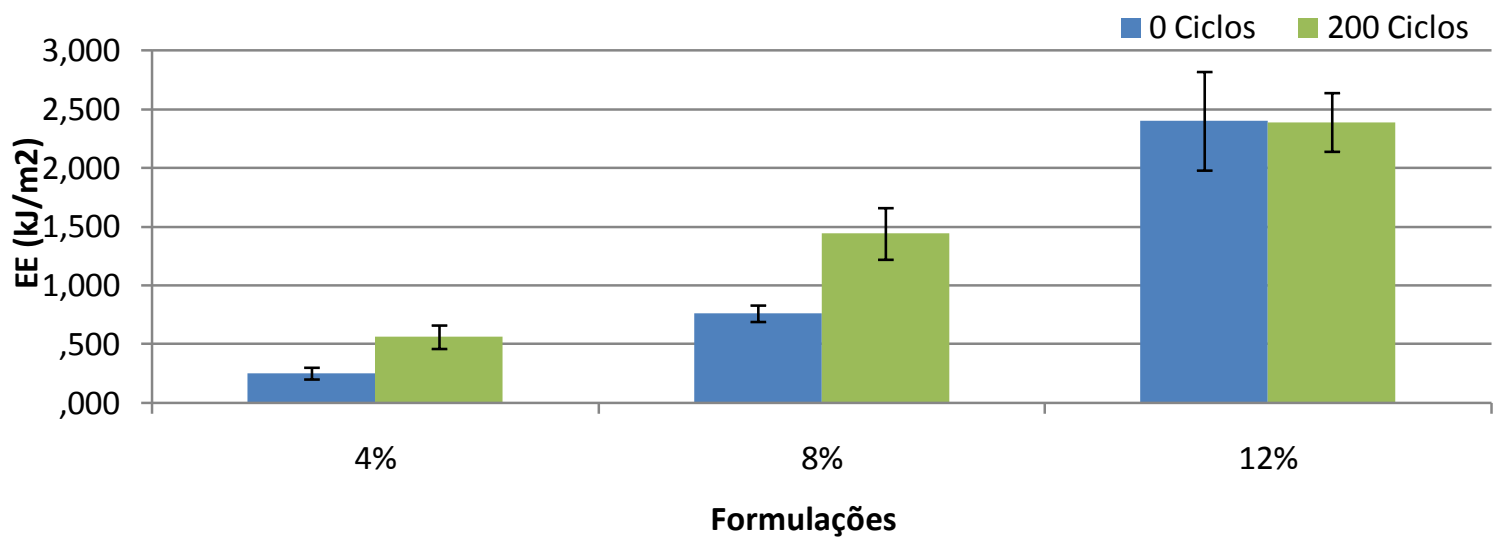

Gráfico 55 - EE das formulações com teores de 4\%, 8\% e 12\% de polpa de celulose com e sem envelhecimento

O Gráfico 56 exibe as curvas de tensão-deformação para as formulações sem envelhecimento. É possível evidenciar o incremento de até $57 \%$ no MOR dos compósitos com o acréscimo de fibras de polpa de celulose quando comparados com o compósito reforçado com $4 \%$ de celulose. Por outro lado, o incremento na EE é da ordem de $860 \%$, ficando evidente que o aporte do reforço no MOR é tênue em relação à melhora produzida na EE.

Resalta-se o aumento significativo na deformação do compósito para as melhoras das propriedades mecânicas introduzidas pelo reforço. Essa deformação pode ser observada no compósito com teor de $4 \%$ que uma flecha especifica de $0,025 \mathrm{~mm} / \mathrm{mm}$ enquanto o compósito com teor de $12 \%$ exibe flecha específica de $0,05 \mathrm{~mm} / \mathrm{mm}$.

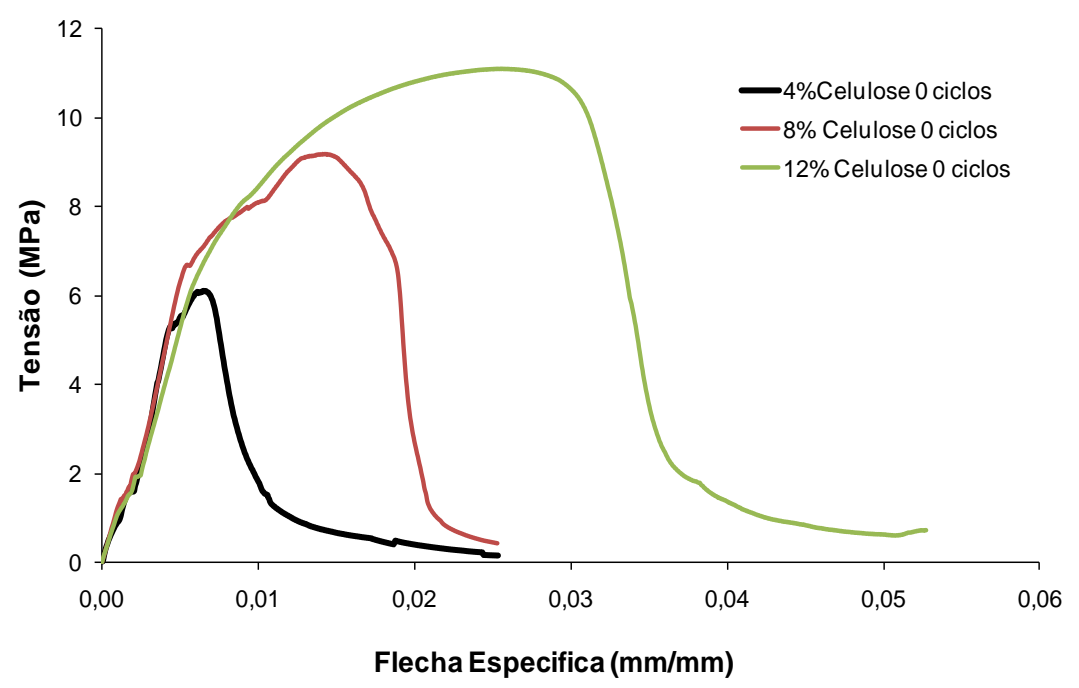

Gráfico 56 - Curvas de tensão x flecha específica das formulações sem envelhecimento 
O Gráfico 57 exibe as curvas de tensão-deformação para as formulações com envelhecimento de 200 ciclos. As melhoras introduzidas no MOR sem envelhecimento chegam a ser de no máximo de $13 \%$ após os compósitos terem sido envelhecidos. Adicionalmente, a EE obteve uma melhora em desempenho nos compósitos com teores de $4 \%$ e $8 \%$ da ordem de $124 \%$ e $90 \%$ respectivamente, quando comparado com o compósito correspondente sem envelhecer. Os compósitos com teor de $12 \%$ mantiveram a propriedade de EE praticamente inalterada.

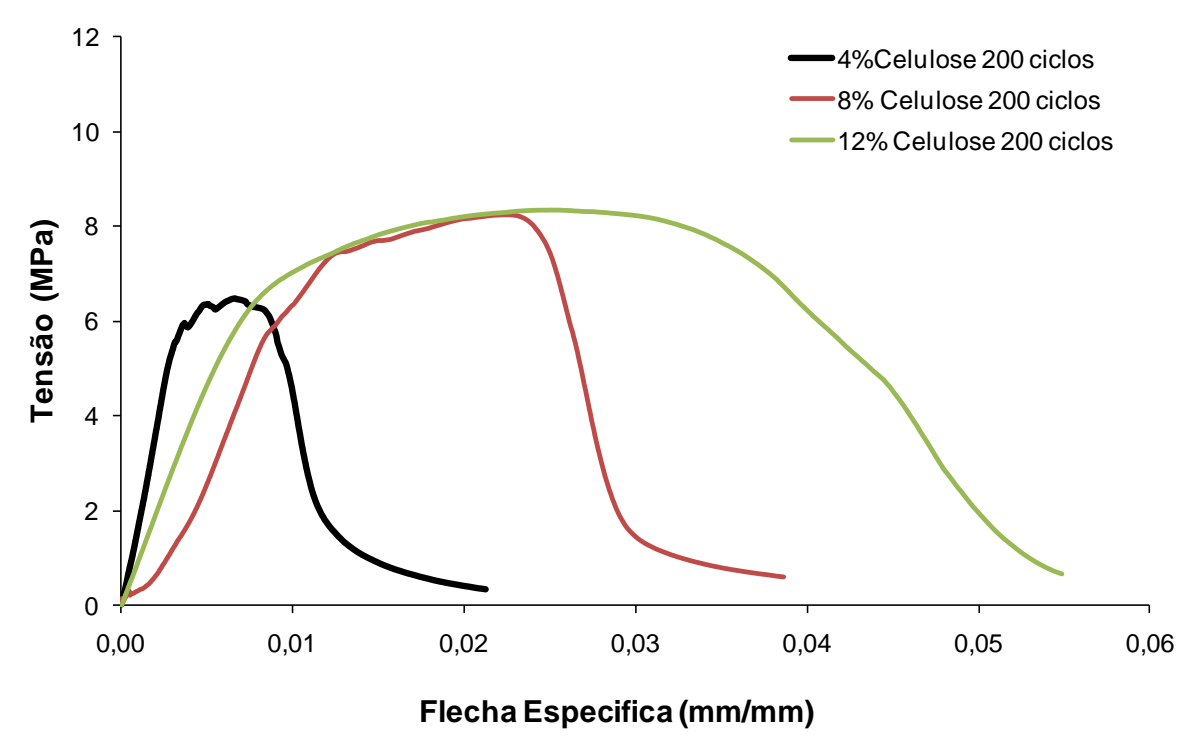

Gráfico 57 - Curvas de tensão x flecha específica das formulações com 200 ciclos de envelhecimento

O Gráfico 58, referente às curvas representativas dos compósitos reforçados com $4 \%$ de polpa de celulose, envelhecidos e sem envelhecer, exibe melhora da EE nos compósitos envelhecidos sem afetar significativamente o MOR, mantendo a deformação apresentada nos compósitos sem envelhecer. Isso pode ser atribuído ao escorregamento das fibras na matriz, durante a solicitação, sem produzir efeito significativo no MOR , devido ao baixo teor de fibras quando comparado a $8 \%$ e $12 \%$ e a progressiva reação da pozolana e do cimento remanecente sem hidratar. Essa hipótese condiz com a pesquisa realizada por Atahan, Oktar e Tasdemir (2009) onde concluem que o tempo de cura e a relação a/c afetam significativamente o grau de hidratação da pasta de cimento, podendo variar de $46 \%$ a $80 \%$ no grau de hidratação do material reativo disponível. No caso das matrizes extrudadas ao 
trabalhar-se com relações de a/c baixas, espera-se que exista material reativo disponível, o que foi constatado por Pong (2001).

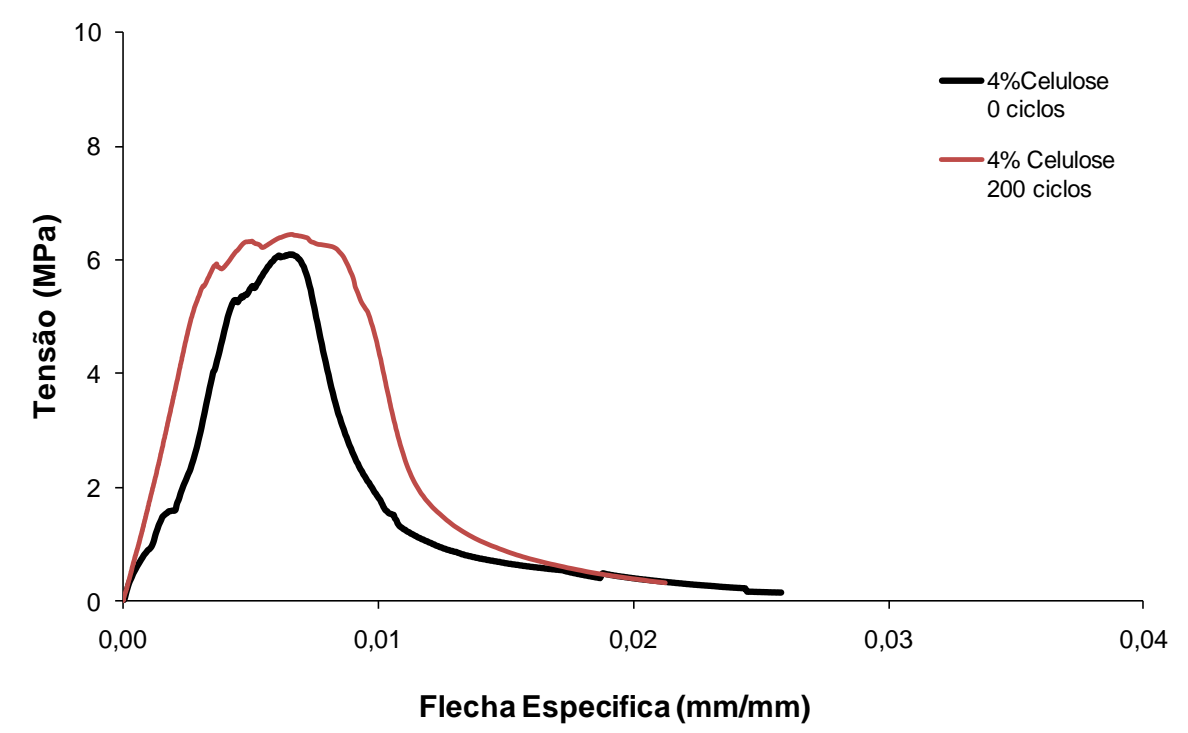

Gráfico 58 - Curvas representativas de tensão x flecha específica das formulações com 4\% de celulose com e sem envelhecimento

No Gráfico 59 é possível apreciar as curvas representativas dos compósitos reforçados com $8 \%$ de celulose antes e depois dos 200 ciclos de envelhecimento. Os compósitos envelhecidos a 200 ciclos exibem redução no desempenho de MOR da ordem de $20 \%$, porém apresentam um incremento de EE da ordem de $90 \%$. O que pode ser atribuída à transferência de esforço matriz-fibra, pelo escorregamento friccional, apresentando uma maior deformação se comparada à curva representativa do compósito sem envelhecer. 


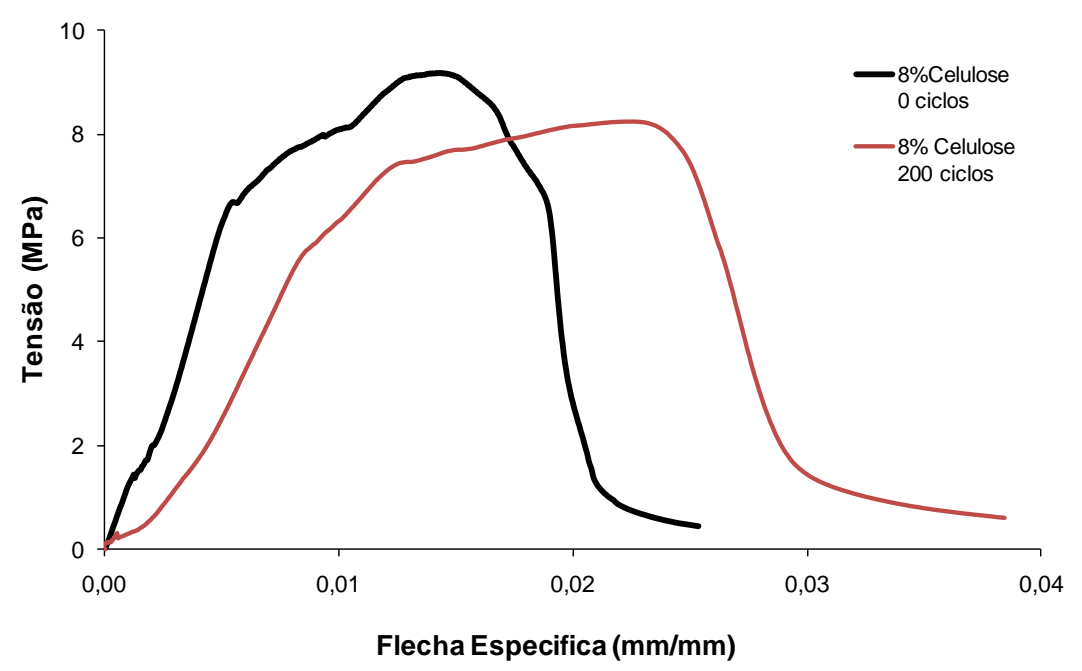

Gráfico 59 - Curvas representativas de tensão x flecha específica das formulações com $8 \%$ de celulose com e sem envelhecimento

O Gráfico 60 , referente às curvas representativas dos compósitos reforçados com $12 \%$ de polpa de celulose antes e depois dos 200 ciclos de envelhecimento, apresenta uma acentuada redução da ordem de $30 \%$ do MOR, porém com EE praticamente inalterada. A manutenção da EE não exibe maior deformação no compósito como pode ser constatado no Gráfico 54.

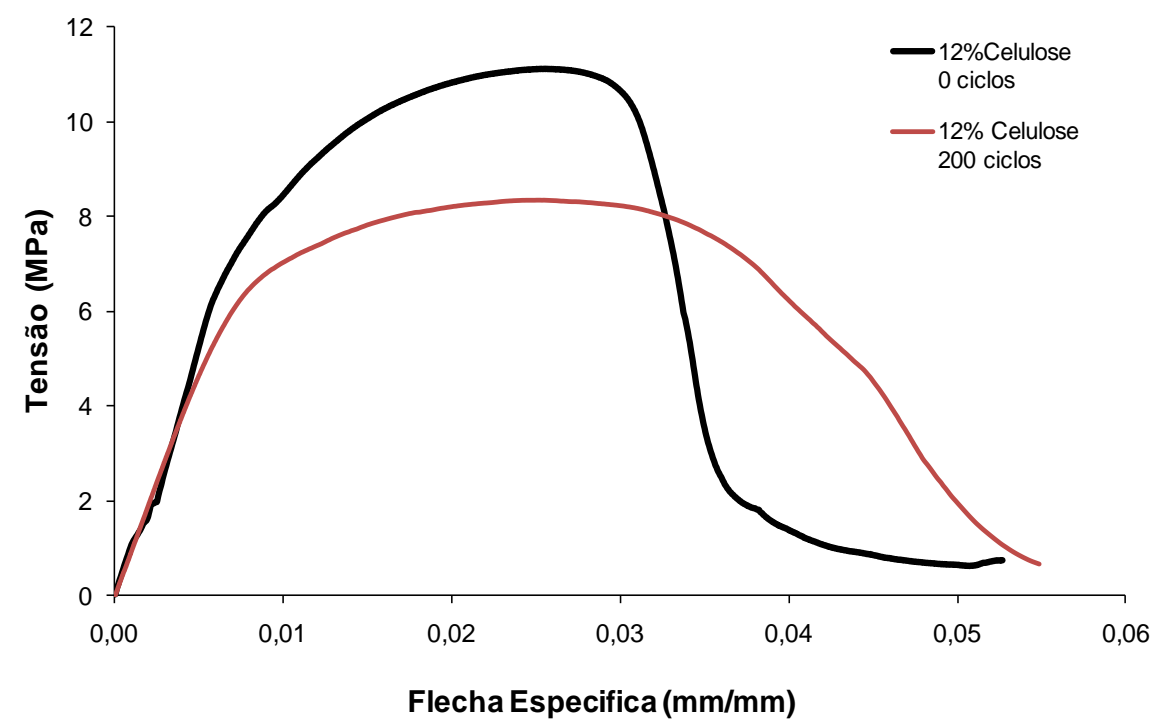

Gráfico 60 - Curvas representativas de tensão x flecha específica das formulações com $12 \%$ de celulose com e sem envelhecimento 
A Tabela 36 apresenta o desempenho físico dos compósitos, reforçados com teores de $4 \%$, $8 \%$ e $12 \%$ de polpa de celulose, antes e depois dos 200 ciclos de envelhecimento.

É possível constatar, de forma geral, uma redução da DA com o aumento do teor de polpa de celulose, assim como um aumento correspondente da AA e da PA. Esses efeitos são esperados devido às imperfeições introduzidas pelas fibras como também à capacidade de absorver água dessas fibras. Por outro lado, as fibras vegetais não são as únicas responsáveis por esses efeitos, pois os poros da matriz também contribuem para absorver água.

Tabela 36 - Propriedades físicas dos compósitos reforçados com celulose com e sem envelhecimento

\begin{tabular}{lccccccc}
\hline Formulação & Ciclos & $\begin{array}{c}\text { AA } \\
(\% \text { massa })\end{array}$ & DVP & $\begin{array}{c}\text { DA } \\
\left(\mathbf{g} / \mathrm{cm}^{3}\right)\end{array}$ & DVP & $\begin{array}{c}\text { PA } \\
(\% \text { volume })\end{array}$ & DVP \\
\hline M96C4 & 0 & 24,24 & 0,26 & 1,459 & 0,008 & 35,36 & 0,30 \\
M96C4 & 200 & 19,43 & 3,02 & 1,466 & 0,004 & 28,48 & 4,41 \\
M92C8 & 0 & 30,52 & 0,15 & 1,312 & 0,005 & 40,05 & 0,27 \\
M92C8 & 200 & 29,29 & 0,17 & 1,323 & 0,031 & 38,75 & 0,99 \\
M88C12 & 0 & 35,54 & 1,04 & 1,246 & 0,005 & 44,29 & 1,20 \\
M88C12 & 200 & 33,61 & 1,05 & 1,253 & 0,014 & 42,12 & 1,00 \\
\hline
\end{tabular}

O Gráfico 61 exibe a AA para os compósitos envelhecidos e sem envelhecer. É possivel observar que com o envelhecimento existe redução na $A A$, isso acontece provavelmente por causa da reação de hidratação continuada da pozolana e cimento Portland remanecente. A maior AA, no caso de $8 \%$ e $12 \%$ de polpa de celulose, quando comparada com $4 \%$, pode ser uma explicação para a perda do desempenho de MOR após o envelhecimento. Essa hipotese é levantada devido a provável variação dimensional da matriz, influenciada pela AA e pelo elevado teor de fibras. Isso pode estar ocasionando danos na interface matriz-fibra, promovendo a queda do desempenho de MOR, e possível escorregamento friccional matriz-fibra durante solicitação de carregamento. 


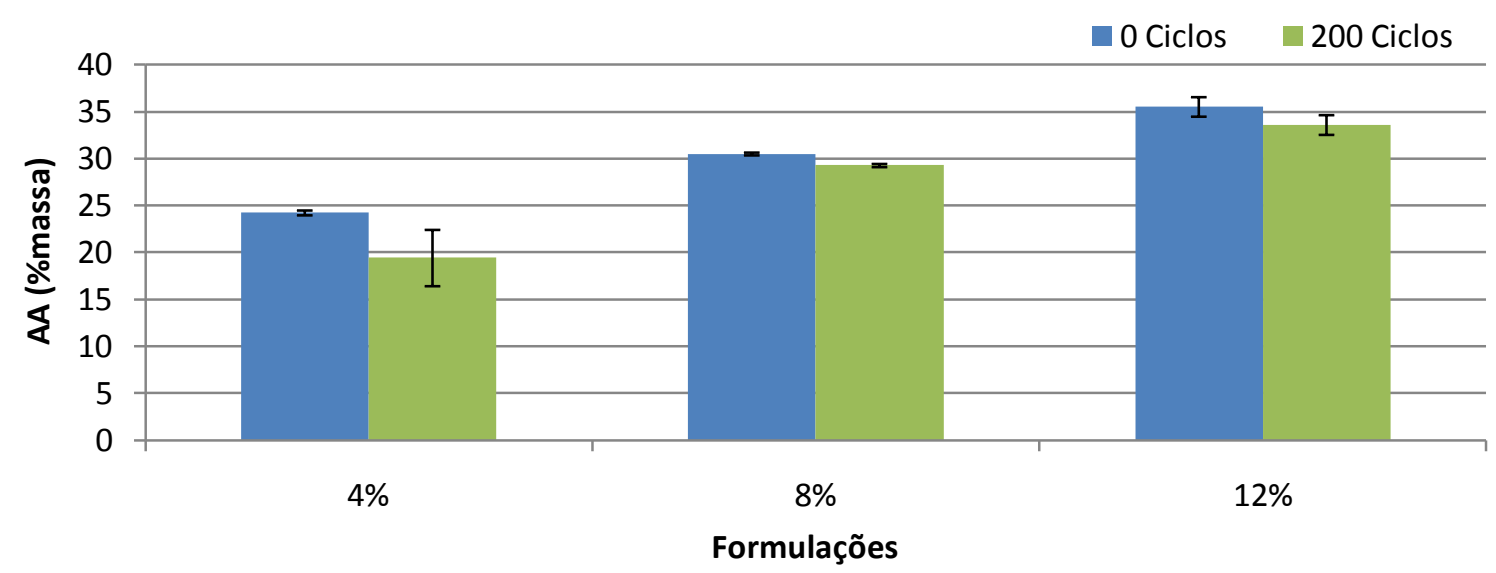

Gráfico 61 - AA das formulações com teores de 4\%, $8 \%$ e 12\% de polpa de celulose com e sem envelhecimento

O Gráfico 62 apresenta os resultados de DA para os compósitos reforçados com 4\%, 8\% e 12\% com e sem 200 ciclos de envelhecimento. É possível constatar que os compósitos envelhecidos não apresentam variação significativa quando comparados aos correlatos sem envelhecer. Por outro lado, com o incremento da polpa celulósica a DA dos compósitos tende a diminuir.

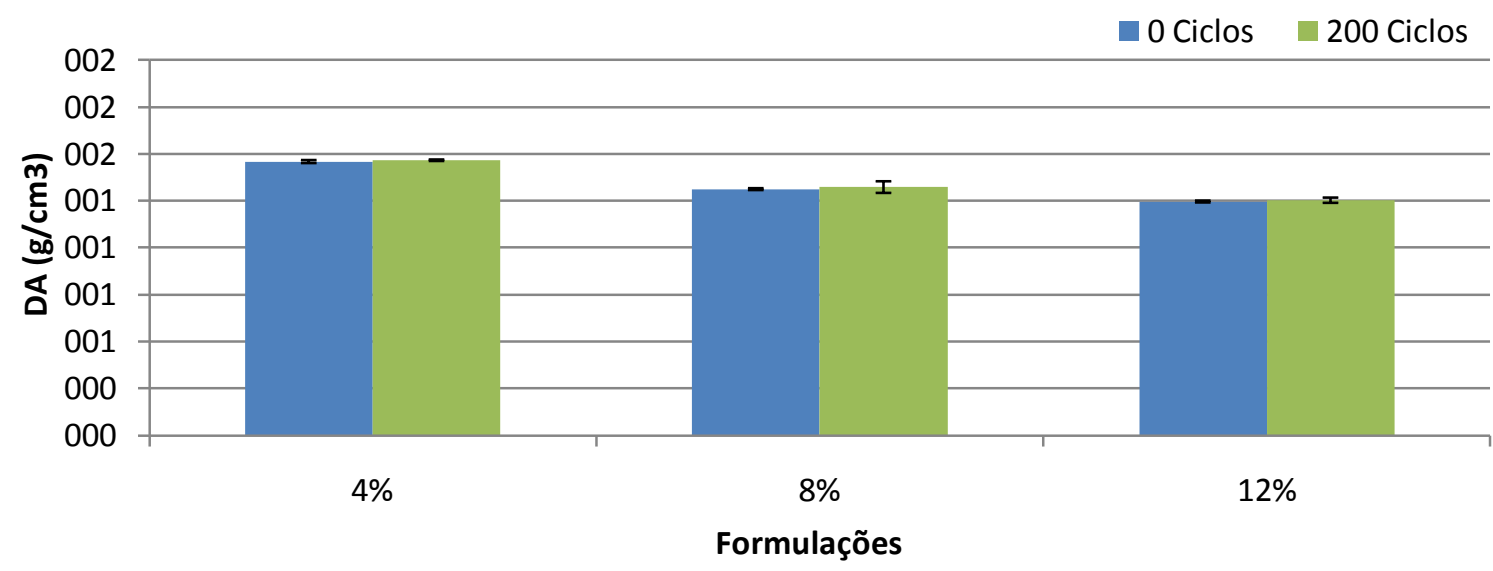

Gráfico 62 - DA das formulações com teores de 4\%, 8\% e 12\% de polpa de celulose com e sem envelhecimento 


\subsection{REPRODUTIBILIDADE DA PRODUÇÃO DE COMPÓSITOS EXTRUDADOS (MÓDULO DE WEIBULL)}

A determinação do parâmetro de Weibull $\left(m_{w}\right)$ foi realizada utilizando no mínimo 30 corpos-de-prova conforme sugerido por Zanotto e Migliore (1991), para avaliar a reprodutibilidade de produção do compósito por extrusão. As formulações selecionadas para o estudo foram a matriz sem reforço e matriz reforçada com a máxima quantidade de fibras de PP conforme Tabela 37. Foram escolhidas essas duas formulações devido à grande variação dos parâmetros reológicos, conforme apresentado no item 4.

As matérias-prima utilizadas encontram-se caracterizadas no item 3.2.

Os corpos-de-prova foram produzidos segundo os procedimentos descritos no item 3.4.2, utilizando o misturador planetário de volume de $20 \mathrm{~L}$, extrusora sem vácuo de rosca e o processo de cura acelerada a vapor. Cada formulação foi estudada considerando séries de pelo menos trinta corpos-de-prova.

Tabela 37 - Formulações utilizadas para determinar os módulos de Weibull

\begin{tabular}{lcccc}
\hline Formulação & $\begin{array}{c}\text { Cimento } \\
\text { (\%massa) }\end{array}$ & $\begin{array}{c}\text { Sílica Ativa } \\
\text { (\%massa) }\end{array}$ & $\begin{array}{c}\text { Calcário } \\
\text { (\%massa) }\end{array}$ & $\begin{array}{c}\text { Fibras (PP) } \\
\text { (\%massa) }\end{array}$ \\
\hline M100 & 33,3 & 33,3 & 33,3 & - \\
M98,5PP1,5 & 32,9 & 32,8 & 32,8 & 1,5 \\
\hline
\end{tabular}

O coeficiente $m_{w}$ é adimensional e fornece uma avaliação de homogeneidade do material e, conseqüentemente, da dispersão de seus valores de resistência e de sua confiabilidade. Assim, quanto maior $0 m_{w}$, maior é a confiabilidade do compósito, pois a dispersão dos módulos de ruptura medidos é menor

Os valores de $m_{w}$ determinados para as formulações de M100 e M98,5PP1,5 foram 10,3 e 9,6 respectivamente, conforme pode ser observado nos Gráficos 63 e 64. $O R^{2}$ determinado para a formulação $M 100$ foi de 0,95 e para a formulação M98,5PP1,5 de 0,79 evidenciando o maior afastamento da linearidade dos valores de MOR. Esse maior afastamento pode estar sendo promovido pela razão de aspecto dos reforços de fibras de PP que são um obstáculo ao fluxo da pasta e introdutores de defeitos no compósito. 


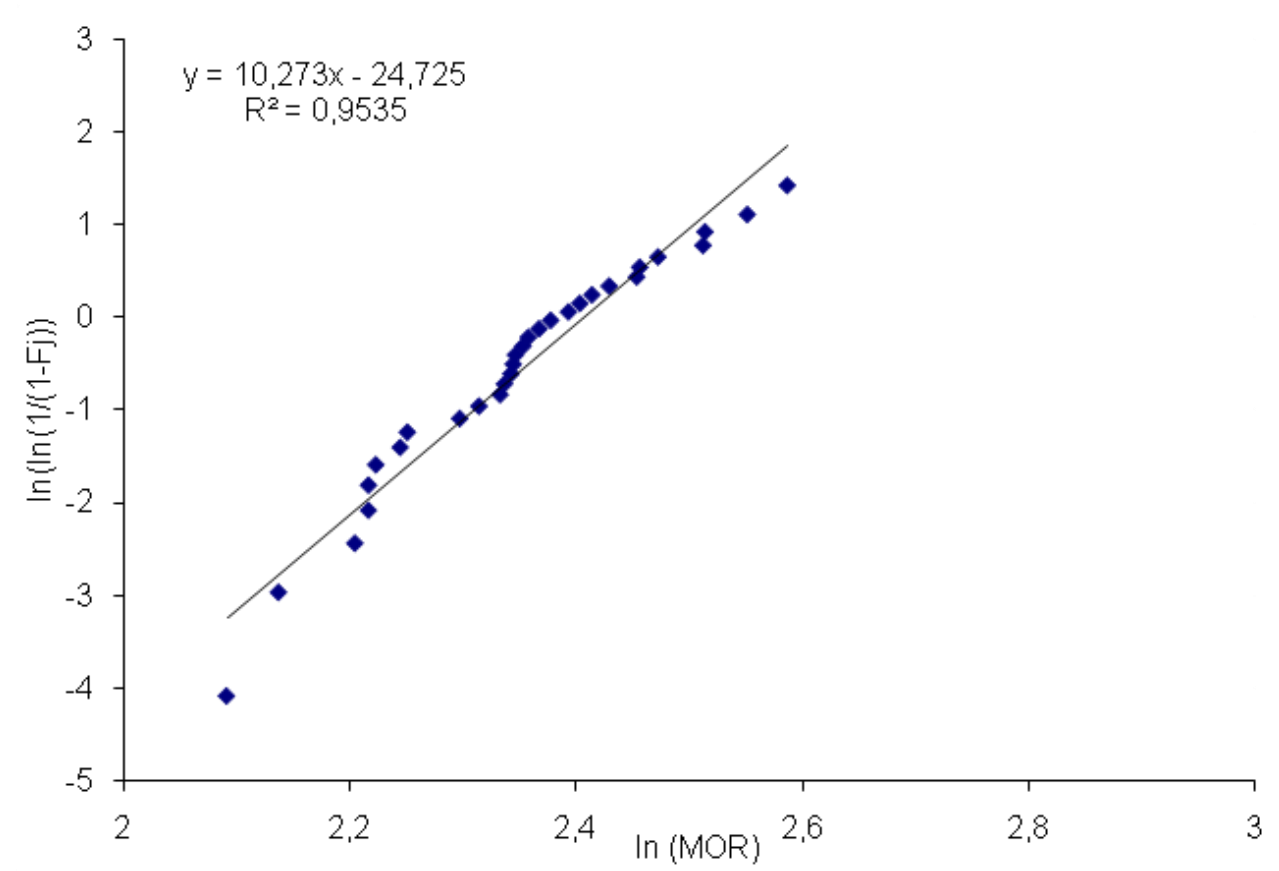

Gráfico 63 - Linearização dos valores de MOR da formulação da matriz sem reforço para determinação do módulo de Weibull

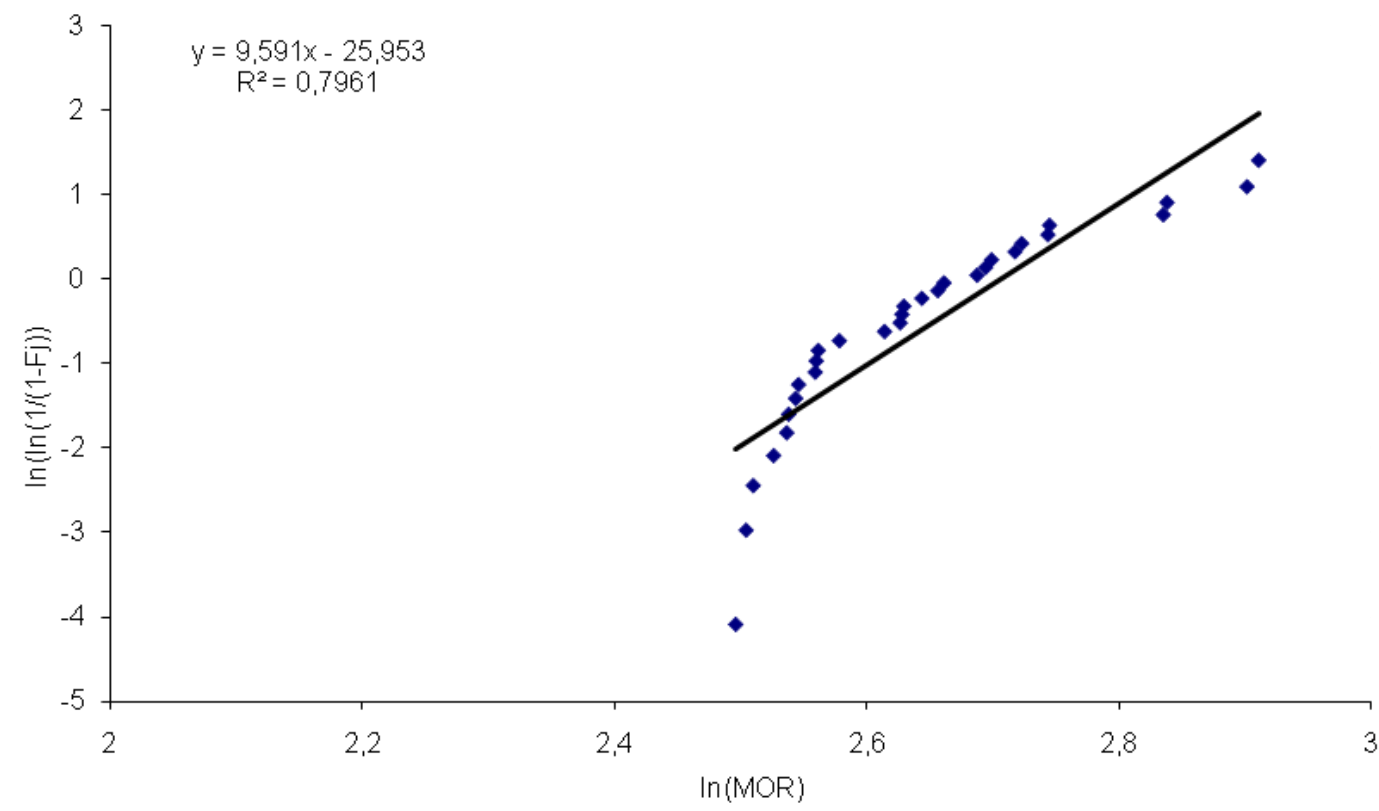

Gráfico 64 - Linearização dos valores de MOR da formulação da matriz com reforço para determinação do módulo de Weibull

A matriz apresenta uma reprodutibilidade ou confiabilidade maior quando comparada com a matriz com reforço de PP. Esse resultado é coerente com a tendência do módulo de Weibull encontrado por Toutanji et al. (1994) em compósitos reforçados com fibras de carbono testados na flexão, adicionalmente eles constatam 
que $0 m_{w}$ é maior quando testados na tração e menor na flexão para uma mesma formulação.

As fibras de PP, conforme visto no item 4.5.4, aumentam a pressão de extrusão da matriz pura, devido provalvemente ao fato de serem um obstáculo ao fluxo da pasta, promovendo durante o fluxo o alinhamento das fibras na direção da extrusão. O alinhamento na direção de extrusão foi constatado por Shao, Qiu e Shah (2001) em estudo realizado em diversos compósitos reforçados com fibras polimericas. Outra contribuição para a redução do $m_{w}$ pode ser atribuída ao aumento da população de imperfeições introduzidas pelas fibras de PP, uma vez que elas apresentam razão de aspecto elevada da ordem de 231, podendo significar um distúrbio no empacotamento das partículas. Outro aspecto que pode influenciar a reprodutibilidade é o grau de alinhamento na direção da extrusão atingida pelas fibras.

\subsection{CUSTOS DA PRODUÇÃO DE COMPÓSITOS EXTRUDADOS}

Os custos das matérias-primas utilizadas na elaboração da matriz e do reforço são apresentados na Tabela 38. Os valores apresentados foram levantados no estado de São Paulo no período de maio a julho de 2010. Os valores considerados como custos dos compósitos correspondem unicamente às matériasprimas e aditivos utilizados, desconsiderando a incidência no custo dos equipamentos utilizados e da mão-de-obra. Adicionalmente foi determinado o custo normalizado em relação do MOR dos compósitos. 
Tabela 38 - Custo unitário das matérias-primas

\begin{tabular}{lcc}
\hline Matéria-prima & Unidade & Custo (R\$) \\
\hline CPV ARI & $\mathrm{kg}$ & 0,50 \\
Calcário & $\mathrm{kg}$ & 0,05 \\
Sílica ativa & $\mathrm{kg}$ & 1,20 \\
Celulose de eucalipto & $\mathrm{kg}$ & 1,44 \\
Fibras de PP 6mm & $\mathrm{kg}$ & 7,00 \\
Superplastificante (poliéter carboxílico) & $\mathrm{kg}$ & 12,00 \\
Modificador reológico (HPMC) & $\mathrm{kg}$ & 45,00 \\
Água potável & $\mathrm{m}^{3}$ & 9,34 \\
\hline
\end{tabular}

Os compósitos elaborados unicamente com calcário ou sílica ativa como matriz, não são viáveis do ponto de vista de propriedades mecânicas. Essa consideração foi realizada na modelagem das matrizes com o intuito de determinar as diferentes variedades de comportamentos dos compósitos gerados, tanto em termos de custo como no aspecto de propriedades mecânicas e físicas. As formulações apresentadas na Tabela 39 correspondem ao delineamento experimental para a determinação dos coeficientes do modelo de custo da matriz.

Tabela 39 - Custos das formulações da matriz para a determinação dos coeficientes do modelo para uma tonelada de compósito

\begin{tabular}{|c|c|c|c|c|c|c|c|c|}
\hline Formulação & $\begin{array}{l}\text { CPV } \\
\text { (R\$) }\end{array}$ & $\begin{array}{l}\text { Sílica } \\
\text { ativa } \\
\text { (R\$) }\end{array}$ & $\begin{array}{c}\text { Calcário } \\
(\mathrm{R} \$)\end{array}$ & $\begin{array}{l}\text { Dispersante } \\
\quad(\mathrm{R} \$)\end{array}$ & $\begin{array}{l}\text { Modif. } \\
\text { Reológico } \\
\text { (R\$) }\end{array}$ & $\begin{array}{l}\text { Água } \\
\text { (R\$) }\end{array}$ & $\begin{array}{l}\text { Total } \\
(\mathrm{R} \$ / \mathrm{t})\end{array}$ & $\begin{array}{c}\text { Custo } \\
\text { Normalizado } \\
\text { (R\$/t.MPa) }\end{array}$ \\
\hline CPV100 & 500,00 & 0,00 & 0,00 & 240,00 & 900,00 & 1,70 & $1.641,60$ & 145,92 \\
\hline S100 & 0,00 & $2.341,00$ & 0,00 & 240,00 & 900,00 & 3,20 & $2.341,70$ & 2855,73 \\
\hline C100 & 0,00 & 0,00 & 50,00 & 240,00 & 900,00 & 1,50 & $1.191,50$ & 916,54 \\
\hline CPV50S50 & 250,00 & 600,00 & 0,00 & 240,00 & 900,00 & 1,90 & $1.991,90$ & 355,70 \\
\hline S50C50 & 0,00 & 600,00 & 25,00 & 240,00 & 900,00 & 1,90 & $1.766,80$ & 2637,01 \\
\hline CPV50C50 & 250,00 & 0,00 & 25,00 & 240,00 & 900,00 & 1,10 & $1.416,70$ & 161,36 \\
\hline CPV33S33СC33 & 166,50 & 399,60 & 16,70 & 240,00 & 900,00 & 1,60 & $1.724,30$ & 146,50 \\
\hline CPV66S16CC16 & 333,40 & 200,00 & 8,30 & 240,00 & 900,00 & 1,60 & $1.683,40$ & 194,39 \\
\hline CPV16S66CC16 & 83,35 & 801,10 & 8,30 & 240,00 & 900,00 & 2,10 & $2.034,90$ & 328,74 \\
\hline CPV16S16CC66 & 83,35 & 200,00 & 33,40 & 240,00 & 900,00 & 2,10 & $1.458,80$ & 181,44 \\
\hline
\end{tabular}


A Tabela 40 apresenta o modelo implantado para os custos das matrizes com composição de CPV, S e CC.

Tabela 40 - Modelo quadrático aplicado ao custo da matriz

\begin{tabular}{cccc}
\hline Propriedade & Equação & Modelo & $\mathbf{R}^{2}$ \\
\hline Custo & $\begin{array}{c}\text { Custo }=1618 * \mathrm{CPV}+2373 * \mathrm{~S}+1190 * \mathrm{CC}-82 * \\
\mathrm{CPV} * \mathrm{~S}+1254 * \mathrm{CPV} * \mathrm{CC}-1037 * \mathrm{~S} * \mathrm{CC}\end{array}$ & Quadrático & 0,9803 \\
\hline
\end{tabular}

O Gráfico 65 apresenta a variação das matrizes de acordo com o modelo quadrático. Os valores dos aditivos, modificador reológico e dispersante, correspondem de $54 \%$ a $95 \%$ do valor total da matriz. Esse valor comparado com o valor comercial do fibrocimento, praticado no estado de São Paulo entre maio e julho de 2010 foi de 600 a $700 \mathrm{R} \$ / \mathrm{t}$, o que significa um valor muito elevado, onde unicamente os preços dos aditivos superam amplamente o preço do fibrocimento comercial elevando os custos de processabilidade, ressalta-se que essa comparação de custos não foi realizada em condições semelhantes de produção nem contempla todos os custos envolvidos,. O valor das matérias-primas representam de 5 a $46 \%$ do custo da matriz evidenciando que o custo é inferior ao dos aditivos dentro da composição de preços da matriz.
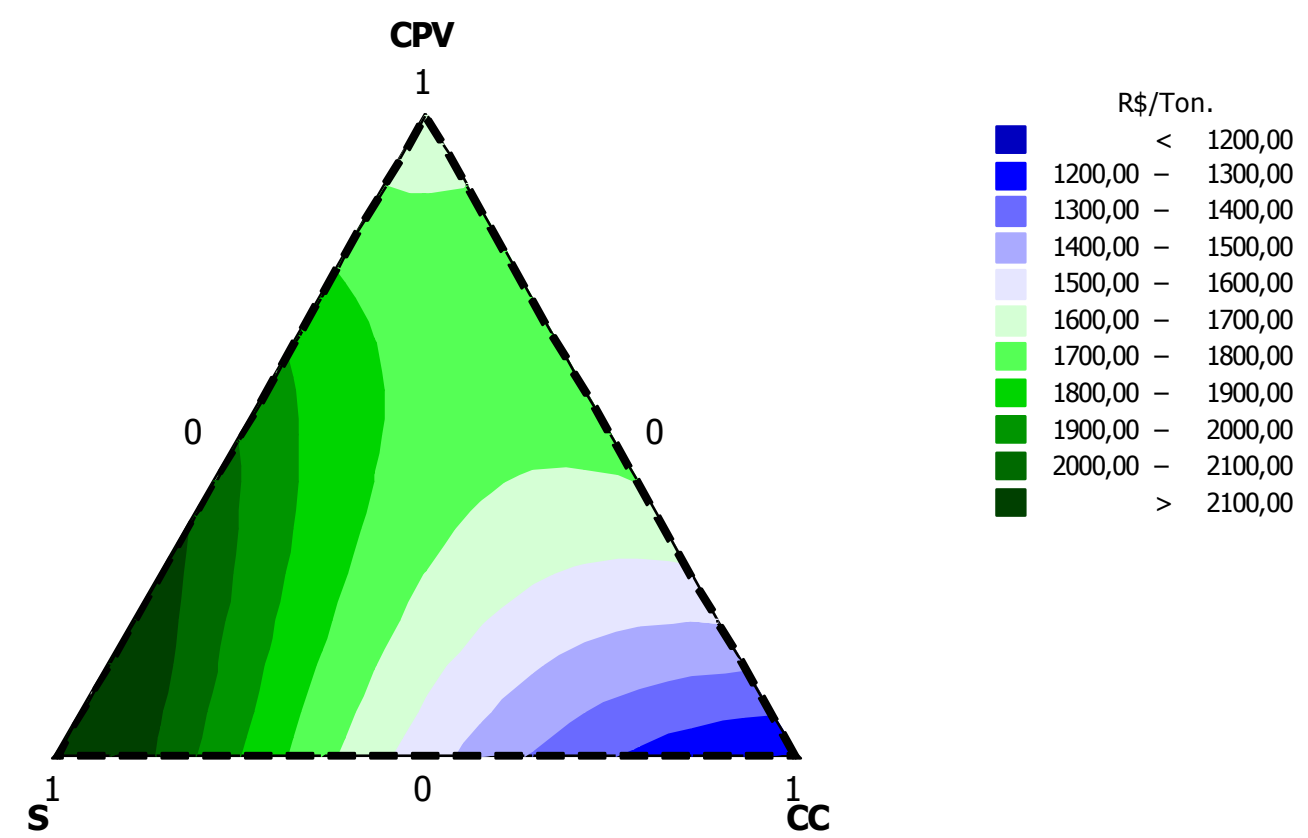

Gráfico 65 - Variação do custo da matriz com combinações de CPV, S e CC 
Selecionando a matriz com componentes de $33,33 \%$ de CPV, $33,33 \%$ de $\mathrm{S}$ e $33,33 \%$ de CC é avaliada a variação do custo do compósito devido à incidência das fibras de C e PP.

Tabela 41 - Custos das formulações reforçadas para a determinação dos coeficientes do modelo

\begin{tabular}{lccccc}
\hline Formulação & $\begin{array}{c}\text { Matriz } \\
\mathbf{( R \$ )}\end{array}$ & $\begin{array}{c}\text { Celulose } \\
\mathbf{( R \$ )}\end{array}$ & $\begin{array}{c}\text { Polipropileno } \\
\mathbf{( R \$ )}\end{array}$ & $\begin{array}{c}\text { Total } \\
\mathbf{( R \$} / \mathbf{t})\end{array}$ & $\begin{array}{c}\text { Custo } \\
\text { Normalizado } \\
\mathbf{( R \$ / t . M P a )}\end{array}$ \\
\hline M88C12 & $1.517,50$ & 172,80 & 0,00 & $1.690,30$ & 133,30 \\
M88C10,5PP1,50 & $1.517,50$ & 151,20 & 105,00 & $1.773,60$ & 204,33 \\
M100 & $1.724,40$ & 0,00 & 0,00 & $1.724,40$ & 146,51 \\
M98,5PP1,50 & $1.698,50$ & 0,00 & 0,00 & $1.803,50$ & 113,50 \\
M88C11,3PP0,75 & $1.517,50$ & 162,70 & 52,50 & $1.732,60$ & 278,55 \\
M99,3PP0,75 & $1.712,30$ & 0,00 & 52,50 & $1.764,80$ & 150,84 \\
M94C6 & $1.620,90$ & 86,40 & 0,00 & $1.707,30$ & 167,55 \\
M93,3C5,3PP1,5 & $1.608,80$ & 76,30 & 105,00 & $1.790,20$ & 93,48 \\
M93,6C5,6PP0,75 & $1.614,00$ & 80,60 & 52,50 & $1.747,20$ & 115,48 \\
M90,8C8,8PP0,38 & $1.565,70$ & 126,70 & 26,60 & $1.719,10$ & 142,07 \\
M90,8C8PP1,11 & $1.565,70$ & 115,20 & 77,70 & $1.758,60$ & 325,06 \\
\hline M96,813C2,8PP0,375 & $1.669,40$ & 40,30 & 26,00 & $1.736,00$ & 158,83 \\
M96,1C2,81PP1,125 & $1.657,10$ & 40,30 & 78,80 & $1.705,30$ & 92,68 \\
\hline
\end{tabular}

A Tabela 42 apresenta o modelo quadrático ajustado ao custo dos compósitos reforçados com fibras de $\mathrm{C}$ e $\mathrm{PP}$.

Tabela 42 - Modelo quadrático aplicado ao custo do reforço

\begin{tabular}{cccc}
\hline Propriedade & Equação & Modelo & $\mathbf{R}^{\mathbf{2}}$ \\
& & \\
\hline Custo & Custo $=1730 * \mathrm{M}+3353 * \mathrm{C}+138517 * \mathrm{PP}-2157 *$ & \multirow{2}{*}{ Quadrático } & 0,7239 \\
& $\mathrm{M} * \mathrm{C}-134780 * \mathrm{M} * \mathrm{PP}-124371 * \mathrm{C} * \mathrm{PP}$ & & \\
\hline
\end{tabular}

O Gráfico 66 apresenta a variação do custo da matriz reforçada com PP e C. É possível observar duas tendências bem definidas, a primeira referente ao 
decréscimo de até $2 \%$ no custo do compósito quando adicionado predominantemente $\mathrm{C}$ até o teor de $12 \%$, por outro lado o incremento de reforços predominantemente de PP, aumenta o custo do compósito até em 4,6\%, para o teor de reforço de $1,5 \%$.
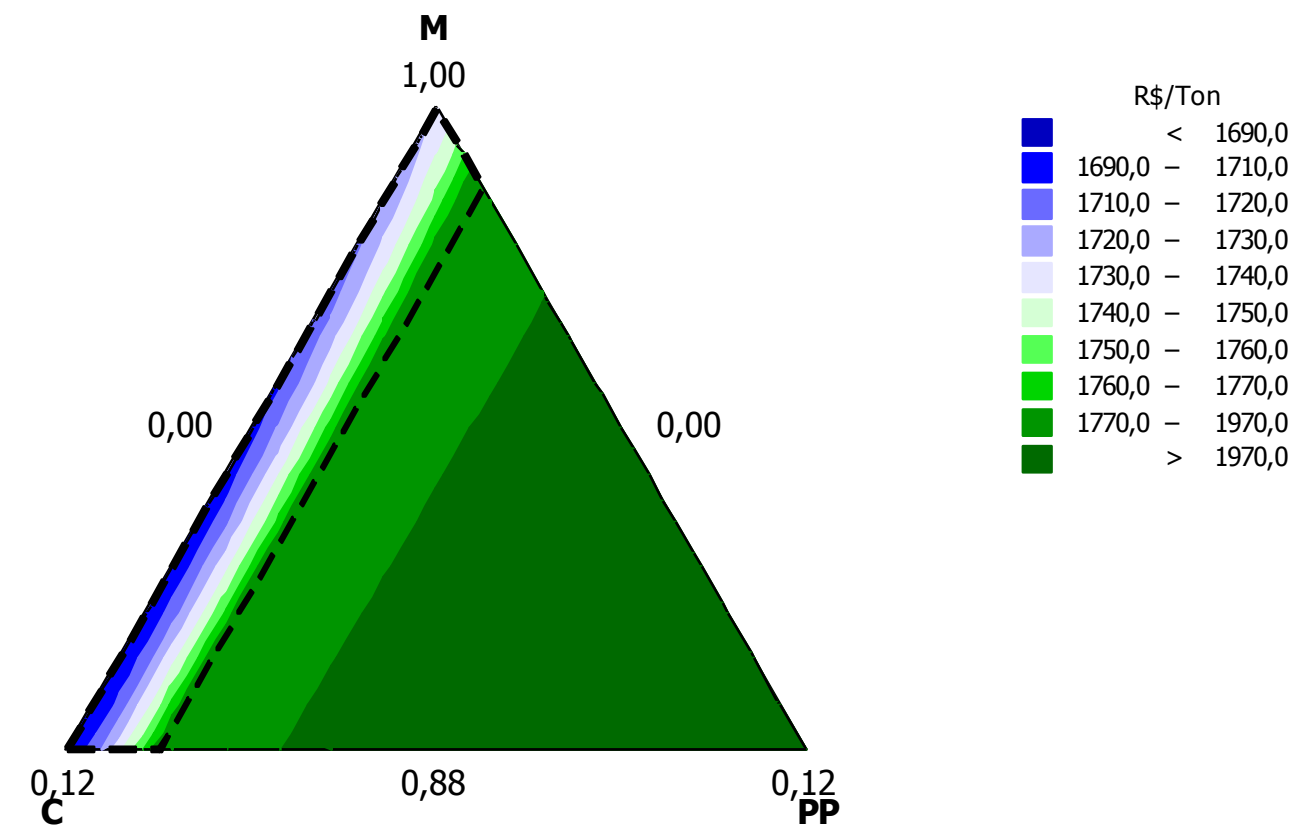

Gráfico 66 - Variação do custo da matriz reforçada com PP e C

\subsection{DISCUSSÃO COMPLEMENTAR}

Os resultados mostram que as propriedades mecânicas e físicas da matriz reforçada com $4 \%$ de celulose mantêm as propriedades após 200 ciclos de envelhecimento. Por outro lado, não acontece o mesmo com os reforços de $8 \% \mathrm{e}$ $12 \%$. Isso provavelmente acontece em razão a uma maior degradação do compósito devido à incompatibilidade de variação dimensional entre a matriz e a fibra, amplificada com o aumento do teor de fibras celulósicas. Esses resultados mostram que um compósito com mesma matriz pode apresentar diferentes comportamentos após o envelhecimento, em razão do teor de fibras. O resultado mostra a necessidade de realizar uma avaliação criteriosa, de envelhecimento, antes de decidir se o emprego de uma matriz ou teor de fibra vai fornecer os resultados desejados após envelhecimento. 
Os módulos de Weibull determinados para a matriz reforçada e sem reforço mostram o problema de reprodutibilidade que as fibras introduzem no compósito quando avaliado na flexão, visto que o módulo de Weibull decresce de 10,3 para 9,6. Essa queda de reprodutibilidade significa a perda de eficiência no dimensionamento do compósito atribuível às imperfeições da matriz e ao grau de alinhamento das fibras. Weibull mostra-se uma importante ferramenta de avaliação, capaz de identificar a convergência ou dispersão do valor médio do MOR das amostras, isto é, a sua reprodutibilidade. Esse parâmetro é de importância como dado adicional característico da formulação em avaliação.

Os preços comerciais dos aditivos, modificador e dispersantes, utilizados na extrusão, representam elevada porcentagem na composição de preços do compósito, entre $54 \%$ a $95 \%$ no valor da massa da matriz. O reforço com fibras de PP aumenta o custo do compósito, por outro lado as fibras de $\mathrm{C}$ reduzem o custo do compósito. O preço de mercado do fibrocimento produzido por Hatschek, incluindo os impostos do setor, encontra-se na média aproximada de $64 \%$ menor aos determinados utilizando unicamente os valores das matérias-primas e aditivos do fibrocimento extrudado. Isso significa uma limitante para a implantação do processo de extrusão em análise no presente estudo. Porém, é possível explorar a flexibilidade de elaboração de elementos com configuração diferenciada para ganhar competitividade, uma vez que os processos existentes no mercado, especialmente aqueles que utilizam técnicas baseadas em sucção-prensagem para a fabricação de placas, são carentes de versatilidade na elaboração de produtos com configuração complexa (seção alveolar, por exemplo). 


\section{CONSIDERAÇÕES}

Matérias-primas: O calcário e o cimento Portland por apresentarem distribuição granulométrica semelhante competem pelo espaço ocupado, por outro lado as partículas de sílica ativa mostram distribuição próxima do calcário e do cimento o que não é coerente para partículas de tamanho submicron como é o caso da sílica. Essa grande dificuldade na sua dispersão leva a comprometer o preenchimento dos espaços. A utilização de modelos de empacotamento na seleção da distribuição granulométrica das matérias-primas é uma opção para superar deficiências de empacotamento que podem limitar o desempenho do compósito.

Uma opção em potencial para reduzir a quantidade de modificador reológico utilizado no processo de extrusão é o metacaulim, devido ao comportamento pseudoplástico e sua pozolanicidade.

Reômetro extrusor: Esse equipamento mostra-se capaz de avaliar as características da pasta durante o fluxo na extrusão, quantificando os efeitos das diferentes matérias-primas e seus teores na deformação da pasta, na forças de friç̧ao entre a pasta e o corpo da boquilha, no efeito da velocidade na deformação da pasta e o efeito da velocidade na fricção entre a pasta e o corpo da boquilha. A quantificação da plasticidade da pasta com esse equipamento fica subjetiva, o ensaio de squeeze flow apresenta-se como equipamento capaz de quantificar a plasticidade das pastas altamente coesas podendo dar uma melhor avaliação do comportamento reológico da pasta. Estudos de comportamentos de pastas utilizando reômetro extrusor e squeeze flow possivelmente proporcionem resultados complementares na avaliação da extrudabilidade de pastas.

Processo de elaboração de compósitos: A etapa de mistura das matériasprimas mostra-se como etapa crítica na homogeinização da pasta onde a sequência dos materiais, a misturar assim como o tempo e velocidades de mistura afetam significativamente na distribuição homogênea das matérias-primas dentro da pasta. O estudo para determinar a sequência, tempo e velocidade de mistura é de relevância para obter uma mistura com adequada homogeinização. A utilização de um medidor de torção acoplado ao misturador pode ser uma ferramenta útil para determinar protocolos na homogeinização de matérias-primas numa pasta. As extrusoras de rosca e extrusoras de pistão têm tipos de fluxo de pasta semelhante 
durante a extrusão, porém as de pistão apresentam fluxo de pasta de maior estabilidade.

Modelos estatisticos dos compósitos extrudados: Os modelos implementados apresentam $R^{2}$ baixos devido a ter-se trabalhado com faixas de matérias-primas amplas, a utilização de faixas mais estreitas de teores de cimento, sílica e calcário na matriz podem ajudar a refinar os modelos proporcionando $R^{2}$ maiores, isto é maior precisão nos modelos. A determinação da demanda de água dos sistemas cimentícios é um importante ponto de partida no ajuste do comportamento reológico de uma formulação cimentícia extrudável, a introdução das fibras de reforço no sistema torna a metodologia inviável existindo a necessidade de uma alternativa de determinação da demanda de água de um sistema de material particulado com fibras de reforço.

O envelhecimento acelerado tem-se mostrado capaz de fornecer resposta em curto prazo, porém evidencia-se a necessidade estudar o efeito do tempo de transição de temperatura, uma vez que mudança brusca de temperatura no meio submete as solicitações de tenções severas no compósito podendo ser muito distantes da situação real de envelhecimento do compósito. 


\section{CONCLUSÕES}

Os resultados obtidos mostram a viabilidade da metodologia proposta como ferramenta para o desenvolvimento de compósitos extrudados, onde as caracterizações das matérias-primas fornecem subsídios para a compreensão dos efeitos nos parâmetros reológicos, demanda de água e desempenhos mecânicos e físicos dos compósitos. Os modelos mostraram diferentes tendências promovidas pelas adições de sílica ativa (S) e calcário (CC) assim como pelos reforços de polipropileno (PP) e celulose de eucalipto (C) fornecendo importante subsídio para a seleção da matriz como também do reforço. $O$ estudo de envelhecimento utilizado forneceu dados do comportamento da degradação acelerada, constatando variações e manutenções das propriedades mecânicas e físicas relevantes para ambientes que se aproximem ao simulado. A avaliação da reprodutibilidade dos compósitos extrudados, utilizando o módulo de Weibull, identifica a variabilidade dos MOR entre matrizes puras e reforçadas.

A partir desses resultados obtêm-se as seguintes conclusões específicas:

> Influência das matérias-primas e aditivos nos parâmetros reológicos: O maior efeito na pressão dos extrudados foi promovido pelas fibras de PP; por outro lado, as fibras de $\mathrm{C}$, devido à capacidade de absorver água, não apresentam variação expressiva nos parâmetros reológicos, resultando em uma pressão de extrusão estável mesmo com o aumento do teor de fibras utilizado.

A sílica ativa (S), embora apresente formas esféricas, nas condições estudadas não foi capaz de facilitar o fluxo da pasta, mesmo reduzindo alguns parâmetros reológicos, repercutindo em aumento da pressão de extrusão com a elevação do teor. Esse efeito pode ser atribuído a dificuldade de dispersar as partículas de S, em razão da elevada área superficial, com o agravante adicional do baixo teor de água utilizado no processo de extrusão.

A adição do CC teve a tendência de aumentar todos os parâmetros reológicos em maior magnitude, quando comparada com à sílica ativa (S) nas mesmas proporções de adição, refletindo em uma maior pressão de extrusão. Isso acontece em virtude da configuração irregular das partículas de CC, que é muito diferente da forma esférica. 
O teor de água apresentou significativa influência nos parâmetros reológicos, onde o aumento do teor produziu uma redução generalizada em todos os parâmetros reológicos e conseqüentemente na pressão de extrusão.

O HPMC aumentou os parâmetros reológicos, já que a utilização do teor de $3 \%$ resultou o expressivo aumento de $531 \%$ na pressão total de extrusão quando comparado com o teor de 1\%. Esses parâmetros mostraram a eficiência desse modificador reológico em dar coesão à pasta com baixos teores.

O dispersante poliéter carboxílico diminuiu todos os parâmetros reológicos da pasta promovendo a redução da pressão total da extrusão.

O lubrificante propileno glicol exerceu efeito reduzido como lubrificante da pasta cimentícia nos teores utilizados.

O HPMC, com o aumento de seu teor, teve a tendência de reduzir as propriedades mecânicas e físicas da matriz, embora a literatura indique que a interface matriz-fibra é melhorada com esse aumento de teor.

O dispersante reduziu a pressão de extrusão em razão da disponibilidade de água adicional na mistura o que promoveu a separação entre as partículas e levou à queda das propriedades mecânicas e físicas.

$>$ Comportamento da demanda de áqua nos sistemas particulados: A metodologia utilizada para a determinação da demanda de água para matrizes cimentícias processadas por extrusão apresentou-se coerente aos materiais analisados em respeito à água requerida para cobrir as partículas e preencher os espaços capilares, deixando explicito o teor de água demandado pelos particulados. Através da metodologia abordada, destacou-se que os sistemas de matrizes CPV, CC e $\mathrm{S}$ apresentam as seguintes características: os particulados de $\mathrm{S}$ requerem uma maior demanda de água em relação aos particulados de CPV e CC; as formulações em que predomina o CPV, embora com tamanho médio de partículas com área específica inferior e próximas ao do CC, exigiram um teor de demanda de água maior comparado às formulações em que prevalece o CC, isso pela elevada reatividade própria do CPV; as formulações com predominância de CC apresentaram as menores demandas de água, pelo fato das partículas serem inertes; misturas com particulados de baixa área específica e partículas inertes predominantes demandaram menor quantidade água, isso pôde ser observado na redução do teor de água no setor de composições com domínio de CPV e CC. 
> Modelagem das propriedades mecânicas e físicas das misturas: Os modelos das propriedades mecânicas e físicas implementados para as matrizes reproduziram de forma aceitável as propriedades do compósito principalmente quando se refere à matriz pura em relação à matriz reforçada. Os modelos quadráticos para - MOR e LOP, linear para MOE e cúbico para O EE ajustaram-se satisfatoriamente para o coeficiente de determinação $R^{2} \quad 60 \%$ e $95 \%$ de significância estatística, mostrando-se de maior dificuldade de modelar a EE. Os modelos empregados para o reforço utilizando a matriz $M$ foram de maior complexidade quando comparados com os das matrizes puras, isto é cúbico para MOR, LOP, MOE e cúbico completo para EE. Essa necessidade de utilizar modelos cúbicos e cúbicos completos pôde ser atribuída às imperfeições da matriz, ocasionadas pelo reforço, e diferentes alinhamentos fibras de PP e C.

Desempenho mecânico das formulações: As formulações M93,3C5,3PP1,5, M98,5PP1,5 e M96,1C2,81PP1,125 apresentaram os desempenhos mecânicos mais elevados dentre as formulações elaboradas. A formulação M93,3C5,3PP1,5 apresentou MOR de 19,15 MPa e EE de 2,63 kJ/m², a formulação M98,5PP1,5 apresentou MOR de $15,89 \mathrm{MPa}$ e EE de $6,15 \mathrm{~kJ} / \mathrm{m}^{2}$ e a formulação M96,1C2,81PP1,125 apresentou MOR de 18,5 MPa e EE de 1,24 kJ/m². Esses valores encontram-se proximos dos compósitos reforçados com fibras minerais tradicionais, porém com a vantagem de apresentarem absorção de energia superior ao fibrocimento convencional.

> Efeito do envelhecimento acelerado: O estudo de envelhecimento mostrou sua relevância em compósitos extrudados com reforço de $\mathrm{C}$, onde a matriz reforçada com $4 \%$ apresentou as propriedades mecânicas inalteradas, não acontecendo o mesmo com reforços de $8 \%$ e $12 \%$.

Reprodutibilidade da propriedade mecânica MOR: Foi avaliada a reprodutibilidade do MOR na flexão de quatro pontos, mediante o módulo de Weibull, da matriz $\mathrm{M}$ e da mesma reforçada com fibras de PP, o que identificou a influência negativa do efeito das fibras nessa reprodutibilidade.

> Competitividade econômica dos compósitos extrudados: Os preços comerciais dos aditivos, modificador e dispersantes, utilizados na extrusão representaram elevada porcentagem na composição de preços do compósito, entre 54\% a 95\% no valor da massa da matriz. O reforço com fibras de PP teve a tendência de aumentar o valor total do fibrocimento o que ocorre inversamente quando o 
compósito foi reforçado com C. O preço de mercado do fibrocimento produzido por Hatschek é aproximadamente $64 \%$ menor do que os determinados utilizando unicamente os valores das matérias-primas e aditivos do fibrocimento extrudado no presente estudo. Isso significa uma limitante para a implantação do processo, por outro lado é possível explorar a flexibilidade de elaboração do fibrocimento com configuração diferenciada para ganhar competitividade, uma vez que os processos existentes no mercado são carentes de versatilidade para a elaboração de produtos com configuração complexa.

\subsection{PROPOSTA PARA TRABALHOS FUTUROS}

Sugere-se para estudos futuros referente a fibrocimento por extrusão os seguintes tópicos:

> Avaliação de modificadores reológicos de menor custo viáveis para o processo de extrusão;

> Estudo de métodos de homogeneização de materiais cimentícios com reforço utilizando baixa relação a/c;

> Estudo de métodos para determinação de teor mínimo de modificador reológico e dispersantes requeridos para a extrusão;

> Projeto de empacotamento de partículas que promova a redução de uso de modificadores reológicos;

> Avaliação de técnicas alternativas para a caracterização reológica de misturas de alta viscosidade próprias para a extrusão.

> Estudo da utilização do metacaulim como pozolana e modificador reológico;

> Estudo da seqüência de mistura para viabilizar a homogeneização do material estudado. 


\section{REFERÊNCIAS}

AGOPYAN, V. Materiais reforçados com fibras para a construção civil nos países em desenvolvimento: uso de fibras vegetais. São Paulo, 1991. 204p. Tese (Livre-Docência) - Escola Politécnica, Universidade de São Paulo, São Paulo, 1991.

AKERS, S. A. S.; STUDINKA, J. B. Ageing behavior of cellulose fibre cement composites in natural weathering and accelerated test. International Journal of Cement Composites and Lightweight Concrete, v.11, 1989. p.93-97.

AMERICAN CONCRETE INSTITUTE. ACI544.1R, State-of-the-art report on fiber reinforced concrete. Detroit, MI, USA, 1996.

AMERICAN SOCIETY FOR TESTING AND MATERIALS. ASTM C948-81: test method for dry and wet bulk density, water absorption, and apparent porosity of thin sections of glass-fiber reinforced concrete. West Conshohocken, PA, USA. 1981.

ASAGA, K.; ROY, D. M. Rheological properties of cement mixes: IV. Effects of superplasticizers on viscosity and yield stress. Cement and Concrete Research, v.10, 1980. p.287-295.

ASSOCIAÇÃO BRASILEIRA DE NORMAS TÉCNICAS. NBR 14344: Pasta celulósica - Determinação da drenabilidade - Método Canadian Standard freeness. Rio de Janeiro, 2003. 14 p.

ATAHAN, H. N.; OKTAR, O.N.; TASDEMIR, M. A. Effects of water-cement ratio and curing time on the critical pore width of hardened cement paste.

Construction and Building Materials, v.23, 2009. p.1196-1200.

BANTHIA, N. Micro fiber reinforced cement composites. The Indian Concrete Journal, v. 70, 1996. p.533-542.

BARNES, H. A.; HUTTON, J. F.; WALTERS, K. An introduction to rheology, Elsevier Science Publishers B. V., Amsterdam, The Netherlands. 1989. 
BARROS NETO, B.; SCARMÍNIO, I. S.; BRUNS, R. E. Planejamento e Otimização de Experimentos. Campinas: Editora da UNICAMP, 2003. 299 p.

BENBOW, J. J.; BRIDGWATER, J. The cutting of paste extrudates. Chemical Engineering Science, v.48, 1993. p.3088-3091.

BENBOW, J. J.; JAZAYERI, S. H.; BRIDGWATER, J. The flow of paste through dies of complicated geometry. Powder Technology, v. 65, 1991. p.393-401.

BENBOW, J. J.; OXLEY, E. W.; BRIDGWATER, J. The extrusion mechanics of pastes-the influence of paste formulation on extrusion parameters. Chemical Engineering Science, v. 42, n. 9, 1987. p.2151.

BENTUR, A. Fibre reinforced cementitious materials. Materials Science of Concrete, The American Ceramic Society, Ed. J.P.Skalny, 1989. p.223-285.

BENTUR, A.; AKERS, S. A. S. The microstructure and ageing of cellulose fibre reinforced autoclaved cement composites, The International journal of cement composites and Lightweight concrete, v.11, 1989. p.111-115.

BENTUR, A.; MINDESS, S. Fibre Reinforced Cementitious Composites, Modernc Concrete Technology Series, $2^{\text {nd }}$ ed., 2007. New York: Taylor \& Francis Group, USA, 601p.

BETTERMAN, L. R.; OUYANG, C.; SHAH, S. P. Fiber matrix interface in microfiber-reinforced mortar. Advanced Cement-Based Materials, v.2, 1995. p.53-61.

BLANKENHORN, P. R.; BLANKENHORN, B. D.; SILSBEE, M. R.; DICOLA, M. Effects of fiber surface treatments on mechanical properties of wood fiber-cement composites, Cement and Concrete Research, v.31, 2001. p.1049-1055.

BOX, G. E. P.; HUNTER, W. G.; HUNTER, J. S. Statistics for experimenters: An introduction to Design, Data Analysis, and Model Building. New York: John Wiley \& Sons, 1978.

BURBIDGE, A. S.; BRIDGWATER, J. The single screw extrusion of paste. Chemical Engineering Science, v. 50, 1995. p.2531-2543. 
BURBIDGE, A. S.; BRIDGWATER, J.; SARACEVIC, C. Liquid migration in paste extrusion. Chemical Engineering Research and Design, v. 73, 1995. p.810816.

CASTRO, A. L.; PANDOFELLI, V. C. Revisão: Conceitos de dispersão e empacotamento de partículas para a produção de concretos especiais aplicados na construção civil. Cerâmica, v.55, 2009. p.18-32.

CHEN, Z. C.; MURAKAMI, K. I. T. Effect of particle packing on extrusion behavior of paste. Journal of Material Science, v. 35, 2000. p.5301-5307.

CLARKE, B. Rheology of coarse settling suspensions. Transactions of the British Ceramic Society, v.62, 1967. p.251-256.

CORNELL, J. A. Experiments with mixtures: designs, models and the analysis of mixture data. $3^{\text {rd }}$ Ed., New York: John Wiley and sons, 2002.

COUTTS, R. S. P. A review of Australian research into natural fibre cement composites. Cement and Concrete Composites, v.27, 2005. p.518-526.

COUTTS, R. S. P. From forest to factory to fabrication. In: Swamy R.N. editor, $4^{\text {th }}$ INTERNATIONAL SYMPOSIUM FIBRE REINFORCED CEMENT AND CONCRETE. Proceedings...London: E\&FN Spon, 1992. p.31-47.

DAIMOND, M.; ROY, D. M. Rheological properties of cement mixes: I. Method, preliminary Experiments, and adsorption studies. Cement and Concrete Research, v. 8, 1978. p.753-769.

DAS, R. N.; MADHUSOODANA, C. D.; OKADA, K. Rheological studies on cordierite honeycomb extrusion. Journal of the European Ceramic Society, v.22, 2002. p.2893-2900.

DEMING, S.N.; MORGAN, S.L. Experimental Design: a Chemometric Approach, New York: Elsevier Publishing Company, Inc. 1990.

DIAS, C. M. R. Efeitos do envelhecimento na microestrutura e no comportamento mecânico dos fibrocimentos. 2005. 125p. Dissertação (Mestrado) - Escola Politécnica, Universidade de São Paulo, São Paulo, 2005. 
DIAS, C. M. R.; SAVASTANO JR., H.; JOHN, V. M. Exploring the potential of functionally graded materials concept for the development of fiber cement, Construction and Building Materials, v. 24, 2010, p.140-146.

EUROPEAN STANDARD. EN949: fibre-cement profiled sheets and fitting for roofing - products specification and test methods. British Standards Institution, London, UK. 1994.

FERRARIS, C. F.; OBLA, K. H.; HILL, H. The influence of mineral admixtures on the rheology of cement paste and concrete. Cement and Concrete Research, v. 31,2001 . p. 245-255.

GALLIAS, J. L.; KARA-ALI, R.; BIGAS, J. P. The effect of fine mineral admixtures on water requeriment of cement pastes. Cement and Concrete Research, v.30, 2000. p.1543-1549.

GUSTAFSSON, J.; CIOVICA, L.; PELTONEN, J. The ultrastructure of spruce kraft pulps studied by atomic force microscopy (AFM) and X-ray photoelectron spectroscopy (XPS). Polymer, v.44, 2003. p. 661-670.

GUTIÉRREZ, R. M.; DÍAZ, L. N.; DELVASTO, S. Effect of pozzolans on the performance of fiber-reinforced mortars. Cement and Concrete Composites, v.27, 2005. p.593-598.

HACHMI, M. H.; MOSLEMI, M. A. Correlation between wood-cement compatibility and wood extractives, Forest Production Journal, v.39, 1989. p 55-58.

HANNANT, D. J. Fibre Cements and Fibre Concretes, Great Britain: John Wiley \& Sons. 1986.

HERSCHEL, W. H.; BULKLEY, R. Measurement of Consistency as Applied to Rubber-Benzene Solutions, Am. Soc. Testing Mater., Vol. 26, 1926. p.621-633.

HORST G. G. Extrusion of FRC products: technology and practical aspects, Conference of Inorganic-Bonded wood and fiber composites materials, v. 8, Sun Valley, Idaho, USA, 2002. 
HUNGER, M.; BROUWERS, H. J. H. Flow analysis of water-powder mixtures: Application to specific surface area and shape factor, Cement and Concrete Composites, v.31, n.1, 2009. p.39-59.

IVESON, S. M.; LITSTER, J. D.; HAPGOOD, K.; ENNIS, B. J. Nucleation, growth and breakage phenomena in agitated wet granulation processes: a review. Powder Technology, v.117, 2001. p.3-39.

KANDA, T.; LI, V.C. Interface property and apparent strength of high-strength hydrophilic fiber in cement matrix. Journal of Materials in Civil Engineering, 1998. p.5-13.

KHAYAT, K. L. Viscosity Enhacing admixtures for cement based materials - An overview. Cement and Concrete Composites, v. 20, 1998. p.171-188.

LANGE, F.; MORTEL, H.; RUDERT, V. Dense packing of cement pastes and resulting consequences on mortar properties. Cement Concrete Research, v. 27,1997 . p.1481-1488.

LI, V. C. Large volume, high-performance applications of fibers in civil engineering. Journal of Applied Polymer Science, v.83, 2002. p.660-686.

LI, V. C.; WU, H. C.; MAALEJ, M.; MISHRA, D. K. Tensile behavior of cementbased composites with random discontinuous steel fibers. American Ceramic Society Journal, v.79, 1996. p.74-78.

MAALEJ, M.; HASHIDA, T.; LI, V. C. Effect of fiber volume fraction on the offcrack-plane fracture energy in strain hardening engineered cementitious composites. Journal American Ceramic, v.78, 1995. p.3369-3375.

MACVICAR, R.; MATUANA, L. M.; BALATINECZ, J. J. Aging mechanism in cellulose fiber reinforced cement composites. Cement and Concrete Composites, v.21, 1999. p.189-196.

MAGGIO, R. D.; FRANCHINI, M.; GUERRININ, G.; POLI, S.; MIGLIARESI, C. Fiber matrix adhesion in fiber reinforced CAC-MDF composites. Cement and Concrete Composite, v.19, 1997. p.139-147. 
MINDESS, S.; YOUNG, J. F. Concrete. Prentice-Hall, New Jersey: Inc. Englewood Cliffs, 1981.

MOHR, B. J.; BIERNACKI, J. J.; KURTIS, K. E. Microstructural and chemical effects of wet/dry cycling on pulp fiber-cement composites. Cement and Concrete Research, v.36, 2006. p.1240-1251.

MOHR, B. J.; BIERNACKI, J. J.; KURTIS, K. E. Supplementary cementitious materials for mitigating degradation of kraft pulp fiber-cement composites.

Cement and Concrete Research, v.37, 2007. p.1531-1543.

MOHR, B. J.; NANKO, H.; KURTIS, K. E. Durability of kraft pulp fiber-cement composites to wet/dry cycling. Cement \& Concrete Composites, v. 27, 2005. p.435-448.

NANKO, H.; ASANO, S.; OHSAWA, J. Shirinkage behavior of pulp fibers during drying. TAPPI INTERNATIONAL PAPER PHYSICS CONFERENCE, 1991, Kona. Proceedings...Kona: 1991. p365-374

NEVILLE, A. M. Propriedades do concreto. 2 Ed., São Paulo, Editora Pini, 1997.

OLIVEIRA, I. R.; STUDART, A. R.; PILEGGI, R. G.; PANDOLFELLI, V. C. Dispersão e empacotamento de partículas. São Paulo: Fazendo Arte, 2000.

ONADA, G. Y. The rheology of organic binder solutions. In: ONADA, G. W.; HENCH, L.L. Ceramic processes before firing. New York: Wiley, 1979. Cap. 19, p.235-251.

ORTEGA, F. S.; PILEGGI, R. G.; PANDOLFELLI, V. C. Análise da relação entre distância de separação entre partículas (IPS) e viscosidade de suspensões, Cerâmica, v. 45, n. 295, 1999.

PELED, A; SHAH, S. Processing effects in cementitious composites: extrusion and casting. Journal of Materials in Civil Engineering, v. 15, 2003. p.192-199. 
PONG, L. C. Building products development using extrusion techinique. 2001. 150 p. Tese (Mestrado) - The Hong Kong University of Science and Technology. 2001.

POURCHEZ, J.; GOVIN, A.; GROSSEAU, P.; GUYONNERT, R.; RUOT, B. Alkaline stability of cellulose ethers and impact of their degradation products on cement hydration. Cement and Concrete Research, v.36, 2006. p.1252-1256

POWERS, T. C. The properties of fresh concrete. New York: John Wiley \& Sons, 1968.

QIAN, X.; ZHOU, X.; MU, B.; LI, Z. Fiber alignment and property direction dependency of FRC extrudate. Cement and Concrete Research, v. 33, 2003. p.1575-1581.

RACMACHANDRAN, V.S. Concrete admixture handbook: Properties, science, and technology, New Jersey: Noyes, 1995.

REED, J. Introduction to the principles of ceramic processing. New York: John Wiley \& Sons, 1988.

REED, J. S. Principles of ceramic processing. Alfred, New York: John Wiley \& Sons, 1995.

RILEM 49TFR. Testing Methods for Fibre Reinforced Cement-Based Composites. Reunion Internationale Des Laboratoires D'Essais Et Des Recheches Sr lex Materiaux Et Les Constructions (RILEM) - Materiaux et Constructions, v.17, n.102, 1984. p.441-456.

ROMANO, R. C. O.; SCHREURS, H. ; JOHN, V. M. ; PILLEGI, R. G. Influência da técnica de dispersão nas propriedades da sílica ativa. Cerâmica, v. 54, n. 332, 2008. p.456-461.

SAARELA, J.; TÖRMÄANEN, M.; MYLLYLÄ, R. Measuring pulp consistency and fines content with a streak camera. Institute of Physics Publishing. Measurement Science and Technology, v.14, 2003. p.1801-1806. 
SAMARRI, M. A.; ELVERY, R. H. The influence of fibers upon crack development in reinforced concrete subject to uniaxial tension. Magazine of Concrete

Research, v.26, 1974. p.203-211.

SAVASTANO JR, $\mathrm{H}$. Zona de transição entre fibras e pasta de cimento Portland: caracterização e inter-relação com as propriedades mecânicas do compósito. 1992. 249p. Tese (Doutorado) - Escola Politécnica, Universidade de São Paulo, São Paulo, 1992.

SAVASTANO JR., H.; WARDEN, P. G.; COUTTS, R. S. P. Microstructureand mechanical properties of waste fibre-cement composites. Cement and Concrete Composites, v.27, 2005. p.583-592.

SAVASTANO JUNIOR, H.; DANTAS, F. A. Z.; AGOPYAN, V. Materiais reforaçados com fibras: correlação entre a zona de transição fibra-matriz e as propriedades mecânicas. São Paulo: IPT/Pini, 1994. 56p. (Publicação IPT 2158 - Boletim 67).

SCHEFFÉ, H. Experiments with mixtures. Journal of the Royal Statistical Society B, v.20, 1958. p.344-360.

SENFF, L.; HOTZA, D.; REPETTE, W. L. Comportamento reológico das pastas de cimento com adição de sílica ativa, nanossílica e dispersante policarboxílico. Revista Matéria, v.15, 2010. p.12-20.

SHAH S. P. Do fibers increase the tensile strength of cement-based materials. ACI Materials Journal, v.88, 1991. p.595-602.

SHAH, S. P.; PELED, A.; DEFORD, D.; AKKAYA, Y.; SRINIVASAN, R. Extrusion technology for the production of fiber-cement composites. In: INORGANICBONDED WOOD AND FIBER COMPOSITE MATERIALS CONFERENCE, Sun valley, ID, USA. 1998.

SHAO, Y. Characterization of high performance fiber-reinforced cement composites. 1995. 146 p. Tese (Doutorado) - Faculdade de Engenharia Civil, Evanston, IL, 1995.

SHAO, Y.; MORAS, S.; ULKEM, N.; KUBES, G. Wood fibre-cement composites by extrusion. Canadian Journal of Civil Engineering, v. 27, 2000. p.543-552. 
SHAO, Y.; QIU, J.; SHAH, S.P. Microstructure of extrude cement-bonded fiberboard. Cement and Concrete Research, v.31, 2001. p.1153-1161.

SHAO, Y.; SHAH, S. Mechanical properties of PVA fiber reinforced cement composites fabricated by extrusion processing. ACI Material Journal, v. 94, 1997. p.555-564.

SHEN, B. Experimental approaches for determining rheological properties of cement-based extrudates. 124 p. Tese (Mestrado) - Universidade de Ciências e Tecnologia de Hong Kong, Hong Kong, 2003.

SILVA, A. C. Estudo da durabilidade de compósitos reforçados com fibras de celulose. 2002. 127 p. Dissertação (Mestrado) - Escola Politécnica, Universidade de São Paulo, São Paulo, 2002.

SRINIVASAN, R.; DEFORD, D.; SHAH, P. S. The use of extrusion rheometry in the development of extrudate fiber-reinforced cement composites. Concrete Science and Engineering, v. 1, 1999. p.26-36.

SWAMY, R. N. Influence of slow crack growth on the fracture resistance of fibre cement composites. The International Journal of Cement Composites, v.2, 1980. p.43-53.

TAKASHIMA, H.; MIYAGAY, K.; HASHIDA, T.; LI, V. C. A design approach for the mechanical properties of polypropylene discontinuous fiber reinforced cementitious composites by extrusion molding. Engineering Fracture Mechanics, v. 70, 2003. p.853-870.

TALBOT, A. N. A proposed method of estimating the density and strength of concrete and of proportioning the materials by the experimental and analytical consideration of the voids in the mortar and concrete, v.21, 1921. 940p.

TAYLOR, H. F. W. Cement Chemistry, $2^{\text {nd }}$ Ed., London: Thomas Telford, 1997.

TOLÊDO FILHO, R. D. Materiais compósitos reforçados com fibras naturais vegetais. In: MATERIAIS NÃO CONVENCIONAIS PARA CONSTRUÇOES RURAIS 2. Campina Grande. Anais...Campina Grande: UFPB/SBEA, 1997. p.4982 
TOLÊDO FILHO, R. D.; SCRIVENER, K.; ENGLAND, G. L.; GHAVAMI, K. Durability of alkali sensitive sisal and coconut fibres in cement based composites. Cement \& Concrete Composites, v.6, 2000. p.127-43.

TOUTANJI, H. A.; EL-KORCHI, T.; KATZ, R. N. Strength and reliability of carbonfiber-reinforced cement composites. Cement and Concrete Composites, v.16, 1994. p.15-21.

VIKAN, H.; JUSTNES H. Rheology of cementitious paste with sílica fume or limestone. Cement and Concrete Research, v.37, 2007. p.1512-1517.

\section{VLACHOPOULOS, J.; WAGNER, J. R. The SPE guide on extrusion} technology and troubleshooting. Brookfield: SPE Society of Plastics Engineers, 2001.

WEYER, H. J.; MÜLLER, I.; SCHMITT, B.; BOSBACH, D.; PUTNIS, A. Timeresolved monitoring of cement hydration: influence of cellulose ethers on hydration kinetics. Nuclear Instruments and Methods in Physics Research B, v.238, 2005. p.102-106.

WONG, H. C. H. Effects of water content, packing density and solid surface area on cement paste rheology. 2000. 204 p. Thesis (PH.D.) - University of Hong Kong, Hong Kong, 2007.

YOUNG, R. F. A review of the mechanisms of set-retardation in Portland cement pastes containing organic admixtures. Cement and Concrete Research, v. 2, 1972. p.415-433.

ZANOTTO, E. D.; MIGLIORE. A. R. Jr. Propriedades mecanicas de materiais ceramicos: Uma introdução. Ceramicca, v. 37, n. 247, 1991. 


\section{APÊNDICE A - Estudo Preliminar das Formulações}

Neste Apêndice, apresenta-se o estudo preliminar de formulações cimentícias processadas por extrusão. Essas formulações adotam teores de aditivos fixos, utilizando unicamente o ajuste da relação água/cimento (a/c), por tentativa e erro, como meio de tornar viável a extrusão.

No desenvolvimento do presente trabalho, foi utilizado um misturador planetário de $6 \mathrm{~L}$ de capacidade que dispõe de duas velocidades de mistura: 140 rpm e 285 rpm. Foram elaborados os compósitos empregando uma extrusora com capacidade de processamento de até $100 \mathrm{~kg} / \mathrm{h}$ sem vácuo, com diâmetro de barril de $45 \mathrm{~mm}$ e comprimento de rosca de $25 \mathrm{~cm}$.

Baseado na literatura foi estimado o teor de água necessário para a elaboração de compósitos por extrusão. Partindo disso, foram realizadas as aproximações seguintes.

Antes de dar inicio à extrusão, a mistura cimentícia é misturada à matériaprima em pó em baixa rotação (mistura distributiva), com a finalidade de promover a distribuição homogênea dos particulados. $O$ tempo de mistura é em torno de 5 min. Posteriormente se procede a introduzir água e fibras (quando corresponda), continuando com a mistura aproximadamente por mais $5 \mathrm{~min}$. Em seguida, alimentase a extrusora com essa pasta para obterem-se placas com seção transversal de 40 $\mathrm{mm} \times 6 \mathrm{~mm}$, que são curadas por 2 dias, seladas em pacotes plásticos, para posteriormente serem submersas em água saturada em hidróxido de cálcio por mais 26 dias. Em seguida, são cortadas em comprimentos de $160 \mathrm{~mm}$, obtendo-se assim os corpos-de-prova (CPs).

Após 28 dias de cura, realizaram-se ensaios mecânicos (flexão com quatro cutelos) e físicos, baseado nas recomendações da RILEM (Testing Methods for Fibre Reinforced Cement-Baseda Composites) TECHNICAL COMMITTEE 49 TFR. 


\section{Formulações extrudáveis}

\subsection{REFORÇO DE MATRIZ CIMENTÍCIA DE CPV COM FIBRAS DE PVA}

Para análise do efeito do reforço da matriz cimentícia com PVA, foram elaborados CPs unicamente com cimento CPV (formulação CPV100) e placas com reforço de fibras de PVA (formulação CPV100PVA1) em teor de 1\% em relação à massa do cimento. A formulação é detalhada na Tabela 1.

Durante a elaboração dos CPs, foi observado um aumento da viscosidade da mistura em razão da introdução das fibras de PVA.

As fibras de PVA, como mostram a Tabela 2 e o Gráfico 4, conferem ductilidade à matriz frágil de cimento CPV, influenciando principalmente O MOE, reduzindo-o, provavelmente, por causa das imperfeições introduzidas, e aumentando a EE.

As propriedades físicas são influenciadas pelas imperfeições introduzidas na matriz, produzindo aumento de PA e AA e diminuição na DA, conforme observado nos Gráficos 5, 6 e 7.

\subsection{MATRIZ COM CPV, SÍLICA ATIVA E CALCÁRIO, REFORÇADA COM CELULOSE E PVA}

Foram elaborados compósitos com proporções próximas às utilizadas na indústria do fibrocimento (formulação CPV63S4CC26C3PVA1,8) e comparados com os corpos elaborados com unicamente cimento CPV, formulação CPV100. A formulação CPV63S4CC26C3PVA1,8 é descrita na Tabela 1.

$\mathrm{Na}$ elaboração dos corpos-de-prova, foi preciso aumentar o teor de água da mistura, isso, em parte, por causa da capacidade de absorver água da fibra celulósica, assim como também pelo aumento da viscosidade que a fibra pode estar ocasionando na mistura. 
O desempenho do MOR da formulação CPV63S4CC26C3PVA1,8 não apresentou variação em comparação a fórmula CPV100, como observado na Tabela 2. A principal variação ocorre nos MOE e EE.

As propriedades físicas dos compósitos elaborados com a formulação CPV63S4CC26C3PVA1,8 apresentam aumento no PA, AA em relação aos corpos elaborados com a formulação CPV100, assim como também apresentam diminuição na DA, como pode ser observado nos Gráficos 5,6 e 7 . Isso é promovido às estruturas tubulares das fibras celulósicas de eucalipto assim como às imperfeições introduzidas pelas fibras.

\subsection{REFORÇO DE MATRIZ CIMENTÍCIA DE CPIII COM FIBRAS DE POLIPROPILENO}

O cimento CPIII conhecido como cimento de alto forno é elaborado com escória de alto forno que normalmente é um passivo ambiental. Isso torna o CPIII um cimento interessante na elaboração de compósitos cimentícios.

Para verificar o efeito do reforço de polipropileno na matriz cimentícia CPIII foi elaborado CPs reforçados com 1\% em massa de fibras de PP (formulação CPIII99PP1) para ser comparadas com o desempenho dos CPs elaborados unicamente com cimento CPIII (formulação CPIII100(a/C=0,2)). Essas formulações são detalhadas na Tabela 1.

O cimento CPIII não requer a mesma quantidade de água necessária para o cimento CPV na elaboração de CPs por extrusão.

Os CPs reforçados com PP, comparados aos corpos elaborados com a fórmula CPIII100 $(\mathrm{a} / \mathrm{c}=0,2)$, apresentam ductilidade na fratura, porém reduzindo MOE, em razão das imperfeições introduzidas na matriz. Isso pode ser observado no Gráfico 10.

A formulação CPIII99PP1 mostra diminuição na densidade aparente (DA) e aumento nas propriedades de AA e PA, o que pode ser observado nos Gráficos 5, 6 e 7. Esses efeitos são em razão das imperfeições introduzidas pelas fibras. 


\subsection{REDUÇÃO DO TEOR DE ÁGUA NA MATRIZ CIMENTÍCIA CPIII}

Para reduzir o teor de água da mistura cimentícia foi aumentado o nível de dispersante para $1 \%$, obtendo-se uma redução de a/c de 0,20 a 0,17 nos CPs elaborados unicamente com cimento CPIII. A formulação CPIII100 $(\mathrm{a} / \mathrm{c}=0,17)$ detalhada na Tabela 1 corresponde à formulação com relação $a / c$ reduzida.

Os CPs da formulação CPIII100 $(\mathrm{a} / \mathrm{C}=0,17)$ apresentam desempenho de MOR, LOP, MOE e EE melhorados, comparados aos compósitos elaborados com a formulação CPIII100 (a/C = 0,2), conforme pode ser observado nos Gráficos 1, 2, 3 e 4. Os desempenhos mecânicos melhorados podem ser atribuídos à redução de vazios na matriz graças à menor relação a/c, obtendo-se, assim, uma matriz mais compacta.

As propriedades físicas dos CPs elaborados com a formulação CPIII100 $(\mathrm{a} / \mathrm{c}=0,17)$ apresentam AA e PA reduzidos e DA incrementados em relação aos da formulação CPIII100 (a/c=0,2). Isso pode ser observado nos Gráficos 5, 6 e 7 .

\subsection{MATRIZ CIMENTÍCIA CPIII COM ADIÇÃO DE SÍLICA}

Para observar o efeito da sílica ativa foram elaborados CPs com pasta de cimento CPIII com $10 \%$ de substituição de sílica ativa. A formulação obtida é a CPIII90S10 descrita em detalhe na Tabela 1.

Nas propriedades mecânicas, os compósitos elaborados com a formulação CPIII90S10 unicamente apresentaram melhoria no MOE, mostrado no Gráfico 3, mantendo as demais características semelhantes em relação aos corpos elaborados apenas com cimento, formulação CPIII100 (a/c=0,2).

As propriedades físicas dos compósitos elaborados com CPIII90S10 apresentaram melhoria na AA e na PA em relação aos corpos elaborados apenas com cimento, formulação CPIII100(a/c = 0,2). Isso observado nos Gráficos 5 e 7 . 
1.6 MATRIZ COM CPIIE, SÍLICA ATIVA E CALCÁRIO, REFORÇADO COM CELULOSE E PP

Com o objetivo de se observar o efeito de níveis de PP, 1,8\% e 0,9\% em relação à massa do material cimentício, em uma matriz complexa, foram elaborados CPs em dois níveis de PP e utilizando cimento CPIIE com adições de calcário, sílica e celulose de eucalipto. As formulações CPIIE63S5CC19C9PP1,8 para o teor de 1,8\% em massa e CPIIE63S5CC19PP0,9 para o teor de 0,9\% em massa utilizadas são descritas em detalhe na Tabela 1.

Durante a elaboração do $\mathrm{CP}$, observou-se que com maiores teores de fibras de PP existe uma tendência de formação de emaranhados de fibras, que podem ser percebidas no tato. Estudos posteriores são necessários para confirmar tal observação.

As propriedades mecânicas dos compósitos com a formulação CPIIE63S5CC19PP0,9 apresentam melhores propriedades de EE em relação à formulação CPIIE63S5CC19C9PP1,8, conforme observado no Gráfico 4. Isso se deve provavelmente a um maior número de fibras efetivamente trabalhando durante a solicitação. Sobretudo, destaca-se a ausência de imperfeições introduzidas pela polpa de celulose na formulação CPIIE63S5CC19PP0,9.

As propriedades físicas dos compósitos elaborados com CPIIE63S5CC19PP0,9 apresentam menor quantidade de imperfeições em razão da menor quantidade de fibras, repercutindo em melhores propriedades físicas, especialmente no que toca à $\mathrm{PA}$ e à $\mathrm{AA}$, de acordo com o observado nos Gráficos 5 e 7.

\subsection{MATRIZ COM CPV E CALCÁRIO REFORÇADO COM MACRO FIBRAS DE SISAL}

Com a finalidade de observar o efeito da macrofibra de sisal numa matriz cimentícia composta de CPV e calcário, foram elaborados CPs contendo teores de 
$6 \%, 8 \%$ e $10 \%$ em massa de fibras de sisal. As formulações CPVCCSISAL, CPVCCSISAL8 e CPVCCSISAL10 são detalhadas na Tabela 1.

Durante a elaboração dos CPs, foi observado que a macrofibra absorve grandes quantidades de água da mistura, na medida em que é aumentado o teor dessa fibra. Com o aumento do teor de fibras, é afetado principalmente a EE, como pode ser observado no Gráfico 4.

As propriedades físicas dos compósitos são afetadas com o aumento do teor de fibras, aumentando a AA e a PA e diminuindo a DA. Esses efeitos podem ser observados nos Gráficos 5, 6 e 7.

\subsection{MATRIZ COM CPV E CALCÁRIO REFORÇADO COM MACRO FIBRAS DE COCO}

Com a finalidade de observar o efeito da macrofibra de coco numa matriz cimentícia composta de CPV e calcário, foram elaborados CPs contendo teores de $6 \%, 8 \%$ e $10 \%$ em massa de fibras de coco. As formulações, CPVCCCOCO6, CPVCCCOCO8 e CPVCCCOCO10 são detalhadas na Tabela 1.

As propriedades mecânicas dos compósitos elaborados com coco apresentam ganhos em EE, embora não sejam de grande magnitude, como pode ser observado no Gráfico 4.

As propriedades físicas dos compósitos são afetadas com o aumento do teor de fibras, aumentando a AA e a PA e diminuindo a DA, por causa das imperfeições introduzidas e pela própria capacidade de absorver água da fibra. Esses efeitos podem ser observados nos Gráficos 5, 6 e 7.

\section{Resultados e discussão}

A diferente quantidade de água demandada pelos cimentos CPV e CPIII, para tornar viável a extrusão, varia de 0,25 para 0,2 da relação a/c respectivamente. Essa 
diferença de água pode estar influenciada não unicamente pela densidade de empacotamento, assim como também, pela área superficial do material. $\mathrm{A}$ área especifica superficial do cimento CPV é $1,57 \mathrm{~m}^{2} / \mathrm{g}$ e para o cimento CPIII é 1,07 $\mathrm{m}^{2} / \mathrm{g}$, o que evidencia a necessidade de maior quantidade de água necessária para o molhamento do particulado no caso do cimento CPV.

Aumentando o teor de dispersante como apresentado nas formulações CPIII100 $(a / c=0,2)$ e CPIII100 $(a / c=0,17)$, é possível reduzir a relação a/c do sistema, isso expondo a efetividade do dispersante em uso.

A adição de quantidades de sílica ativa de $10 \%$ em massa para o cimento CPV não demandou maior quantidade de água, comparada à utilizada no sistema composto unicamente por cimento CPV. Assim, a relação a/c se manteve em 0,2.

A adição de fibras de PP, em teor de $1 \%$ em massa, na matriz composta unicamente por cimento CPIII não ocasiona demanda adicional de água, se comparada à matriz cimentícia composta unicamente por cimento CPIII. Isto é, a relação a/c se manteve em 0,2. O mesmo acontece para adições de fibras de PVA a uma matriz de cimento CPV, permanecendo a relação a/c em 0,25.

A extrusão de formulações contendo teores de celulose como as formulações CPVCCSISAL8, CPVCCSISAL10, CPVCCCOCO8 e CPVCCCOCO10 exigiu maiores relações a/c, isso muito provavelmente pela capacidade de absorver água das fibras.

As formulações contendo o sistema completo, ou seja, cimento, calcário, sílica ativa, celulose e fibras, apresentam a maior demanda de água para o seu processamento. As formulações CPV63S4CC26C3PVA1,8, CPIIE63S5CC19C9PP1,8 e CPIIE63S5CC19PP0,9 demandam maior quantidade de água, provavelmente porque as fibras celulósicas absorvem parte dessa água, além de introduzirem maior quantidade de vazios a serem preenchidos com água devido as fibras poliméricas utilizadas, ainda podendo existir uma baixa densidade de empacotamento do material cimentício. 


\section{Considerações adicionais}

Como observado nesse estudo preliminar, as propriedades de cada componente do sistema, assim como os aditivos em uso, exercem relevante influência no comportamento reológico do sistema para tornar possível a extrusão. Não é factível estabelecer uma relação água/cimento geral para todas as formulações, evidenciando-se a necessidade de compreender o comportamento reológico influenciado pelas propriedades de cada componente do sistema, assim como as demandas de água respectivas. 
Tabela 43 - Formulações extrudáveis dos compósitos cimentícios

\begin{tabular}{|c|c|c|c|c|c|c|c|c|c|c|c|}
\hline $\mathrm{a}$ & $\begin{array}{l}\text { Formulação } \\
\text { CPV100 }\end{array}$ & \multicolumn{2}{|c|}{$\begin{array}{c}\text { Cimento } \\
\text { (\%massa) }\end{array}$} & $\begin{array}{c}\mathbf{a} / \mathbf{c} \\
0,25\end{array}$ & $\begin{array}{c}\text { Sílica } \\
\text { Ativa } \\
\text { (\%massa) } \\
-\end{array}$ & $\begin{array}{c}\text { Calcário } \\
\text { (\%massa) }\end{array}$ & $\begin{array}{c}\text { Celulose } \\
\text { (\%massa) }\end{array}$ & \multicolumn{2}{|c|}{$\begin{array}{l}\text { Fibras } \\
\text { (\%massa) }\end{array}$} & $\begin{array}{c}\text { HPMC* } \\
\text { (\%massa) } \\
0,5\end{array}$ & $\begin{array}{c}\text { ADVA } \\
\text { FLOW* } \\
\text { (\%massa) } \\
0,5\end{array}$ \\
\hline$b$ & CPV100PVA1 & 99 & CPV & 0,25 & - & - & - & 1 & PVA & 0,5 & 0,5 \\
\hline C & CPV63S4CC26C3PVA1,8 & 63,6 & CPV & 0,45 & 4,8 & 26,7 & 3 & 1,8 & PVA & 0,5 & 0,5 \\
\hline f & CPIII99PP1 & 99 & CPIII & 0,2 & - & - & - & 1 & PP & 0,5 & 0,5 \\
\hline$g$ & CPIII90S10 & 90 & CPIII & 0,2 & 10 & - & - & - & - & 0,5 & 0,5 \\
\hline $\mathrm{h}$ & CPIIE63S5CC19C9PVA1,8 & 63,3 & CPIIE & 0,45 & 5,4 & 19,7 & 9,8 & 1,8 & PVA & 0,5 & 0,5 \\
\hline $\mathrm{i}$ & CPIIE63S5CC19C9PP1,8 & 63,3 & CPIIE & 0,45 & 5,4 & 19,7 & 9,8 & 1,8 & PP & 0,5 & 0,5 \\
\hline I & CPVCCSISAL8 & 65,9 & CPV & 0,4 & - & 26,1 & 8 & - & - & 0,5 & 0,5 \\
\hline $\mathrm{m}$ & CPVCCSISAL10 & 64,5 & CPV & 0,4 & - & 25,6 & 10 & - & - & 0,5 & 0,5 \\
\hline $\mathrm{n}$ & CPVCCCOCO6 & 67,3 & CPV & 0,4 & - & 26,7 & 6 & - & - & 0,5 & 0,5 \\
\hline 0 & CPVCCCOCO8 & 65,9 & CPV & 0,4 & - & 26,1 & 8 & - & - & 0,5 & 0,5 \\
\hline$p$ & CPVCCCOCO10 & 64,5 & CPV & 0,4 & - & 25,6 & 10 & - & - & 0,5 & 0,5 \\
\hline
\end{tabular}


Tabela 44 - Propriedades mecânicas dos compósitos cimentícios

\begin{tabular}{lcccccccc}
\hline Formulação & $\begin{array}{c}\text { MOR } \\
\text { (MPa) }\end{array}$ & $\begin{array}{cccccc}\text { DVP } \\
\text { CPV100 }\end{array}$ & $\begin{array}{c}\text { LOP } \\
\text { (MPa) }\end{array}$ & $\begin{array}{c}\text { DVP } \\
\text { (MPa) }\end{array}$ & $\begin{array}{c}\text { MOE } \\
\text { DVP }\end{array}$ & $\begin{array}{c}\text { EE } \\
\left(\mathbf{k J} / \mathbf{m}^{2}\right)\end{array}$ & DVP \\
CPV100PVA1 & 7,11 & 6,29 & 1,26 & 30469 & 8414 & 0,19 & 0,08 \\
CPV63S4CC26,C3PVA1,8 & 7,75 & 0,62 & 5,42 & 0,50 & 10992 & 1060 & 2,14 & 0,63 \\
CPIII100(a/c=0,2) & 8,56 & 0,64 & 8,01 & 0,65 & 16463 & 2178 & 0,28 & 0,08 \\
CPIII100(a/c=0,17) & 12,70 & 1,04 & 12,3 & 1,12 & 23871 & 2766 & 1,16 & 0,49 \\
CPIII99PP1 & 9,26 & 0,80 & 7,43 & 0,86 & 3946 & 405,8 & 3,45 & 0,34 \\
CPIII90S10 & 9,37 & 1,43 & 8,98 & 1,47 & 20657 & 2100 & 0,43 & 0,20 \\
CPIIE63S5CC19C9PVA1,8 & 5,42 & 0,46 & 4,74 & 0,45 & 8299 & 348,9 & 1,26 & 0,43 \\
CPIIE63S5CC19C9PP1,8 & 5,83 & 1,12 & 4,44 & 0,91 & 7007 & 781,0 & 1,33 & 0,09 \\
CPIIE63S5CC19PP0,9 & 6,24 & 1,05 & 4,78 & 0,71 & 8099 & 981,6 & 2,07 & 0,62 \\
CPVCCSISAL6 & 6,65 & 1,08 & 6,25 & 0,98 & 13184 & 2286 & 0,22 & 0,08 \\
CPVCCSISAL8 & 6,55 & 0,44 & 6,08 & 0,55 & 11087 & 735 & 0,83 & 0,24 \\
CPVCCSISAL10 & 6,80 & 0,48 & 6,46 & 0,49 & 9082 & 1081 & 0,70 & 0,07 \\
CPVCCCOCO6 & 6,44 & 0,96 & 5,66 & 0,97 & 11735 & 1048 & 0,06 & 0,01 \\
CPVCCCOCO8 & 6,06 & 0,65 & 5,76 & 0,73 & 12251 & 822 & 0,06 & 0,01 \\
CPVCCCOCO10 & 6,25 & 0,74 & 5,90 & 0,98 & 9193 & 1139 & 0,30 & 0,14 \\
\hline
\end{tabular}


Tabela 45 - Propriedades físicas dos compósitos cimentícios

\begin{tabular}{lcccccc}
\hline Formulação & $\begin{array}{c}\text { A.A. } \\
\text { (\%massa) }\end{array}$ & DVP & $\begin{array}{c}\text { D.A. } \\
\left(\mathbf{g} / \mathrm{cm}^{3}\right)\end{array}$ & DVP & $\begin{array}{c}\text { P.A. } \\
\text { (\%em volume) }\end{array}$ & DVP \\
\hline CPV100 & 13,07 & 0,17 & 2,05 & 0,011 & 26,80 & 0,23 \\
CPV100PVA1 & 15,90 & 0,23 & 1,90 & 0,010 & 30,22 & 0,27 \\
CPV63S4CC26,C3PVA1,8 & 28,68 & 0,04 & 1,45 & 0,002 & 41,62 & 0,05 \\
CPIII100(a/c=0,2) & 14,42 & 0,30 & 1,82 & 0,022 & 26,27 & 0,63 \\
CPIII100(a/c=0,17) & 11,36 & 0,27 & 2,02 & 0,007 & 22,97 & 0,50 \\
CPIII99PP1 & 15,02 & 0,53 & 1,81 & 0,001 & 27,22 & 0,97 \\
CPIII90S10 & 12,43 & 0,03 & 1,77 & 0,005 & 22,01 & 0,10 \\
CPIIE63S5CC19C9PVA1,8 & 33,72 & 0,09 & 1,37 & 0,002 & 46,09 & 0,08 \\
CPIIE63S5CC19C9PP1,8 & 35,99 & 0,25 & 1,31 & 0,008 & 47,01 & 0,10 \\
CPIIE63S5CC19PP0,9 & 34,72 & 0,18 & 1,32 & 0,011 & 45,86 & 0,31 \\
CPVCCSISAL6 & 23,08 & 0,57 & 1,62 & 0,012 & 37,34 & 0,66 \\
CPVCCSISAL8 & 26,94 & 0,37 & 1,51 & 0,012 & 40,59 & 0,24 \\
CPVCCSISAL10 & 26,49 & 0,27 & 1,51 & 0,007 & 39,90 & 0,24 \\
CPVCCCOCO6 & 21,08 & 0,13 & 1,64 & 0,005 & 34,66 & 0,13 \\
CPVCCCOCO8 & 23,96 & 0,37 & 1,54 & 0,015 & 36,86 & 0,27 \\
CPVCCCOCO10 & 26,53 & 0,17 & 1,47 & 0,007 & 39,20 & 0,17 \\
\hline
\end{tabular}

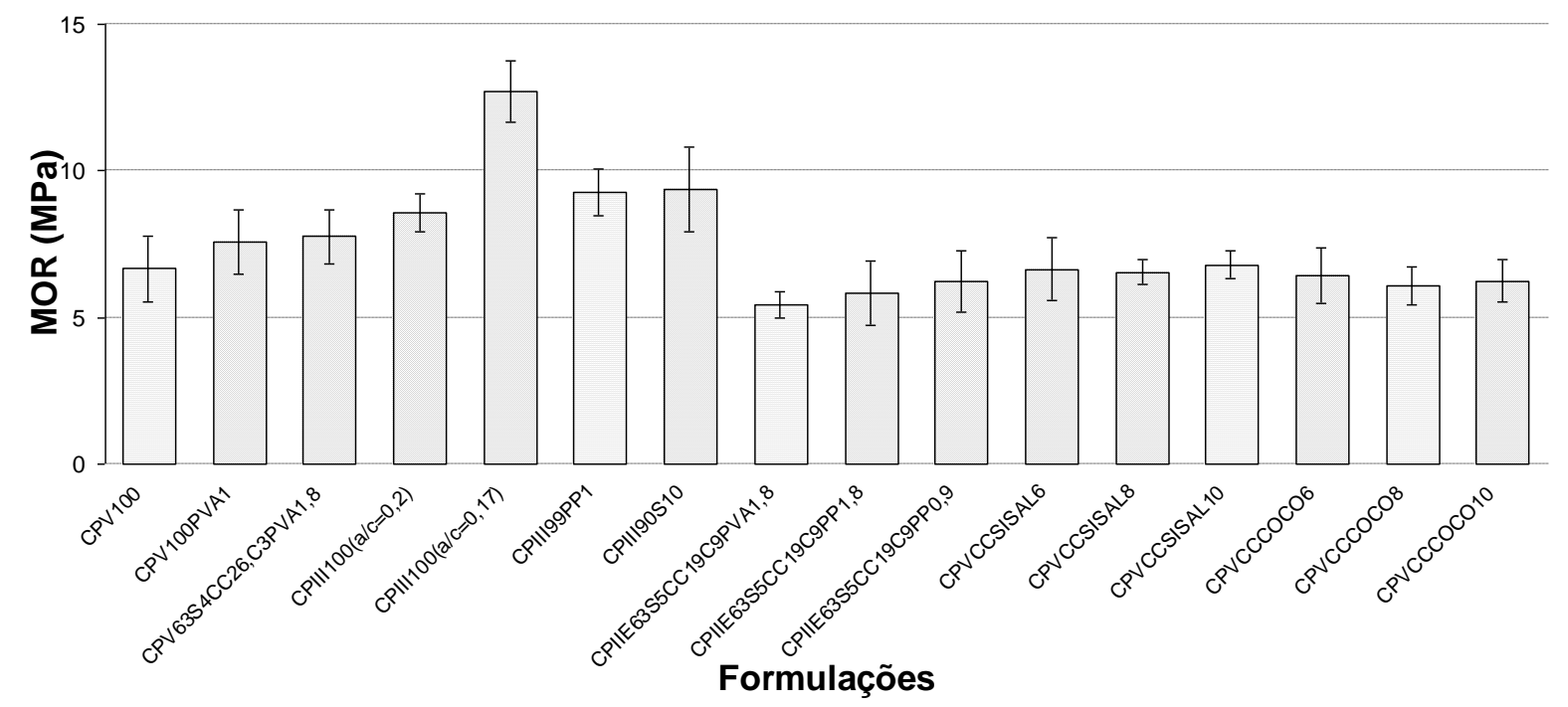

Gráfico 67 - Módulo de Ruptura dos compósitos cimentícios 


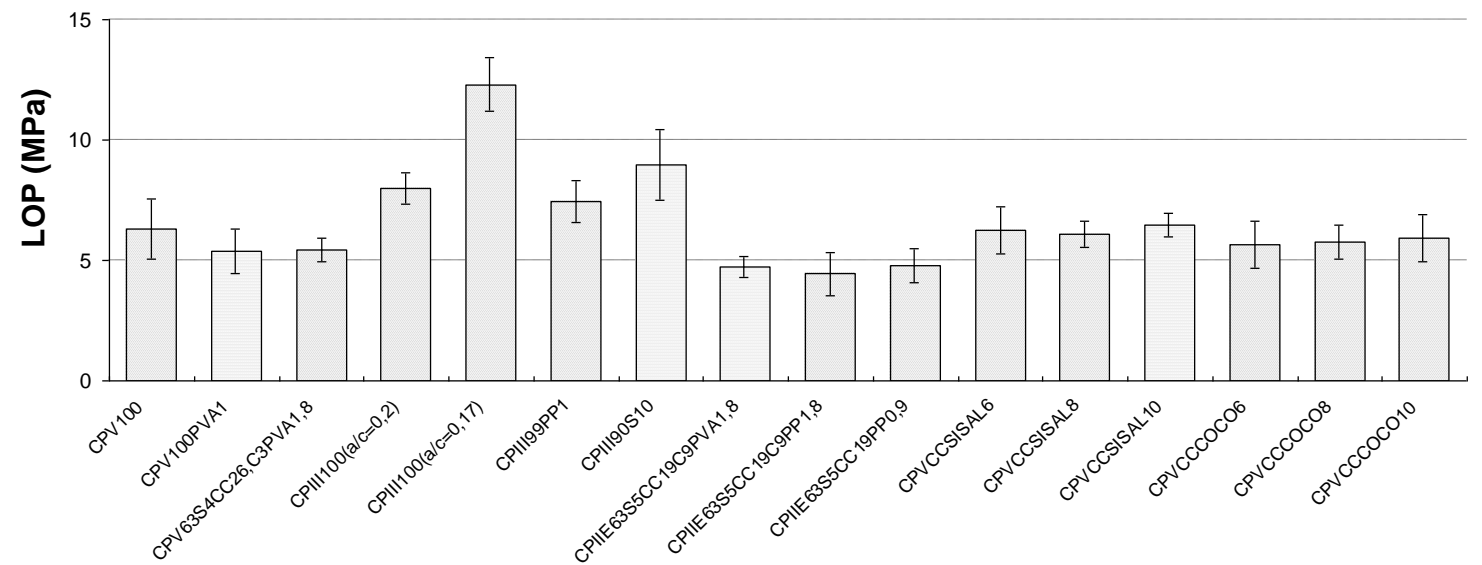

Formulações

Gráfico 68 - Limite de proporcionalidade dos compósitos cimentícios

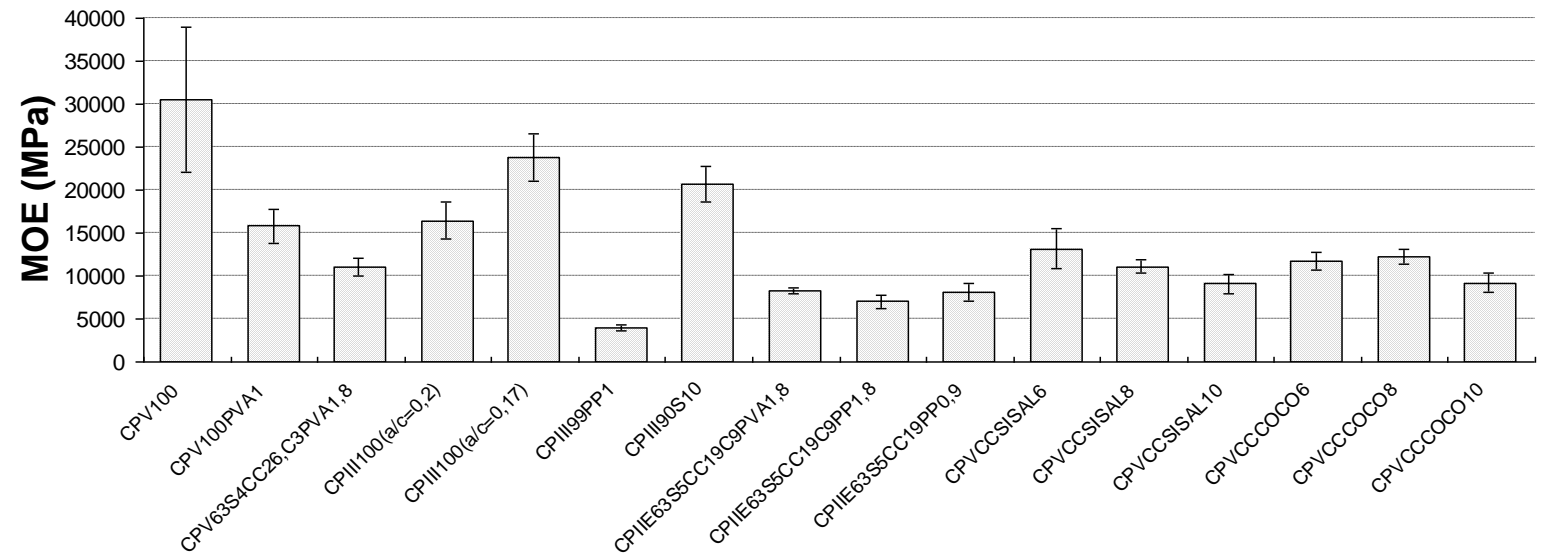

Formulações

Gráfico 69 - Módulo de elasticidade dos compósitos cimentícios 


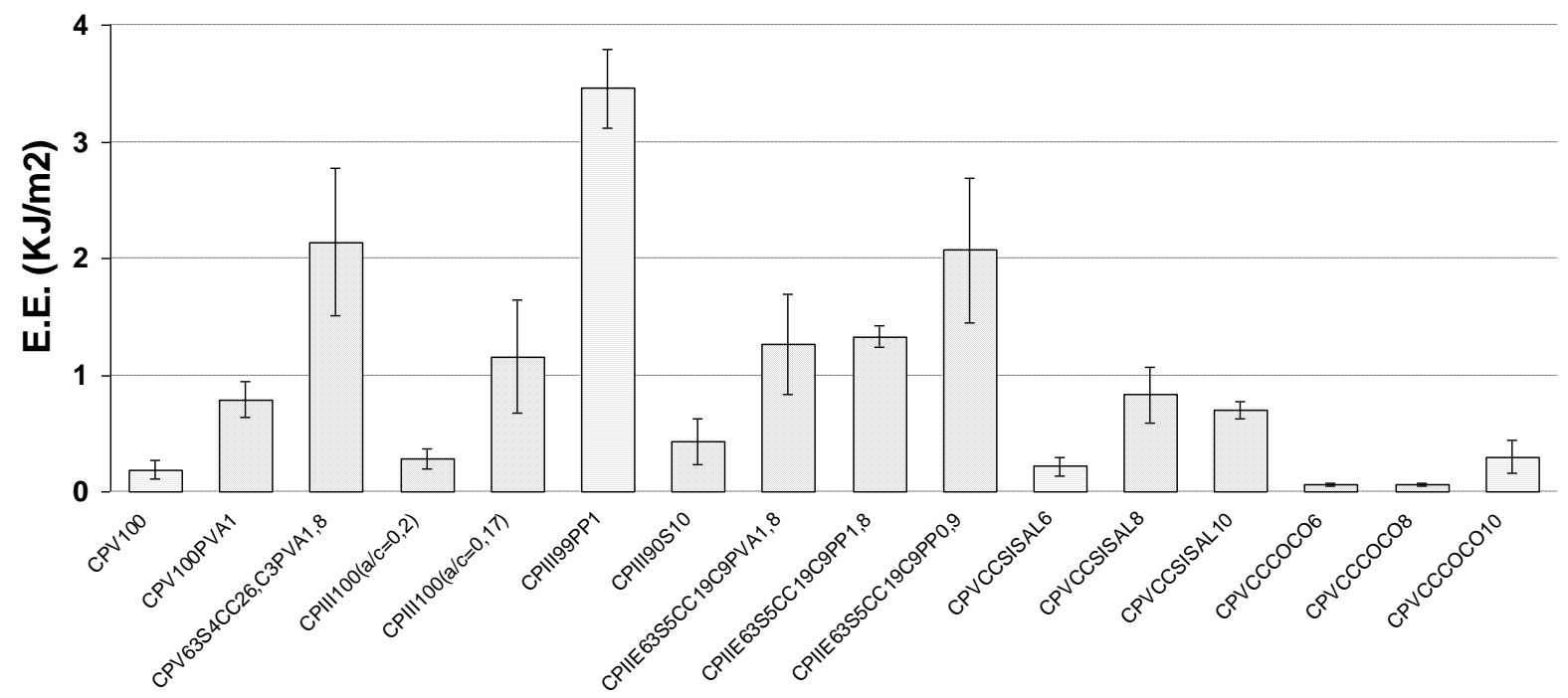

Formulações

Gráfico 70 - Energia específica dos compósitos cimentícios

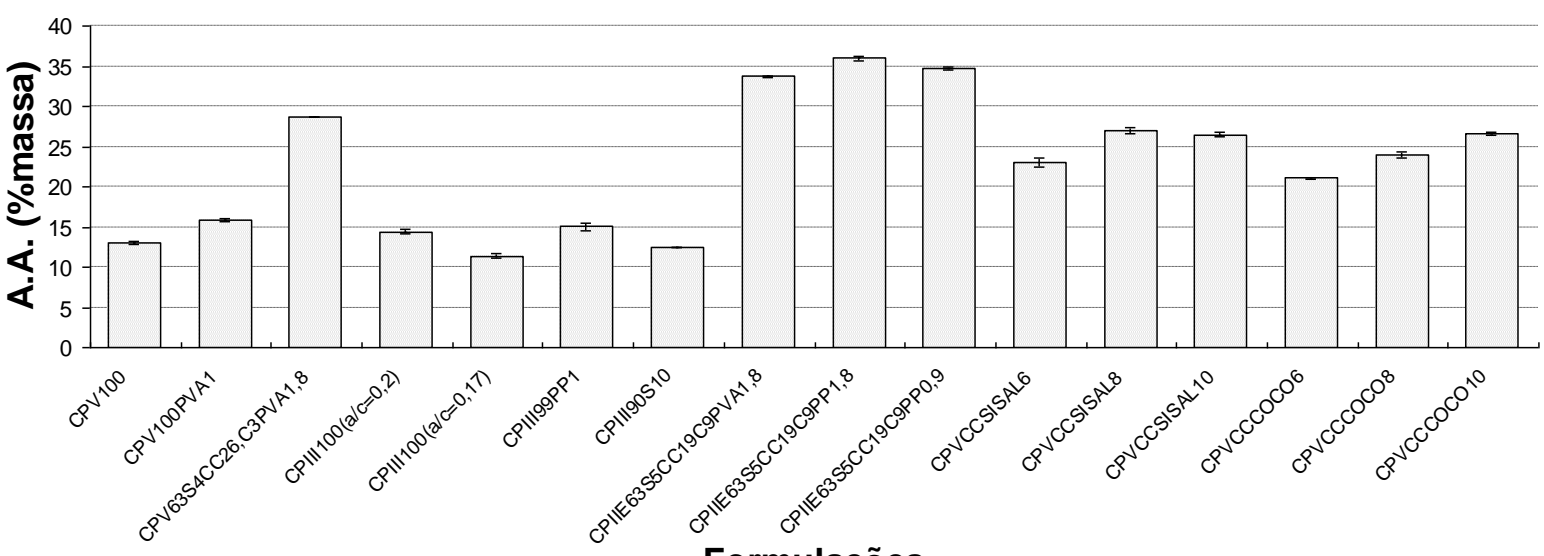

Formulações

Gráfico 71 - Absorção de água dos compósitos cimentícios 


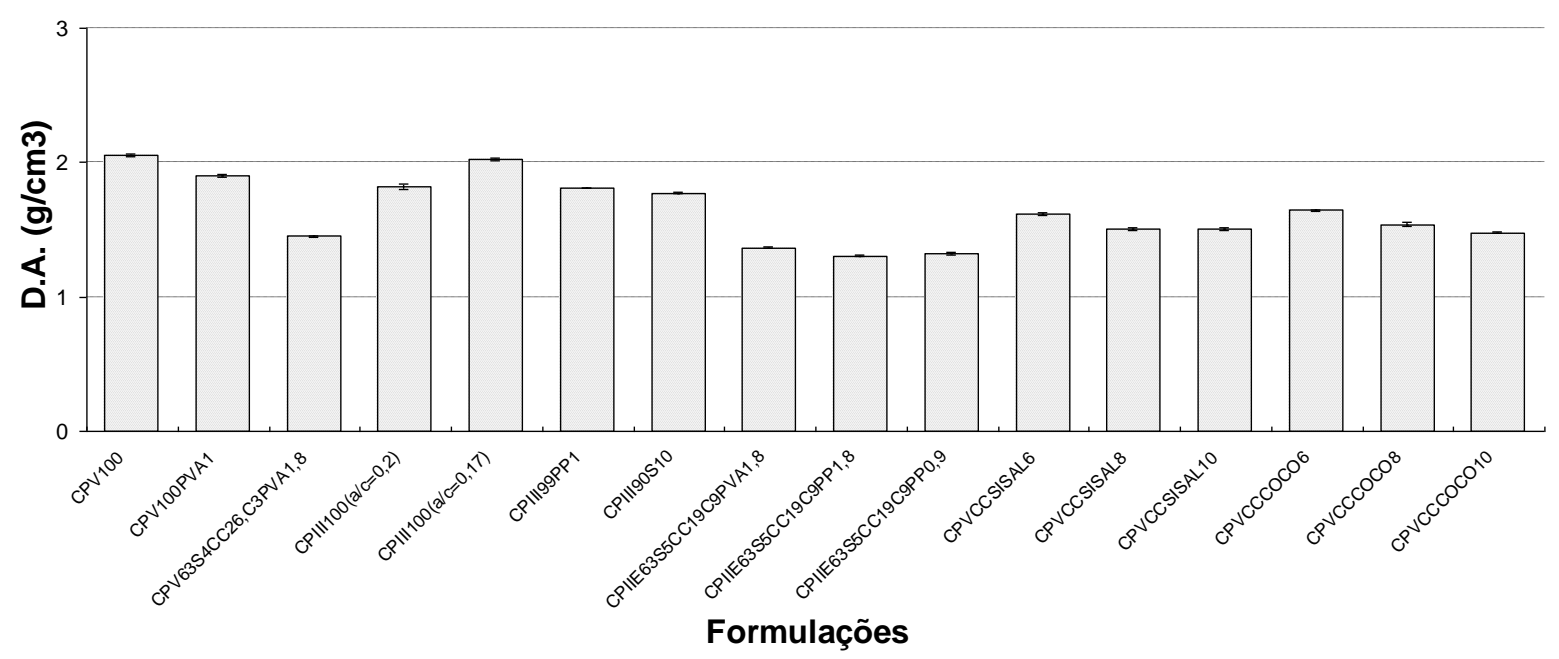

Gráfico 72 - Densidade aparente dos compósitos cimentícios

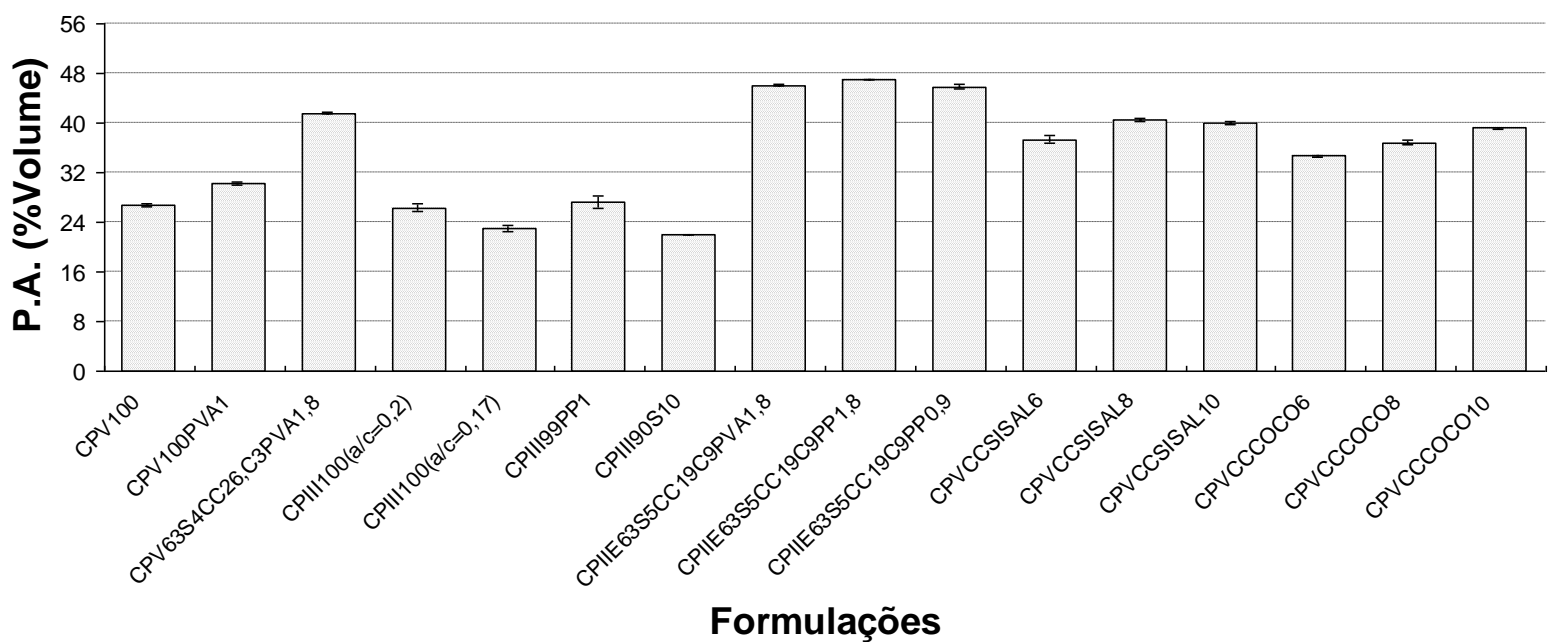

Gráfico 73 - Porosidade aparente dos compósitos cimentícios 


\section{APÊNDICE B - Resultados das propriedades mecânicas, físicas e demanda de água das formulações utilizadas na modelagem dos}

\section{compósitos extrudados}

Propriedades físicas da matriz com diferentes teores de CPV, S e CC

\begin{tabular}{|c|c|c|c|}
\hline Formulação & $\begin{array}{l}\text { A.A. } \\
(\%)\end{array}$ & $\begin{array}{c}\text { D.A. } \\
\left(\mathrm{g} / \mathrm{cm}^{3}\right)\end{array}$ & $\begin{array}{l}\text { P.A. } \\
\text { (\%) }\end{array}$ \\
\hline \multirow{6}{*}{ CPV100 } & 13,16 & 1,97 & 25,92 \\
\hline & 13,07 & 1,98 & 25,88 \\
\hline & 13,05 & 1,99 & 25,91 \\
\hline & 13,29 & 1,97 & 26,25 \\
\hline & 13,17 & 1,95 & 25,69 \\
\hline & 13,07 & 1,94 & 25,31 \\
\hline Média & 13,14 & 1,97 & 25,83 \\
\hline \multirow[t]{3}{*}{ Desvio Padrão } & 0,09 & 0,02 & 0,31 \\
\hline & 42,03 & 1,15 & 48,16 \\
\hline & 40,63 & 1,21 & 49,04 \\
\hline \multirow{4}{*}{$\mathrm{S} 100$} & 43,53 & 1,12 & 48,76 \\
\hline & 41,07 & 1,16 & 47,50 \\
\hline & 40,84 & 1,16 & 47,24 \\
\hline & 41,06 & 1,15 & 47,17 \\
\hline Média & 41,53 & 1,16 & 47,98 \\
\hline \multirow[t]{3}{*}{ Desvio Padrão } & 1,09 & 0,03 & 0,80 \\
\hline & 16,54 & 1,77 & 29,34 \\
\hline & 15,07 & 1,75 & 26,41 \\
\hline \multirow{4}{*}{ C100 } & 15,35 & 1,75 & 26,82 \\
\hline & 15,27 & 1,74 & 26,62 \\
\hline & 14,73 & 1,82 & 26,85 \\
\hline & 14,57 & 1,88 & 27,32 \\
\hline Média & 15,25 & 1,79 & 27,23 \\
\hline Desvio Padrão & 0,70 & 0,05 & 1,08 \\
\hline
\end{tabular}

Formulação

CPV50S50

Média

Desvio Padrão

A.A.

D.A.

$(\%) \quad\left(\mathbf{g} / \mathrm{cm}^{3}\right) \quad(\%)$

$16,17 \quad 1,54 \quad 24,93$

$16,28 \quad 1,55 \quad 25,20$

16,02

$1,55 \quad 24,77$

16,12

1,52

24,55

$16,13 \quad 1,57 \quad 25,25$

$16,49 \quad 1,55 \quad 25,62$

$16,20 \quad 1,55 \quad 25,05$

\begin{tabular}{cccc} 
Desvio Padrão & 0,17 & 0,01 & 0,38 \\
\hline & 13,50 & 1,89 & 25,55 \\
& 13,69 & 1,87 & 25,55 \\
CPV50C50 & 13,66 & 1,87 & 25,54 \\
& 13,81 & 1,86 & 25,64 \\
& 13,89 & 1,86 & 25,89 \\
Média & 13,95 & 1,86 & 25,99 \\
& 13,75 & 1,87 & 25,69
\end{tabular}

Desvio Padrão

0,17

$0,01 \quad 0,20$

23,86

$1,48 \quad 35,20$

$23,59 \quad 1,50 \quad 35,44$

$23,89 \quad 1,52 \quad 36,30$

S50C50

$23,42 \quad 1,47 \quad 34,33$

23,64 $1,50 \quad 35,57$

$22,88 \quad 1,57 \quad 35,85$

Média $\quad 23,55 \quad 1,51 \quad 35,45$

Desvio Padrão

0,37

$0,04 \quad 0,66$ 
continuação

\begin{tabular}{|c|c|c|c|c|c|c|c|}
\hline Formulação & $\begin{array}{l}\text { A.A. } \\
\text { (\%) }\end{array}$ & $\begin{array}{c}\text { D.A. } \\
\left(\mathrm{g} / \mathrm{cm}^{3}\right)\end{array}$ & $\begin{array}{l}\text { P.A. } \\
\text { (\%) }\end{array}$ & Formulação & $\begin{array}{l}\text { A.A. } \\
(\%)\end{array}$ & $\begin{array}{c}\text { D.A. } \\
\left(\mathrm{g} / \mathrm{cm}^{3}\right)\end{array}$ & $\begin{array}{l}\text { P.A. } \\
\text { (\%) }\end{array}$ \\
\hline \multirow{6}{*}{ CPV33S33C33 } & 11,24 & 1,62 & 18,18 & \multirow{6}{*}{ CPV16S66C16 } & 18,87 & 1,39 & 26,19 \\
\hline & 11,41 & 1,61 & 18,38 & & 19,07 & 1,39 & 26,59 \\
\hline & 11,35 & 1,63 & 18,47 & & 18,73 & 1,38 & 25,82 \\
\hline & 11,24 & 1,62 & 18,25 & & 18,69 & 1,39 & 26,11 \\
\hline & 11,33 & 1,63 & 18,48 & & 19,23 & 1,38 & 26,60 \\
\hline & 11,31 & 1,63 & 18,42 & & 19,42 & 1,39 & 27,12 \\
\hline Média & 11,31 & 1,62 & 18,36 & Média & 19,00 & 1,39 & 26,41 \\
\hline Desvio Padrão & 0,07 & 0,01 & 0,12 & Desvio Padrão & 0,29 & 0,01 & 0,46 \\
\hline \multirow{6}{*}{ CPV66S16C16 } & 12,10 & 1,85 & 22,38 & \multirow{6}{*}{ CPV16S16C66 } & 16,00 & 1,61 & 25,70 \\
\hline & 12,12 & 1,84 & 22,33 & & 16,01 & 1,61 & 25,74 \\
\hline & 12,36 & 1,81 & 22,43 & & 16,12 & 1,61 & 25,93 \\
\hline & 12,41 & 1,80 & 22,36 & & 16,17 & 1,60 & 25,93 \\
\hline & 12,31 & 1,82 & 22,41 & & 16,11 & 1,60 & 25,84 \\
\hline & 12,22 & 1,82 & 22,28 & & 16,17 & 1,60 & 25,85 \\
\hline Média & 12,25 & 1,83 & 22,36 & Média & 16,10 & 1,60 & 25,83 \\
\hline Desvio Padrão & 0,13 & 0,02 & 0,06 & Desvio Padrão & 0,08 & 0,00 & 0,10 \\
\hline
\end{tabular}

Propriedades mecânicas da matriz com diferentes teores de CPV, S e CC

\begin{tabular}{lcccc}
\hline Formulação & $\begin{array}{c}\text { MOR } \\
\text { (MPa) }\end{array}$ & $\begin{array}{c}\text { LOP } \\
\text { (MPa) }\end{array}$ & $\begin{array}{c}\text { MOE } \\
(\mathbf{M P a})\end{array}$ & $\begin{array}{c}\text { E.E. } \\
\left(\mathbf{k J} / \mathbf{m}^{2}\right)\end{array}$ \\
\hline \multirow{4}{*}{ CPV100 } & 11,49 & 11,12 & 20725 & 0,09 \\
& 10,60 & 10,06 & 22147 & 0,07 \\
& 11,57 & 10,92 & 22655 & 0,09 \\
& 12,03 & 11,25 & 21287 & 0,12 \\
Média & 11,40 & 10,77 & 22422 & 0,09 \\
Desvio Padrão & 11,25 & 10,66 & 21495,50 & 0,09 \\
& 10,39 & 9,85 & 19737 & 0,09 \\
\hline
\end{tabular}

\begin{tabular}{lcccc}
\hline Formulação & $\begin{array}{c}\text { MOR } \\
(\mathbf{M P a})\end{array}$ & $\begin{array}{c}\text { LOP } \\
(\mathbf{M P a})\end{array}$ & $\begin{array}{c}\text { MOE } \\
(\mathbf{M P a})\end{array}$ & $\begin{array}{c}\text { E.E. } \\
\left(\mathbf{k J} / \mathbf{m}^{2}\right)\end{array}$ \\
\hline \multirow{4}{*}{ S100 } & 0,54 & 0,54 & 1149 & 0,00 \\
& 0,90 & 0,90 & 1915 & 0,01 \\
& 0,90 & 0,90 & 1477 & 0,01 \\
& 0,90 & 0,90 & 1969 & 0,01 \\
Média & 0,72 & 0,72 & 1641 & 0,01 \\
Desvio Padrão & 0,16 & 0,16 & 303,01 & 0,01 \\
\hline & 0,86 & 0,96 & 1532 & 0,02 \\
& 0,82 & 1613,83 & 0,01 \\
& & & & continua
\end{tabular}


continuação

\begin{tabular}{|c|c|c|c|c|c|c|c|c|c|}
\hline Formulação & $\begin{array}{l}\text { MOR } \\
\text { (MPa) }\end{array}$ & $\begin{array}{l}\text { LOP } \\
\text { (MPa) }\end{array}$ & $\begin{array}{l}\text { MOE } \\
(\mathrm{MPa})\end{array}$ & $\begin{array}{c}\text { E.E. } \\
\left(\mathrm{kJ} / \mathrm{m}^{2}\right)\end{array}$ & Formulação & $\begin{array}{l}\text { MOR } \\
\text { (MPa) }\end{array}$ & $\begin{array}{c}\text { LOP } \\
(\mathrm{MPa})\end{array}$ & $\begin{array}{l}\text { MOE } \\
(\mathrm{MPa})\end{array}$ & $\begin{array}{c}\text { E.E. } \\
\left(\mathrm{kJ} / \mathrm{m}^{2}\right)\end{array}$ \\
\hline \multirow{6}{*}{ C100 } & 1,75 & 1,75 & 1367 & 0,04 & \multirow{6}{*}{ CPV33S33C33 } & 11,43 & 11,36 & 5873 & 0,36 \\
\hline & 1,47 & 1,47 & 1393 & 0,05 & & 10,46 & 10,26 & 5951 & 0,26 \\
\hline & 1,23 & 1,23 & 1695 & 0,02 & & 12,97 & 12,89 & 6185 & 0,39 \\
\hline & 1,51 & 1,51 & 1674 & 0,05 & & 12,51 & 12,40 & 5878 & 0,38 \\
\hline & 0,91 & 0,91 & 1723 & 0,01 & & 11,36 & 11,26 & 5846 & 0,31 \\
\hline & 0,92 & 0,91 & 1975 & 0,02 & & 11,89 & 11,89 & 6294 & 0,33 \\
\hline Média & 1,30 & 1,30 & 1637,83 & 0,03 & Média & 11,77 & 11,68 & 6004,50 & 0,34 \\
\hline Desvio Padrão & 0,34 & 0,34 & 227,51 & 0,02 & Desvio Padrão & 0,89 & 0,93 & 188,50 & 0,05 \\
\hline \multirow{6}{*}{ CPV50S50 } & 5,15 & 5,15 & 12813 & 0,03 & \multirow{6}{*}{ CPV66S16C16 } & 8,82 & 8,19 & 18677 & 0,07 \\
\hline & 5,96 & 5,96 & 13116 & 0,03 & & 8,49 & 8,17 & 19322 & 0,05 \\
\hline & 5,02 & 5,02 & 13917 & 0,04 & & 7,56 & 7,24 & 17954 & 0,05 \\
\hline & 5,80 & 5,80 & 15403 & 0,03 & & 9,53 & 9,23 & 17844 & 0,05 \\
\hline & 6,83 & 6,83 & 12415 & 0,12 & & 8,15 & 7,68 & 19267 & 0,05 \\
\hline & 4,86 & 4,86 & 12884 & 0,04 & & 9,43 & 9,08 & 21480 & 0,08 \\
\hline Média & 5,60 & 5,60 & 13424,67 & 0,05 & Média & 8,66 & 8,27 & 19090,67 & 0,06 \\
\hline Desvio Padrão & 0,74 & 0,74 & 1089,71 & 0,04 & Desvio Padrão & 0,76 & 0,77 & 1327,47 & 0,01 \\
\hline \multirow{6}{*}{ CPV50C50 } & 7,54 & 7,54 & 15327 & 0,14 & \multirow{6}{*}{ CPV16S66C16 } & 6,20 & 6,15 & 4160 & 0,14 \\
\hline & 8,31 & 8,31 & 16134 & 0,25 & & 5,48 & 5,28 & 4248 & 0,10 \\
\hline & 7,82 & 7,82 & 13604 & 0,37 & & 6,20 & 6,11 & 4291 & 0,13 \\
\hline & 9,69 & 9,69 & 14596 & 0,10 & & 6,18 & 6,04 & 3869 & 0,14 \\
\hline & 10,82 & 10,82 & 15804 & 0,15 & & 6,87 & 6,81 & 3580 & 0,19 \\
\hline & 8,49 & 8,49 & 13738 & 0,10 & & 6,22 & 6,15 & 4114 & 0,14 \\
\hline Média & 8,78 & 8,78 & 14867,17 & 0,19 & Média & 6,19 & 6,09 & 4043,67 & 0,14 \\
\hline Desvio Padrão & 1,25 & 1,25 & 1061,90 & 0,11 & Desvio Padrão & 0,44 & 0,49 & 270,89 & 0,03 \\
\hline \multirow{6}{*}{ S50C50 } & 0,51 & 0,51 & 766 & 0,01 & \multirow{6}{*}{ CPV16S16C66 } & 7,14 & 7,10 & 5045 & 0,15 \\
\hline & 0,80 & 0,80 & 1143 & 0,01 & & 8,84 & 8,71 & 5254 & 0,22 \\
\hline & 0,81 & 0,81 & 1031 & 0,01 & & 9,21 & 9,07 & 6424 & 0,19 \\
\hline & 0,71 & 0,72 & 931 & 0,01 & & 8,14 & 8,05 & 5476 & 0,18 \\
\hline & 0,55 & 0,55 & 786 & 0,01 & & 8,16 & 8,02 & 5252 & 0,18 \\
\hline & 0,62 & 0,62 & 790 & 0,01 & & 6,73 & 6,62 & 5261 & 0,12 \\
\hline Média & 0,67 & 0,67 & 907,83 & 0,01 & Média & 8,04 & 7,93 & 5452,00 & 0,17 \\
\hline Desvio Padrão & 0,13 & 0,13 & 154,83 & 0,00 & Desvio Padrão & 0,95 & 0,93 & 495,32 & 0,03 \\
\hline
\end{tabular}


Propriedades físicas da matriz M reforçada com PP e C

\begin{tabular}{|c|c|c|c|}
\hline Formulação & $\begin{array}{l}\text { A.A. } \\
\text { (\%) }\end{array}$ & $\begin{array}{l}\text { D.A. } \\
\left(\mathrm{g} / \mathrm{cm}^{3}\right)\end{array}$ & $\begin{array}{l}\text { P.A. } \\
\text { (\%) }\end{array}$ \\
\hline \multirow{6}{*}{ M88C12 } & 31,82 & 1,29 & 41,18 \\
\hline & 30,04 & 1,32 & 39,59 \\
\hline & 31,48 & 1,30 & 40,77 \\
\hline & 30,25 & 1,31 & 39,62 \\
\hline & 30,94 & 1,30 & 40,14 \\
\hline & 29,87 & 1,31 & 39,02 \\
\hline Média & 30,73 & 1,30 & 40,05 \\
\hline Desvio Padrão & 0,80 & 0,01 & 0,81 \\
\hline \multirow{6}{*}{ M88C10,5PP1,50 } & 29,56 & 1,27 & 37,40 \\
\hline & 27,94 & 1,28 & 35,68 \\
\hline & 28,01 & 1,28 & 35,74 \\
\hline & 27,44 & 1,28 & 35,16 \\
\hline & 28,29 & 1,27 & 35,91 \\
\hline & 29,34 & 1,26 & 37,12 \\
\hline Média & 28,43 & 1,27 & 36,17 \\
\hline Desvio Padrão & 0,84 & 0,01 & 0,89 \\
\hline \multirow{6}{*}{ M100 } & 11,47 & 1,62 & 18,54 \\
\hline & 11,41 & 1,61 & 18,38 \\
\hline & 11,35 & 1,63 & 18,47 \\
\hline & 11,24 & 1,62 & 18,25 \\
\hline & 11,33 & 1,63 & 18,48 \\
\hline & 11,31 & 1,63 & 18,42 \\
\hline Média & 11,35 & 1,62 & 18,42 \\
\hline Desvio Padrão & 0,08 & 0,01 & 0,10 \\
\hline \multirow{6}{*}{ M98,5PP1,5 } & 12,77 & 1,71 & 21,83 \\
\hline & 12,60 & 1,71 & 21,53 \\
\hline & 12,44 & 1,74 & 21,64 \\
\hline & 13,13 & 1,70 & 22,33 \\
\hline & 13,68 & 1,66 & 22,68 \\
\hline & 13,72 & 1,66 & 22,83 \\
\hline Média & 13,06 & 1,70 & 22,14 \\
\hline Desvio Padrão & 0,55 & 0,03 & 0,55 \\
\hline \multirow{6}{*}{ M88C11,3PP7,5 } & 28,91 & 1,27 & 36,69 \\
\hline & 29,38 & 1,27 & 37,31 \\
\hline & 28,80 & 1,27 & 36,68 \\
\hline & 27,74 & 1,29 & 35,83 \\
\hline & 29,02 & 1,29 & 37,37 \\
\hline & 29,49 & 1,28 & 37,89 \\
\hline Média & 28,89 & 1,28 & 36,96 \\
\hline Desvio Padrão & 0,62 & 0,01 & 0,72 \\
\hline
\end{tabular}

\begin{tabular}{|c|c|c|c|}
\hline Formulação & $\begin{array}{l}\text { A.A. } \\
(\%)\end{array}$ & $\begin{array}{l}\text { D.A. } \\
\left(\mathrm{g} / \mathrm{cm}^{3}\right)\end{array}$ & $\begin{array}{l}\text { P.A. } \\
\text { (\%) }\end{array}$ \\
\hline \multirow{6}{*}{ M99,3РP0,75 } & 10,90 & 1,82 & 19,80 \\
\hline & 10,83 & 1,82 & 19,76 \\
\hline & 10,57 & 1,85 & 19,59 \\
\hline & 11,10 & 1,80 & 19,92 \\
\hline & 10,96 & 1,81 & 19,84 \\
\hline & 10,93 & 1,81 & 19,82 \\
\hline Média & 10,88 & 1,82 & 19,79 \\
\hline Desvio Padrão & 0,18 & 0,02 & 0,11 \\
\hline \multirow{6}{*}{ M94C6 } & 22,62 & 1,38 & 31,29 \\
\hline & 22,56 & 1,37 & 30,94 \\
\hline & 22,54 & 1,38 & 31,17 \\
\hline & 22,38 & 1,38 & 30,92 \\
\hline & 22,68 & 1,37 & 31,10 \\
\hline & 22,44 & 1,38 & 31,00 \\
\hline Média & 22,54 & 1,38 & 31,07 \\
\hline Desvio Padrão & 0,11 & 0,01 & 0,14 \\
\hline \multirow{6}{*}{ M93,3C5,3PP1,5 } & 23,33 & 1,39 & 32,38 \\
\hline & 22,87 & 1,39 & 31,89 \\
\hline & 22,97 & 1,39 & 31,99 \\
\hline & 22,34 & 1,40 & 31,21 \\
\hline & 22,93 & 1,40 & 32,02 \\
\hline & 23,27 & 1,39 & 32,24 \\
\hline Média & 22,95 & 1,39 & 31,95 \\
\hline Desvio Padrão & 0,35 & 0,00 & 0,41 \\
\hline \multirow{6}{*}{ M93,6C5,6PP0,75 } & 21,67 & 1,44 & 31,18 \\
\hline & 21,69 & 1,47 & 31,90 \\
\hline & 21,74 & 1,45 & 31,46 \\
\hline & 21,83 & 1,46 & 31,97 \\
\hline & 21,64 & 1,45 & 31,44 \\
\hline & 21,64 & 1,46 & 31,49 \\
\hline Média & 21,70 & 1,45 & 31,58 \\
\hline Desvio Padrão & 0,07 & 0,01 & 0,30 \\
\hline \multirow{6}{*}{ M90,8C8,8PP0,38 } & 27,12 & 1,34 & 36,32 \\
\hline & 27,06 & 1,34 & 36,35 \\
\hline & 27,24 & 1,35 & 36,69 \\
\hline & 27,55 & 1,34 & 36,78 \\
\hline & 27,25 & 1,34 & 36,58 \\
\hline & 27,55 & 1,33 & 36,72 \\
\hline Média & 27,30 & 1,34 & 36,57 \\
\hline Desvio Padrão & 0,21 & 0,01 & 0,20 \\
\hline
\end{tabular}


continuação

\begin{tabular}{lccc}
\hline Formulação & $\begin{array}{c}\text { A.A. } \\
\text { (\%) }\end{array}$ & $\begin{array}{c}\text { D.A. } \\
\left(\mathbf{g} / \mathbf{c m}^{3}\right)\end{array}$ & $\begin{array}{c}\text { P.A. } \\
\mathbf{( \% )}\end{array}$ \\
\hline & 38,59 & 1,07 & 41,12 \\
& 38,60 & 1,05 & 40,67 \\
M90,8C8PP1,11 & 39,19 & 1,08 & 42,41 \\
& 40,08 & 1,06 & 42,45 \\
Média & 39,71 & 1,05 & 41,76 \\
Desvio Padrão & 39,21 & 1,09 & 42,80 \\
\hline \multirow{3}{*}{ M96,813C2,8PP0,375 } & 39,23 & 1,07 & 41,87 \\
& 0,60 & 0,02 & 0,84 \\
\hline & 19,43 & 1,48 & 28,85 \\
& 19,47 & 1,48 & 28,84 \\
Média & 19,38 & 1,48 & 28,86 \\
\hline & 19,41 & 1,49 & 28,77 \\
\hline & 19,15 & 1,52 & 29,07 \\
& 19,39 & 1,49 & 28,87 \\
& 0,12 & 0,01 & 0,10 \\
\hline & & &
\end{tabular}

\begin{tabular}{lccc}
\hline Formulação & $\begin{array}{c}\text { A.A. } \\
\text { (\%) }\end{array}$ & $\begin{array}{c}\text { D.A. } \\
\left(\mathbf{g} / \mathbf{c m}^{\mathbf{3}}\right)\end{array}$ & $\begin{array}{c}\text { P.A. } \\
\mathbf{( \% )}\end{array}$ \\
\hline & 16,68 & 1,60 & 26,65 \\
& 16,79 & 1,61 & 26,96 \\
$\mathbf{M 9 6 , 1 C 2 , 8 1 P P 1 , 1 2 5}$ & 16,45 & 1,59 & 26,13 \\
& 16,73 & 1,58 & 26,51 \\
& 16,58 & 1,59 & 26,34 \\
Média & 16,84 & 1,62 & 27,19 \\
Desvio Padrão & 16,68 & 1,60 & 26,63 \\
& 0,14 & 0,01 & 0,40 \\
\hline
\end{tabular}


Propriedades mecânicas da matriz M reforçada com PP e C

\begin{tabular}{|c|c|c|c|c|c|c|c|c|c|}
\hline Formulação & $\begin{array}{l}\text { MOR } \\
(\mathrm{MPa})\end{array}$ & $\begin{array}{c}\text { LOP } \\
(\mathrm{MPa})\end{array}$ & $\begin{array}{l}\mathrm{MOE} \\
(\mathrm{MPa})\end{array}$ & $\begin{array}{c}\text { E.E. } \\
\left(\mathrm{kJ} / \mathrm{m}^{2}\right)\end{array}$ & Formulação & $\begin{array}{l}\text { MOR } \\
(\mathrm{MPa})\end{array}$ & $\begin{array}{c}\text { LOP } \\
(\mathrm{MPa})\end{array}$ & $\begin{array}{l}\text { MOE } \\
(\mathrm{MPa})\end{array}$ & $\begin{array}{c}\text { E.E. } \\
\left(\mathrm{kJ} / \mathrm{m}^{2}\right)\end{array}$ \\
\hline & 12,69 & 7,84 & 6078 & 2,95 & & 15,56 & 4,92 & 12700 & 5,91 \\
\hline & 12,38 & 5,69 & 4994 & 3,46 & & 18,20 & 6,93 & 11089 & 6,08 \\
\hline \multirow[t]{4}{*}{ M88C12 } & 12,33 & 6,24 & 5864 & 4,44 & M98,5PP1,5 & 17,03 & 5,30 & 15457 & 5,86 \\
\hline & 11,56 & 5,71 & 5393 & 4,39 & & 17,08 & 7,65 & 20278 & 7,25 \\
\hline & 13,91 & 5,39 & 5830 & 4,67 & & 13,84 & 5,32 & 16058 & 6,22 \\
\hline & 13,18 & 6,92 & 6973 & 2,89 & & 13,65 & 3,97 & 12692 & 5,61 \\
\hline Média & 12,68 & 6,30 & 5855,33 & 3,80 & Média & 15,89 & 5,68 & 14712,33 & 6,15 \\
\hline \multirow[t]{3}{*}{ Desvio Padrão } & 0,73 & 0,85 & 613,07 & 0,73 & Desvio Padrão & 1,70 & 1,24 & 3016,67 & 0,53 \\
\hline & 7,94 & 3,37 & 5352 & 2,92 & & 7,50 & 3,63 & 4464 & 2,16 \\
\hline & 7,88 & 3,94 & 4334 & 3,77 & & 6,31 & 2,77 & 3971 & 2,00 \\
\hline \multirow[t]{4}{*}{ M88C10,5PP1,50 } & 8,95 & 4,23 & 6150 & 3,98 & M88C11,3PP7,5 & 6,34 & 3,26 & 4337 & 2,90 \\
\hline & 7,00 & 4,73 & 5154 & 2,14 & & 5,77 & 3,66 & 4465 & 2,63 \\
\hline & 9,90 & 5,23 & 5583 & 4,38 & & 6,46 & 3,68 & 4490 & 1,81 \\
\hline & 10,40 & 5,70 & 5142 & 4,63 & & 4,91 & 2,63 & 4376 & 1,75 \\
\hline Média & 8,68 & 4,53 & 5285,83 & 3,64 & Média & 6,22 & 3,27 & 4350,50 & 2,21 \\
\hline \multirow[t]{3}{*}{ Desvio Padrão } & 1,19 & 0,78 & 545,21 & 0,86 & Desvio Padrão & 0,78 & 0,43 & 178,09 & 0,42 \\
\hline & 11,43 & 11,36 & 5873 & 0,36 & & 12,59 & 10,23 & 19752 & 0,80 \\
\hline & 10,46 & 10,26 & 5951 & 0,26 & & 9,95 & 7,96 & 20500 & 0,58 \\
\hline \multirow[t]{4}{*}{ M100 } & 12,97 & 12,98 & 6185 & 0,39 & M99,3РP0,75 & 12,66 & 8,69 & 24476 & 0,65 \\
\hline & 12,51 & 12,40 & 5878 & 0,38 & & 10,80 & 8,80 & 19230 & 0,95 \\
\hline & 11,36 & 11,26 & 5846 & 0,31 & & 11,50 & 9,00 & 19430 & 0,60 \\
\hline & 11,89 & 11,89 & 6294 & 0,33 & & 12,70 & 9,46 & 22114 & 0,70 \\
\hline Média & 11,77 & 11,69 & 6004,50 & 0,34 & Média & 11,70 & 9,02 & 20917,00 & 0,71 \\
\hline Desvio Padrão & 0,82 & 0,87 & 172,08 & 0,04 & Desvio Padrão & 1,05 & 0,70 & 1856,86 & 0,13 \\
\hline
\end{tabular}


continuação

\begin{tabular}{|c|c|c|c|c|c|c|c|c|c|}
\hline Formulação & $\begin{array}{l}\text { MOR } \\
(\mathrm{MPa})\end{array}$ & $\begin{array}{l}\text { LOP } \\
(\mathrm{MPa})\end{array}$ & $\begin{array}{l}\text { MOE } \\
(\mathrm{MPa})\end{array}$ & $\begin{array}{c}\text { E.E. } \\
\left(\mathbf{k J} / \mathrm{m}^{2}\right)\end{array}$ & Formulação & $\begin{array}{l}\text { MOR } \\
(\mathrm{MPa})\end{array}$ & $\begin{array}{l}\text { LOP } \\
(\mathrm{MPa})\end{array}$ & $\begin{array}{l}\text { MOE } \\
(\mathrm{MPa})\end{array}$ & $\begin{array}{c}\text { E.E. } \\
\left(\mathrm{kJ} / \mathrm{m}^{2}\right)\end{array}$ \\
\hline \multirow{6}{*}{ M94C6 } & 11,87 & 7,05 & 8390 & 2,35 & \multirow{6}{*}{ M90,8C8PP1,11 } & 6,21 & 2,71 & 1210,50 & 2,59 \\
\hline & 11,80 & 7,26 & 11065 & 1,60 & & 5,19 & 2,40 & 216 & 1,96 \\
\hline & 8,76 & 5,80 & 7208 & 1,49 & & 7,23 & 3,02 & 2205 & 3,22 \\
\hline & 10,40 & 7,13 & 7581 & 2,50 & & 5,18 & 1,97 & 1392 & 2,22 \\
\hline & 8,56 & 5,06 & 7562 & 1,70 & & 3,76 & 1,60 & 1538 & 1,72 \\
\hline & 9,77 & 5,84 & 8030 & 1,56 & & 4,88 & 1,94 & 1319 & 2,20 \\
\hline Média & 10,19 & 6,36 & 8306,00 & 1,87 & Média & 5,41 & 2,27 & 1313,42 & 2,32 \\
\hline Desvio Padrão & 1,31 & 0,83 & 1289,71 & 0,40 & Desvio Padrão & 1,08 & 0,49 & 586,87 & 0,48 \\
\hline \multirow{6}{*}{ M93,3C5,3PP1,5 } & 18,94 & 17,42 & 10260 & 2,25 & \multirow{6}{*}{ M96,813C2,8PP0,375 } & 10,06 & 5,90 & 12408 & 1,94 \\
\hline & 20,35 & 16,00 & 10912 & 3,71 & & 11,55 & 6,80 & 13197 & 1,89 \\
\hline & 17,96 & 15,00 & 13800 & 2,65 & & 13,13 & 8,14 & 14430 & 2,36 \\
\hline & 19,17 & 17,69 & 11572 & 2,38 & & 10,49 & 6,91 & 10396 & 2,02 \\
\hline & 18,53 & 16,25 & 10912 & 2,46 & & 10,31 & 6,13 & 12311 & 1,74 \\
\hline & 19,93 & 16,16 & 11635 & 2,36 & & 10,06 & 5,90 & 12408 & 1,94 \\
\hline Média & 19,15 & 16,42 & 11515,17 & 2,63 & Média & 10,93 & 6,63 & 12525,00 & 1,98 \\
\hline Desvio Padrão & 0,81 & 0,90 & 1121,09 & 0,50 & Desvio Padrão & 1,10 & 0,79 & 1203,22 & 0,19 \\
\hline \multirow{6}{*}{ M93,6C5,6PP0,75 } & 16,79 & 11,19 & 9125 & 5,23 & \multirow{6}{*}{ M96,1C2,81PP1,125 } & 20,12 & 17,94 & 14974 & 1,07 \\
\hline & 13,35 & 9,21 & 6581 & 3,94 & & 17,64 & 16,94 & 13642 & 1,43 \\
\hline & 15,32 & 9,41 & 10153 & 5,34 & & 19,80 & 19,75 & 13014 & 1,28 \\
\hline & 15,28 & 9,35 & 9388 & 5,69 & & 18,04 & 18,04 & 14581 & 1,47 \\
\hline & 14,81 & 10,03 & 10379 & 4,72 & & 17,47 & 17,27 & 14042 & 1,19 \\
\hline & 15,25 & 9,30 & 8624 & 6,04 & & 17,34 & 17,11 & 15474 & 1,00 \\
\hline Média & 15,13 & 9,75 & 9041,67 & 5,16 & Média & 18,40 & 17,84 & 14287,83 & 1,24 \\
\hline Desvio Padrão & 1,01 & 0,70 & 1250,32 & 0,68 & Desvio Padrão & 1,13 & 0,95 & 823,00 & 0,17 \\
\hline \multirow{6}{*}{ M90,8C8,8PP0,38 } & 12,35 & 8,28 & 5762 & 4,97 & & & & & \\
\hline & 10,60 & 6,27 & 7619 & 2,61 & & & & & \\
\hline & 11,44 & 8,77 & 6131 & 3,13 & & & & & \\
\hline & 13,29 & 8,49 & 7071 & 4,27 & & & & & \\
\hline & 11,25 & 7,29 & 6853 & 3,28 & & & & & \\
\hline & 13,64 & 7,18 & 8280 & 4,79 & & & & & \\
\hline Média & 12,10 & 7,71 & 6952,67 & 3,84 & & & & & \\
\hline Desvio Padrão & 1,10 & 0,87 & 848,78 & 0,89 & & & & & \\
\hline
\end{tabular}


Demanda de água dos sistemas particulados

\begin{tabular}{|c|c|c|c|c|c|c|c|c|c|}
\hline Formulação & $a / s$ & $u$ & $u_{a}$ & $\boldsymbol{u}_{w}$ & $\varepsilon$ & $\varepsilon_{a}$ & $\varepsilon_{w}$ & FVS & $\begin{array}{l}\text { Demanda } \\
\text { de água }\end{array}$ \\
\hline CPV100 & 0,150 & 0,579 & 0,138 & 0,441 & 0,367 & 0,087 & 0,279 & 0,680 & \\
\hline CPV100 & 0,180 & 0575 & 0,046 & 0,529 & 0,365 & 0,030 & 0,336 & 0,641 & $x$ \\
\hline CPV100 & 0,200 & 0,626 & 0,037 & 0,588 & 0,385 & 0,023 & 0,362 & 0,616 & \\
\hline S100 & 0,290 & 2,232 & 1,601 & 0,631 & 0,69 & 0,495 & 0,190 & 0,580 & \\
\hline S100 & 0,360 & 0,873 & 0,089 & 0,784 & 0,466 & 0,040 & 0,41 & 0,538 & \\
\hline S100 & 0,430 & 0,979 & 0,042 & 0,937 & 0,495 & 0,020 & 0,473 & 0,496 & $x$ \\
\hline C100 & 0,115 & 0,416 & 0,110 & 0,306 & 0,294 & 0,077 & 0,210 & 0,720 & \\
\hline C100 & 0,130 & 0,375 & 0,029 & 0,346 & 0,272 & 0,021 & 0,250 & 0,706 & $x$ \\
\hline C100 & 0,170 & 0,457 & 0,005 & 0,452 & 0,314 & 0,004 & 0,310 & 0,654 & \\
\hline CPV50S50 & 0,186 & 1,652 & 1,187 & 0,465 & 0,623 & 0,447 & 0,175 & 0,650 & \\
\hline CPV50S50 & 0,194 & 0,554 & 0,068 & 0,485 & 0,356 & 0,044 & 0,312 & 0,641 & $x$ \\
\hline CPV50S50 & 0,210 & 0,589 & 0,064 & 0,526 & 0,371 & 0,040 & 0,331 & 0,625 & \\
\hline S50C50 & 0,160 & 0,681 & 0,297 & 0,383 & 0,405 & 0,177 & 0,228 & 0,691 & \\
\hline S50C50 & 0,210 & 0,529 & 0,026 & 0,503 & 0,346 & 0,017 & 0,329 & 0,636 & $x$ \\
\hline S50C50 & 0,240 & 0,583 & 0,008 & 0,575 & 0,368 & 0,005 & 0,363 & 0,607 & \\
\hline CPV50C50 & 0,090 & 0,923 & 0,672 & 0,251 & 0,480 & 0,349 & 0,131 & 0,757 & \\
\hline CPV50C50 & 0,125 & 0,414 & 0,065 & 0,349 & 0,293 & 0,046 & 0,247 & 0,70 & $x$ \\
\hline CPV50C50 & 0,150 & 0,447 & 0,029 & 0,419 & 0,309 & 0,020 & 0,289 & 0,66 & \\
\hline CPV33S33C33 & 0,110 & 1,738 & 1,457 & 0,281 & 0,635 & 0,532 & 0,102 & 0,743 & \\
\hline CPV33S33C33 & 0,126 & 0,404 & 0,083 & 0,322 & 0,288 & 0,059 & 0,229 & 0,720 & $x$ \\
\hline CPV33S33C33 & 0,186 & 0,537 & 0,062 & 0,475 & 0,349 & 0,040 & 0,309 & 0,646 & \\
\hline CPV66S16C16 & 0,100 & 0,873 & 0,599 & 0,273 & 0,466 & 0,320 & 0,146 & 0,745 & \\
\hline CPV66S16C16 & 0,118 & 0,352 & 0,029 & 0,322 & 0,260 & 0,022 & 0,239 & 0,718 & $x$ \\
\hline CPV66S16C16 & 0,180 & 0,526 & 0,034 & 0,492 & 0,345 & 0,022 & 0,322 & 0,636 & \\
\hline CPV16S66C16 & 0,230 & 0,838 & 0,298 & 0,541 & 0,456 & 0,162 & 0,294 & 0,621 & \\
\hline CPV16S66C16 & 0,240 & 0,583 & 0,018 & 0,564 & 0,368 & 0,012 & 0,356 & 0,611 & $x$ \\
\hline CPV16S66C16 & 0,270 & 0,739 & 0,105 & 0,635 & 0,425 & 0,060 & 0,365 & 0,585 & \\
\hline CPV16S16C66 & 0,070 & 1,116 & 0,934 & 0,182 & 0,528 & 0,441 & 0,086 & 0,800 & \\
\hline CPV16S16C66 & 0,100 & 0,325 & 0,065 & 0,261 & 0,246 & 0,049 & 0,197 & 0,755 & $x$ \\
\hline CPV16S16C66 & 0,180 & 0,493 & 0,024 & 0,469 & 0,330 & 0,016 & 0,314 & 0,648 & \\
\hline
\end{tabular}

